\title{
Economic and Technical Assessment of Wood Biomass Fuel Gasification for Industrial Gas Production
}

Anastasia M. Gribik

Ronald E. Mizia

Harry Gatley

Benjamin Phillips

September 2007

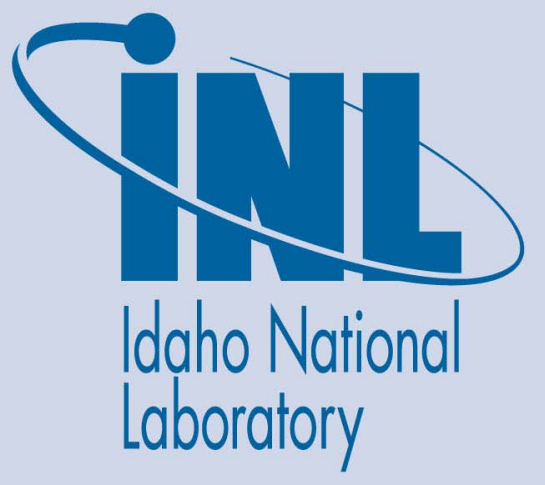

The INL is a U.S. Department of Energy National Laboratory operated by Battelle Energy Alliance 
INL/EXT-07-13292

\title{
Economic and Technical Assessment of Wood Biomass Fuel Gasification for Industrial Gas Production
}

\author{
Anastasia M. Gribik ${ }^{1}$ \\ Ronald E. Mizia ${ }^{1}$ \\ Harry Gatley ${ }^{2}$ \\ Benjamin Phillips ${ }^{2}$ \\ ${ }^{1}$ INL \\ ${ }^{2}$ Emery Energy
}

September 2007

Idaho National Laboratory

Idaho Falls, Idaho 83415

Prepared for the

U.S. Department of Energy

Assistant Secretary for Energy Efficiency and Renewable Energy

Under DOE Idaho Operations Office

Contract DE-AC07-05ID14517 


\section{DISCLAIMER}

This information was prepared as an account of work sponsored by an agency of the U.S. Government. Neither the U.S. Government nor any agency thereof, nor any of their employees, makes any warranty, expressed or implied, or assumes any legal liability or responsibility for the accuracy, completeness, or usefulness, of any information, apparatus, product, or process disclosed, or represents that its use would not infringe privately owned rights. References herein to any specific commercial product, process, or service by trade name, trade mark, manufacturer, or otherwise, does not necessarily constitute or imply its endorsement, recommendation, or favoring by the U.S. Government or any agency thereof. The views and opinions of authors expressed herein do not necessarily state or reflect those of the U.S. Government or any agency thereof. 



\section{EXECUTIVE SUMMARY}

The Department of Energy, Energy Efficiency and Renewable Energy Program has developed a national strategy for increasing woody biomass utilization. The intent of this strategy is to explore equipment and materials that enable creation of a reliable, sustainable supply of woody biomass and to encourage the formation of stable markets for converting that biomass supply into energy. The effort proposed in this project supports this strategy in terms of enhancing industrial energy security, specifically in the forest products industry, through fuel flexibility for industry.

Lime kilns are used throughout the forest products industry, specifically in the pulp and paper sector, to convert lime mud $\left(\mathrm{CaCO}_{3}\right)$ to lime $(\mathrm{CaO})$ for reuse in the causticizing process. The conversion of lime mud to lime requires a significant amount of heat for the reaction to proceed, generally supplied by burning natural gas or fuel oil in the lime kiln. On average, lime kilns require seven to eight million BTUs per ton of lime product or between 1,500 and 2,000 standard cubic feet per minute of natural gas to produce 350 tons of lime per day. Substituting synthesis gas for industrial gas in lime kilns would aid in reducing the forest products industry's dependence on and consumption of fossil fuels.

This project addresses both the technical and economic feasibility of replacing industrial gas in lime kilns with synthesis gas from the gasification of hog fuel. The technical assessment includes a materials evaluation, processing equipment needs, and suitability of the heat content of the synthesis gas as a replacement for industrial gas. The economic assessment includes estimations for capital, construction, operating, maintenance, and management costs for the reference plant. To perform these assessments, detailed models of the gasification and lime kiln processes were developed using Aspen Plus, a steady state process modeling simulator. The material and energy balance outputs from the Aspen Plus model were used as inputs to both the material and economic evaluations. Figure ES - 1 presents the block flow diagram detailing the major plant areas included in the Aspen Plus process model.

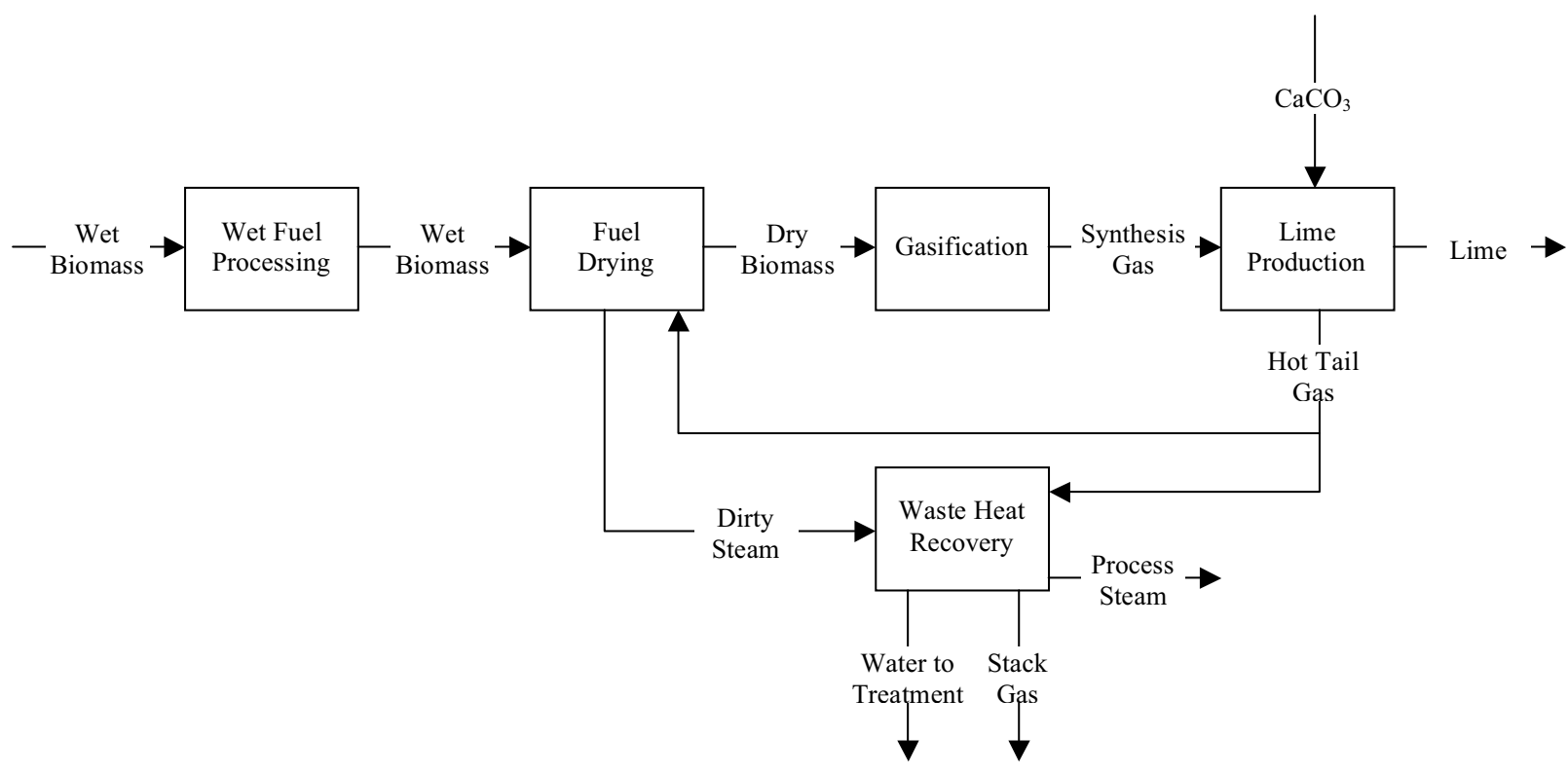

Figure ES - 1. Block Flow Diagram for the Hog Fuel Project

Three scenarios were modeled in Aspen Plus to assess the technical feasibility of gasifying hog fuel. The base case was for a lime kiln operated on natural gas. Case A assumed operation of two gasifiers, with each gasifier having the capacity to process up to 150 tons per day ( 6.25 tons per hour) of 
dried biomass at $10 \%$ moisture. Additionally, it was assumed that a tar cracker would be required between the gasifier and the lime kiln to prevent condensation of tars and oils present after gasification. The total raw biomass feedrate required for this case was 15.17 tons per hour. Case B assumed operation of two gasifiers, with each gasifier having the capacity to process up to 150 tons per day (6.25 tons per hour) of dried biomass at $10 \%$ moisture. This case assumed no tar cracker between the gasifier and the lime kiln. Condensation of tars and oils are avoided in this case by insulating the piping from the reactor outlet to the lime kiln inlet with refractory to maintain a high gas temperature and limiting the piping length. The total raw biomass feedrate required for this case was 14.47 tons per hour.

The gasifier is a refractory lined pressure vessel that will be designed to the requirements of the American Society of Mechanical Engineers Section VIII, Division 1 or 2 codes. The gasifier design is based on Emery Energy Company's E-100A gasifier. The design life is 20 years with anticipated component refurbishment during scheduled maintenance shutdowns. The maximum operating temperature range is $2000-2200^{\circ} \mathrm{F}$ with a hot gas outlet temperature of $950^{\circ} \mathrm{F}$ to preclude the formation of tars and oils. Given the elevated operating temperature of the gasifier, it is necessary to select robust materials for the gasifier components, specifically the refractory. Given these high temperatures, high purity alumina or chromia refractories may be more desirable than traditional silica refractories and proper selection of materials for the ash grate is essential.

The economic viability of firing synthesis gas generated from the gasification of hog fuel as a substitute for natural gas in a lime kiln was assessed using standard economic evaluation methods. The total project investment, based on the total equipment costs, along with the variable and fixed operating costs were calculated for each case. The present worth of the offset cost of utilizing biomass versus natural gas along with the capital investments were then calculated for various project payback periods and interest rates. The following table presents the total project investment, yearly manufacturing costs, and the present worth for an interest rate of $10 \%$ and project lives of 10 and 20 years for the various cases considered.

Table ES - 1 Economic Results Summary

\begin{tabular}{|c|c|c|c|}
\hline & Base Case & Case A & Case B \\
\hline Total Project Investment (TPI) & NA & $\$ 35,496,589$ & $\$ 28,415,837$ \\
\hline Yearly Manufacturing Costs & $\$ 6,270,198$ & $\$ 5,372,873$ & $\$ 5,250,369$ \\
\hline \multicolumn{4}{|l|}{ Present Worth $(i=10 \%)$} \\
\hline 10 Year Project Investment & NA & $-\$ 30,041,148$ & $-\$ 22,141,254$ \\
\hline 20 Year Project Investment & NA & $-\$ 27,905,151$ & $-\$ 19,713,650$ \\
\hline
\end{tabular}

Given the high TPI required for this project and the small offset in the yearly manufacturing costs, utilization of a gasification system for the production of synthetic industrial gas for use in a lime kiln is not economically feasible at this point in time based on the economic evaluation methods utilized in this study. However, several options exist which could improve the economics of this system and cause it to become economically desirable, such as a credit for utilization of biomass as a feedstock or a significant increase in the price of natural gas. In addition, increasing the capacity or output of synthetic natural gas (i.e. increasing the scale of the facility) could improve the project economics. 


\section{CONTENTS}

EXECUTIVE SUMMARY iii

ACRONYMS and NOMENCLATURE vii

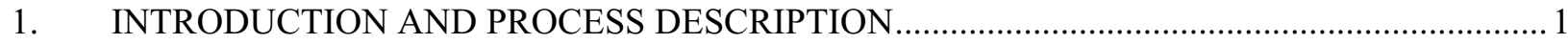

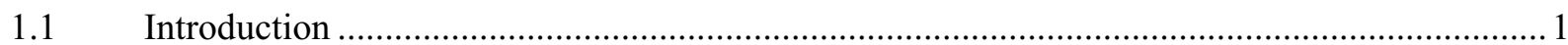

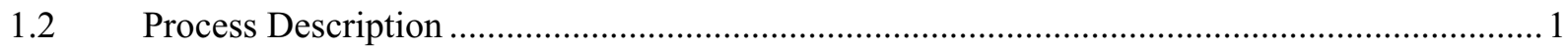

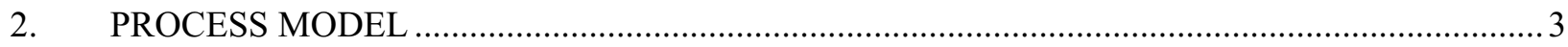

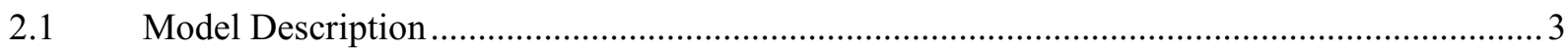

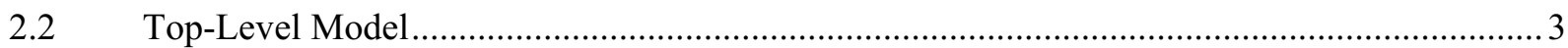

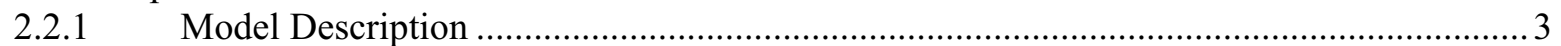

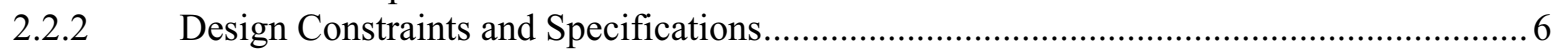

2.2.3 Data Sources, Assumptions, and Limitations …........................................................ 6

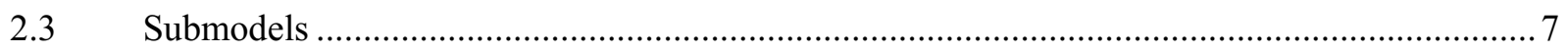

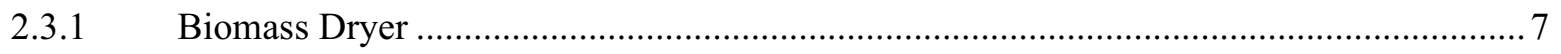

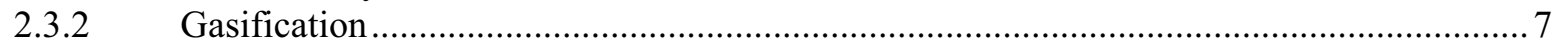

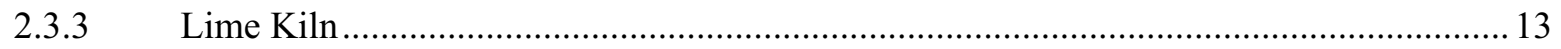

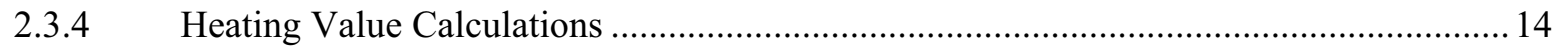

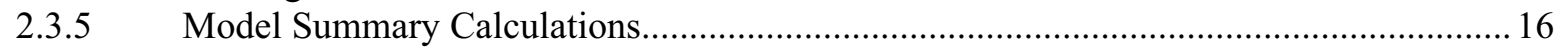

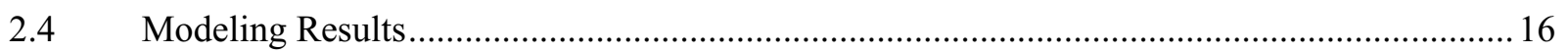

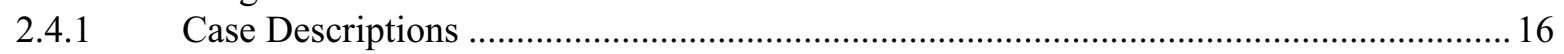

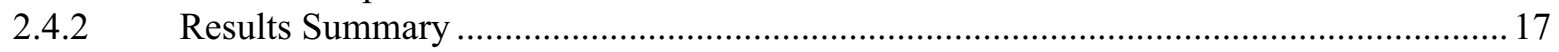

2.4.3 Areas for Future Improvement of the Model ............................................................. 17

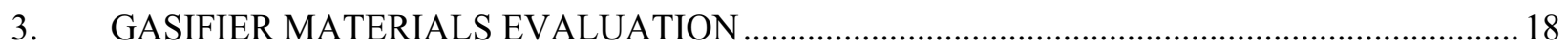

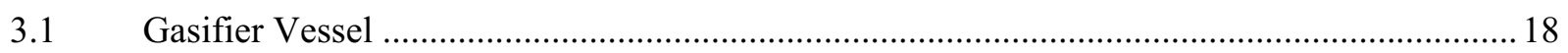

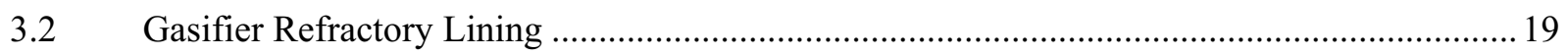

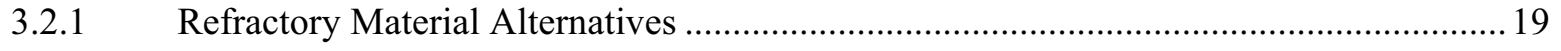

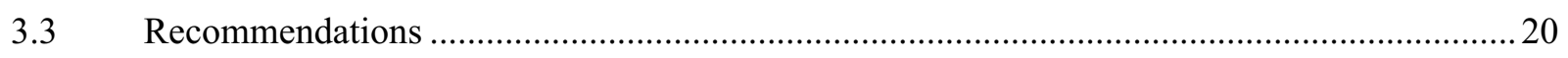

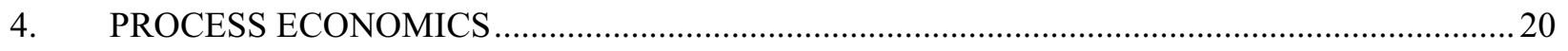

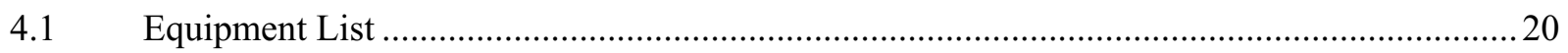

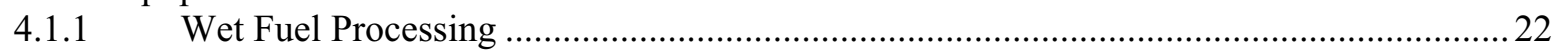

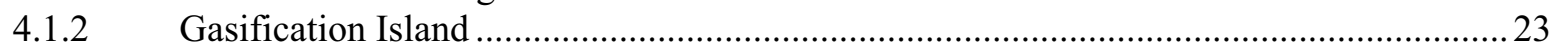

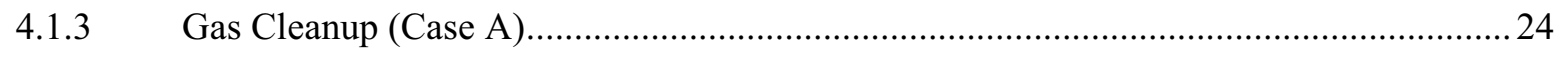

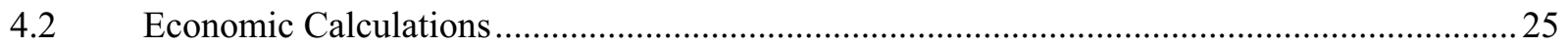

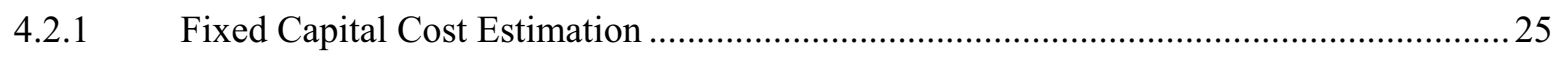

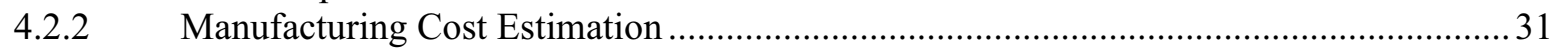

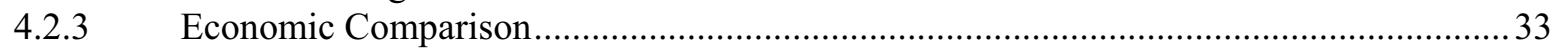

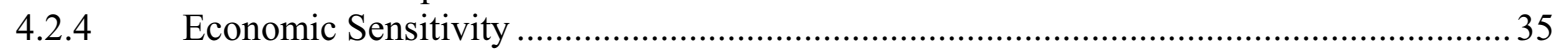

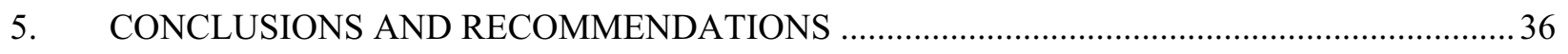

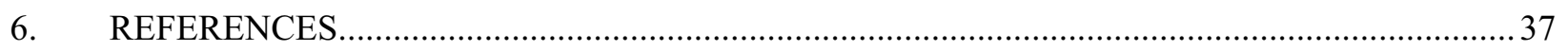

Appendix A. Hog Fuel Project Case Study Results ……......................................................... A-1

Appendix B. Aspen Plus Model Report for Case A …............................................................ B-1

Appendix C. Fortran User Kinetic Subroutine.............................................................................. 


\section{FIGURES}

Figure 1. Block Flow Diagram for the Hog Fuel Project....................................................................2

Figure 2. Top-Level Aspen Plus Process Flowsheet......................................................................... 4

Figure 3. Aspen Plus Process Flowsheet for BM-DRYER Hierarchy Block ............................................ 7

Figure 4. Aspen Plus Process Flowsheet for GASIFIER Hierarchy Block ............................................. 8

Figure 5. Aspen Plus Process Flowsheet for LIMEKILN Hierarchy Block ............................................. 13

Figure 6. Aspen Plus Process Flowsheet for BIOMASS-HHV Hierarchy Block.................................. 15

Figure 7. Proposed Gasifier Wall Construction Details (Emery Energy Company)................................. 19

Figure 8. Hog Fuel Gasification Process Flow Diagram ..................................................................... 21

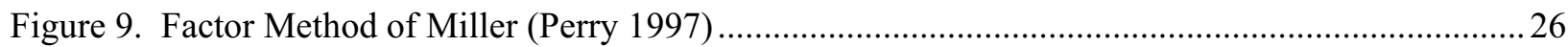

\section{TABLES}

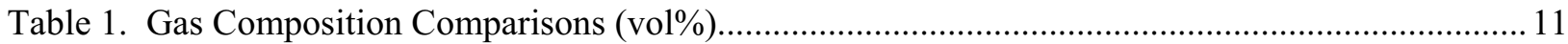

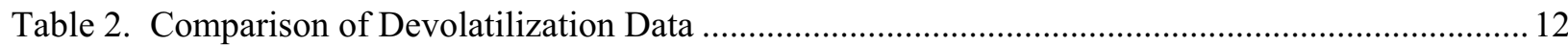

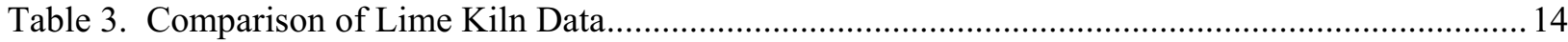

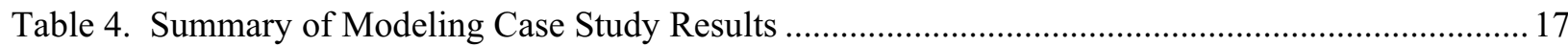

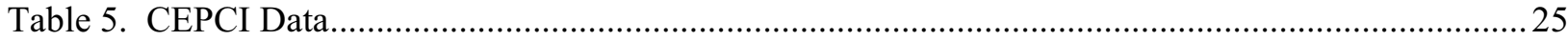

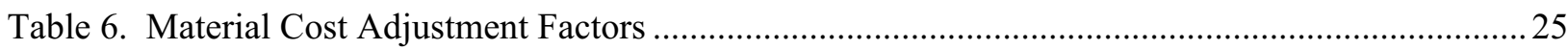

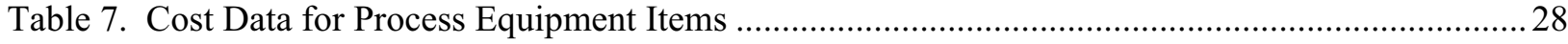

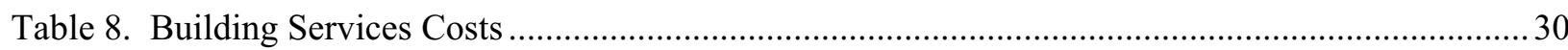

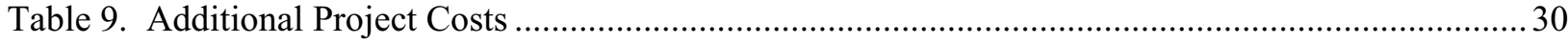

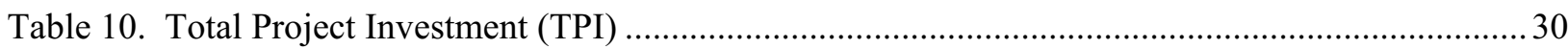

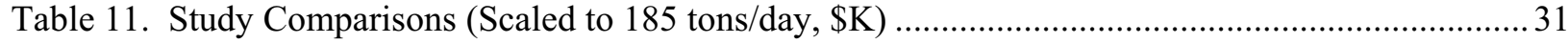

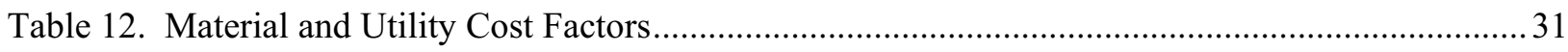

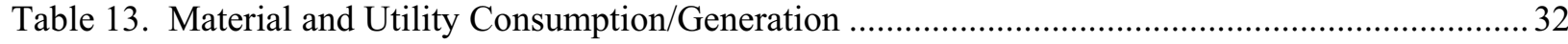

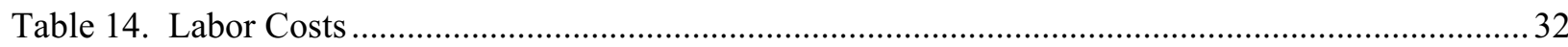

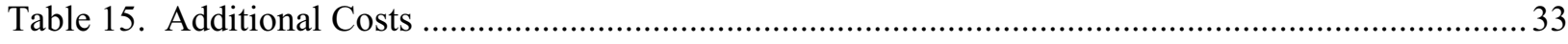

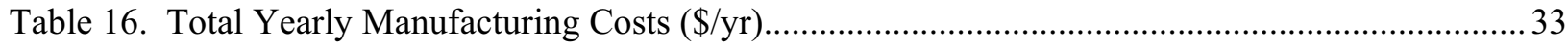

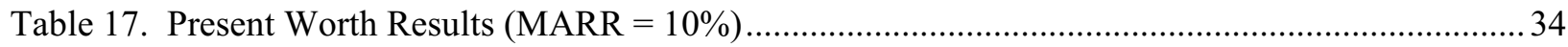

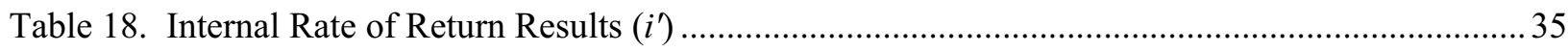

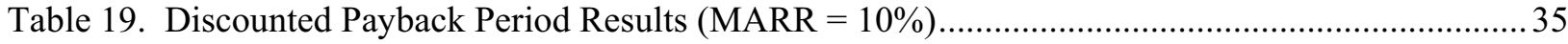

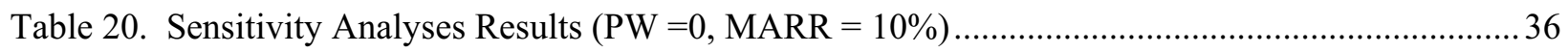




\section{ACRONYMS AND NOMENCLATURE}

\begin{tabular}{|c|c|}
\hline $\begin{array}{l}\text { ASME } \\
\text { BDT }\end{array}$ & $\begin{array}{l}\text { American Society of Mechanical Engineers } \\
\text { bone dry ton }\end{array}$ \\
\hline BTG & Biomass Technology Group \\
\hline $\mathrm{CaCO}_{3}$ & lime mud \\
\hline $\mathrm{CaO}$ & lime \\
\hline CEPCI & Chemical Engineering Plant Cost Index \\
\hline DOE & Department of Energy \\
\hline EERE & Energy Efficiency and Renewable Energy \\
\hline HHV & higher heating value \\
\hline INL & Idaho National Laboratory \\
\hline IP & intermediate pressure \\
\hline IRR & internal rate of return \\
\hline LHV & lower heating value \\
\hline LP & low pressure \\
\hline MARR & minimum annual rate of return \\
\hline NREL & National Renewable Energy Laboratory \\
\hline PNNL & Pacific Northwest National Laboratory \\
\hline PW & present worth \\
\hline TPI & total project investment \\
\hline$A i$ & frequency factor for species $i$ \\
\hline$C_{1}$ & equipment cost at capacity $q_{1}$ \\
\hline$C_{2}$ & equipment cost at capacity $q_{2}$ \\
\hline$E i$ & activation energy for species $i$ \\
\hline$F_{k}$ & cash flow at the end of period $k$ \\
\hline$i$ & effective interest rate \\
\hline$[i]$ & concentration of species $i$ \\
\hline$i^{\prime}$ & internal rate of return \\
\hline$k$ & index for each compounding period \\
\hline$k_{j}$ & kinetic expression for the oxidizing or gasifying species $j$ \\
\hline$k_{m}$ & mass transfer coefficient \\
\hline$N$ & number of compounding periods in the planning horizon \\
\hline$n$ & exponential factor for cost estimation \\
\hline$q_{1}$ & equipment capacity \\
\hline$q_{2}$ & equipment capacity \\
\hline$R$ & gas constant \\
\hline$r$ & initial particle radius \\
\hline$r_{c}$ & current particle radius \\
\hline$r_{i}$ & reaction rate for species $i$ \\
\hline$T$ & temperature \\
\hline$U_{s}$ & current solid velocity \\
\hline$U_{s o}$ & initial solid velocity \\
\hline$\alpha$ & hydrogen content of the char \\
\hline$\beta$ & oxygen content of the char \\
\hline$\chi$ & fuel ash content \\
\hline$\varepsilon$ & char bed void space \\
\hline$\gamma$ & ratio of $\mathrm{CO}_{2}$ versus $\mathrm{CO}$ for char oxidation \\
\hline$v_{p}$ & particle density number \\
\hline$\theta^{\prime}$ & discounted payback period \\
\hline
\end{tabular}




\section{Economic and Technical Assessment of Wood Biomass Fuel Gasification for Industrial Gas Production}

\section{INTRODUCTION AND PROCESS DESCRIPTION}

The objective of the wood biomass fuel gasification project, funded by the Department of Energy (DOE) Energy Efficiency and Renewable Energy (EERE) Program, was to perform a technical and economic assessment of materials, conceptual designs, and equipment needs for the gasification of forest product biomass to produce synthesis gas suitable for combustion in a lime kiln or a similar industrial process. The objective was accomplished through the completion of a feasibility study for a fixed-bed gasifier and associated equipment required to produce synthesis gas from standard hog fuel as a substitute for natural gas in a conventional lime kiln. An economic assessment was also performed for the reference plant. This project ultimately provides greater understanding of the technical and economic feasibility of using forest product biomass to reduce industrial use of natural gas in the forest products industry. The following sections of this report outline the process model developed for the project, assess gasifier materials issues, and present an economic assessment of the project.

\subsection{Introduction}

The DOE EERE Program has developed a national strategy for increasing woody biomass utilization. The intent of this strategy is to explore equipment and materials that enable creation of a reliable, sustainable supply of woody biomass and to encourage the formation of stable markets for converting that biomass supply into energy. The effort proposed in this project supports this strategy in terms of enhancing industrial energy security, specifically in the forest products industry, through fuel flexibility for industry.

Lime kilns are used throughout the forest products industry, specifically in the pulp and paper sector, to convert $\mathrm{CaCO}_{3}$ (lime mud) to $\mathrm{CaO}$ (lime) for reuse in the causticizing process. The conversion of lime mud to lime requires a significant amount of heat for the reaction to proceed, generally supplied by burning natural gas or fuel oil in the lime kiln. On average, lime kilns require seven to eight million BTUs per ton of lime product or between 1,500 and 2,000 standard cubic feet per minute (scfm) of natural gas to produce 350 tons of lime per day. Substituting synthesis gas for industrial gas in lime kilns would aid in reducing the forest products industry's dependence on and consumption of fossil fuels.

This project addresses both the technical and economic feasibility of replacing industrial gas in lime kilns with synthesis gas from the gasification of hog fuel. The technical assessment includes a materials evaluation, processing equipment needs, and suitability of the heat content of the synthesis gas as a replacement for industrial gas. The economic assessment includes estimations for capital, construction, operating, maintenance, and management costs for the reference plant. To perform these assessments, detailed models of the gasification and lime kiln processes were developed using Aspen Plus, a steady state process modeling simulator. The material and energy balance outputs from the Aspen Plus model were used as inputs to both the material and economic evaluations.

\subsection{Process Description}

To perform the technical and economic assessments, it was necessary to identify all necessary equipment items and create a general block flow diagram for the production of the synthesis gas, which 
would be used as a basis for the development of the Aspen Plus model. Figure 1 presents the generalized block flow diagram for the synthesis gas production. Major units include wet fuel processing, fuel drying, gasification, lime production, and waste heat recovery.

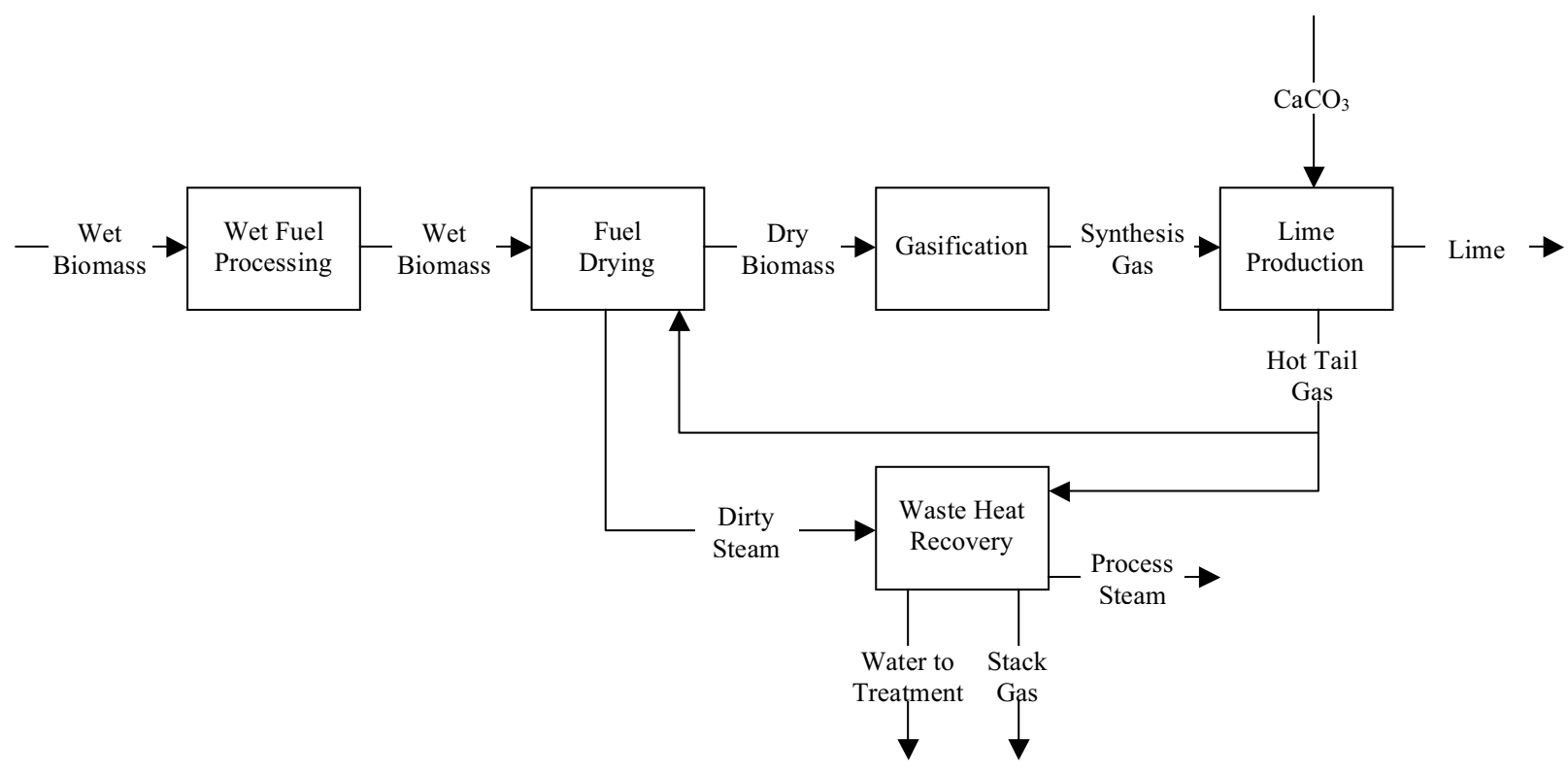

Figure 1. Block Flow Diagram for the Hog Fuel Project

Each process area presented in the block flow diagram is briefly described below:

- Wet Fuel Processing - Wet fuel, at approximately 50\% moisture by weight, is delivered to the facility via truck. The trucks are weighed using electronic scales and the fuel is unloaded and transferred to a wet fuel storage pile; the storage pile provides seven days of storage. Wet fuel leaves the fuel storage pile and has any metal, stones, and dirt removed. The fuel is then sized; any oversized material is resized using a hammermill. The wet sized fuel is then transferred to an intermediate storage facility providing 12 hours of storage.

- Fuel Drying - The wet fuel is dried using a steam drying system. The material is continuously fed from the intermediate storage facility to a plug screw feeder. The wet feed then enters the dryer via a disc shredder and is dispersed into an atmosphere of superheated steam. The steam acts as a transport gas for the material through a drying duct where the moisture evaporates via indirect heat exchange with a portion of the hot tail gas from the lime kiln. The dried product is separated from the steam in a high efficiency cyclone, and discharged to the gasifier at approximately $10 \%$ moisture by weight. Steam is recycled back through the dryer using a centrifugal fan. Waste heat can be recovered by passing the surplus steam through a reboiler. Advantages of the superheated steam dryer include: no particle emissions to the atmosphere, low primary energy requirements, minimum thermal degradation due to the short residence time and absence of oxygen, accurate control of product moisture, and no risk of explosion.

- Gasification - The biomass is gasified in an atmospheric or near atmospheric air blown countercurrent gasifier based on Emery Energy Company's E-100A gasifier design. The gasifier is a refractory lined pressure vessel designed to American Society of Mechanical Engineers (ASME) codes. Fuel enters at the top of the gasifier, undergoing devolatilization as it flows down towards the ash grate, where a hot char pile develops. Air enters at the bottom 
of the gasifier and reacts with the char providing the heat for the gasification reactions and fuel devolatilization. A low value BTU synthesis gas is removed from the top of the gasifier. The ash is removed from the bottom of the unit through the ash grate. The temperature of the ash is controlled by the amount of air fed to the gasifier in order to prevent slagging. An optional tar cracker can be included to convert the tars and oils present in the synthesis gas to carbon monoxide $(\mathrm{CO})$, carbon dioxide $\left(\mathrm{CO}_{2}\right)$, hydrogen $\left(\mathrm{H}_{2}\right)$, and water $\left(\mathrm{H}_{2} \mathrm{O}\right)$.

- Lime Kiln - The synthesis gas is delivered to the lime kiln to be combusted to provide the heat necessary to convert $\mathrm{CaCO}_{3}$ to $\mathrm{CaO}$ and $\mathrm{CO}_{2}$. The synthesis gas flow to the kiln is dictated by the amount of heat necessary to drive the conversion of $\mathrm{CaCO}_{3}$. Tail gas from the kiln is used to dry the $\mathrm{CaCO}_{3}$ mud and provide steam generation.

- Waste Heat Recovery - Waste heat is recovered from the dirty steam produced in the fuel dryer and the hot tail gas from the kiln to produce intermediate pressure (IP) and low pressure (LP) process steam.

\section{PROCESS MODEL}

\subsection{Model Description}

The plant model was developed using Aspen Plus. Aspen Plus is a steady-state process simulator that includes extensive thermodynamic databases, built-in routines for common unit operations, and the ability to properly handle complex chemical feedstocks such as coal and biomass. Due to the size and complexity of the process modeled, the simulation was constructed using "hierarchy" blocks, which is a method for nesting one simulation within another simulation. In this fashion, submodels for each major plant section can be constructed separately and then combined to represent the entire process. To facilitate utility tracking, Aspen Plus "utility" blocks were used to track IP and LP steam generated throughout the process.

\subsection{Top-Level Model}

\subsubsection{Model Description}

The top-level Aspen Plus flowsheet is shown in Figure 2. The principal purpose of this flowsheet is to tie together all of the detailed hierarchy blocks, or submodels. However, for convenience, some unit operations are modeled directly on the top-level flowsheet. A brief summary of these operations is presented below, while the individual hierarchy blocks are discussed in detail in Section 2.3 of this report.

- Gas Compression - The gas pressure of certain streams must be adjusted between blocks; hence, three compressors, Compr blocks, are included on the top-level flowsheet. Block AIR-BLWR is used to simulate a blower that increases the pressure of air from near atmospheric to $25 \mathrm{psi}$ in preparation for injection into the gasifier. Block AIRBLWR2 is used to simulate a blower that increases the pressure of air from near atmospheric to $24 \mathrm{psi}$ in preparation for injection into the tar cracker. Block TG-BLWR is used to simulate a blower which draws tail gas from the lime kiln and fuel dryer heat exchanger, and increases the pressure to atmospheric so it can be ejected out the stack.

- Steam Generation - LP steam is generated at 54 psi by recovering heat from the discharge steam from the biomass dryer in a reboiler. LP steam generation is modeled in a heat exchanger, Heater block, LPSTM. The outlet temperature of the dirty water exiting the 


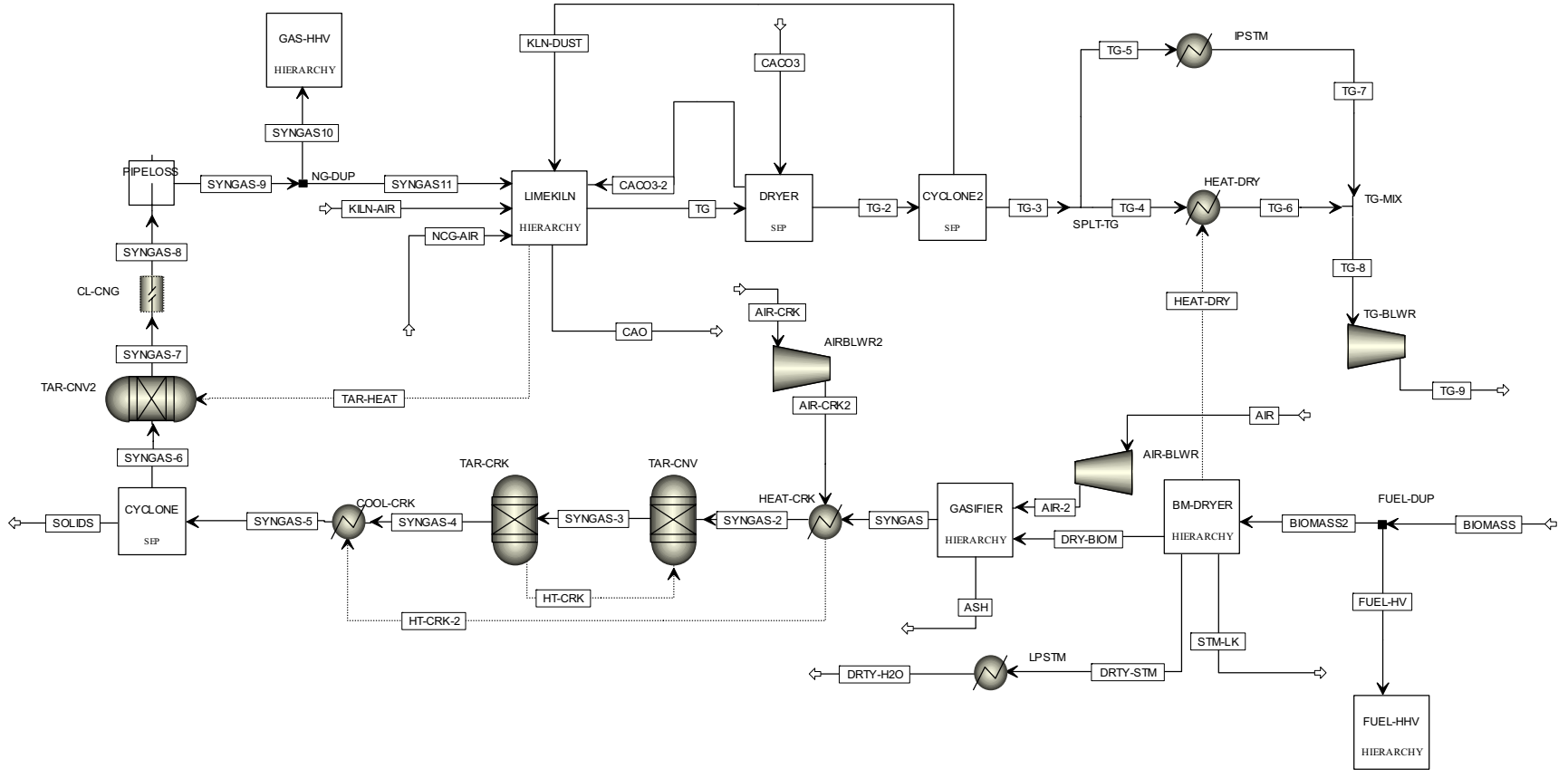

Figure 2. Top-Level Aspen Plus Process Flowsheet 
reboiler was set to $176^{\circ} \mathrm{F}$, this temperature was specified by the manufacturer, GEA Barr-Rosin, in the heat and mass balance of the Exergy ${ }^{\circledR}$ dryer. A pressure drop of one psi was assumed for the water exiting the reboiler. IP steam is generated at $170 \mathrm{psi}$ by recovering heat from the portion of the tail gas not diverted to the biomass dryer. IP steam generation is also modeled using a Heater block, IPSTM. The outlet temperature of the tail gas exiting the IP steam generator is set to $250^{\circ} \mathrm{F}$ and a pressure drop of two psi was assumed.

- Tar Cracking and Conversion - A tar cracker is modeled using the TAR-CNV and TAR-CRK reactor blocks. TAR-CNV converts $96 \%$ of the non-conventional tar component present in the synthesis gas stream to carbon, hydrogen, and oxygen, which is dependent upon the ultimate analysis of the tar, using a reactor yield block, RYield. The $96 \%$ tar conversion is based on published conversion data from Biomass Technology Group (BTG) (BTG 2007).

Fortran calculator block TARYLD is used to maintain the mass balance and block temperature when converting the tar. TAR-CRK reacts the carbon, hydrogen, and oxygen from the tar and the methane $\left(\mathrm{CH}_{4}\right), \mathrm{CO}_{2}, \mathrm{CO}$, oxygen $\left(\mathrm{O}_{2}\right), \mathrm{H}_{2} \mathrm{O}$, and $\mathrm{H}_{2}$ from the synthesis gas and air streams at $1742^{\circ} \mathrm{F}$ to equilibrium using a Gibbs reactor block, RGibbs. It is necessary to preheat the air for cracking, AIR-CRK, and the synthesis gas entering the tar cracker to $1652^{\circ} \mathrm{F}$ using the hot synthesis gas exiting from the cracker. A heat exchanger is modeled using two interdependent Heater blocks, HEAT-CRK and COOL-CRK. A pressure loss of two psi is assumed for both the hot and cold synthesis gas streams exiting the heat exchanger and a minimum temperature approach of $90^{\circ} \mathrm{F}$ is assumed by setting the preheat temperature to $1652^{\circ} \mathrm{F}$. The remaining non-conventional, highly refractory tar component is broken down to carbon, hydrogen, and oxygen using an additional RYield block, TAR-CNV2, prior to the syngas being fed to the lime kiln. Again, a Fortran calculator block, TARYLD2, is used to maintain the mass balance and block temperature when converting the tar.

- Solids Separation - The cyclone downstream of the gasifier and tar cracker, CYCLONE, is modeled using a generic separation block, Sep. This block removes all of the solid materials, including ash, unreacted fuel, and char from the gas stream. Solids are assumed to leave this block at atmospheric pressure and a pressure drop of two psi was assumed for the gas stream exiting the cyclone. The CYCLONE block is actually modeling two cyclones, one before and one after the tar cracker. The cyclone downstream of the lime kiln, CYCLONE2, is also modeled using a Sep block. This block separates the $\mathrm{CaO}$ dust from the tail gas. The $\mathrm{CaO}$ dust is then recycled back to the lime kiln, a pressure drop of one psi was assumed.

- Piping - Heat loss and pressure drop are simulated for the length of piping between the gasifier and lime kiln using a Heater block, PIPELOSS. Pressure drop in the piping is assumed to be $0.5 \mathrm{psi}$. The outlet temperature of the piping was set to $600^{\circ} \mathrm{F}$ to account for heat loss.

- $\quad$ Lime Kiln Dryer - The block DRYER, a Sep block, is used to simulate drying the moist $\mathrm{CaCO}_{3}$ mud using heat from the hot tail gas from the lime kiln. The hot mud outlet temperature is specified at $635^{\circ} \mathrm{F}$ (Gorog 2002). The evaporated water leaves the dryer with the tail gas and the hot $\mathrm{CaCO}_{3}$ is passed to the lime kiln.

- Biomass Dryer Heat Exchanger - A Heater block is used to simulate the heat loss from the portion of the tail gas used to dry the wet biomass. The heat required is dictated by the amount of moisture evaporated and removed from the biomass. A pressure drop of two psi was assumed for the tail gas exiting the heat exchanger. 


\subsubsection{Design Constraints and Specifications}

The following design constraints are specified in the top-level model to control the operation of the biomass dryer, gasifier, and lime kiln:

- The flow of air to the gasifier is varied in the design specification AIR-GASF to maintain an ash outlet temperature of $2000^{\circ} \mathrm{F}$. This ash temperature was chosen since it is well below the ash softening point for hog fuel, which is approximately $2400^{\circ} \mathrm{F}$, and provides the exit gas a suitable temperature for either tar cracking or tar retention (Zygarlicke 2004).

- The flow of air to the tar cracker is varied in the design specification AIR-CRK so that the heat generated in the TAR-CRK block is equal to the heat required to convert the non-conventional tar to carbon, hydrogen, and oxygen while maintaining the inlet temperature of the gas stream across the TAR-CNV block.

- The flow of air to the lime kiln is varied in the design specification AIR-KILN so that there is $1.8 \%$ excess oxygen, on a mass basis, after the fuel is fired in the lime kiln. The amount of excess air was taken from a Weyerhaeuser lime kiln overview presentation for the Kamloops lime kiln (Gorog 2002).

- The flow of biomass to the biomass dryer is varied in the design specification FUEL. This design specification varies the feed rate of the fuel so that the outlet temperature of the tail gas exiting the lime kiln is approximately $1250^{\circ} \mathrm{F}$ (Gorog 2002 ).

- The design specification DRY-KILN sets the calculated duty of the $\mathrm{CaCO}_{3}$ dryer, DRYER, to zero by adjusting the outlet flash temperature of the tail gas exiting the dryer.

- $\quad$ SPLT-TG controls the amount of tail gas sent to the heat exchanger used to dry the biomass SPLT-TG. This specification sets the outlet temperature of the tail gas leaving the heat exchanger to $250^{\circ} \mathrm{F}$ by adjusting the flow of tail gas to the heat exchanger HEAT-DRY.

- To maintain the temperature of the gas entering and exiting block TAR-CNV2, specification TARTEMP adjusts the heat stream to the block to the amount of duty required to convert tar to carbon, hydrogen, and oxygen. This heat stream is supplied from a heat stream in the LIMEKILN hierarchy, since this conversion would actually take place in the lime kiln burner.

- A Fortran calculator block, GASF-P, is used to set the pressure of the first block in the GASIFIER hierarchy to the outlet pressure of the AIR-BLWR block. This calculator block also adjusts the pressure of AIRBLWR2 to match the outlet pressure of the synthesis gas stream exiting the gasifier.

\subsubsection{Data Sources, Assumptions, and Limitations}

A combination of open literature and operating data was used to specify parameters for the unit operations, calculator blocks, and design specifications used in the top-level model. Proximate and ultimate analyses for hog fuel were obtained from literature (Zygarlicke 2004). Compressor efficiencies in this model have been set at Aspen Plus defaults of $72 \%$. This can have a significant impact on the power requirements for the blowers used in this model; thus, it is recommended to tune these results based on performance data from vendors for more accurate modeling results. In addition, generalized pressure drops are assumed for the majority of the process equipment items; again, it is recommended to obtain pressure drop data from the vendors for the appropriate equipment items for increased accuracy. 


\subsection{Submodels}

\subsubsection{Biomass Dryer}

\subsubsection{Submodel Description}

Biomass drying is modeled using design data supplied by GEA Barr-Rosin. The Aspen Plus flowsheet for this hierarchy block is shown in Figure 3. Biomass drying is simply modeled in Aspen Plus using four blocks. MOISTYLD, the first block, is modeled as a RYield reactor in Aspen Plus. In MOISTYLD, a Fortran calculator block is utilized to partition water from the solid biomass into the vapor phase, the moisture content of the biomass after drying is assumed to be $10 \%$ on a mass basis.

Additionally, the pressure is raised to the pressure required to saturate the steam in the drying loop, 58.2 psi. In the second block, heat from the HEAT-DRY block in the top-level model is passed to the SPR-HTR, a Heater block, to raise the temperature of the outlet stream to $419^{\circ} \mathrm{F}$. In the third block, DISCHRG, water vapor is separated from the biomass using a Sep block. The fourth block, STM-SPLT, separates a small percentage of the steam generated in the block lost to steam leakage using a Sep block, the remainder of the steam is sent to the reboiler in the top-level model.

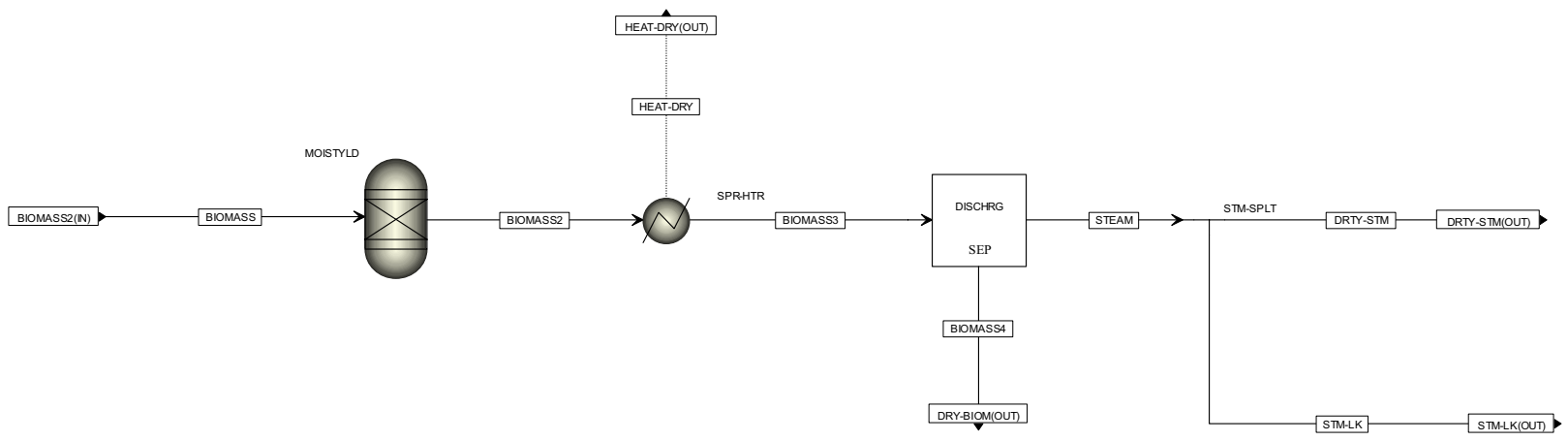

Figure 3. Aspen Plus Process Flowsheet for BM-DRYER Hierarchy Block

\subsubsection{Data Sources, Assumptions, and Limitations}

The heat and mass balance of the Exergy Dryer® from GEA Barr-Rosin was utilized as inputs to the unit operations used to model the biomass dryer. However, this data was for a steam to wet biomass heat exchanger; hence, it is recommended to tune these results based on heat and mass balance data from GEA Barr-Rosin for a tail gas to wet biomass heat exchanger, which was not available at the time of modeling.

\subsubsection{Gasification}

\subsubsection{Submodel Description}

Drying, devolatilization, and gasification of the biomass and ash separation are performed in the GASIFIER hierarchy block. Drying and devolatilization are performed separately from gasification to mimic the countercurrent operation of the fixed bed gasifier modeled, where the heat required to dry and devolatilize the fuel is exchanged with the outlet synthesis gas stream to determine the outlet temperature of the gas leaving the gasification zone. The Aspen Plus flowsheet for this hierarchy block is shown in Figure 4. 


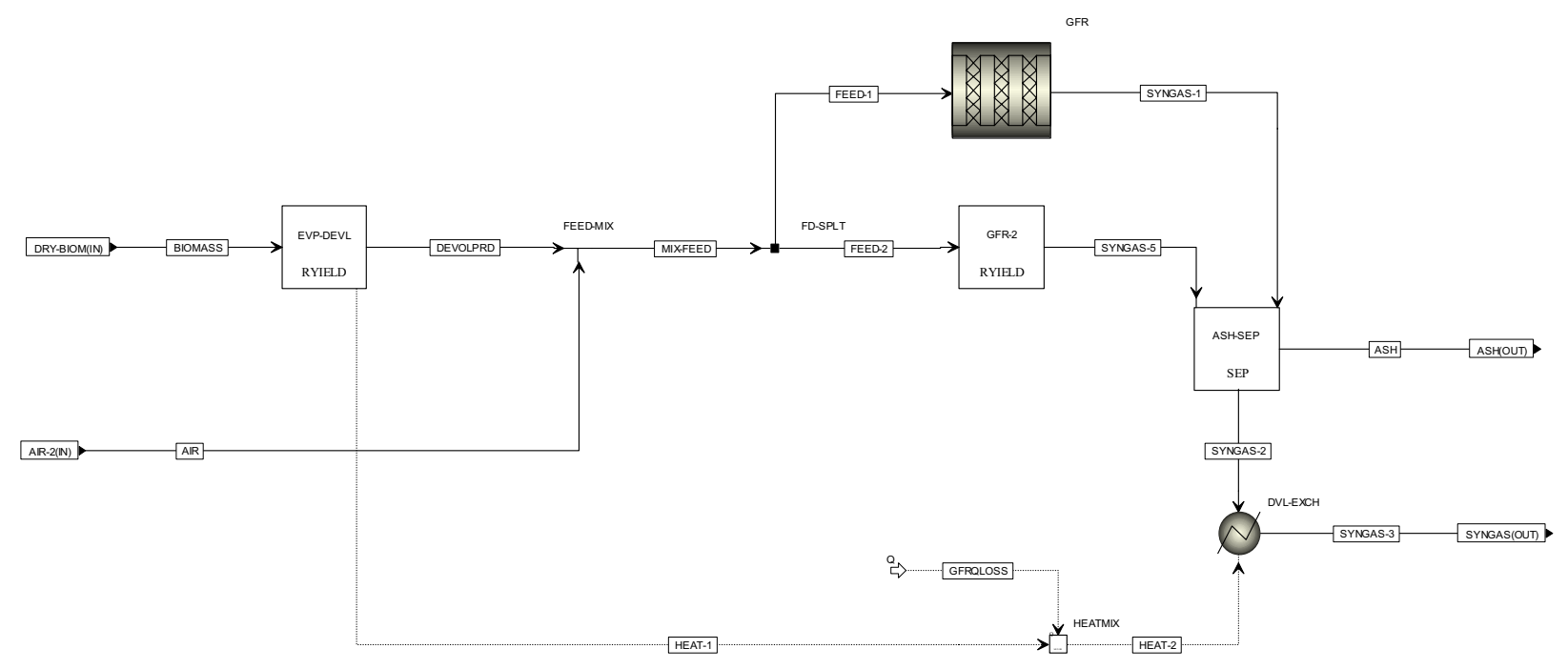

Figure 4. Aspen Plus Process Flowsheet for GASIFIER Hierarchy Block

Biomass drying and devolatilization are modeled simply in Aspen Plus using a single block. In this block, EVP-DEVL, the temperature is raised to the devolatilization temperature of $1652^{\circ} \mathrm{F}$. Heat transfer from the gasifier outlet hot gas stream provides the heat required for drying and devolatilization. EVP-DEVL is modeled as a RYield reactor in Aspen Plus, and a Fortran calculator block, EVPDVL, is utilized to partition water from the solid biomass into the vapor phase. This Fortran block is also used to partition the carbon, hydrogen, and oxygen present in the fuel as water, char, tar, and gas products, including $\mathrm{CO}, \mathrm{CO}_{2}, \mathrm{H}_{2}$, and $\mathrm{CH}_{4}$. The amount of devolatilization products formed was taken from a study which evaluated the amount of various devolatilization products from biomass, including tar cracking reactions. This study was well suited for this modeling application, since the devolatilization experiments for wood were conducted using three to five millimeter wood chips versus typical experiments, which devolatilize fine particles of wood, such as sawdust (Fagbemi 2001).

After drying and devolatilization, four Aspen Plus blocks are used to model the remaining sections of the gasifier. First, air from the top-level model is mixed with the hot devolatilization products from the EVP-DEVL block. The flow is then split, and sent to one of two gasifier blocks. The first block, GFR, is modeled using a plug flow reactor block, RPlug, supplemented with a Fortran user kinetic subroutine. The second block, GFR-2, uses a Fortran calculator block, RNX-2, to assign product yields to an Aspen Plus RYield block to match the yields generated in the rigorous GFR block. Both gasifier blocks specify a pressure drop of $0.54 \mathrm{psi}$ (Emery 2007). Next, the ash species generated in the gasification reaction, are separated from the gas products using a Sep block. Finally, the outlet temperature of the gases and tar leaving the gasifier is determined by the DVL-EXCH Heater block, which removes the required heat from the hot gas stream to devolatilize and dry the biomass. Heat loss from the gasifier is assumed to be one percent of the enthalpy of the products entering the reactor and is calculated in the Fortran block GFRQLOSS (Emery 2007).

\subsubsection{Design Constraints and Specifications}

The Fortran kinetic user subroutine is used to calculate the rate generation or depletion for each component in the system. This kinetic routine was developed based upon the kinetics described in the Modeling Wood Gasification in a Countercurrent Fixed-Bed Reactor (Di Blasi 2004). Individual kinetic expressions for the reactions modeled in the subroutine were obtained from literature. The reactions modeled can be broken down into gas phase reactions and char reactions. 
Gas phase reactions include the reaction of $\mathrm{CH}_{4}, \mathrm{CO}$, and $\mathrm{H}_{2}$ with $\mathrm{O}_{2}$ and the forward and reverse water gas shift reactions. Kinetic expressions for the oxidation reactions were taken from "Solid Fuels Combustion and Gasification" (Souza-Santos 2004). The reaction of $\mathrm{CH}_{4}$ and $\mathrm{O}_{2}$ can be represented by the following chemical reaction and kinetic rate expression:

$$
\begin{aligned}
& \mathrm{CH}_{4}+2 \mathrm{O}_{2} \rightarrow \mathrm{CO}_{2}+2 \mathrm{H}_{2} \mathrm{O} \\
& r_{\mathrm{CH}_{4}}=\varepsilon \cdot A_{\mathrm{CH}_{4}} \cdot T^{-1} \cdot \exp \left(\frac{-E_{\mathrm{CH}_{4}}}{T}\right) \cdot\left[\mathrm{CH}_{4}\right] \cdot\left[\mathrm{O}_{2}\right]
\end{aligned}
$$

where $\varepsilon$ is the void space in the bed, $A_{C H 4}$ is the frequency factor, $E_{C H 4}$ is the activation energy, $T$ is the temperature in the reactor, $\left[\mathrm{CH}_{4}\right]$ is the concentration of methane in the reactor, and $\left[\mathrm{O}_{2}\right]$ is the concentration of oxygen in the reactor (Souza-Santos 2004). Similar expressions for the reactions of CO and $\mathrm{H}_{2}$ with $\mathrm{O}_{2}$ are defined as follows:

$$
\begin{aligned}
& 2 \mathrm{CO}+\mathrm{O}_{2} \rightarrow 2 \mathrm{CO}_{2} \\
& r_{\mathrm{CO}}=2 \cdot \varepsilon \cdot A_{\mathrm{CO}} \cdot \exp \left(\frac{-E_{\mathrm{CO}}}{T}\right) \cdot[\mathrm{CO}] \cdot\left[\mathrm{O}_{2}\right]^{0.25} \cdot\left[\mathrm{H}_{2} \mathrm{O}\right]^{0.5} \\
& 2 \mathrm{H}_{2}+\mathrm{O}_{2} \rightarrow 2 \mathrm{H}_{2} \mathrm{O} \\
& r_{\mathrm{H}_{2}}=2 \cdot \varepsilon \cdot A_{\mathrm{H}_{2}} \cdot T^{-1.5} \cdot \exp \left(\frac{-E_{\mathrm{H}_{2}}}{T}\right) \cdot\left[\mathrm{H}_{2}\right]^{1.5} \cdot\left[\mathrm{O}_{2}\right]
\end{aligned}
$$

where $A_{C O}$ and $A_{H 2}$ are the frequency factors, $E_{C O}$ and $E_{H 2}$ are the activation energies, [CO] is the concentration of carbon monoxide in the reactor, $\left[\mathrm{H}_{2} \mathrm{O}\right]$ is the concentration of water in the reactor, and $\left[\mathrm{H}_{2}\right]$ is the concentration of hydrogen in the reactor (Souza-Santos 2004).

To accurately model the water gas shift reaction, kinetic expressions were entered in the user subroutine for both the forward and reverse gas shift reactions. The forward reaction is represented in the code by the following chemical reaction and kinetic rate expression:

$$
\begin{aligned}
& \mathrm{CO}+\mathrm{H}_{2} \mathrm{O} \rightarrow \mathrm{CO}_{2}+\mathrm{H}_{2} \\
& r_{f w g s}=\varepsilon \cdot A_{f w g s} \cdot \exp \left(\frac{-E_{f w g s}}{R \cdot T}\right) \cdot\left[\mathrm{H}_{2} \mathrm{O}\right] \cdot[\mathrm{CO}]^{0.5}
\end{aligned}
$$

where $A_{f w g s}$ is the frequency factor, $E_{f w g s}$ is the activation energy, and $R$ is the gas constant (Enick 2005). The reverse water gas shift reaction rate expression takes a similar form to the forward reaction:

$$
\begin{aligned}
& \mathrm{CO}_{2}+\mathrm{H}_{2} \rightarrow \mathrm{CO}+\mathrm{H}_{2} \mathrm{O} \\
& r_{r w g s}=\varepsilon \cdot A_{r w g s} \cdot \exp \left(\frac{-E_{r w g s}}{R \cdot T}\right) \cdot\left[\mathrm{H}_{2}\right]^{a} \cdot\left[\mathrm{CO}_{2}\right]
\end{aligned}
$$


where $A_{r w g s}$ is the frequency factor, $E_{r w g s}$ is the activation energy, and $a$ is the exponential factor for the hydrogen concentration; $a$ is equal to $1 / 3$ when the temperature is less than $1472^{\circ} \mathrm{F}$ and equal to $1 / 2$ when temperature is greater than $1472^{\circ} \mathrm{F}$ (Bustamante 2005).

The combustion and gasification reactions of char are heterogeneous and best described by the unreacted core, shrinking particle model. The mechanisms of diffusion through the gas film surrounding the particle and chemical kinetics are considered for the global reaction rate. To account for the simultaneous effects of these two mechanisms, an effective volumetric reaction rate is introduced which assumes a linear dependency on the oxidizing/gasifying species concentration. Thus, shrinkage of the particle occurs as a consequence of the heterogeneous reactions (Di Blasi 2004). The following oxidation and gasification reactions were included in the model:

$$
\begin{aligned}
& \mathrm{CH}_{\alpha} \mathrm{O}_{\beta}+\mathrm{O}_{2} \rightarrow\left(2-2 \gamma-\beta+\frac{\alpha}{2}\right) \mathrm{CO}+\left(2 \gamma+\beta-\frac{\alpha}{2}-1\right) \mathrm{CO}_{2}+\frac{\alpha}{2} \mathrm{H}_{2} \mathrm{O} \\
& \mathrm{CH}_{\alpha} \mathrm{O}_{\beta}+\mathrm{CO}_{2} \rightarrow 2 \mathrm{CO}+\beta \mathrm{H}_{2} \mathrm{O}+\left(\frac{\alpha}{2}-\beta\right) \mathrm{H}_{2} \\
& \mathrm{CH}_{\alpha} \mathrm{O}_{\beta}+\left(2-\frac{\alpha}{2}+\beta\right) \mathrm{H}_{2} \rightarrow \mathrm{CH}_{4}+\beta \mathrm{H}_{2} \mathrm{O} \\
& \mathrm{CH}_{\alpha} \mathrm{O}_{\beta}+(1-\beta) \mathrm{H}_{2} \mathrm{O} \rightarrow \mathrm{CO}+\left(1-\beta+\frac{\alpha}{2}\right) \mathrm{H}_{2}
\end{aligned}
$$

where $\alpha$ is the hydrogen content of the char, $\beta$ is the oxygen content of the char, and $\gamma$ defines the ratio of $\mathrm{CO}_{2}$ versus $\mathrm{CO}$ formed in the char oxidation reaction (Di Blasi 2004). Gamma is defined as a function of reaction temperature as follows (Souza-Santos 2004):

$$
\gamma=\frac{2+2500 \cdot \exp \left(\frac{-6240}{T}\right)}{2+2 \cdot 2500 \cdot \exp \left(\frac{-6240}{T}\right)}
$$

The following reaction rates, $r_{i}$, are considered for each of the oxidation and gasification reactions:

$$
\begin{aligned}
& r_{i}=\frac{[i]}{\frac{1}{k_{m}}+\frac{1}{k_{i}}} \cdot v_{p} \\
& i=\mathrm{O}_{2}, \mathrm{CO}_{2}, \mathrm{H}_{2}, \mathrm{H}_{2} \mathrm{O}
\end{aligned}
$$

where $[i]$ is the concentration of the oxidizing or gasifying species, $k_{m}$ is the mass transfer coefficient $(0.15 \mathrm{~m} / \mathrm{s}), k_{i}$ is the kinetic expression for the oxidizing or gasifying species, and $v_{p}$ is the particle density number. The kinetic expression for each oxidizing/gasifying species takes the following form:

$$
k_{i}=A_{i} \cdot \exp \left(\frac{-E_{i}}{T_{s}}\right)
$$


where $A_{i}$ is the frequency factor for each oxidizing/gasifying species, $E_{i}$ is the activation energy for each oxidizing/gasifying species, and $T_{s}$ is the temperature of the solid (Di Blasi 2004). The values for the frequency factors and activation energies were taken from the fixed bed model developed by Hobbs (1992). To simplify the Aspen Plus model, it was assumed that the temperature of the solid is equal to the overall temperature in the reactor, given the long solids residence time compared to the time for the heat to distribute through the small particles. The particle density number is a function of the ash content of the fuel and the ratio of the current particle velocity to the initial particle velocity. The particle density number is defined in terms of the following expressions:

$$
\begin{aligned}
& v_{p}=\frac{3(1-\varepsilon)}{r_{c}} \\
& \left(\frac{r_{c}}{r}\right)^{3}=(1-\chi) \cdot \frac{U_{s}}{U_{s o}}+\chi
\end{aligned}
$$

where $r_{c}$ is the current particle radius, $r$ is the initial particle radius, $\chi$ is the ash content of the fuel, $U_{s}$ is the current solid velocity, and $U_{s o}$ is the initial solid velocity (Di Blasi 2004). The kinetic user subroutine used in the model and model results are presented in Appendices C and A, respectively.

\subsubsection{Results Comparison}

To assess the predictive capabilities of the kinetic model, model results were compared to actual gas compositions from industrial and laboratory scale updraft biomass gasifiers. Table 1 compares the operational gas compositions with those predicted by the Aspen Plus model for the Wellman single stage gasifier and a laboratory scale gasifier at Pacific Northwest National Laboratory (PNNL). Mass flows for biomass, air/oxygen, and steam were obtained directly from the technical articles, or back calculated from material balances. Biomass proximate and ultimate analyses were updated for the appropriate carbon, hydrogen, oxygen, moisture, and ash contents of the fuels. As shown below, the Aspen Plus kinetic model adequately predicts gas composition within $5 \%$ of measured results.

\begin{tabular}{|c|c|c|}
\hline & Actual & Aspen Plus \\
\hline \multicolumn{3}{|c|}{ Wellman Single Stage Gasifier (McLellan 2000) } \\
\hline $\mathrm{H}_{2}$ & 7.9 & 6.6 \\
\hline $\mathrm{CH}_{4}$ & 1.2 & 2.5 \\
\hline $\mathrm{H}_{2} \mathrm{O}$ & 38.8 & 38.0 \\
\hline $\mathrm{CO}$ & 18.3 & 17.2 \\
\hline $\mathrm{N}_{2}$ & 29.4 & 29.5 \\
\hline $\mathrm{CO}_{2}$ & 4.4 & 5.7 \\
\hline \multicolumn{3}{|c|}{ PNNL Laboratory Results (Baker 1984) } \\
\hline $\mathrm{H}_{2}$ & 27.5 & 28.9 \\
\hline $\mathrm{CH}_{4}$ & 4.8 & 7.8 \\
\hline $\mathrm{CO}$ & 51.6 & 52.7 \\
\hline $\mathrm{CO}_{2}$ & 15.1 & 11.1 \\
\hline
\end{tabular}

Table 1. Gas Composition Comparisons (vol\%) 


\subsubsection{Data Sources, Assumptions, and Limitations}

As mentioned previously, biomass drying and devolatilization are modeled simply in Aspen Plus using a single yield block supplemented with a Fortran block to determine the devolatilization products. Again, the amount of the devolatilization products formed was taken from the Fagbemi study; however, the devolatilization products from this study were altered slightly to maintain a similar tar composition for the tar produced from devolatilization in this study when compared to the tar composition in Fagbemi, as well as maintain the material balance for carbon, hydrogen, and oxygen. Table 2 compares the data presented in Fagbemi versus the devolatilization data used in the Aspen Plus model. For future models, devolatilization measurements should be obtained for the specific fuel in question, and tests should be run if measurements are not available.

Table 2. Comparison of Devolatilization Data

\begin{tabular}{|c|c|c|}
\hline & Fagbemi & Aspen Plus \\
\hline \multicolumn{3}{|c|}{ Devolatilization Products } \\
\hline Gas Mass \% & 47 & 47 \\
\hline Tars Mass $\%$ & 10 & 10.5 \\
\hline Char Mass \% & 20 & 22 \\
\hline Water Mass \% & 22 & 20.5 \\
\hline \multicolumn{3}{|l|}{ Fuel Composition } \\
\hline Carbon & 45.68 & 44.74 \\
\hline Hydrogen & 6.3 & 5.5 \\
\hline Oxygen & 47.42 & 43.45 \\
\hline Ash & 0.3 & 6.31 \\
\hline \multicolumn{3}{|l|}{ Tar Composition } \\
\hline Carbon & 53.9 & 59.5 \\
\hline Hydrogen & 6.8 & 7.1 \\
\hline Oxygen & 39.3 & 33.4 \\
\hline
\end{tabular}

The kinetic data for the gas phase and char reactions were pieced together from the most reliable and recent literature sources available. However, there is significant variation in the rates for many of the reactions present in this model. In addition, kinetic data for some reactions, such as the forward and reverse water gas shift reactions, have only been validated over a narrow temperature range. Thus, future work should involve verification of the various kinetic expressions to minimize uncertainty. Furthermore, formation of $\mathrm{NO}_{\mathrm{x}}$ and $\mathrm{SO}_{\mathrm{x}}$ is not included in this model. Incorporation of these criteria pollutants and their corresponding kinetic expressions should be included in future versions of the model.

The model does not account for gasification of the tars created during devolatilization. This is because the concentration of tars created in the devolatilization routine match literature data for the tar and oil concentrations in updraft biomass gasification, approximately 50 grams per normal cubic meter (Evans 1998). In addition, the model does not have predictive capabilities for char conversion. In the model, it is assumed that $95 \%$ of the char is converted to gas products, which is a conservative assumption for a properly operated updraft biomass gasifier. 


\subsubsection{Lime Kiln}

\subsubsection{Submodel Description}

The lime kiln is modeled in the LIMEKILN hierarchy to predict the amount of fuel necessary to fire a standard lime kiln. The lime kiln was modeled based upon information from a Weyerhaeuser lime kiln overview presentation for the Kamloops lime kiln (Gorog 2002). The Aspen Plus flowsheet of the LIMEKILN hierarchy is shown in Figure 5.

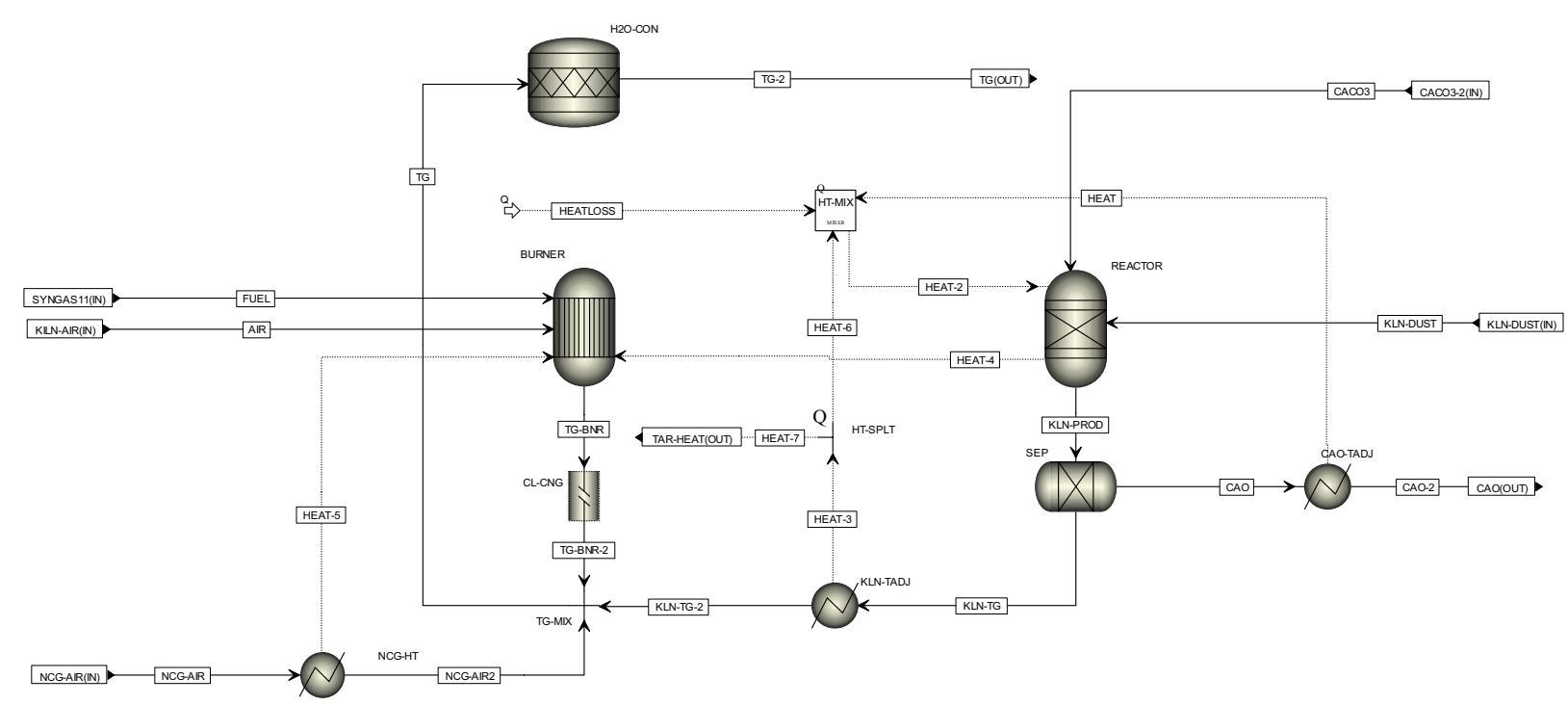

Figure 5. Aspen Plus Process Flowsheet for LIMEKILN Hierarchy Block

The LIMEKILN hierarchy is comprised of the following Aspen Plus unit operation blocks:

- BURNER - Combusts the synthesis gas and the air supplied to the lime kiln. This block is modeled using a RGibbs block at atmospheric pressure. The heat streams fed to the reactor dictate the reaction temperature of the block.

- CL-CNG - This block changes the stream class to MIXCISLD, since solid components are used in the lime kiln.

- REACTOR - This block reacts the $\mathrm{CaCO}_{3}$ to $\mathrm{CaO}$ and $\mathrm{CO}_{2}$ with the heat supplied from the BURNER block using a RGibbs block. The temperature of this reactor block is set at $2282^{\circ} \mathrm{F}$, the average temperature for the lime reaction (Speight 2002).

- $\quad$ SEP - This Sep block separates the $\mathrm{CaO}$ from the tail gas after the REACTOR block. However, a portion of the $\mathrm{CaO}$ product leaves with the tail gas as entrained $\mathrm{CaO}$ dust.

- KLN-TADJ - Cools the tail gas from the REACTOR block to the temperature of the tail gas from TG-BNR, $1250^{\circ} \mathrm{F}$, using a Heater block, as specified in the Weyerhaeuser presentation.

- CAO-TADJ - This Heater block cools the $\mathrm{CaO}$ product from the REACTOR block to $1300^{\circ} \mathrm{F}$. Again this temperature was specified in the Weyerhaeuser presentation. 
- HT-SPLT - Provides the heat required to the top-level model to convert the tar present in the synthesis gas to carbon, hydrogen, and oxygen based on a design specification in the top-level model which controls the split in HT-SPLT.

- $\quad$ NCG-HT - Heats the additional air fed to the gasifier to the outlet temperature of the tail gas using a Heater block. The excess air flow was specified in the Weyerhaeuser presentation.

- H2O-CON - The water fed with the $\mathrm{CaCO}_{3}$ is converted to water in a stoichiometric reactor block, RStoic. Two types of water were used in this simulation to track the water dried from the lime mud and the water present in the tail gas after being burned in the lime kiln.

- HT-MIX - This block is used to mix all of the heat generated and consumed internally in the lime kiln to accurately predict the amount of fuel required to fire the lime kiln. The stream HEATLOSS was specified to match the heat loss listed in the Weyerhaeuser presentation.

\subsubsection{Data Sources, Assumptions, and Limitations}

The lime kiln was modeled based upon information from a Weyerhaeuser lime kiln overview presentation for the Kamloops lime kiln (Gorog 2002). The data from this report is for a specific kiln, it would be beneficial to verify the kiln requirements for other operational lime kilns. However, the results generated in the Aspen Plus model closely match the data from the Weyerhaeuser presentation as shown in the following table, when natural gas is used to fire the lime kiln.

Table 3. Comparison of Lime Kiln Data

\begin{tabular}{|c|c|c|}
\hline & Weyerhaeuser & Aspen Plus \\
\hline \multicolumn{3}{|l|}{ Mass Flows (ton/hr) } \\
\hline Mud Feed & 30.69 & 30.69 \\
\hline Kiln Product & 14.75 & $14.75^{1}$ \\
\hline Combustion Air & 42.10 & $41.29^{1}$ \\
\hline Natural Gas & 2.24 & $2.29^{1}$ \\
\hline Kiln Dust & 1.35 & 1.34 \\
\hline Tail Gas from Drier & 60.8 & $61.4^{1}$ \\
\hline \multicolumn{3}{|c|}{ Kiln Heat Requirement (MMBTU/ton) } \\
\hline Natural Gas Model & 7.17 & $7.17^{1}$ \\
\hline
\end{tabular}

1 - Indicates value predicted by Aspen Plus process model

\subsubsection{Heating Value Calculations}

\subsubsection{Submodel Description}

Two hierarchy blocks are included in the simulation that do not represent process unit operations: BIOMASS-HHV and GAS-HHV. These blocks are included as checks to calculate the heating value of the biomass feed and the synthesis gas. Because these blocks are similar, only one of them will be detailed in this report. The Aspen Plus flowsheet for hierarchy block BIOMASS-HHV is shown in Figure 6. 


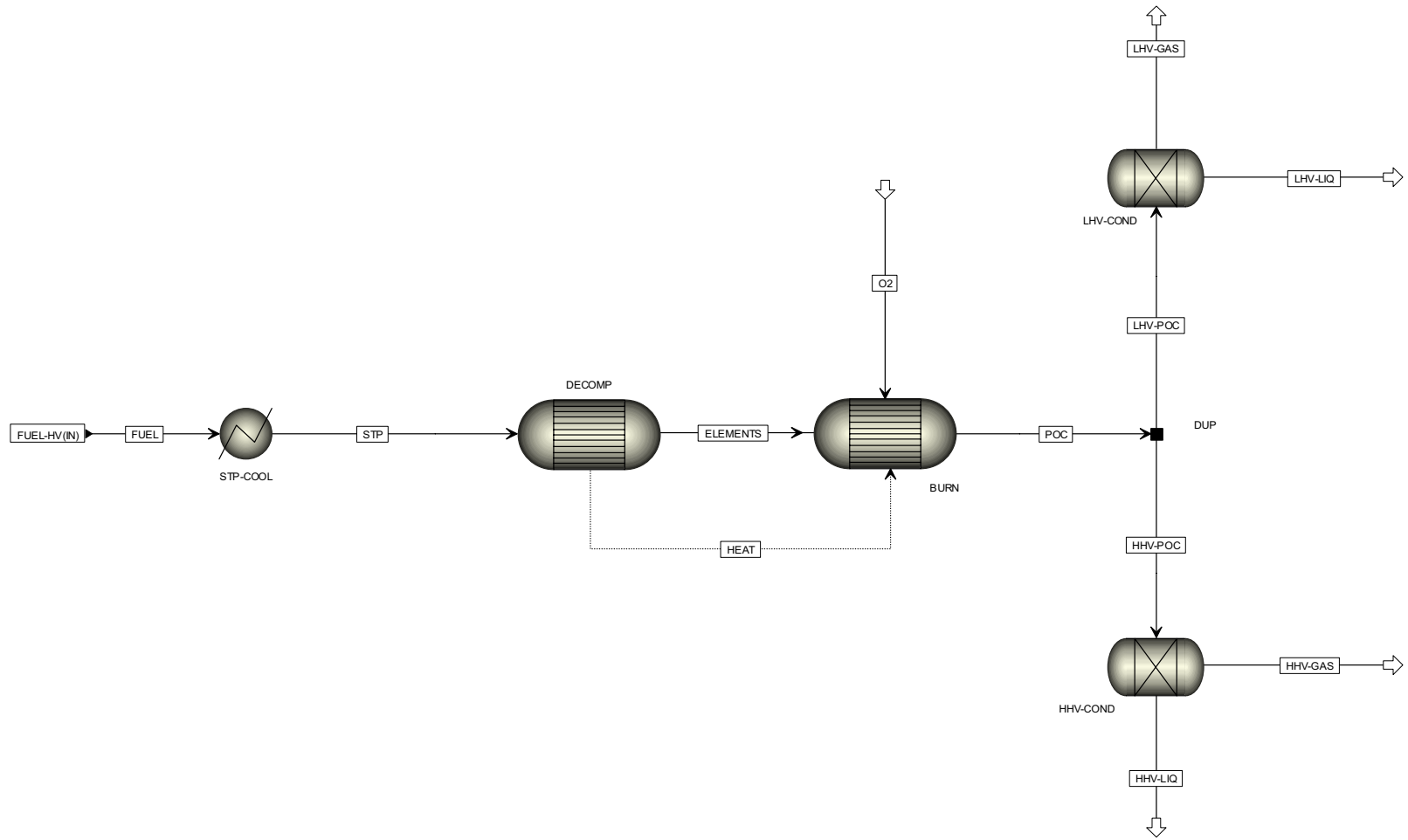

Figure 6. Aspen Plus Process Flowsheet for BIOMASS-HHV Hierarchy Block

The biomass feed is set to standard conditions for temperature and pressure in Heater block STP-COOL $\left(68^{\circ} \mathrm{F}\right.$ and $\left.14.7 \mathrm{psi}\right)$. This stream is then decomposed into $\mathrm{H}_{2} \mathrm{O}$, carbon $(\mathrm{C}), \mathrm{H}_{2}, \mathrm{O}_{2}$ in RYield block DECOMP using a Fortran calculator block similar to that previously described for tar decomposition. To maintain the heat balance, all heat generated from decomposition of the biomass is transferred with the effluent gas to RStoic block BURN. In this block, a stoichiometric amount of oxygen is added to completely combust the gas. An unrealistically high temperature is predicted, but because temperature is a state function this will not adversely impact final calculation of the heating value for the biomass. The hot gas stream exiting block BURN is duplicated into two identical streams in Dupl block DUP. Each resulting stream is subsequently cooled back to $68^{\circ} \mathrm{F}$ either in block LHV-COND or HHVCOND, both of which are modeled as Sep blocks. These two blocks are specified to partition all gas species from the remaining solid ash. However, block LHV-COND partitions water as liquid with the ash, whereas block HHV-COND partitions water as vapor with the other gases. The resulting duty of each block is divided by the mass flow rate of biomass entering the hierarchy block to calculate the heating value of the biomass. Due to the different handling of water, the value calculated for LHVCOND is the lower heating value (LHV) for the biomass, while the value calculated for HHV-COND is the higher heating value (HHV) for the biomass.

\subsubsection{Design Constraints and Specifications}

The three calculator blocks used in this hierarchy block are briefly described below:

- DECOMP - The biomass proximate and ultimate analyses are utilized to calculate appropriate yield values for block DECOMP.

- $\mathbf{O 2}$ - The stoichiometric amount of oxygen required for complete combustion of gas stream ELEMENTS is calculated, and the result is used to set the flow of stream $\mathrm{O}_{2}$. 
- CALC - The duties of blocks LHV-COND and HHV-COND are divided by the flow rate to calculate the LHV and HHV of the biomass. The results are written to the Aspen Plus control panel.

\subsubsection{Data Sources, Assumptions, and Limitations}

To perform a rigorous heating value calculation, a correction for free-moisture hydrogen is generally included. Because such a correction is not included in the calculation described above, the result will differ slightly from the input heating value for the biomass (i.e., Aspen Plus's built-in handling of enthalpy in block DECOMP does include a correction for free-moisture hydrogen). However, the calculations in this hierarchy block are performed only as a means to quickly identify a gross error in the model, and the accuracy is sufficient to accomplish this purpose.

\subsubsection{Model Summary Calculations}

Fortran calculator block CALC (discussed previously in Section 2.3.4) provides the results of the biomass and synthesis gas heating value calculation:

- LHV calculation (wet and dry basis)

- HHV calculation (wet and dry basis)

In addition, the CALC block provides results for the cold gas efficiency and the total heat supplied (MMBTU) to the lime kiln.

\subsection{Modeling Results}

\subsubsection{Case Descriptions}

Three scenarios were considered as part of the hog fuel project. The assumptions for each case are summarized briefly below:

- $\quad$ Base Case - Model for lime kiln operated on natural gas, based on Kamloops kiln.

- Case A - Two gasifiers will be operated. Each gasifier has a capacity to process up to 150 tons per day (6.25 tons per hour) of dried biomass at 10\% moisture. Additionally, it is assumed that a tar cracker is required between the gasifier and the lime kiln to prevent condensation of tars and oils present after gasification. Total raw biomass feedrate for this case is 15.17 tons per hour.

- Case B - Two gasifiers will be operated. Each gasifier has a capacity to process up to 150 tons per day (6.25 tons per hour) of dried biomass at 10\% moisture. This case assumes no tar cracker between the gasifier and the lime kiln and one less cyclone between the gasifier and the kiln; hence, CYCLONE only has a pressure drop of one psi. Condensation is avoided in this case by insulating the piping from the reactor outlet to the lime kiln inlet with refractory to maintain a high gas temperature, above $750^{\circ} \mathrm{F}$ (Knoeff 2007), and limiting the piping length to 65 feet (Mudge 1986). The outlet temperature of the PIPING block is set to $850^{\circ} \mathrm{F}$. Total raw biomass feedrate for this case is 14.47 tons per hour. 


\subsubsection{Results Summary}

A summary of the modeling results for the case studies is presented in Table 4. A more complete summary for each case can be found in Appendix A. In addition, a complete Aspen Plus model report for Case A is presented in Appendix B.

Table 4. Summary of Modeling Case Study Results

\begin{tabular}{|c|c|c|c|}
\hline & Base Case & Case A & Case B \\
\hline Biomass to Gasifier (50\% Moisture, tons $/ \mathrm{hr}$ ) & NA & 15.17 & 14.47 \\
\hline Air to Gasifier (tons/hr) & NA & 6.28 & 6.09 \\
\hline Gasifier Operating Pressure (psi) & NA & 25 & 17 \\
\hline Gasifier Exit Temperature $\left({ }^{\circ} \mathrm{F}\right)$ & NA & 940 & 947 \\
\hline \multicolumn{4}{|l|}{ Gasifier Exit Gas Composition (vol\%) } \\
\hline $\mathrm{N}_{2}$ & NA & 29.2 & 29.5 \\
\hline $\mathrm{CO}_{2}$ & NA & 4.3 & 4.7 \\
\hline $\mathrm{CO}$ & NA & 31.3 & 30.7 \\
\hline $\mathrm{Ar}$ & NA & 0.4 & 0.4 \\
\hline $\mathrm{H}_{2} \mathrm{O}$ & NA & 16.7 & 16.4 \\
\hline $\mathrm{H}_{2}$ & NA & 13.8 & 14.0 \\
\hline Tars and Oils Concentration $\left(\mathrm{mg} / \mathrm{Nm}^{3}\right)$ & NA & 49.5 & 49.2 \\
\hline Air to Tar Cracker (tons/hr) & NA & 2.96 & NA \\
\hline Tar Cracker Heat Exchanger Exit Temperature $\left({ }^{\circ} \mathrm{F}\right)$ & NA & 1000 & NA \\
\hline Gas to Lime Kiln (tons/hr) & 2.29 & 17.0 & 13.5 \\
\hline Gas Temperature to Lime $\operatorname{Kiln}\left({ }^{\circ} \mathrm{F}\right)$ & 68 & 600 & 850 \\
\hline Air to Lime Kiln (tons/hr) & 41.29 & 31.7 & 32.9 \\
\hline \multicolumn{4}{|l|}{ Synthesis Gas Composition to Lime Kiln (vol\%) } \\
\hline $\mathrm{N}_{2}$ & Natural Gas & 32.1 & 29.5 \\
\hline $\mathrm{CO}_{2}$ & Natural Gas & 6.8 & 4.7 \\
\hline $\mathrm{CO}$ & Natural Gas & 27.7 & 30.7 \\
\hline $\mathrm{O}_{2}$ & Natural Gas & 0.04 & 0 \\
\hline $\mathrm{Ar}$ & Natural Gas & 0.4 & 0.4 \\
\hline $\mathrm{H}_{2} \mathrm{O}$ & Natural Gas & 8.6 & 16.4 \\
\hline $\mathrm{H}_{2}$ & Natural Gas & 24.2 & 14.0 \\
\hline Tars and Oils Concentration $\left(\mathrm{mg} / \mathrm{Nm}^{3}\right)$ & Natural Gas & 1.6 & 49.2 \\
\hline Cold Gas Efficiency & NA & $83.7 \%$ & $88.2 \%$ \\
\hline Heat Supplied to Lime Kiln (MMBTU) & 105.58 & 100.15 & 103.16 \\
\hline IP Steam Generated (tons/hr) & 7.84 & 1.56 & 1.36 \\
\hline LP Steam Generated (tons $/ \mathrm{hr}$ ) & 0 & 5.94 & 5.66 \\
\hline Power Required (HP) & 489 & 1014 & 816 \\
\hline
\end{tabular}

\subsubsection{Areas for Future Improvement of the Model}

Several areas where the model can be improved have been discussed previously in this report. These items, and other potential improvement areas, are summarized below:

- Tune efficiencies used in compressor block to actual operational parameters based on feedback from the appropriate technology vendors. 
- Rigorously model or obtain data from the appropriate technology vendors for pressure drop in the gasifier, cyclones, tar cracker, and piping.

- Update the biomass dryer process blocks with results from an updated mass and energy balance from GEA Barr-Rosin which incorporates using hot tailgas from the lime kiln to indirectly dry the biomass instead of steam.

- Incorporation of a devolatilization routine into the kinetic model to increase predictive capabilities and/or obtaining actual devolatilization data for the feed material in question from laboratory experiments.

- Include a model for tar pyrolysis in the kinetic model to increase predictive capabilities.

- Include formation of $\mathrm{NO}_{\mathrm{x}}$ and $\mathrm{SO}_{\mathrm{x}}$ in the kinetic model.

- Additional validation of kinetic expressions utilized in the kinetic model based on laboratory or industrial process results.

- Validation of lime kiln model with operational data from additional lime kilns.

\section{GASIFIER MATERIALS EVALUATION}

The gasifier is a refractory lined pressure vessel that will be designed to the requirements of the ASME Section VIII, Division 1 or 2 codes. The design life is 20 years with anticipated component refurbishment during scheduled maintenance shutdowns. The nominal operating temperature range is $2000-2200^{\circ} \mathrm{F}$. The hot gas composition is shown above, in Table 4. In addition to the gas components listed in Table 4 small amount $\mathrm{H}_{2} \mathrm{~S}, \mathrm{HCN}$, and other corrosive materials will be present. The gas composition for biomass gasification falls into the ranges described for various coal gasification environments (Barton 1981; Nangia 1982). In general, the data in the literature for material performance of gasifiers is based on performance in coal gasification systems. The subsequent sections will discuss materials issues associated with the gasifier vessel and the refractory lining.

\subsection{Gasifier Vessel}

The biomass gasifier vessel will be a refractory lined steel shell where the insulating capabilities of the refractory liner will set the shell temperature. The vessel shell will have various nozzle penetrations for biomass feed, synthesis gas removal, air, instrumentation probes, ash removal, and possible cooling water for the rotating grate. Based on the operating temperature and gas composition, the shell material can be susceptible to hydrogen attack, high-temperature sulfidation attack, metal wall thinning due to spallation, and possible aqueous corrosion due to condensate formation during shutdown.

The rotating ash grate material is of particular concern due to the expected exposure temperature of about $2000^{\circ} \mathrm{F}$, and the possibility of carbonaceous char deposits. These deposits could induce metal dusting which is defined as a process of highly accelerated material wastage preceded by the saturation of the material with carbon (Natesan 2002). This operating temperature is well above the maximum that ASME allows for a pressure vessel boundary material but these rules do not apply as the grate is not a pressure component. The mechanical design of the grate will have to take into account high temperature mechanical loading issues such as fatigue and creep. Consequently, the use of air cooling of this grate has been specified. The tentative material choice of Emery Energy Company for this component is Type 310 
stainless steel. However, other high temperature alloys such as Inconel alloy 693 and alloy 602CA may provide better performance (Natesan 2003; Natesan 2006; Wilson 2007).

\subsection{Gasifier Refractory Lining}

The refractory lining for the gasifier vessel will provide thermal insulation for the metallic pressure vessel and erosion resistance in high wear areas. The lining system proposed by Emery Energy Company is shown in Figure 7. An initial problem which was noted with the material choices here is that the manufacturer's data for the Versaflow Thermax Plus $\left(75.9 \% \mathrm{SiO}_{2}, 21.1 \% \mathrm{Al}_{2} \mathrm{O}_{3}\right)$ has a maximum recommended temperature of $2000^{\circ} \mathrm{F}$. A general rule of thumb for refractory design is that the systems are operated at $80 \%$ of the maximum recommended temperature. Another problem is that this refractory has a high silica content which may make it susceptible to silica volatilization (Sadler 1979).

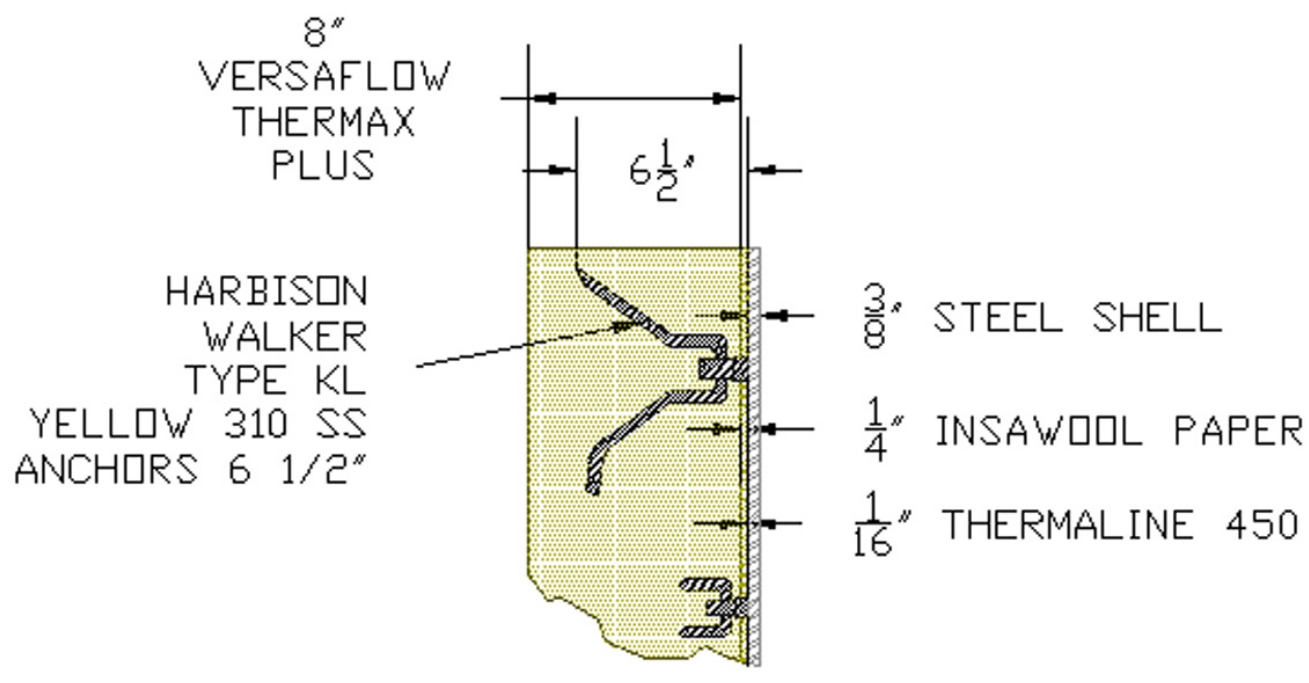

Figure 7. Proposed Gasifier Wall Construction Details (Emery Energy Company)

To evaluate this design, an analysis was performed to predict the gasifier wall temperature using MathCad software. It was assumed that eight inches of Versaflow Thermax Plus refractory was installed over the gasifier wall with a gas temperature of $2000^{\circ} \mathrm{F}$. The predicted wall temperature is $651^{\circ} \mathrm{F}$.

This temperature presents additional problems for this design. The Thermaline 450 epoxy coating (applied to prevent condensate corrosion) has a maximum recommended temperature limit of $450^{\circ} \mathrm{F}$. Some other coating system or a corrosion resistant metallic coating (weld overlay) would need to be evaluated. Another issue is the choice of metallic anchors for the refractory. These anchors are generally recommended for use below $2000^{\circ} \mathrm{F}$. Above this temperature, ceramic anchors would be used.

\subsubsection{Refractory Material Alternatives}

Refractory materials with higher alumina contents have been used and tested for coal gasification service (Sadler 1979; Nangia 1982). A refractory vendor recommended the following refractory compositions for $2100^{\circ} \mathrm{F}$ with a six or nine inch thickness (Langenohl 2007):

- RESOCAST $17 \mathrm{AG},\left(95 \%\right.$ alumina), $3400^{\circ} \mathrm{F}$ maximum service temperature, gun installation 
- $\quad$ RESOCAST $17 \mathrm{AC},\left(95 \%\right.$ alumina), $3400^{\circ} \mathrm{F}$ maximum service temperature, vibration casting installation

- $\quad$ EZ CAST $3400,\left(98.7 \%\right.$ alumina), $3400^{\circ} \mathrm{F}$ maximum service temperature, vibration casting installation

A recently presented paper reviewed refractory material for biomass gasifiers with emphasis on systems used for treatment of black liquor from the pulp and paper industry (Bennett 2007). This process was assumed to be a worst case for biomass gasification. The report describes good performance of a newly patented refractory, Aurex $95 \mathrm{P}$. This material is a chrome-alumina $\left(92.0 \% \mathrm{CrO}_{2}, 4.7 \% \mathrm{Al}_{2} \mathrm{O}_{3}\right.$, $3.3 \% \mathrm{P}_{2} \mathrm{O}_{5}$ ) brick.

\subsection{Recommendations}

A major factor of gasifier operation that will affect the material choices will be the nominal operating temperature. The process modeling performed by the Idaho National Laboratory (INL) has set the operating temperature range to $2000^{\circ} \mathrm{F}$, with the possibility of localized hot spots. These parameters will preclude downstream condensation of tars and oils which can cause operational difficulties. However, the gasifier temperature envisioned by Emery Energy is $1,600^{\circ} \mathrm{F}$. This temperature difference has major implications for the materials choices and expected life of the rotating ash grate. Therefore, it is recommended that a design study be conducted to analyze the problems of downstream piping and component tar deposition at the $1,600^{\circ} \mathrm{F}$ gasifier temperature as compared to providing robust materials for the rotating ash grate for service at $2,000^{\circ} \mathrm{F}$. Based on these results, the choices for the refractory lining system and the material for the rotating grate should be given further evaluation.

\section{PROCESS ECONOMICS}

The economic viability of firing synthesis gas generated from the gasification of hog fuel as a substitute for natural gas in a lime kiln was assessed using standard economic evaluation methods. The economics were evaluated for the two cases described in Section 2.4.1, Case A (tar cracker) and Case B (no tar cracker). The total project investment, based on the total equipment costs, along with the variable and fixed operating costs were first calculated for the cases. The present worth of the offset cost of utilizing biomass versus natural gas along with the capital investments were then calculated for various project payback periods and interest rates. The following sections describe the methods used to calculate the capital costs, fixed and variable operating costs, and the methods used for the economic assessments. First, a detailed description of the process equipment items, which were costed for this study, are presented.

\subsection{Equipment List}

The equipment items priced for this study are divided into three categories, wet fuel processing, gasification island, and gas cleanup. Wet fuel processing includes all of the equipment necessary to receive, store, size, and dry the incoming biomass. The gasification island includes equipment items for gasifying and removing particulate from the synthesis gas. Gas cleanup includes equipment items for removing the tars and oils from the synthesis gas. Figure 8 presents the process flow diagram for the Hog Fuel Gasification Project. It is assumed that any wastewater generated can be treated at existing wastewater facilities and the tailgas from the system undergoes gas cleanup at existing facilities. 


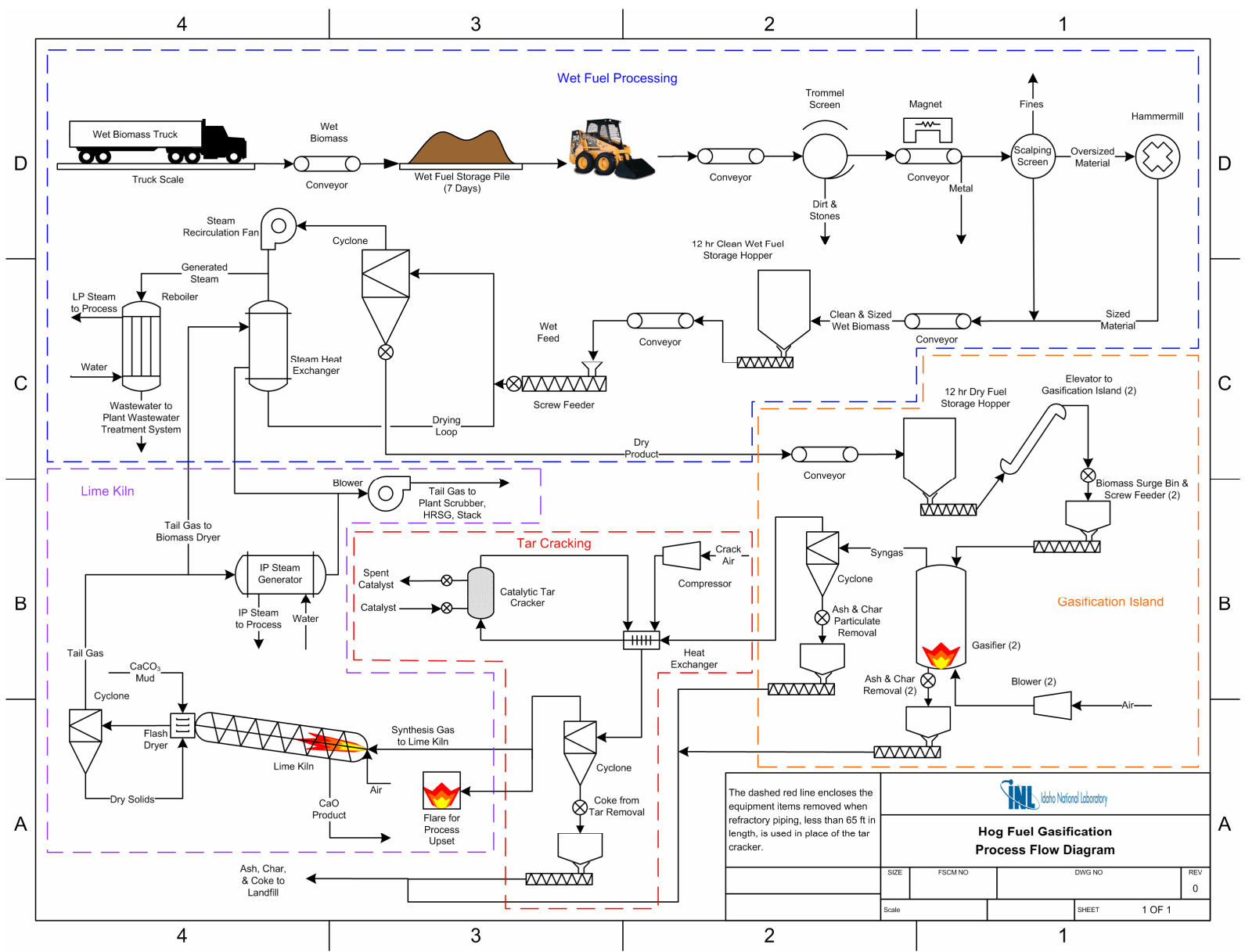

Figure 8. Hog Fuel Gasification Process Flow Diagram 


\subsubsection{Wet Fuel Processing}

- Truck Scale - Heavy duty truck scale with 90,000 pound capacity. Includes digital weight indicator, ticket printer, remote display, traffic lights, foundation construction, and installation.

- Wet Biomass Conveyor to Wet Fuel Storage - Covered belt conveyor rated for 20 tons per hour of 50\% moisture biomass, including $7.5 \mathrm{HP}$ motor. Conveying distance of 100 feet with a 15-degree incline. The conveyor includes walkway and railings for one side, steel discharge chute, and belt cleaner.

- Wet Fuel Storage Pile - The wet fuel storage pile is an open bunker style storage pile with seven days of wet biomass storage capacity. The bunker has a concrete floor and walls and an apron for loading. The dimensions of the bunker are 150 feet by 62 feet by 10 feet.

- Front End Loader - Compact front end loader with a bucket capacity of 1.8 cubic yards. Used to transfer fuel from the storage pile to the conveyor.

- Wet Biomass Conveyor to Particulate Removal - Covered belt conveyor rated for 20 tons per hour of 50\% moisture biomass, including $7.5 \mathrm{HP}$ motor. Conveying distance of 100 feet with a 15-degree incline. The conveyor includes walkway and railings for one side, steel discharge chute, and belt cleaner.

- Trommel Screen - Stones and dirt are removed from the wood residue using a trommel screen. The trommel screen can accept up to 20 tons per hour and includes conveyors to and from the unit. Includes a $49 \mathrm{HP}$ engine.

- Wet Biomass Conveyor with Ferrous Metal Removal - Covered belt conveyor rated for 20 tons per hour of $50 \%$ moisture biomass, including $7.5 \mathrm{HP}$ motor. Conveying distance of 100 feet with a 15-degree incline. The conveyor includes walkway and railings for one side, steel discharge chute, belt cleaner, and magnetic pulley for metal removal.

- Scalping Screen - Rated for 20 tons per hour with screen designed to pass all material smaller than 30 millimeters, includes 5 HP motor and oversized and sized material discharge chutes.

- Hammermill - Rated for 10 tons per hour (50\% of feedstock flow). Designed to reduce the oversized material from the scalping screen to less than 30 millimeters, includes $200 \mathrm{HP}$ motor.

- Wet Biomass Conveyor to Storage - Covered belt conveyor rated for 20 tons per hour of $50 \%$ moisture biomass, including $7.5 \mathrm{HP}$ motor. Conveying distance of 150 feet with a 15-degree incline. The conveyor includes walkway and railings for one side, steel discharge chute, and belt cleaner.

- Sized Wet Fuel Storage Silo - Metal silo with 20,000 cubic foot wet fuel storage capacity, approximately 12 hours of storage. Maximum height of 38 feet.

- Silo Discharge - 16-inch diameter by 12 -foot-long horizontal screw feeder rated for 20 tons per hour of $50 \%$ moisture biomass. Includes $10 \mathrm{HP}$ motor.

- Wet Biomass Conveyor to Biomass Dryer-Covered belt conveyor rated for 20 tons per hour of 50\% moisture biomass, including $7.5 \mathrm{HP}$ motor. Conveying distance of 100 feet with 
a 15-degree incline. The conveyor includes walkway and railings for one side, steel discharge chute, and belt cleaner.

- Superheated Steam Dryer - Up to 20 tons per hour of 50\% moisture biomass is continuously metered using plug screw feeder to the drying system. The wet feed then enters the dryer via a disc shredder and is dispersed into an atmosphere of superheated steam. The steam acts as a transport gas for the material through a drying duct where the moisture evaporates via a heat exchanger with a portion of the hot tail gas from the lime kiln. The dried product is separated from the steam in a high efficiency cyclone, and discharged to the gasifier at approximately $10 \%$ moisture. Steam is recycled back through the dryer using a centrifugal fan. Includes motors for all equipment items which sums to $794 \mathrm{HP}$.

- Reboiler - Waste heat is recovered from the steam exiting the superheated steam dryer by passing the surplus stream through a reboiler.

\subsubsection{Gasification Island}

- Dry Biomass Conveyor to Storage - Covered belt conveyor rated for 10 tons per hour of $10 \%$ moisture biomass, including 7.5 HP motor. Conveying distance of 150 feet with a 15 -degree incline. The conveyor includes walkway and railings for one side, steel discharge chute, and belt cleaner.

- Dry Fuel Storage Silo - Metal silo with 20,000 cubic foot dry fuel storage capacity, approximately 12 hours of storage. Maximum height of 38 feet.

- Silo Discharge - 16-inch diameter by 12-foot-long horizontal screw feeder rated for 10 tons per hour of $10 \%$ moisture biomass. Includes $10 \mathrm{HP}$ motor.

- Fuel Elevator (2) - Bucket elevator rated for 10 tons per hour of 10\% moisture wood chips. Conveying height of 100 feet with 14 by 7 inch polyethylene buckets. Includes 5 HP motor.

- Dry Fuel Feed Bin (2) - Metal bin with 300 cubic foot dry fuel storage capacity.

- Dry Fuel Screw Feeder (2) - 16-inch diameter by 6-foot-long horizontal screw feeder rated for 5 tons per hour of $10 \%$ moisture biomass. Includes $10 \mathrm{HP}$ motor.

- Dry Fuel Rotary Airlock Valve (2) - 16 inch rotary airlock valve rated for pressures up to 25 psi and temperatures up to $1000^{\circ} \mathrm{F}$.

- Gasifier (2) - Near atmospheric, air blown, countercurrent gasifier based on Emery Energy Company's E-100A gasifier design. The gasifier is a refractory lined pressure vessel designed to ASME codes rated for 150 tons per day of $10 \%$ moisture biomass and pressures up to 25 psi. Fuel enters at the top of the gasifier and flows down, undergoing devolatilization, towards the ash grate, where a hot char pile develops. Air enters at the bottom of the gasifier and reacts with the char providing the heat for the gasification reactions and fuel devolatilization. A low value BTU synthesis gas is removed from the top of the gasifier at approximately $950^{\circ} \mathrm{F}$. The ash is removed from the bottom of the unit through the ash grate. The temperature of the ash, $2000^{\circ} \mathrm{F}$, is controlled by the amount of air fed to the gasifier in order to prevent slagging

- Blower (Case A, 2) - Air blower rated for 1,400 standard cubic feet per minute at 25 psi. 
- Blower (Case B, 2) - Air blower rated for 1,400 standard cubic feet per minute at 17 psi.

- Ash Storage Bin (2) - High temperature metal bin, rated for up to $2000^{\circ} \mathrm{F}$, with 300 cubic foot ash storage capacity. It should be noted that the ash would cooled with water but this bin and other items associated with ash handling may experience temperature excursions up to $2000^{\circ} \mathrm{F}$.

- Ash Screw Feeder (2) -Horizontal screw feeder rated for 1 tons per hour of high temperature ash $\left(2000^{\circ} \mathrm{F}\right)$. Includes $10 \mathrm{HP}$ motor.

- Ash Rotary Airlock Valve (2) - Rotary airlock valve rated for pressures up to 25 psi and temperature up to $2000^{\circ} \mathrm{F}$.

- Ash Cyclone - High temperature $\left(1000^{\circ} \mathrm{F}\right)$, above atmospheric pressure (up to $25 \mathrm{psi}$ ), cyclone rated for 10,000 standard cubic feet per minute of syngas flow.

- Particulate Storage Bin - High temperature metal bin, rated for $1000^{\circ} \mathrm{F}$, with 300 cubic foot particulate storage capacity. It should be noted that the particulate would be cooled with water but this bin and other items associated with particulate handling may experience temperature excursions up to $1000^{\circ} \mathrm{F}$.

- Particulate Screw Feeder - Horizontal screw feeder rated for 1 tons per hour of high temperature particulate $\left(1000^{\circ} \mathrm{F}\right)$. Includes $10 \mathrm{HP}$ motor.

- Particulate Rotary Airlock Valve - Rotary airlock valve rated for pressures up to 25 psi and temperatures up to $1000^{\circ} \mathrm{F}$.

\subsubsection{Gas Cleanup (Case A)}

- Gas Cleanup Blower - Air blower rated for 1,400 standard cubic feet per minute at 25 psi.

- Heat Exchanger - Compact type heat exchanger rated for temperatures up to $1800^{\circ} \mathrm{F}$. Constructed of high temperature metal alloy, such as Inconel. Area for heat exchange is approximately 7,700 square feet.

- Catalytic Tar Cracker - Bubbling fluidized bed reactor which converts tars and oils to CO and $\mathrm{H}_{2}$. This unit is rated for $96 \%$ conversion of tars, oils, and methane; requires an inlet feed temperature of $1652^{\circ} \mathrm{F}$; and has an outlet temperature of $1742^{\circ} \mathrm{F}$. The reactor is required to accommodate 10,000 standard cubic feet per minute of syngas flow. The catalyst used in the reactor is a commercially available nickel catalyst.

- Tar Cracker Rotary Airlock Valve (2) - Rotary airlock valve rated for pressures up to 25 psi and temperatures up to $1800^{\circ} \mathrm{F}$, or water cooled.

- Particulate Cyclone - High temperature $\left(1000^{\circ} \mathrm{F}\right)$, above atmospheric pressure (up to $25 \mathrm{psi}$ ), cyclone rated for 10,000 standard cubic feet per minute of syngas flow.

- Gas Cleanup Particulate Storage Bin - High temperature metal bin, rated for $1000^{\circ} \mathrm{F}$, with 300 cubic foot particulate storage capacity. Again, it should be noted that the particulate would be cooled with water but this bin and other items associated with particulate handling may experience temperature excursions up to $1000^{\circ} \mathrm{F}$. 
- Gas Cleanup Particulate Screw Feeder - Horizontal screw feeder rated for 1 ton per hour of high temperature particulate $\left(1000^{\circ} \mathrm{F}\right)$, includes $10 \mathrm{HP}$ motor.

- Particulate Rotary Airlock Valve - Rotary airlock valve rated for pressures up to 25 psi and temperatures up to $1000^{\circ} \mathrm{F}$.

\subsection{Economic Calculations}

\subsubsection{Fixed Capital Cost Estimation}

The capital costs presented are for inside the battery limits, and exclude costs for administrative offices, storage areas, utilities, and other essential and nonessential auxiliary facilities. The estimate presented is a study (factored) estimate which has a probable error up to $\pm 30 \%$ (Perry 1997). Fixed capital costs were estimated from vendor quotes, literature estimates, and scaled estimates (capacity, year, and material) from previous quotes. Capacity adjustments were based on the six-tenths factor rule:

$$
C_{2}=C_{1}\left(\frac{q_{2}}{q_{1}}\right)^{n}
$$

where $C_{l}$ is the cost of the equipment item at capacity $q_{1}, C_{2}$ is the cost of the equipment at capacity $q_{2}$, and $n$ is the exponential factor, which typically has a value of 0.6 (Peters 1991).

Cost indices were used to adjust equipment prices from previous years to values in 2007 using the Chemical Engineering Plant Cost Index (CEPCI).

Table 5. CEPCI Data

\begin{tabular}{c|c|c|c}
\hline Year & CEPCI & Year & CEPCI \\
\hline 1990 & 357.6 & 1999 & 390.6 \\
1991 & 361.3 & 2000 & 394.1 \\
1992 & 358.2 & 2001 & 394.3 \\
1993 & 359.2 & 2002 & 395.6 \\
1994 & 368.1 & 2003 & 402 \\
1995 & 381.1 & 2004 & 444.2 \\
1996 & 381.7 & 2005 & 468.2 \\
1997 & 386.5 & 2006 & 499.6 \\
1998 & 389.5 & Dec-07 & 509.8 \\
\hline
\end{tabular}

Cost adjustment factor for materials, listed in Table 6, were used to adjust cost estimates for carbon steel to equivalent alloy costs (Perry 1997).

Table 6. Material Cost Adjustment Factors

\begin{tabular}{l|c}
\hline Year & Factor \\
\hline Stainless Steel Alloys & 1.8 \\
Moly/Nickel Alloys & 3.3 \\
\hline
\end{tabular}


After cost estimates were obtained for each of the equipment items, the costs for field erection, equipment foundations and structural supports, piping, equipment insulation, piping insulation, electrical work, instrumentation, miscellaneous costs, and building costs were estimated using the Factor Method of Miller. The Factor Method of Miller allows the estimation of the above costs based on the delivered equipment cost and the unit complexity. Figure 9 presents the tables in Perry's Chemical Engineering Handbook used for the Factor Method of Miller.

Based on the Factor Method of Miller and the quotes for the equipment items listed in Section 4.1 costs were calculated for equipment field erection, equipment foundations and structural supports, piping, equipment insulation, piping insulation, electrical work, instrumentation, miscellaneous costs, and building costs. When delivery was not included in the price, it was assumed that equipment delivery would be approximately four percent of the unit cost. Table 7 lists all costs for the equipment items, as well as the total costs for the fuel processing section and the gasification section for Cases A and B, which includes the gasification island and gas cleanup operations; an indication is made if the quote has been updated for capacity ${ }^{1}$, year $^{2}$, or material ${ }^{3}$. It was assumed that the plant is located in a temperate climate, and the plant design would be mainly open air with minor buildings.

TABLE 9-52 Factor Method of Miller (Based on Delivered-Equipment Costs = 100)*

\begin{tabular}{|c|c|c|c|c|c|c|c|c|}
\hline & & \multicolumn{7}{|c|}{$\begin{array}{l}\text { Battery-limit costs (range of factors in percent of basic equipment); } \\
\text { average unit cost of main-plant item (MPI) }\end{array}$} \\
\hline & & $\begin{array}{l}\text { Under } \\
\$ 0000\end{array}$ & $\begin{array}{l}\$ 9000 \text { to } \\
\$ 15,000\end{array}$ & $\begin{array}{l}\$ 15,000 \text { to } \\
\$ 21,000\end{array}$ & $\begin{array}{l}\$ 21,000 \text { to } \\
\$ 30,000\end{array}$ & $\begin{array}{l}\$ 30,000 \\
\text { to } \$ 39,000\end{array}$ & $\begin{array}{c}\$ 39,000 \\
\text { to } \$ 51,000\end{array}$ & $\$ 51,000$ \\
\hline \multirow[t]{3}{*}{$\begin{array}{l}\text { Field erection of basic } \\
\text { equipment }\end{array}$} & $\begin{array}{l}\text { High percentage of equipment } \\
\text { involving high field labor }\end{array}$ & $23 / 18$ & $21 / 17$ & $19.5 / 16$ & $18.5 / 15$ & $17.5 / 14.2$ & $16.5 / 135$ & $15.5 / 13$ \\
\hline & $\begin{array}{l}\text { Average (mild steel) } \\
\text { equipment }\end{array}$ & $18 / 12.5$ & $17 / 115$ & 1610.8 & $15 / 10$ & $14.2 / 9.2$ & $13.5 / 8.5$ & $13 / 8$ \\
\hline & $\begin{array}{l}\text { High percentage of corrosion } \\
\text { materials and other high- } \\
\text { unit-cost equipment } \\
\text { involving little field erection }\end{array}$ & $12.5 / 7.5$ & $11.5 / 6.7$ & $10.8 / 6$ & $10 / 5.5$ & $2.2 / 2$ & $8.5 / 5$ & $8 / 48$ \\
\hline \multirow[t]{5}{*}{$\begin{array}{l}\text { Equipment foundations and } \\
\text { structural supports }\end{array}$} & $\begin{array}{l}\text { High: predominance of } \\
\text { corpressors or mild steel } \\
\text { equipment requiring hesvy } \\
\text { foundations }\end{array}$ & & & $17 / 12$ & $15 / 10$ & $14 / 9$ & $12 / 8$ & $10.5 / 6$ \\
\hline & $\begin{array}{l}\text { Average: for mild steel } \\
\text { fabricated-equipment solids }\end{array}$ & & & $12.5 / 7$ & $11 / 6$ & $9.5 / 5$ & $8 / 4$ & $7 / 3$ \\
\hline & $\begin{array}{l}\text { Average: for predominance of } \\
\text { alloy and other high-unit- } \\
\text { price fabricated equipment }\end{array}$ & $7 / 3$ & $8 / 3$ & $8.5 / 3$ & $7.5 / 3$ & $65 / 2.5$ & $5.5 / 2$ & $4.5 / 1.5$ \\
\hline & $\begin{array}{l}\text { Low: equipment more or less } \\
\text { sitting on floor }\end{array}$ & 50 & 40 & $3 / 0$ & $2.5 \% 0$ & 20 & $1.5 / 0$ & 10 \\
\hline & Piling or rock excavation & & & \multicolumn{3}{|c|}{ Increase above values by 25 to $100 \%$} & & \\
\hline \multirow[t]{4}{*}{$\begin{array}{l}\text { Piping, including ductwork } \\
\text { but excluding insulation }\end{array}$} & $\begin{array}{l}\text { Highi gases and liquids, } \\
\text { petrocherricals, plants with } \\
\text { substantial ductwork }\end{array}$ & $105 / 66$ & $90 / 58$ & $80 / 48$ & $70 / 40$ & $58 / 34$ & $50 / 30$ & $42 / 25$ \\
\hline & $\begin{array}{l}\text { Average for chemical plants: } \\
\text { liquids, electrolytic plants }\end{array}$ & $66 / 33$ & $58 / 27$ & $48 / 22$ & $40 / 16$ & $34 / 12$ & $30 / 10$ & $25 \%$ \\
\hline & Liquids and solids & $33 / 13$ & $27 / 10$ & $22 / 8$ & 166 & $12 / 5$ & $10 / 4$ & $9 / 3$ \\
\hline & Low: solids & $13 / 5$ & $10 / 4$ & $8 / 3$ & $6 / 2$ & $5 / 1$ & $4 / 0$ & 30 \\
\hline \multirow[t]{3}{*}{ Insulation of equipment only } & $\begin{array}{l}\text { Very high: substantial mild } \\
\text { steel equipment requiring } \\
\text { lagging and very bw } \\
\text { temperatures }\end{array}$ & $13 / 10$ & $11.5 / 8.5$ & $10 / 7.4$ & $9 / 6.2$ & $7.8 / 5.3$ & $6.8 / 4.5$ & $5.8 / 3.5$ \\
\hline & $\begin{array}{l}\text { Hight substantial equipment } \\
\text { requiring lagging and high } \\
\text { temperatures } \\
\text { (petrochemicals) }\end{array}$ & $10.3 / 7.5$ & 96.3 & $7.8 / 5.2$ & $6.7 / 4.2$ & $5.7 / 3.4$ & $47 / 3.8$ & $4.8 / 2.5$ \\
\hline & $\begin{array}{l}\text { Average for chemical plants } \\
\text { Low }\end{array}$ & $\begin{array}{c}7.83 .4 \\
3.50\end{array}$ & $\begin{array}{l}6.5 / 2.6 \\
2.7 / 0\end{array}$ & $\begin{array}{l}5.52 .1 \\
2.20\end{array}$ & $\begin{array}{l}4.5 / 1.7 \\
1.80\end{array}$ & $\begin{array}{c}3.6 / 1.4 \\
1.510\end{array}$ & $\begin{array}{c}2.2 / 1.1 \\
1.2 \%\end{array}$ & $\begin{array}{l}2.2 / 8 \\
1 / 0\end{array}$ \\
\hline \multirow[t]{4}{*}{ Insulation of piping only } & $\begin{array}{l}\text { Very high: substantial mild } \\
\text { steel piping requiring lagging } \\
\text { snd very low temperatures }\end{array}$ & $22 / 16$ & $19 / 13$ & $16 / 11$ & 149 & $12 / 7$ & $9 / 5$ & $6 / 3.5$ \\
\hline & $\begin{array}{l}\text { High: substantial piping } \\
\text { requiring lagging and high } \\
\text { temperatures } \\
\text { (petrochemicals) }\end{array}$ & $18 / 14$ & $15 / 12$ & $13 / 10$ & $11 / 8$ & $2 / 6$ & $7 / 4$ & $4.5 / 2.5$ \\
\hline & Average for chemical plants & $16 / 12$ & $14 / 10$ & $12 / 8$ & $10 / 6$ & $8 / 4$ & $6 / 2$ & $4 / 2$ \\
\hline & Low & $14 / 8$ & $12 / 6$ & $10 / 5$ & $8 / 4$ & $6 / 3$ & $4 / 2$ & $2 / 1$ \\
\hline
\end{tabular}

Figure 9. Factor Method of Miller (Perry 1997) 
TABLE 9-52 Factor Method of Miller (Based on Delivered-Equipment Costs $=100)($ Conduded)

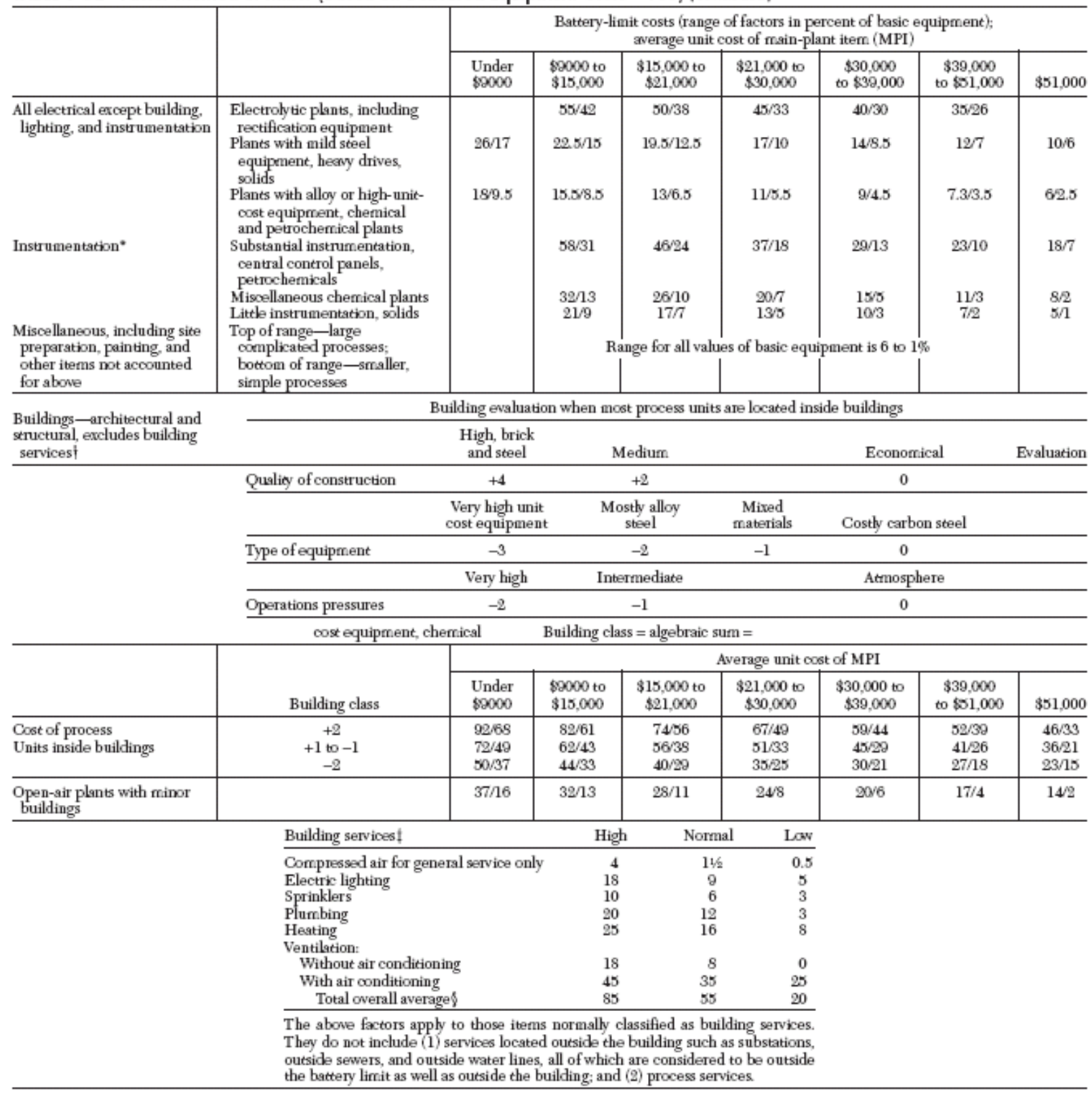

*Courtesy C. A. Miller of Canadian Industries Ltd. and the American Association of Cost Engineers.

Note: The average unit cost of the main-plant items is the total cost of the MPI divided by the total number of itens. Figures include up to 3 percent for BL outside lighting, which is not covered in building services.

"Tokal instrumentation cost does not vary a great deal with size and hence is not readily calculated as a percentage of basic equipment. This is perticularly true for distillation systems. If in doubt, detailed estimates should be made.

†When building specifications and dimensions are known, a high-speed building-cost estimate is recommended, especially if buildings are a significant item of cost. If a separate estimate is not possible, evaluate the buildings as shown before selecting the factors.

†The following factors are for battery-lirit (process) buildings only and are expressed in percentage of the building architectural and structural cost. They are not related to the basic equipment cost.

\$The totals provide the ranges for the type of building imolved and are useful when individual service requirements are not known. Note that the overall averages are not the sum of the individual columns.

Figure 9. Factor Method of Miller (Perry 1997) - continued 
Table 7. Cost Data for Process Equipment Items

\begin{tabular}{|c|c|c|c|c|c|c|c|c|c|c|c|c|c|c|c|}
\hline & Unit Cost & $\begin{array}{c}\text { Delivery } \\
\text { Cost }\end{array}$ & $\begin{array}{l}\text { Installation } \\
\text { Complexity }\end{array}$ & $\begin{array}{l}\text { Field } \\
\text { Erection }\end{array}$ & \begin{tabular}{|c|} 
Equipment \\
Foundations \\
and Supports
\end{tabular} & Piping & \begin{tabular}{|c|} 
Equipment \\
Insulation
\end{tabular} & \begin{tabular}{|c|} 
Piping \\
Insulation
\end{tabular} & Electrical & $\begin{array}{c}\text { Instrumen- } \\
\text { tation }\end{array}$ & Misc & Building & Capacity & Brand & Model \# \\
\hline \multicolumn{16}{|l|}{ Fuel Processing } \\
\hline Truck Scales & $\$ 75,000$ & Included & $\mathrm{NA}$ & Included & Included & $\mathrm{NA}$ & $\mathrm{NA}$ & $\mathrm{NA}$ & Included & $\mathrm{NA}$ & $\$ 2,625$ & $\$ 6,000$ & $90000 \mathrm{lb}$ & Fairbanks & Talon HV \\
\hline Conveyor & $\$ 83,000$ & $\$ 4,016$ & Low & $\$ 5,569$ & $\$ 435$ & $\mathrm{NA}$ & $\mathrm{NA}$ & $\mathrm{NA}$ & $\$ 3,698$ & $\$ 2,610$ & $\$ 3,046$ & $\$ 6,961$ & $100 \mathrm{ft}, 24 \mathrm{in}, 15^{\circ}$ & Thomas Conveyor & $\mathrm{BC}$ \\
\hline Wet Fuel Storage Pile & $\$ 103,368$ & Included & $\mathrm{NA}$ & Included & Included & $\mathrm{NA}$ & $\mathrm{NA}$ & $\mathrm{NA}$ & $\mathrm{NA}$ & $\mathrm{NA}$ & $\$ 3,618$ & $\$ 8,269$ & 7 days & MUTH 2007 & INL \\
\hline Front End Loader & $\$ 108,450$ & $\$ 5,248$ & $\mathrm{NA}$ & $\mathrm{NA}$ & $\mathrm{NA}$ & $\mathrm{NA}$ & $\mathrm{NA}$ & $\mathrm{NA}$ & $\mathrm{NA}$ & $\mathrm{NA}$ & $\$ 3,979$ & $\$ 9,096$ & $\mathrm{NA}$ & Caterpillar & 914G \\
\hline Conveyor & $\$ 83,000$ & $\$ 4,016$ & Low & $\$ 5,569$ & $\$ 435$ & $\mathrm{NA}$ & $\mathrm{NA}$ & $\mathrm{NA}$ & $\$ 3,698$ & $\$ 2,610$ & $\$ 3,046$ & $\$ 6,961$ & $100 \mathrm{ft}, 24 \mathrm{in}, 15^{\circ}$ & Thomas Conveyor & $\mathrm{BC}$ \\
\hline Trommel Screen & $\$ 93,000$ & $\$ 4,500$ & Low & $\$ 6,240$ & $\$ 488$ & $\mathrm{NA}$ & $\mathrm{NA}$ & $\mathrm{NA}$ & $\$ 4,144$ & $\$ 2,925$ & $\$ 3,413$ & $\$ 7,800$ & 20 tons $/ \mathrm{hr}$ & Wildcat & 510 Cougar \\
\hline \multicolumn{16}{|l|}{ Magnetic Conveyor } \\
\hline Conveyor & $\$ 83,000$ & $\$ 4,016$ & Low & $\$ 5,569$ & $\$ 435$ & $\mathrm{NA}$ & $\mathrm{NA}$ & $\mathrm{NA}$ & $\$ 3,698$ & $\$ 2,610$ & $\$ 3,046$ & $\$ 6,961$ & $100 \mathrm{ft}, 24 \mathrm{in}, 15^{\circ}$ & Thomas Conveyor & $\mathrm{BC}$ \\
\hline Magnetic Pulley & $\$ 3,000$ & $\$ 145$ & Low & $\$ 315$ & $\$ 79$ & NA & $\mathrm{NA}$ & NA & $\$ 432$ & $\mathrm{NA}$ & $\$ 110$ & $\$ 833$ & 24 in, 30 in diameter & Storch Magnetics & Pulley \\
\hline Scalping Screen & $\$ 34,000$ & $\$ 1,645$ & Low & $\$ 2,566$ & $\$ 356$ & $\mathrm{NA}$ & $\mathrm{NA}$ & $\mathrm{NA}$ & $\$ 2,406$ & $\$ 2,317$ & $\$ 1,248$ & $\$ 2,852$ & 20 tons $/ \mathrm{hr}$ & West Salem Machinery & $36-7$ \\
\hline Hammermill & $\$ 65,000$ & $\$ 3,145$ & Low & $\$ 4,361$ & $\$ 341$ & $\mathrm{NA}$ & $\mathrm{NA}$ & $\mathrm{NA}$ & $\$ 2,896$ & $\$ 2,044$ & $\$ 2,385$ & $\$ 5,452$ & 10 tons $/ \mathrm{hr}$ & West Salem Machinery & $32-40 \mathrm{~b}$ \\
\hline Conveyor & $\$ 119,000$ & $\$ 5,758$ & Low & $\$ 7,985$ & $\$ 624$ & NA & NA & NA & $\$ 5,302$ & $\$ 3,743$ & $\$ 4,367$ & $\$ 9,981$ & $150 \mathrm{ft}, 24 \mathrm{in}, 15^{\circ}$ & Thomas Conveyor & $\mathrm{BC}$ \\
\hline \multicolumn{16}{|l|}{ Wet Fuel Storage } \\
\hline Fuel Storage Hopper & $\$ 322,202$ & Included & Low/Avg & Included & Included & $\mathrm{NA}$ & $\mathrm{NA}$ & $\mathrm{NA}$ & $\$ 13,694$ & $\$ 9,666$ & $\$ 11,277$ & $\$ 25,776$ & $20000 \mathrm{ft}^{3}$ & ORNL 2002 & Updated Quote $^{1,2}$ \\
\hline Screw Feeder & $\$ 10,000$ & $\$ 484$ & Low/Avg & $\$ 954$ & $\$ 577$ & NA & $\mathrm{NA}$ & $\mathrm{NA}$ & $\$ 1,258$ & $\$ 1,573$ & $\$ 367$ & $\$ 2,778$ & $12 \mathrm{ft}, 16$ in diameter & Thomas Conveyor & $\mathrm{SF}$ \\
\hline Conveyor & $\$ 83,000$ & $\$ 4,016$ & Low & $\$ 5,569$ & $\$ 435$ & NA & $\mathrm{NA}$ & $\mathrm{NA}$ & $\$ 3,698$ & $\$ 2,610$ & $\$ 3,046$ & $\$ 6,961$ & $100 \mathrm{ft}, 24 \mathrm{in}, 15^{\circ}$ & Thomas Conveyor & $\mathrm{BC}$ \\
\hline \multicolumn{16}{|l|}{ Drying System } \\
\hline Dryer & $\$ 3,000,000$ & Included & Medium & $\$ 315,000$ & $\$ 150,000$ & Included & $\$ 109,500$ & $\$ 142,500$ & $\$ 127,500$ & $\$ 150,000$ & $\$ 105,000$ & $\$ 240,000$ & 20 tons $/ \mathrm{hr}$ & GEA Barr-Rosin & SHSD \\
\hline Reboiler & $\$ 275,000$ & Included & Medium & $\$ 28,875$ & $\$ 13,750$ & Included & $\$ 10,038$ & $\$ 13,063$ & $\$ 11,688$ & $\$ 13,750$ & $\$ 9,625$ & $\$ 22,000$ & 20 tons $/ \mathrm{hr}$ & GEA Barr-Rosin & SHSD \\
\hline Fuel Processing Cost & $\$ 4,540,020$ & $\$ 36,990$ & $\mathrm{NA}$ & $\$ 388,572$ & $\$ 167,954$ & & \begin{tabular}{|l|l|}
$\$ 119,538$ \\
\end{tabular} & $\$ 155,563$ & $\$ 184,113$ & $\$ 196,460$ & $\$ 160,195$ & $\$ 368,682$ & & & \\
\hline \multicolumn{16}{|l|}{ Gasification Island } \\
\hline Conveyor & $\$ 119,000$ & $\$ 5,758$ & Low & $\$ 7,985$ & $\$ 624$ & $\mathrm{NA}$ & $\mathrm{NA}$ & $\mathrm{NA}$ & $\$ 5,302$ & $\$ 3,743$ & $\$ 4,367$ & $\$ 9,981$ & $150 \mathrm{ft}, 24$ in, $15^{\circ}$ & Thomas Conveyor & $\mathrm{BC}$ \\
\hline \multicolumn{16}{|l|}{ Dry Fuel Storage } \\
\hline Fuel Storage Hopper & $\$ 322,202$ & Included & Low/Avg & Included & Included & $\mathrm{NA}$ & $\mathrm{NA}$ & $\mathrm{NA}$ & $\$ 13,694$ & $\$ 9,666$ & $\$ 11,277$ & $\$ 25,776$ & $20000 \mathrm{ft}^{3}$ & ORNL 2002 & Updated Quote $\mathrm{e}^{1,2}$ \\
\hline Screw Feeder & $\$ 10,000$ & $\$ 484$ & Low/Avg & $\$ 954$ & $\$ 577$ & $\mathrm{NA}$ & $\mathrm{NA}$ & $\mathrm{NA}$ & $\$ 1,258$ & $\$ 1,573$ & $\$ 367$ & $\$ 2,778$ & $12 \mathrm{ft}, 16$ in diameter & Thomas Conveyor & $\mathrm{SF}$ \\
\hline Fuel Elevator & $\$ 69,000$ & $\$ 3,339$ & Low/Avg & $\$ 4,630$ & $\$ 2,170$ & $\mathrm{NA}$ & $\mathrm{NA}$ & $\mathrm{NA}$ & $\$ 3,074$ & $\$ 2,170$ & $\$ 2,532$ & $\$ 5,787$ & $100 \mathrm{ft}, 14 \times 7$ in bucket & Thomas Conveyor & $\mathrm{BE}$ \\
\hline Fuel Elevator & $\$ 69,000$ & $\$ 3,339$ & Low/Avg & $\$ 4,630$ & $\$ 2,170$ & $\mathrm{NA}$ & $\mathrm{NA}$ & $\mathrm{NA}$ & $\$ 3,074$ & $\$ 2,170$ & $\$ 2,532$ & $\$ 5,787$ & $100 \mathrm{ft}, 14 \times 7$ in bucket & Thomas Conveyor & $\mathrm{BE}$ \\
\hline \multicolumn{16}{|l|}{ Dry Fuel Supply } \\
\hline Dry Fuel Feed Bin & $\$ 25,000$ & $\$ 1,210$ & Low/Avg & $\$ 2,031$ & $\$ 1,376$ & $\mathrm{NA}$ & $\$ 813$ & $\mathrm{NA}$ & $\$ 2,162$ & $\$ 2,359$ & $\$ 917$ & $\$ 4,194$ & $300 \mathrm{ft}^{3}$ & SSPF & Updated Quote \\
\hline Screw Feeder & $\$ 10,000$ & $\$ 484$ & Low/Avg & $\$ 954$ & $\$ 577$ & $\mathrm{NA}$ & $\mathrm{NA}$ & $\mathrm{NA}$ & $\$ 1,258$ & $\$ 1,573$ & $\$ 367$ & $\$ 2,778$ & $6 \mathrm{ft}, 16$ in diameter & Thomas Conveyor & SF \\
\hline Rotary Airlock Valve & $\$ 12,500$ & $\$ 605$ & Medium & $\$ 1,867$ & $\$ 1,278$ & $\$ 5,570$ & $\$ 596$ & $\$ 1,573$ & $\$ 1,573$ & $\$ 2,949$ & $\$ 459$ & $\$ 2,949$ & $25 \mathrm{ft}^{3} / \mathrm{min}$ & Andritz-Sprout Bauer & Updated Quote \\
\hline \multicolumn{16}{|l|}{ Dry Fuel Supply } \\
\hline Dry Fuel Feed Bin & $\$ 25,000$ & $\$ 1,210$ & Low/Avg & $\$ 2,031$ & $\$ 1,376$ & $\mathrm{NA}$ & $\$ 813$ & $\mathrm{NA}$ & $\$ 2,162$ & $\$ 2,359$ & $\$ 917$ & $\$ 4,194$ & $300 \mathrm{ft}^{3}$ & SSPF & Updated Quote \\
\hline
\end{tabular}




\begin{tabular}{|c|c|c|c|c|c|c|c|c|c|c|c|c|c|c|c|}
\hline & Unit Cost & $\begin{array}{c}\text { Delivery } \\
\text { Cost }\end{array}$ & $\begin{array}{l}\text { Installation } \\
\text { Complexity }\end{array}$ & $\begin{array}{c}\text { Field } \\
\text { Erection }\end{array}$ & \begin{tabular}{c|} 
Equipment \\
Foundations \\
and Supports
\end{tabular} & Piping & \begin{tabular}{|c|} 
Equipment \\
Insulation
\end{tabular} & $\begin{array}{c}\text { Piping } \\
\text { Insulation }\end{array}$ & Electrical & $\begin{array}{l}\text { Instrumen- } \\
\text { tation }\end{array}$ & Misc & Building & Capacity & Brand & Model \# \\
\hline Screw Feeder & $\$ 10,000$ & $\$ 484$ & Low/Avg & $\$ 954$ & $\$ 577$ & $\mathrm{NA}$ & $\mathrm{NA}$ & $\mathrm{NA}$ & $\$ 1,258$ & $\$ 1,573$ & $\$ 367$ & $\$ 2,778$ & $6 \mathrm{ft}, 16$ in diameter & Thomas Conveyor & $\mathrm{SF}$ \\
\hline Rotary Airlock Valve & $\$ 12,500$ & $\$ 605$ & Medium & $\$ 1,867$ & $\$ 1,278$ & $\$ 5,570$ & $\$ 596$ & $\$ 1,573$ & $\$ 1,573$ & $\$ 2,949$ & $\$ 459$ & $\$ 2,949$ & $25 \mathrm{ft}^{3} / \mathrm{min}$ & Andritz-Sprout Bauer & Updated Quote \\
\hline Blower (Case A) & $\$ 48,800$ & $\$ 2,361$ & Medium & $\$ 5,628$ & $\$ 3,709$ & $\$ 10,232$ & $\$ 1,023$ & $\$ 2,046$ & $\$ 2,763$ & $\$ 4,093$ & $\$ 1,791$ & $\$ 5,372$ & $1400 \mathrm{scfm}+10 \mathrm{psi}$ & Literature & Literature \\
\hline Blower (Case A) & $\$ 48,800$ & $\$ 2,361$ & Medium & $\$ 5,628$ & $\$ 3,709$ & $\$ 10,232$ & $\$ 1,023$ & $\$ 2,046$ & $\$ 2,763$ & $\$ 4,093$ & $\$ 1,791$ & $\$ 5,372$ & $1400 \mathrm{scfm}+10 \mathrm{psi}$ & Literature & Literature \\
\hline Blower (Case B) & $\$ 15,300$ & $\$ 740$ & Medium & $\$ 2,149$ & $\$ 1,564$ & $\$ 5,614$ & $\$ 610$ & $\$ 1,604$ & $\$ 1,564$ & $\$ 2,887$ & $\$ 561$ & $\$ 3,128$ & $1400 \mathrm{scfm}+3 \mathrm{psi}$ & Literature & Literature \\
\hline Blower (Case B) & $\$ 15,300$ & $\$ 740$ & Medium & $\$ 2,149$ & $\$ 1,564$ & $\$ 5,614$ & $\$ 610$ & $\$ 1,604$ & $\$ 1,564$ & $\$ 2,887$ & $\$ 561$ & $\$ 3,128$ & $1400 \mathrm{scfm}+3 \mathrm{psi}$ & Literature & Literature \\
\hline Gasifier & $\$ 2,200,000$ & $\$ 106,452$ & Medium & $\$ 242,177$ & $\$ 115,323$ & $\$ 392,097$ & $\$ 84,185$ & $\$ 109,556$ & $\$ 98,024$ & $\$ 115,323$ & $\$ 80,726$ & $\$ 184,516$ & 150 tons/day & Emery Energy Co. & Updated Quote \\
\hline Gasifier & $\$ 2,200,000$ & $\$ 106,452$ & Medium & $\$ 242,177$ & $\$ 115,323$ & $\$ 392,097$ & $\$ 84,185$ & $\$ 109,556$ & $\$ 98,024$ & $\$ 115,323$ & $\$ 80,726$ & $\$ 184,516$ & 150 tons/day & Emery Energy Co. & Updated Quote \\
\hline \multicolumn{16}{|l|}{ Ash Storage } \\
\hline Bin & $\$ 65,000$ & $\$ 3,145$ & Medium & $\$ 7,155$ & $\$ 3,407$ & $\mathrm{NA}$ & $\$ 2,487$ & $\mathrm{NA}$ & $\$ 2,896$ & $\$ 3,407$ & $\$ 2,385$ & $\$ 5,452$ & $300 \mathrm{ft}^{3}$ & SSPF & Updated Quote \\
\hline Screw Feeder & $\$ 18,000$ & $\$ 871$ & Medium & $\$ 1,463$ & $\$ 991$ & $\mathrm{NA}$ & $\$ 585$ & $\mathrm{NA}$ & $\$ 1,557$ & $\$ 1,698$ & $\$ 660$ & $\$ 3,019$ & 1 ton $/ \mathrm{hr}$ & Thomas Conveyor & Updated Quote $^{3}$ \\
\hline Rotary Airlock Valve & $\$ 34,000$ & $\$ 1,645$ & Medium & $\$ 4,170$ & $\$ 2,584$ & $\$ 8,198$ & $\$ 1,622$ & $\$ 2,673$ & $\$ 2,406$ & $\$ 3,565$ & $\$ 1,248$ & $\$ 4,634$ & $10 \mathrm{ft}^{3} / \mathrm{hr}$ & Andritz-Sprout Bauer & Updated Quote \\
\hline \multicolumn{16}{|l|}{ Ash Storage } \\
\hline Bin & $\$ 65,000$ & $\$ 3,145$ & Medium & $\$ 7,155$ & $\$ 3,407$ & $\mathrm{NA}$ & $\$ 2,487$ & $\mathrm{NA}$ & $\$ 2,896$ & $\$ 3,407$ & $\$ 2,385$ & $\$ 5,452$ & $300 \mathrm{ft}^{3}$ & SSPF & Updated Quote \\
\hline Screw Feeder & $\$ 18,000$ & $\$ 871$ & Medium & $\$ 1,463$ & $\$ 991$ & $\mathrm{NA}$ & $\$ 585$ & $\mathrm{NA}$ & $\$ 1,557$ & $\$ 1,698$ & $\$ 660$ & $\$ 3,019$ & $1 \mathrm{ton} / \mathrm{hr}$ & Thomas Conveyor & Updated Quote $^{3}$ \\
\hline Rotary Airlock Valve & $\$ 34,000$ & $\$ 1,645$ & Medium & $\$ 4,170$ & $\$ 2,584$ & $\$ 8,198$ & $\$ 1,622$ & $\$ 2,673$ & $\$ 2,406$ & $\$ 3,565$ & $\$ 1,248$ & $\$ 4,634$ & $10 \mathrm{ft}^{3} / \mathrm{hr}$ & Andritz-Sprout Bauer & Updated Quote \\
\hline Cyclone & $\$ 95,005$ & $\$ 4,597$ & Medium & $\$ 10,458$ & $\$ 4,980$ & $\$ 16,932$ & $\$ 3,635$ & $\$ 4,731$ & $\$ 4,233$ & $\$ 4,980$ & $\$ 3,486$ & $\$ 7,968$ & $10000 \mathrm{scfm}$ & Fisher-Klosterman & Updated Quote $^{1}$ \\
\hline \multicolumn{16}{|l|}{ Particulate Storage } \\
\hline Bin & $\$ 65,000$ & $\$ 3,145$ & Medium & $\$ 7,155$ & $\$ 3,407$ & $\mathrm{NA}$ & $\$ 2,487$ & $\mathrm{NA}$ & $\$ 2,896$ & $\$ 3,407$ & $\$ 2,385$ & $\$ 5,452$ & $300 \mathrm{ft}^{3}$ & SSPF & Updated Quote \\
\hline Screw Feeder & $\$ 18,000$ & $\$ 871$ & Medium & $\$ 1,463$ & $\$ 991$ & $\mathrm{NA}$ & $\$ 585$ & $\mathrm{NA}$ & $\$ 1,557$ & $\$ 1,698$ & $\$ 660$ & $\$ 3,019$ & 1 ton/hr & Thomas Conveyor & Updated Quote $^{3}$ \\
\hline Rotary Airlock Valve & $\$ 34,000$ & $\$ 1,645$ & Medium & $\$ 4,170$ & $\$ 2,584$ & $\$ 8,198$ & $\$ 1,622$ & $\$ 2,673$ & $\$ 2,406$ & $\$ 3,565$ & $\$ 1,248$ & $\$ 4,634$ & $10 \mathrm{ft}^{3} / \mathrm{hr}$ & Andritz-Sprout Bauer & Updated Quote \\
\hline Box Flare & $\$ 68,000$ & $\$ 3,290$ & Low/Avg & $\$ 4,563$ & $\$ 2,139$ & $\$ 12,119$ & $\$ 2,602$ & $\$ 3,386$ & $\$ 3,030$ & $\$ 3,565$ & $\$ 2,495$ & $\$ 5,703$ & & John Zinc & Updated Quote \\
\hline \multicolumn{16}{|l|}{ Gas Cleanup (Case A) } \\
\hline Blower & $\$ 48,800$ & $\$ 2,361$ & Medium & $\$ 5,628$ & $\$ 3,709$ & $\$ 10,232$ & $\$ 1,023$ & $\$ 2,046$ & $\$ 2,763$ & $\$ 4,093$ & $\$ 1,791$ & $\$ 5,372$ & $1400 \mathrm{scfm}+10 \mathrm{psi}$ & Literature & Literature \\
\hline Heat Exchanger & $\$ 621,100$ & $\$ 30,053$ & Medium & $\$ 68,371$ & $\$ 32,558$ & $\$ 110,696$ & $\$ 23,767$ & $\$ 30,930$ & $\$ 27,674$ & $\$ 32,558$ & $\$ 22,790$ & $\$ 52,092$ & $7700 \mathrm{ft}^{2}$ & Literature & Literature \\
\hline Catalytic Tar Cracker & $\$ 1,339,470$ & $\$ 64,813$ & Medium & $\$ 147,450$ & $\$ 70,214$ & $\$ 238,728$ & $\$ 51,256$ & $\$ 66,703$ & $\$ 59,682$ & $\$ 70,214$ & $\$ 49,150$ & $\$ 112,343$ & $10000 \mathrm{scfm}$ & PHILLIPS 2007 & Updated Quote ${ }^{1,2}$ \\
\hline Rotary Airlock Valve & $\$ 34,000$ & $\$ 1,645$ & Medium & $\$ 4,170$ & $\$ 2,584$ & $\$ 8,198$ & $\$ 1,622$ & $\$ 2,673$ & $\$ 2,406$ & $\$ 3,565$ & $\$ 1,248$ & $\$ 4,634$ & $10 \mathrm{ft}^{3} / \mathrm{hr}$ & Andritz-Sprout Bauer & Updated Quote \\
\hline Rotary Airlock Valve & $\$ 34,000$ & $\$ 1,645$ & Medium & $\$ 4,170$ & $\$ 2,584$ & $\$ 8,198$ & $\$ 1,622$ & $\$ 2,673$ & $\$ 2,406$ & $\$ 3,565$ & $\$ 1,248$ & $\$ 4,634$ & $10 \mathrm{ft}^{3} / \mathrm{hr}$ & Andritz-Sprout Bauer & Updated Quote \\
\hline Cyclone & $\$ 95,005$ & $\$ 4,597$ & Medium & $\$ 10,458$ & $\$ 4,980$ & $\$ 16,932$ & $\$ 3,635$ & $\$ 4,731$ & $\$ 4,233$ & $\$ 4,980$ & $\$ 3,486$ & $\$ 7,968$ & $10000 \mathrm{scfm}$ & Fisher-Klosterman & Updated Quote $^{1}$ \\
\hline \multicolumn{16}{|l|}{ Particulate Storage } \\
\hline Bin & $\$ 65,000$ & $\$ 3,145$ & Medium & $\$ 7,155$ & $\$ 3,407$ & $\mathrm{NA}$ & $\$ 2,487$ & $\mathrm{NA}$ & $\$ 2,896$ & $\$ 3,407$ & $\$ 2,385$ & $\$ 5,452$ & $300 \mathrm{ft}^{3}$ & SSPF & Updated Quote \\
\hline Screw Feeder & $\$ 18,000$ & $\$ 871$ & Medium & $\$ 1,463$ & $\$ 991$ & NA & $\$ 585$ & $\mathrm{NA}$ & $\$ 1,557$ & $\$ 1,698$ & $\$ 660$ & $\$ 3,019$ & $1 \mathrm{ton} / \mathrm{hr}$ & Thomas Conveyor & Updated Quote $^{3}$ \\
\hline Rotary Airlock Valve & $\$ 34,000$ & $\$ 1,645$ & Medium & $\$ 4,170$ & $\$ 2,584$ & $\$ 8,198$ & $\$ 1,622$ & $\$ 2,673$ & $\$ 2,406$ & $\$ 3,565$ & $\$ 1,248$ & $\$ 4,634$ & $10 \mathrm{ft}^{3} / \mathrm{hr}$ & Andritz-Sprout Bauer & Updated Quote \\
\hline Gasification Costs (Case A) & $\$ 7,985,181$ & $\$ \$ 370,789$ & NA & $\$ 887,848$ & $\$ 401,742$ & $\$ 1,270,628$ & $\$ 281,175$ & $\$ 354,919$ & $\$ 371,825$ & $\$ 434,112$ & $\$ 292,459$ & $\$ 702,859$ & & & \\
\hline Gasification Costs (Case B) & $\$ 5,628,806$ & $\$ 256,771$ & NA & $\$ 569,942$ & $\$ 273,840$ & $\$ 860,208$ & \begin{tabular}{|l|}
192,728 \\
\end{tabular} & \begin{tabular}{|l|}
$\$ 241,604$ \\
\end{tabular} & $\mathbf{\$ 2 6 3 , 4 0 5}$ & $\$ 304,057$ & $\$ 205,995$ & $\$ 498,224$ & & & \\
\hline
\end{tabular}


After the total fixed costs were calculated for the various equipment items, the costs associated with building services were calculated according to the Factor Method of Miller (Perry 1997). Table 8 lists the percentage of the building cost and the associated service costs for Cases A and B.

Table 8. Building Services Costs

\begin{tabular}{l|c|c|c}
\hline & $\begin{array}{c}\text { \% of Building } \\
\text { Cost }\end{array}$ & Case A & Case B \\
\hline Compressed Air & $1.5 \%$ & $\$ 16,073$ & $\$ 13,004$ \\
Electric Lighting & $9 \%$ & $\$ 96,439$ & $\$ 78,022$ \\
Sprinklers & $6 \%$ & $\$ 64,292$ & $\$ 52,014$ \\
Plumbing & $12 \%$ & $\$ 128,585$ & $\$ 104,029$ \\
\hline
\end{tabular}

Additional project costs were calculated for field expenses; engineering; contractor's fees, overhead, and profit; and project contingency (Perry 1997). Table 9 lists the percentage of the delivered equipment costs for each of the additional costs and the associated dollar amount for each case.

Table 9. Additional Project Costs

\begin{tabular}{l|c|c|c}
\hline & $\begin{array}{c}\text { \% of Delivered } \\
\text { Equipment Costs }\end{array}$ & Case A & Case B \\
\hline Field Expense & $34 \%$ & $\$ 4,397,213$ & $\$ 3,557,280$ \\
Engineering & $32 \%$ & $\$ 4,138,554$ & $\$ 3,348,028$ \\
Contractor's Fees, Overhead, Profit & $18 \%$ & $\$ 2,327,936$ & $\$ 1,883,266$ \\
Contingency & $36 \%$ & $\$ 4,655,873$ & $\$ 3,766,531$ \\
\hline
\end{tabular}

Finally, the total project investment (TPI), or total fixed cost, is calculated by summing the equipment, building services, and additional project costs. Table 10 lists the TPI for Cases A and B. There were no costs calculated for purchasing land, as it was assumed that the equipment would be installed at an existing facility.

Table 10. Total Project Investment (TPI)

\begin{tabular}{l|c|c}
\hline & Case A & Case B \\
\hline Fuel Processing Costs & $\$ 6,318,085$ & $\$ 6,318,085$ \\
Gasification Costs & $\$ 13,353,539$ & $\$ 9,295,579$ \\
Building Services Costs & $\$ 305,389$ & $\$ 247,068$ \\
Additional Costs & $\$ 15,519,576$ & $\$ 12,555,104$ \\
\hline Total Project Investment (TPI) & $\mathbf{\$ 3 5 , 4 9 6 , 5 8 9}$ & $\mathbf{\$ 2 8 , 4 1 5 , 8 3 7}$ \\
\hline
\end{tabular}

\subsubsection{Comparison of Fuel Processing and Gasification/Gas Cleanup Costs}

The total costs for the fuel processing section and gasification sections (Case A) were compared to results from the recent study by the National Renewable Energy Laboratory (NREL), Thermochemical Ethanol via Indirect Gasification and Mixed Alcohol Synthesis of Lignocellulosic Biomass (Phillips 2007). The scaled cost for fuel processing is with the standard deviation of the average cost of the fuel processing systems presented, while the scaled cost for the gasification and gas cleanup are over two times greater than the average cost of the gasification and gas cleanup systems presented. 
Table 11. Study Comparisons (Scaled to 185 tons/day, \$K)

\begin{tabular}{l|c|c}
\hline Study & Fuel Processing & Gasification \& Gas Cleanup \\
\hline NREL Study & $\$ 5,372$ & $\$ 4,630$ \\
\hline Average & $\pm \$ 1,417$ & $\pm \$ 1,808$ \\
Standard Deviation & $\$ 6,318$ & $\$ 13,499$ \\
\hline Hog Fuel Project &
\end{tabular}

Possibilities for the discrepancy between the two cases include: the NREL estimate was based on $\mathrm{N}^{\text {th }}$ plant component costs while the Hog Fuel project is based on first of a kind plant component costs, many of the equipment item costs in the NREL study were based on other cost estimates rather than directly pricing many of the equipment items. Additionally, the NREL report utilizes a gasifier which is significantly less expensive than the gasifier priced in this study.

\subsubsection{Manufacturing Cost Estimation}

Manufacturing costs are the sum of direct and indirect manufacturing costs. Direct manufacturing costs for this project include the cost of raw materials, utilities, operating labor, and maintenance and repairs. Indirect manufacturing costs include estimates for the cost of payroll overhead, general plant overhead, and insurance and taxes (Perry 1997). Table 12 lists the cost factors used for materials and utilities in this study and the corresponding references. A cost for wastewater treatment is included to differentiate between the base case (natural gas) and the biomass alternatives, since drying the biomass generates a significant amount of wastewater. In addition, cost factors are defined for intermediate pressure and low pressure steam, since all cases produce various amounts of process steam.

Table 12. Material and Utility Cost Factors

\begin{tabular}{|c|c|c|}
\hline & Cost & Source \\
\hline \multicolumn{3}{|l|}{ Materials } \\
\hline Biomass Delivery (50\% Moisture) & $\$ 8.41 /$ ton & Dickinson 2006 \\
\hline Biomass (50\% Moisture) & $\$ 3.04 /$ ton & Weyerhaeuser 2000 \\
\hline Catalyst & $\$ 4.67 / 1 \mathrm{~b}$ & Phillips 2007 \\
\hline Solids Disposal & $\$ 18.00 /$ ton & Phillips 2007 \\
\hline Diesel Fuel (Front Loader) & $\$ 9.01 / \mathrm{hr}$ & Muth 2007 \\
\hline Wastewater Treatment & $\$ 2.07 / 100 \mathrm{ft}^{3}$ & Phillips 2007 \\
\hline \multicolumn{3}{|l|}{ Utilities } \\
\hline Electricity & $\$ 0.06 / \mathrm{kWh}$ & EIA $2007 a$ \\
\hline Natural Gas & $\$ 8.16 / 1000 \mathrm{ft}^{3}$ & EIA $2007 b$ \\
\hline IP Steam & $\$ 4.22 / 1000 \mathrm{lb}$ & Peters 1991 \\
\hline LP Steam & $\$ 2.33 / 1000 \mathrm{lb}$ & Peters 1991 \\
\hline
\end{tabular}

The cost estimate for the biomass delivery was based on a Virginia Tech estimate for silage hauling prices in 2006. The custom rate is $\$ 65$ per hour, which includes fuel prices, labor charges, equipment, and operator time. The rate per ton of fuel delivered was based on three trucks, with a capacity of 23 tons of biomass per truck, each operating for an eight hour shift and delivering biomass from within a 40 mile radius. The cost of the biomass was estimated from the Weyerhaeuser 2020 Report, which lists the average delivered cost at $\$ 18$ per bone dry ton (BDT). The cost of the $50 \%$ moisture biomass was 
calculated by inflating the Weyerhaeuser fuel price to 2007 dollars, account for the moisture level, and subtracting the delivery cost calculated above. The total price for $50 \%$ moisture biomass is $\$ 11.17$ per ton, on a moisture free basis, which equates to $\$ 22.90$ per BDT, which is in agreement with the $\$ 22.90$ per BDT price inflated from year 2000 (Weyerhaeuser 2000).

Consumption of materials and utilities for the base case, Case A, and Case B were estimated from material and energy balances from Aspen Plus as well as electricity requirements for powered equipment provided by vendors.

Table 13. Material and Utility Consumption/Generation

\begin{tabular}{l|c|c|c}
\hline & Base Case & Case A & Case B \\
\hline Materials - Consumed/Generated & 0 & 15.17 & 14.47 \\
\hline Biomass (tons/hr) & 0 & 0.02 & 0 \\
Catalyst (lb/hr) & 0 & 0.66 & 0.63 \\
Solids (tons/hr) & 0 & 246.14 & 234.69 \\
Wastewater (ft $\left.{ }^{3} / \mathrm{hr}\right)$ & 489 & 1864 & 1655 \\
\hline Utilities - Consumed & 1714.56 & 0 & 0 \\
\hline Electricity (HP) & 7.84 & 1.56 & 1.36 \\
Natural Gas (ft $/ \mathrm{min}$ ) & 0 & 5.94 & 5.66 \\
\hline Utilities - Generated & \multicolumn{5}{|l}{} \\
\hline IP Steam (tons/hr) &
\end{tabular}

Labor requirements were estimated based on the labor requirement and costs in the NREL report, changing the number of employees to reflect the specific requirements for this project. It was assumed that there would be one plant engineer required for this operation, but no plant manager. Rather, the single plant engineer would oversee the fuel handling and gasification operations and report to the existing plant manager at the facility. It was assumed that there would be $1 / 4$ of a maintenance supervisor; this operation would borrow a portion of an existing maintenance supervisor. Based on a four shift system, there was assumed to be half a shift supervisor per shift, half a maintenance technician per shift, and two operators per shift. One operator would handle the fuel processing portion of the system and the other would hand the gasification island and the gas cleanup system, if installed. Finally, one clerk is assumed to handle the incoming trucks, telephone calls, and administrative work. Labor rates were inflated at $3.5 \%$ per year for the 2005 salaries listed in the NREL report.

Table 14. Labor Costs

\begin{tabular}{l|c|c|c}
\hline & Number & Salary & Total Cost \\
\hline Plant Engineer & 1 & $\$ 77,200$ & $\$ 77,200$ \\
Maintenance Supervisor & 0.25 & $\$ 71,261$ & $\$ 17,815$ \\
Shift Supervisor & 2 & $\$ 53,446$ & $\$ 106,892$ \\
Maintenance Technician & 2 & $\$ 47,507$ & $\$ 95,015$ \\
Shift Operators & 8 & $\$ 47,507$ & $\$ 380,060$ \\
Clerks and Secretaries & 1 & $\$ 29,692$ & $\$ 29,692$ \\
\hline \multicolumn{3}{|l|}{ Total Salaries }
\end{tabular}


Costs for maintenance and repairs, payroll overhead, plant overhead, and insurance and taxes were calculated as a percentage of capital costs, labor costs, and TPI (Perry 1997). Table 15 lists these costs and the associated percentages.

Table 15. Additional Costs

\begin{tabular}{l|c|c|r|r}
\hline & Dependency & Percentage & Case A & Case B \\
\hline Maintenance and Repairs & Capital & $6 \%$ & $\$ 1,198,621$ & $\$ 951,644$ \\
Payroll Overhead & Labor & $18 \%$ & $\$ 123,668$ & $\$ 123,668$ \\
Plant Overhead & Labor & $50 \%$ & $\$ 353,337$ & $\$ 353,337$ \\
Insurance and Taxes & TPI & $3 \%$ & $\$ 1,064,898$ & $\$ 852,475$ \\
\hline
\end{tabular}

The total manufacturing costs were estimated from the above direct and indirect costs. As shown in Table 16, the yearly manufacturing costs for both Cases A and B, are less than the corresponding manufacturing costs for the natural gas base case. The plant was assumed to operate $90 \%$ of the year. Negative values indicate revenue, while positive values indicate expenses.

Table 16. Total Yearly Manufacturing Costs $(\$ / y r)$

\begin{tabular}{|c|c|c|c|}
\hline & Base Case & Case A & Case B \\
\hline \multicolumn{4}{|l|}{ Direct Costs } \\
\hline \multicolumn{4}{|l|}{ Materials } \\
\hline Biomass & $\$ 0$ & $\$ 1,369,916$ & $\$ 1,306,196$ \\
\hline Catalyst & $\$ 0$ & $\$ 720$ & $\$ 0$ \\
\hline Solids Disposal & $\$ 0$ & $\$ 93,492$ & $\$ 89,160$ \\
\hline Diesel Fuel (Front Loader) & $\$ 0$ & $\$ 71,035$ & $\$ 71,035$ \\
\hline Wastewater Treatment & $\$ 0$ & $\$ 40,170$ & $\$ 38,302$ \\
\hline \multicolumn{4}{|l|}{ Utilities } \\
\hline Electricity & $\$ 176,463$ & $\$ 672,483$ & $\$ 597,342$ \\
\hline Natural Gas & $\$ 6,614,814$ & $\$ 0$ & $\$ 0$ \\
\hline IP Steam & $-\$ 521,080$ & $-\$ 103,663$ & $-\$ 90,547$ \\
\hline LP Steam & $\$ 0$ & $-\$ 218,477$ & $-\$ 208,314$ \\
\hline Labor & $\$ 0$ & $\$ 0$ & $\$ 706,673$ \\
\hline Maintenance & $\$ 0$ & $\$ 0$ & $\$ 1,198,621$ \\
\hline \multicolumn{4}{|l|}{ Indirect Costs } \\
\hline Payroll Overhead & $\$ 0$ & $\$ 123,668$ & $\$ 123,668$ \\
\hline General Overhead & $\$ 0$ & $\$ 353,337$ & $\$ 353,337$ \\
\hline Insurance and Taxes & $\$ 0$ & $\$ 1,064,898$ & $\$ 1,064,898$ \\
\hline Yearly Manufacturing Costs & $\$ 6,270,198$ & $\$ 5,372,873$ & $\$ 5,250,369$ \\
\hline
\end{tabular}

\subsubsection{Economic Comparison}

A comparison of the economics for the natural gas fired kiln (base case) and the gasification alternatives, Cases A and B, was performed to assess the economic desirability of utilizing gasification derived synthesis gas in place of natural gas. To assess the desirability, the present worth, internal rate of 
return (IRR), and the discounted payback period for both cases were calculated. Cash flows for each year were assumed to be the difference between the yearly manufacturing costs of the base case and either Case A or Case B. Inflation was accounted for each year at 3.5\%.

\subsubsection{Present Worth}

The present worth (PW) of the project is calculated by discounting all cash inflows and outflows to the present point in time at a specific interest rate, generally the minimum annual rate of return (MARR). The MARR was assumed to be $10 \%$ for this project. A project is economically viable if the PW is greater than or equal zero.

$$
P W(i \%)=\sum_{k=0}^{N} F_{k}(1+i)^{-k}
$$

where $i$ is the effective interest rate, or MARR, per compounding period, $k$ is the index for each compounding period, $F_{k}$ is the cash flow at the end of period $k$, and $N$ is the number of compounding periods in the planning horizon, i.e. the study period (Sullivan 2003). Present worth calculations were performed for both 10 year and 20 year project periods for the calculated TPI and at $\pm 30 \%$ TPI. As shown in Table 17, the present worth for all variations of Case A and Case B for a project life of either 10 or 20 years are less than zero. Therefore, according to the present worth method, the project is not economically viable.

Table 17. Present Worth Results (MARR $=10 \%)$

\begin{tabular}{l|r|r}
\hline & $\mathrm{N}=10$ years & $\mathrm{N}=20$ years \\
\hline Case A & $-\$ 30,041,148$ & $-\$ 27,905,151$ \\
Case A $(-30 \%$ TPI) & $-\$ 17,426,609$ & $-\$ 14,530,147$ \\
Case A $(+30 \%$ TPI) & $-\$ 42,655,687$ & $-\$ 41,280,156$ \\
Case B & $-\$ 22,141,254$ & $-\$ 19,713,650$ \\
Case B $(-30 \%$ TPI) & $-\$ 11,650,940$ & $-\$ 8,462,871$ \\
Case B $(+30 \%$ TPI $)$ & $-\$ 32,631,600$ & $-\$ 30,964,429$ \\
\hline
\end{tabular}

\subsubsection{Internal Rate of Return}

The IRR method is the most widely used rate of return method for performing engineering economic analyses. This method solves for the interest rate that equates the equivalent worth of an alternative's cash inflows to the equivalent worth of cash outflows, the interest rate at which the PW is zero. The resulting interest is the IRR $\left(i^{\prime}\right)$. For the project to be economically viable the calculated IRR must be greater than the desired MARR (Sullivan 2003).

$$
P W\left(i^{\prime} \%\right)=\sum_{k=0}^{N} F_{k}\left(1+i^{\prime}\right)^{-k}=0
$$

IRR calculations were performed for both 10 year and 20 year project periods for the calculated TPI and at $\pm 30 \%$ TPI. As shown in Table 18, the IRR, for all variations of Case A and Case B for a project life of either 10 or 20 years, is less than the MARR of $10 \%$. Therefore, according to the internal rate of return method, the project is not economically viable. 
Table 18. Internal Rate of Return Results $\left(i^{\prime}\right)$

\begin{tabular}{l|c|c}
\hline & $\mathrm{N}=10$ years & $\mathrm{N}=20$ years \\
\hline Case A & $-19.5 \%$ & $-5.8 \%$ \\
Case A $(-30 \%$ TPI $)$ & $-11.3 \%$ & $-0.2 \%$ \\
Case A $(+30 \%$ TPI $)$ & $-26.7 \%$ & $-10.6 \%$ \\
Case B & $-15.3 \%$ & $-2.9 \%$ \\
Case B (-30\% TPI) & $-6.6 \%$ & $3.1 \%$ \\
Case B $(+30 \%$ TPI $)$ & -22.5 & $-7.8 \%$ \\
\hline
\end{tabular}

\subsubsection{Discounted Payback Period}

All of the economics presented to this point reflect the profitability of a proposed alternative. The discounted payback period, or the breakeven life, indicates a project's liquidity rather than profitability, i.e. how quickly the invested capital would be recovered. The discounted payback period is the first year in which the cumulative discounted cash inflows exceed the capital investment.

$$
\sum_{k=0}^{\theta^{\prime}} F_{k}\left(1+i^{\prime}\right)^{-k} \geq 0
$$

where $\theta^{\prime}$ is the smallest value that satisfies the above equation, or the first year where the cumulative present worth is greater than zero. Discounted payback period calculations were performed for base cases at the calculated TPI and at $\pm 30 \%$ TPI. As shown in Table 19, the discounted payback period for each case and associated variations are significantly longer than 10 or 20 year project investment periods. Therefore, according to the discounted payback period method, the project is considered financially risky.

Table 19. Discounted Payback Period Results $(\mathrm{MARR}=10 \%)$

\begin{tabular}{l|l}
\hline & $\theta^{\prime}$ \\
\hline Case A & Never \\
Case A (-30\% TPI) & Never \\
Case A (+30\% TPI) & Never \\
Case B & Never \\
Case B (-30\% TPI) & Never \\
Case B (+30\% TPI) & Never \\
\hline
\end{tabular}

\subsubsection{Economic Sensitivity}

Sensitivity analyses for biomass utilization credits, $\mathrm{CO}_{2}$ derived biomass credits, and natural gas price increases were performed for the present worth calculations. The credit or price increase was determined to provide a PW of zero for both 10 year and 20 year project periods for the calculated TPI and at $\pm 30 \%$ TPI for Cases $\mathrm{A}$ and $\mathrm{B}$, again an MARR of $10 \%$ was assumed. The $\mathrm{CO}_{2}$ credit is derived from the credit for dry biomass feed, relating the $\mathrm{CO}_{2}$ credit to the percentage of carbon in the fuel and the ratios of the molecular weights of carbon and $\mathrm{CO}_{2}$. 
Table 20. Sensitivity Analyses Results (PW $=0$, MARR $=10 \%)$

\begin{tabular}{|c|c|c|}
\hline & $\mathrm{N}=10$ years & $\mathrm{N}=20$ years \\
\hline \multicolumn{3}{|c|}{ Biomass Credit $(\$ / \mathrm{BDT}) / \mathrm{CO}_{2}$ Credit $\left(\$ /\right.$ ton Biomass Derived $\left.\mathrm{CO}_{2}\right)$} \\
\hline Case A & $81.62 / 49.79$ & $54.67 / 33.35$ \\
\hline Case A $(-30 \%$ TPI $)$ & $47.35 / 28.88$ & $28.74 / 17.36$ \\
\hline Case A $(+30 \% \mathrm{TPI})$ & $115.90 / 70.70$ & $80.87 / 49.33$ \\
\hline Case B & $63.09 / 38.49$ & $40.51 / 24.71$ \\
\hline Case B $(-30 \%$ TPI $)$ & $33.20 / 20.25$ & $17.39 / 10.61$ \\
\hline Case B $(+30 \%$ TPI $)$ & $92.99 / 56.72$ & $63.62 / 38.81$ \\
\hline \multicolumn{3}{|c|}{ Natural Gas Price $\left(\$ / 1000 \mathrm{ft}^{3}\right)$} \\
\hline Case A & 20.20 & 16.22 \\
\hline Case A $(-30 \%$ TPI $)$ & 15.14 & 12.35 \\
\hline Case A $(+30 \%$ TPI $)$ & 25.25 & 20.09 \\
\hline Case B & 17.03 & 13.85 \\
\hline Case B $(-30 \%$ TPI $)$ & 12.83 & 10.60 \\
\hline Case B $(+30 \%$ TPI $)$ & 21.23 & 17.10 \\
\hline
\end{tabular}

The results of the sensitivity analyses, presented in Table 20 above, show that the project can become economically viable if there is a credit for utilization of biomass as a feedstock, through either a direct credit or a credit for biomass based $\mathrm{CO}_{2}$ emissions (green emissions), or if there is a significant increase in the price of natural gas through the project's life starting in year one.

\section{CONCLUSIONS AND RECOMMENDATIONS}

This analysis shows that it is technically feasible to produce synthetic industrial gas via gasification of hog fuel for direct firing a lime kiln. Two options exist for handling the tars and oils produced in updraft biomass gasification: tar removal (via catalytic tar cracking or an alternative tar removal method) or maintaining the temperature of the synthesis gas stream sufficiently above the tar condensation temperature. Given the capital investment required for tar removal mechanisms and the associated loss in the gas heating value, it is recommended to design the gasification and piping system downstream to maintain the synthesis gas temperature above the tar condensation temperature. This requires low moisture levels in the biomass fed to the gasifier and operating the gasifier below, but near the ash softening point to maximize the outlet temperature of the synthesis gas. In addition, it is recommended to limit the length of piping between the gasifier and the lime kiln to 65 feet or less.

To preclude the formation of tars and oils, the operating temperature of the gasifier near the ash grate is $2000^{\circ} \mathrm{F}$, with the possibility of localized hot spots. Given the elevated operating temperature of the gasifier, it is necessary to select robust materials for the gasifier components, specifically the refractory. Given these high temperatures, high purity alumina or chromia refractories may be more desirable than traditional silica refractories and proper selection of materials for the ash grate is essential.

Given the high TPI required for this project and the small offset in the yearly manufacturing costs, utilization of a gasification system for the production of synthetic industrial gas for use in a lime kiln is not economically feasible at this point in time. However, several options exist which could improve the economics of this system and cause it to become economically desirable, such as a credit for utilization of biomass as a feedstock or a significant increase in the price of natural gas. Also, increasing the capacity or output of synthetic natural gas (i.e. increasing the scale of the facility) could improve the economics. 


\section{REFERENCES}

Baker, Ed G., Lyle K. Mudge, and Don H. Mitchell, "Oxygen/Steam Gasification of Wood in a FixedBed Gasifier," Industrial and Engineering Chemistry Process Design and Development, Vol. 23, 1984, pp. 725-728.

Barton, V. L., et al, "Corrosion Performance of Metals in Pilot Plant Coal Gasifiers", The Properties and Performance of Materials in the Coal Gasification Environment, Metals Park, Ohio: American Society for Metals, 1981.

Bennet, J. P., et al, "Issues Impacting Refractory Service Life in Biomass/Waste Gasification", NACE International Corrosion 2007 Conference, Houston, TX. 2007, Paper 07348.

BTG, Tar \& Tar Removal, http://www.btgworld.com/, page visited September 3, 2007.

Bustamante, F., et al, "Uncatalyzed and Wall-Catalyzed Forward Water-Gas Shift Reaction Kinetics," AIChE Journal, Vol. 51, No. 5, May 2005, pp. 1440-1454.

Di Blasi, Colomba, "Modeling Wood Gasification in a Countercurrent Fixed-Bed Reactor," AIChE Journal, Vol. 50, No. 9, September 2004, pp. 2306-2319.

Dickinson, Keith, “2006 Farm Custom-Work Rate Guide,” Virginia Tech, 2006.

Emery Energy Company (hgatley@emergyenergy.com), “RE: Gasifier Questions,” Anastasia M. Gribik (anastasia.gribik@inl.gov), July 31, 2007.

Energy Information Administration (EIA), Average Retail Price of Electricity to Ultimate Customers by End-Use Sector, http://www.eia.doe.gov/cneaf/electricity/epa/epat7p4.html, page updated October 4, 2006, page visited September 12, 2007a.

Energy Information Administration (EIA), Natural Gas Prices, http://tonto.eia.doe.gov/dnav/ng/ng_pri_sum_dcu_nus_m.htm, page updated September 27, 2007, page visited September 27, $2007 \mathrm{~b}$.

Enick, R. M., et al, "High-Temperature Kinetics of the Homogeneous Reverse Water-Gas Shift Reaction," AIChE Journal, Vol. 50, No. 5, May 2004, pp. 1028-1041.

Evans, R. J. and T. A. Milne, Biomass Gasifier "Tars": Their Nature, Formation, and Conversion, NREL/TP-570-25357, November 1998, pp. 13-14.

Fagbemi, L., L. Khezami, and R. Capart, "Pyrolysis Products from Different Biomasses: Application to the Thermal Cracking of Tar," Applied Energy, Vol. 69, 2001, pp. 293-306.

Gorog, J. Peter, Weyerhaeuser, “Lime Sludge Kiln Operation,” December 1, 2002.

Hobbs, Michael L., Predrag T. Radulovic, and L. Douglas Smoot, "Modeling Fixed-Bed Coal Gasifiers," AIChE Journal, Vol. 38, No. 5, May 1992, pp. 681-702.

Knoeff, Harrie (knoef@btgworld.com), “RE: BTG Tar Cracker Information,” Anastasia M. Gribik (anastasia.gribik@inl.gov), August 29,2007. 
Langenohl, M. (mark.langenohl@rescoproducts.com), "Refractory Lining for a proposed Syn Gas Plant in Salt Lake City,” Ronald .E. Mizia (ronald.mizia@inl.gov), September 20, 2007.

McLellan, R., Design of a 2.5 MW(e) Biomass Gasification Power Generation Module, ETSI B/TI/00569/REP, 2000.

Mudge, L. K., et al, Engineering Analysis of Biomass Gasifier Product Gas Cleaning Technology, PNL-5534/UC-61F, August 1986.

Muth, David J. (david.muth@inl.gov), "Pricing Info,” Anastasia M. Gribik (anastasia.gribik@inl.gov), August 28, 2007.

Nangia, V. K., Materials of Construction for Advanced Coal Conversion Systems, Park Ridge, New Jersey: Noyes Data Corporation, 1982, Chapter 5.

Natesan, K. and Z. Zeng, Study of Metal Dusting Phenomenon and Development of Materials Resistant to Metal Dusting, Final Report, ANL-03/33, December 2003.

Natesan, K. and Z. Zeng, Z., Development of Materials Resistant to Metal Dusting Degradation, ANL-06/14, March 2006.

Natesan, K., Study of Metal Dusting Phenomenon and Development of Materials Resistant to Metal Dusting, ANL-02/05, February 2002.

Perry, Robert H. and Don W. Green, Perry's Chemical Engineers' Handbook, New York: McGraw Hill, 1997, pp. 9-54 to $9-79$.

Peters, Max S. and Klaus D. Temmerhaus, Plant Design and Economics for Chemical Engineers, New York: McGraw Hill, 1991, pp. 169 and 815.

Phillips, S., et al, Thermochemical Ethanol via Indirect Gasification and Mixed Alcohol Synthesis of Lignocellulosic Biomass, NREL/TP-510-41168, April 2007, pp. 35-40.

Sadler, L. Y., et al, "Evaluation of Refractory Liner Materials for Use in Nonslagging, High BTU Coal Gasification Reactors," Ceramic Bulletin, Vol. 58, No. 7, 1979, pp 705-714.

Souza-Santos, Marcio L., Solid Fuels Combustion and Gasification, New York: Marcel Dekker, Inc., 2004, pp. 146-157.

Speight, James G., Chemical and Process Design Handbook, New York: McGraw-Hill, 2002, pp. 2.131.

Sullivan, William G., Elin M. Wicks, and James T. Luxhoj, Engineering Economy, Upper Saddle River, New Jersey: Prentice Hall, 2003, pp. 154-178.

Weyerhaeuser, Biomass Gasification Combined Cycle Agenda 2020, DE-FC36-96GO10173, July 2000.

Wilson, .J and D. C. Agarwal, "Case Histories on Successful Applications of Alloy 602CA, UNS N06025, in High Temperature Environments", NACE International Corrosion 2005 Conference, Houston, TX. 2007, Paper 05423.

Zygarlicke, Christopher J., Year 2 Biomass Utilization, 2004-EERC-11-02, November 2004, pp. 12. 


\section{Appendix A}

Hog Fuel Project Case Study Results 

Base Case Aspen Plus Flowsheets

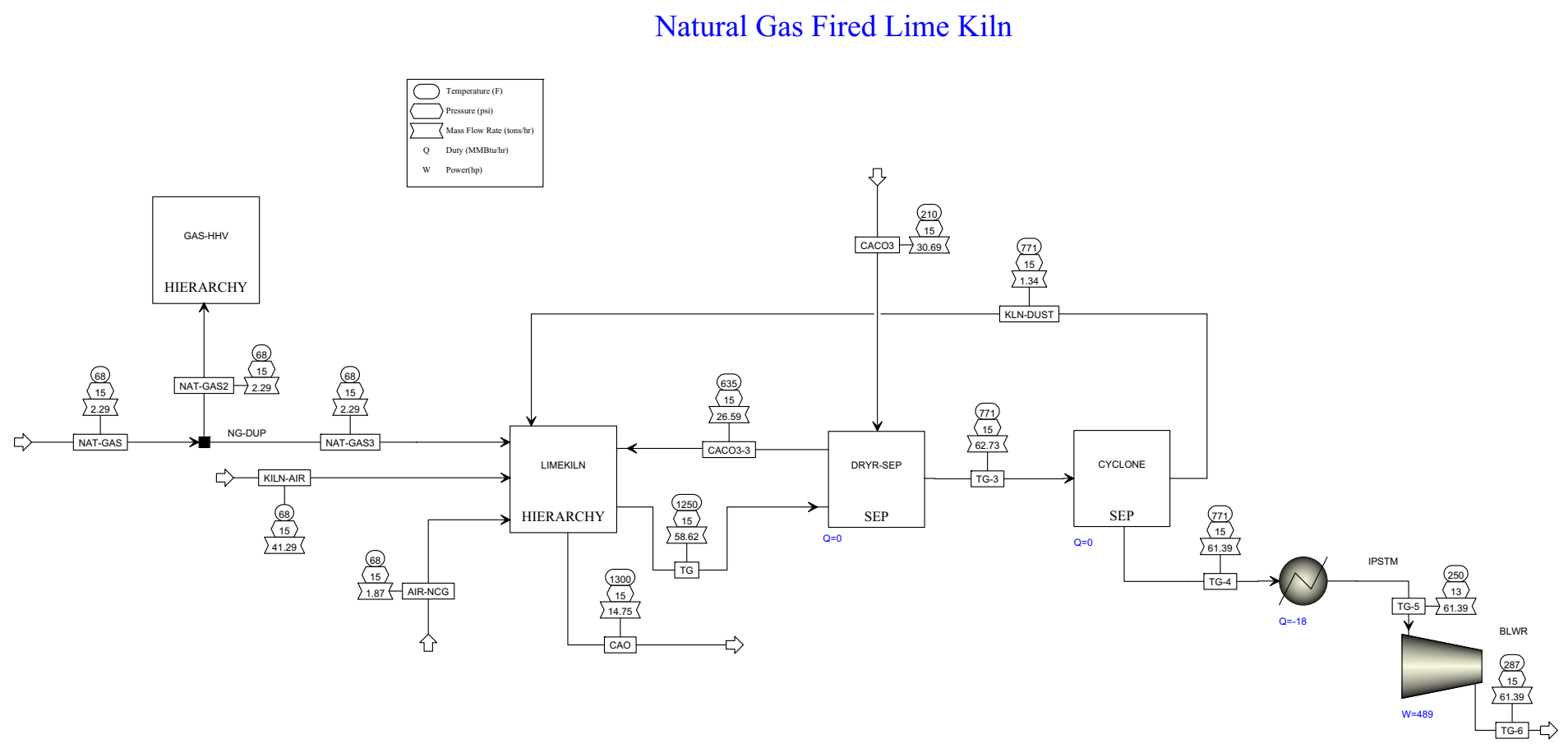

A-1 


\section{Base Case Aspen Plus Flowsheets}

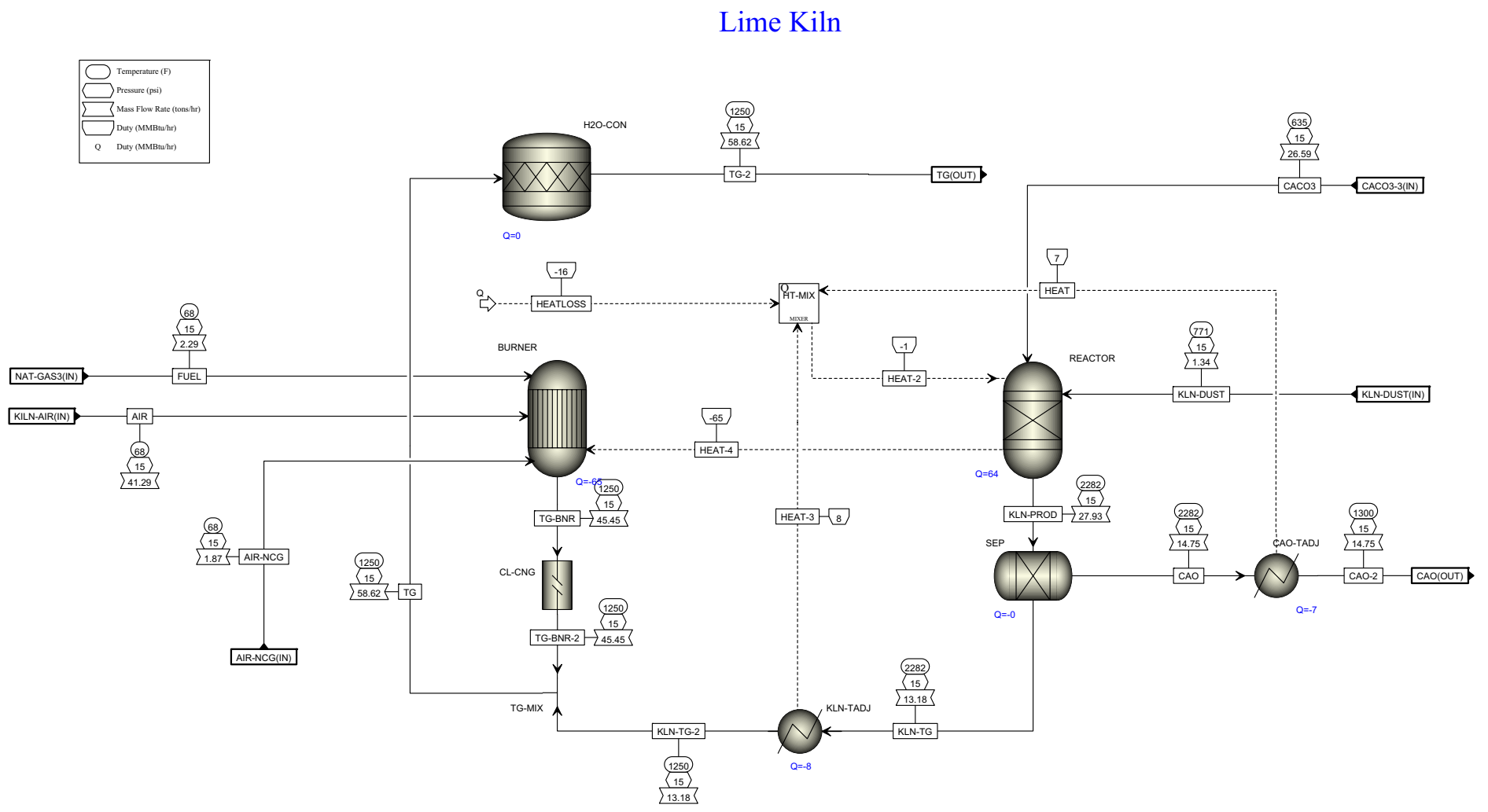




\section{Base Case Aspen Plus Stream Results}

\begin{tabular}{|c|c|c|c|c|c|c|c|c|c|c|c|c|c|c|}
\hline & AIR-NCG & $\mathrm{CACO} 3$ & CACO3-3 & CAO & KILN-AIR & KLN-DUST & NAT-GAS & NAT-GAS2 & NAT-GAS3 & TG & TG-3 & TG-4 & TG-5 & TG-6 \\
\hline \multicolumn{15}{|l|}{ Mixed Substream } \\
\hline Temperature F & 68 & 210 & 635 & & 68 & & 68 & 68 & 68 & 1249.9 & 770.9 & 770.9 & 250 & 287.2 \\
\hline Pressure psi & 14.7 & 14.7 & 14.7 & 14.7 & 14.7 & 14.7 & 14.7 & 14.7 & 14.7 & 14.7 & 14.7 & 14.7 & 12.7 & 14.7 \\
\hline Vapor Frac & 1 & & 1 & & 1 & & 1 & 1 & 1 & 1 & 1 & 1 & 1 & 1 \\
\hline Mole Flow $\mathrm{lbmol} / \mathrm{hr}$ & 129.173 & 484.478 & 29.069 & & 2852.245 & & 266.983 & 266.983 & 266.983 & 3811.513 & 4266.922 & 4266.922 & 4266.922 & 4266.922 \\
\hline Mass Flow tons $/ \mathrm{hr}$ & 1.87 & 4.364 & 0.262 & & 41.291 & & 2.285 & 2.285 & 2.285 & 57.284 & 61.386 & 61.386 & 61.386 & 61.386 \\
\hline Volume Flow cuft/hr & 49749.865 & 174.446 & 23186.855 & & $1.10 \mathrm{E}+06$ & & 102614.677 & 102614.677 & 102614.677 & $4.76 \mathrm{E}+06$ & $3.83 \mathrm{E}+06$ & $3.83 \mathrm{E}+06$ & $2.56 \mathrm{E}+06$ & $2.32 \mathrm{E}+06$ \\
\hline Enthalpy $\mathrm{MMBtu} / \mathrm{hr}$ & -0.029 & -58.639 & -2.888 & & -0.63 & & -8.628 & -8.628 & -8.628 & -158.7 & -219.449 & -219.449 & -237.611 & -236.367 \\
\hline \multicolumn{15}{|l|}{ Mass Flow tons $/ \mathrm{hr}$} \\
\hline $\mathrm{C} 1$ & & & & & & & 2.034 & 2.034 & 2.034 & & & & & \\
\hline $\mathrm{C} 2$ & & & & & & & 0.076 & 0.076 & 0.076 & & & & & \\
\hline $\mathrm{C} 3$ & & & & & & & 0.029 & 0.029 & 0.029 & & & & & \\
\hline I-C4 & & & & & & & 0.039 & 0.039 & 0.039 & & & & & \\
\hline $\mathrm{N}-\mathrm{C} 4$ & & & & & & & 0.008 & 0.008 & 0.008 & & & & & \\
\hline $\mathrm{N}-\mathrm{C5}$ & & & & & & & 0.01 & 0.01 & 0.01 & & & & & \\
\hline I-C5 & & & & & & & 0.01 & 0.01 & 0.01 & & & & & \\
\hline $\mathrm{C} 6$ & & & & & & & 0.012 & 0.012 & 0.012 & & & & & \\
\hline N2 & 1.41 & & & & 31.142 & & 0.056 & 0.056 & 0.056 & 32.609 & 32.609 & 32.609 & 32.609 & 32.609 \\
\hline $\mathrm{CO} 2$ & 0.001 & & & & 0.019 & & 0.012 & 0.012 & 0.012 & 17.73 & 17.73 & 17.73 & 17.73 & 17.73 \\
\hline \multirow{2}{*}{\multicolumn{15}{|c|}{$\mathrm{CACO} 3$}} \\
\hline & & & & & & & & & & & & & & $\mathrm{CAO}$ \\
\hline $\mathrm{CO}$ & & & & & & & & & & 0.003 & 0.003 & 0.003 & 0.003 & 0.003 \\
\hline $\mathrm{O} 2$ & 0.433 & & & & 9.569 & & & & & 1.22 & 1.22 & 1.22 & 1.22 & 1.22 \\
\hline $\mathrm{AR}$ & 0.024 & & & & 0.535 & & & & & 0.559 & 0.559 & 0.559 & 0.559 & 0.559 \\
\hline \multirow{2}{*}{\multicolumn{15}{|c|}{$\mathrm{NO} 2$}} \\
\hline & & & & & & & & & & & & & & \\
\hline $\mathrm{H} 2 \mathrm{O}$ & 0.001 & & & & 0.026 & & & & & 5.164 & 5.164 & 5.164 & 5.164 & 5.164 \\
\hline \multicolumn{15}{|l|}{$\mathrm{H} 2$} \\
\hline \multirow{2}{*}{\multicolumn{15}{|c|}{$\begin{array}{l}\text { H2U-MUD } \\
\text { Mass Frac }\end{array}$}} \\
\hline & & & & & & & & & & & & & & \\
\hline $\mathrm{C} 1$ & & & & & & & 0.89 & 0.89 & 0.89 & & & & & \\
\hline $\mathrm{C} 2$ & & & & & & & 0.033 & 0.033 & 0.033 & & & & & \\
\hline $\mathrm{C} 3$ & & & & & & & 0.013 & 0.013 & 0.013 & & & & & \\
\hline I-C4 4 & & & & & & & 0.017 & 0.017 & 0.017 & & & & & \\
\hline $\mathrm{N}-\mathrm{C} 4$ & & & & & & & 0.003 & 0.003 & 0.003 & & & & & \\
\hline $\mathrm{N}-\mathrm{C} 5$ & & & & & & & 0.004 & 0.004 & 0.004 & & & & & \\
\hline I-C5 & & & & & & & 0.004 & 0.004 & 0.004 & & & & & \\
\hline $\mathrm{C} 6$ & & & & & & & 0.005 & 0.005 & 0.005 & & & & & \\
\hline N2 & 0.754 & & & & 0.754 & & 0.025 & 0.025 & 0.025 & 0.569 & 0.531 & 0.531 & 0.531 & 0.531 \\
\hline $\mathrm{CO} 2$ & & & & & & & 0.005 & 0.005 & 0.005 & 0.31 & 0.289 & 0.289 & 0.289 & 0.289 \\
\hline \multicolumn{15}{|l|}{$\mathrm{CACO} 3$} \\
\hline \multirow{2}{*}{\multicolumn{15}{|c|}{ CAO }} \\
\hline & & & & & & & & & & & & & & \\
\hline $\mathrm{O} 2$ & 0.232 & & & & 0.232 & & & & & 0.021 & 0.02 & 0.02 & 0.02 & 0.02 \\
\hline AR & 0.013 & & & & 0.013 & & & & & 0.01 & 0.009 & 0.009 & 0.009 & 0.009 \\
\hline \multirow{2}{*}{\multicolumn{15}{|c|}{$\mathrm{NO} 2$}} \\
\hline & & & & & & & & & & & & & & No \\
\hline $\mathrm{H} 2 \mathrm{O}$ & 0.001 & & & & 0.001 & & & & & 0.09 & 0.084 & 0.084 & 0.084 & 0.084 \\
\hline H2 & & & & & & & & & & & & & & \\
\hline H2O-MUD & & 1 & 1 & & & & & & & & 0.067 & 0.067 & 0.067 & 0.067 \\
\hline Mole Flow lbmol/hr & & & & & & & & & & & & & & \\
\hline $\mathrm{C} 1$ & & & & & & & 253.631 & 253.631 & 253.631 & & & & & \\
\hline C2 & & & & & & & 5.073 & 5.073 & 5.073 & & & & & \\
\hline $\mathrm{C} 3$ & & & & & & & 1.335 & 1.335 & 1.335 & & & & & \\
\hline $\mathrm{I}-\mathrm{C} 4$ & & & & & & & 1.335 & 1.335 & 1.335 & & & & & \\
\hline $\mathrm{N}-\mathrm{C} 4$ & & & & & & & 0.267 & 0.267 & 0.267 & & & & & \\
\hline N-C5 & & & & & & & 0.267 & 0.267 & 0.267 & & & & & \\
\hline
\end{tabular}




\section{Base Case Aspen Plus Stream Results}

\begin{tabular}{|c|c|c|c|c|c|c|c|c|c|c|c|c|c|c|}
\hline I-C5 & AIR-NCG & $\mathrm{CACO} 3$ & СACO3-3 & CAO & KILN-AIR & KLN-DUST & $\begin{array}{c}\text { NAT-GAS } \\
0.267\end{array}$ & $\begin{array}{c}\text { NAT-GAS2 } \\
0.267\end{array}$ & $\begin{array}{c}\text { NAT-GAS3 } \\
0.267\end{array}$ & TG & TG-3 & TG-4 & TG-5 & TG-6 \\
\hline C6 & & & & & & & 0.267 & 0.267 & 0.267 & & & & & \\
\hline $\mathrm{N} 2$ & 100.693 & & & & 2223.384 & & 4.005 & 4.005 & 4.005 & 2328.081 & 2328.081 & 2328.081 & 2328.081 & 2328.081 \\
\hline $\mathrm{CO} 2$ & 0.039 & & & & 0.855 & & 0.534 & 0.534 & 0.534 & 805.708 & 805.708 & 805.708 & 805.708 & 805.708 \\
\hline \multicolumn{15}{|l|}{$\begin{array}{l}\mathrm{CACO} 3 \\
\mathrm{CAO}\end{array}$} \\
\hline \multicolumn{15}{|l|}{$\mathrm{CAO}$} \\
\hline $\mathrm{CO}$ & & & & & & & & & & 0.241 & 0.241 & 0.241 & 0.241 & 0.241 \\
\hline $\mathrm{O} 2$ & 27.086 & & & & 598.088 & & & & & 76.237 & 76.237 & 76.237 & 76.237 & 76.237 \\
\hline AR & 1.213 & & & & 26.784 & & & & & 27.997 & 27.997 & 27.997 & 27.997 & 27.997 \\
\hline \multicolumn{15}{|l|}{$\mathrm{NO} 2$} \\
\hline \multicolumn{15}{|l|}{ NO } \\
\hline $\mathrm{H} 2 \mathrm{O}$ & 0.129 & & & & 2.849 & & 0.003 & 0.003 & 0.003 & 573.247 & 573.247 & 573.247 & 573.247 & 573.247 \\
\hline $\mathrm{H} 2$ & 0.013 & & & & 0.285 & & & & & 0.002 & 0.002 & 0.002 & 0.002 & 0.002 \\
\hline H2O-MUD & & 484.478 & 29.069 & & & & & & & & 455.409 & 455.409 & 455.409 & 455.409 \\
\hline \multicolumn{15}{|l|}{ Mole Frac } \\
\hline $\mathrm{C} 1$ & & & & & & & 0.95 & 0.95 & 0.95 & & & & & \\
\hline $\mathrm{C} 2$ & & & & & & & 0.019 & 0.019 & 0.019 & & & & & \\
\hline $\mathrm{C} 3$ & & & & & & & 0.005 & 0.005 & 0.005 & & & & & \\
\hline I-C4 & & & & & & & 0.005 & 0.005 & 0.005 & & & & & \\
\hline $\mathrm{N}-\mathrm{C} 4$ & & & & & & & 0.001 & 0.001 & 0.001 & & & & & \\
\hline $\mathrm{N}-\mathrm{C} 5$ & & & & & & & 0.001 & 0.001 & 0.001 & & & & & \\
\hline I-C5 & & & & & & & 0.001 & 0.001 & 0.001 & & & & & \\
\hline $\mathrm{C} 6$ & & & & & & & 0.001 & 0.001 & 0.001 & & & & & \\
\hline $\mathrm{N} 2$ & 0.78 & & & & 0.78 & & 0.015 & 0.015 & 0.015 & 0.611 & 0.546 & 0.546 & 0.546 & 0.546 \\
\hline \multirow{2}{*}{\multicolumn{15}{|c|}{$\mathrm{CACO} 3$}} \\
\hline & & & & & & & & & & & & & & \\
\hline \multirow{2}{*}{\multicolumn{15}{|c|}{$\begin{array}{l}\text { CAO } \\
\text { CO }\end{array}$}} \\
\hline & & & & & & & & & & & & & & \\
\hline $\mathrm{O} 2$ & 0.21 & & & & 0.21 & & & & & 0.02 & 0.018 & 0.018 & 0.018 & 0.018 \\
\hline \multirow{2}{*}{\multicolumn{15}{|c|}{$\mathrm{NO} 2$}} \\
\hline & & & & & & & & & & & & & & \\
\hline \multicolumn{15}{|l|}{ NO } \\
\hline \multirow{2}{*}{\multicolumn{15}{|c|}{$\mathrm{H} 2$}} \\
\hline & & & & & & & & & & & & & & \\
\hline H2O-MUD & & 1 & 1 & & & & & & & & 0.107 & 0.107 & 0.107 & 0.107 \\
\hline \multicolumn{15}{|l|}{ olid Substream } \\
\hline Mass Flow tons $/ \mathrm{hr}$ & & 30.69 & 26.588 & 14.75 & & 1.339 & & & & 58.623 & 62.726 & 61.386 & 61.386 & 61.386 \\
\hline Enthalpy MMBtu/hr & & -330.268 & -269.233 & -135.746 & & -12.641 & & & & -171.054 & -232.09 & -219.449 & -237.611 & -236.367 \\
\hline Temperature F & & 210 & 635 & 1300 & & 770.9 & & & & 1249.9 & 770.9 & & & \\
\hline Pressure $\mathrm{psi}$ & & 14.7 & 14.7 & 14.7 & & 14.7 & & & & 14.7 & 14.7 & 14.7 & 12.7 & 14.7 \\
\hline \multicolumn{15}{|l|}{ Vapor Frac } \\
\hline Mole Flow $\mathrm{lbmol} / \mathrm{hr}$ & & 526.061 & 526.061 & 526.061 & & 47.759 & & & & 47.759 & 47.759 & & & \\
\hline Mass Flow tons $/ \mathrm{hr}$ & & 26.326 & 26.326 & 14.75 & & 1.339 & & & & 1.339 & 1.339 & & & \\
\hline Volume Flow cuft/hr & & 311.289 & 312.885 & 143.299 & & 13.01 & & & & 13.01 & 13.01 & & & \\
\hline Enthalpy MMBtu/hr & & -271.629 & -266.345 & -135.746 & & -12.641 & & & & -12.354 & -12.641 & & & \\
\hline \multicolumn{15}{|l|}{ Mass Flow tons $/ \mathrm{hr}$} \\
\hline $\mathrm{CACO} 3$ & & 26.326 & 26.326 & & & & & & & & & & & \\
\hline $\mathrm{CAO}$ & & & & 14.75 & & 1.339 & & & & 1.339 & 1.339 & & & \\
\hline Mass Frac & & & & & & & & & & & & & & \\
\hline $\mathrm{CACO} 3$ & & 1 & 1 & & & & & & & & & & & \\
\hline CAO & & & & 1 & & 1 & & & & 1 & 1 & & & \\
\hline Mole Flow $\mathrm{lbmol} / \mathrm{hr}$ & & & & & & & & & & & & & & \\
\hline $\mathrm{CACO} 3$ & & 526.061 & 526.061 & & & & & & & & & & & \\
\hline $\mathrm{CAO}$ & & & & 526.061 & & 47.759 & & & & 47.759 & 47.759 & & & \\
\hline Mole Frac & & & & & & & & & & & & & & \\
\hline $\mathrm{CACO} 3$ & & 1 & 1 & & & & & & & & & & & \\
\hline CAO & & & & 1 & & 1 & & & & 1 & 1 & & & \\
\hline
\end{tabular}




\section{Case A Aspen Plus Flowsheets}

\section{Hog Fuel Gasification with Optional Tar Cracker}

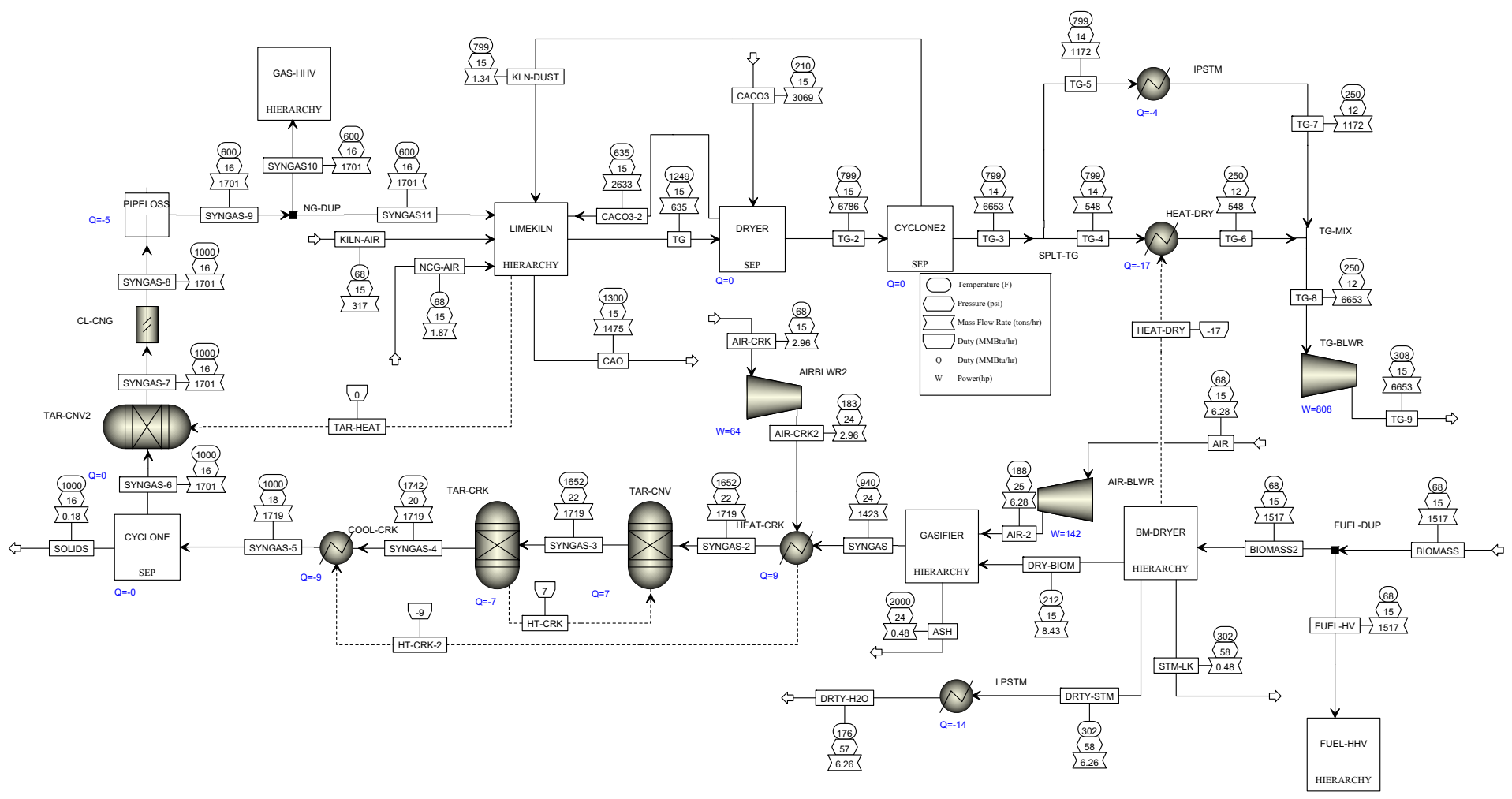


Case A Aspen Plus Flowsheets

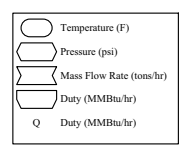

Biomass Drying

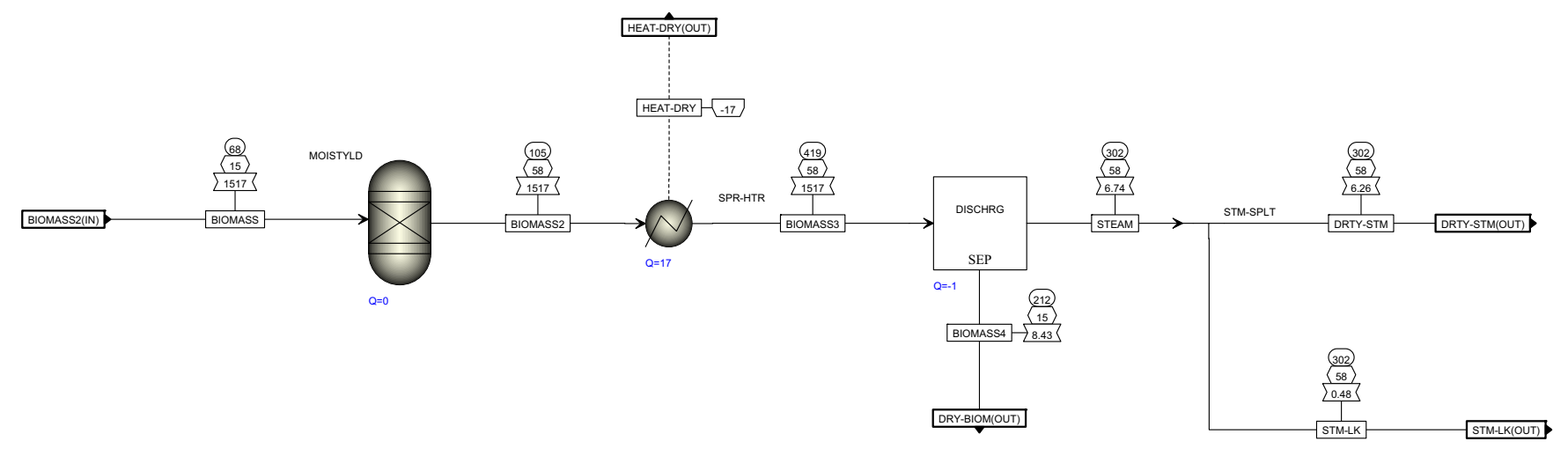


Case A Aspen Plus Flowsheets

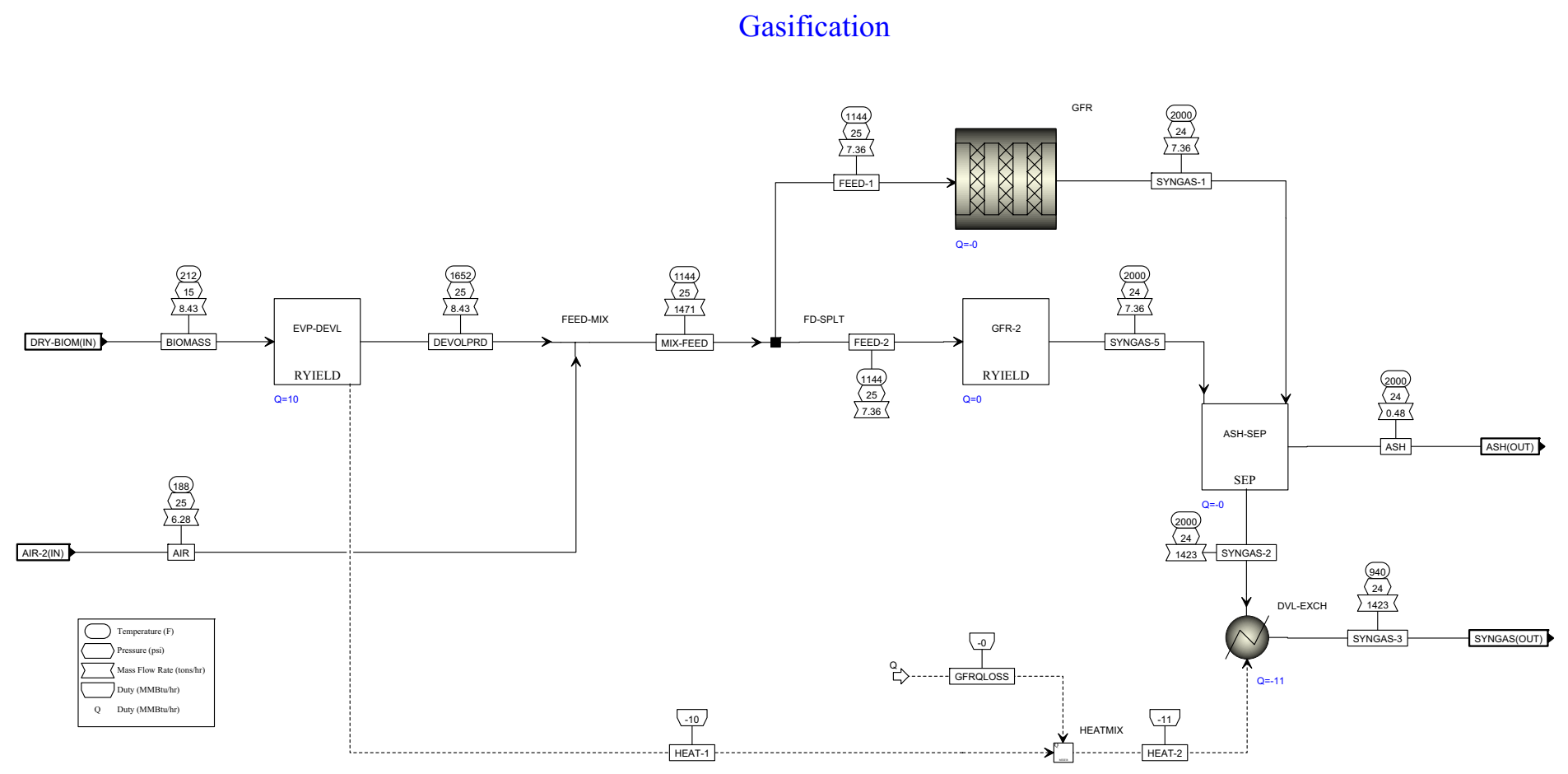

A-7 


\section{Case A Aspen Plus Flowsheets}

Lime Kiln

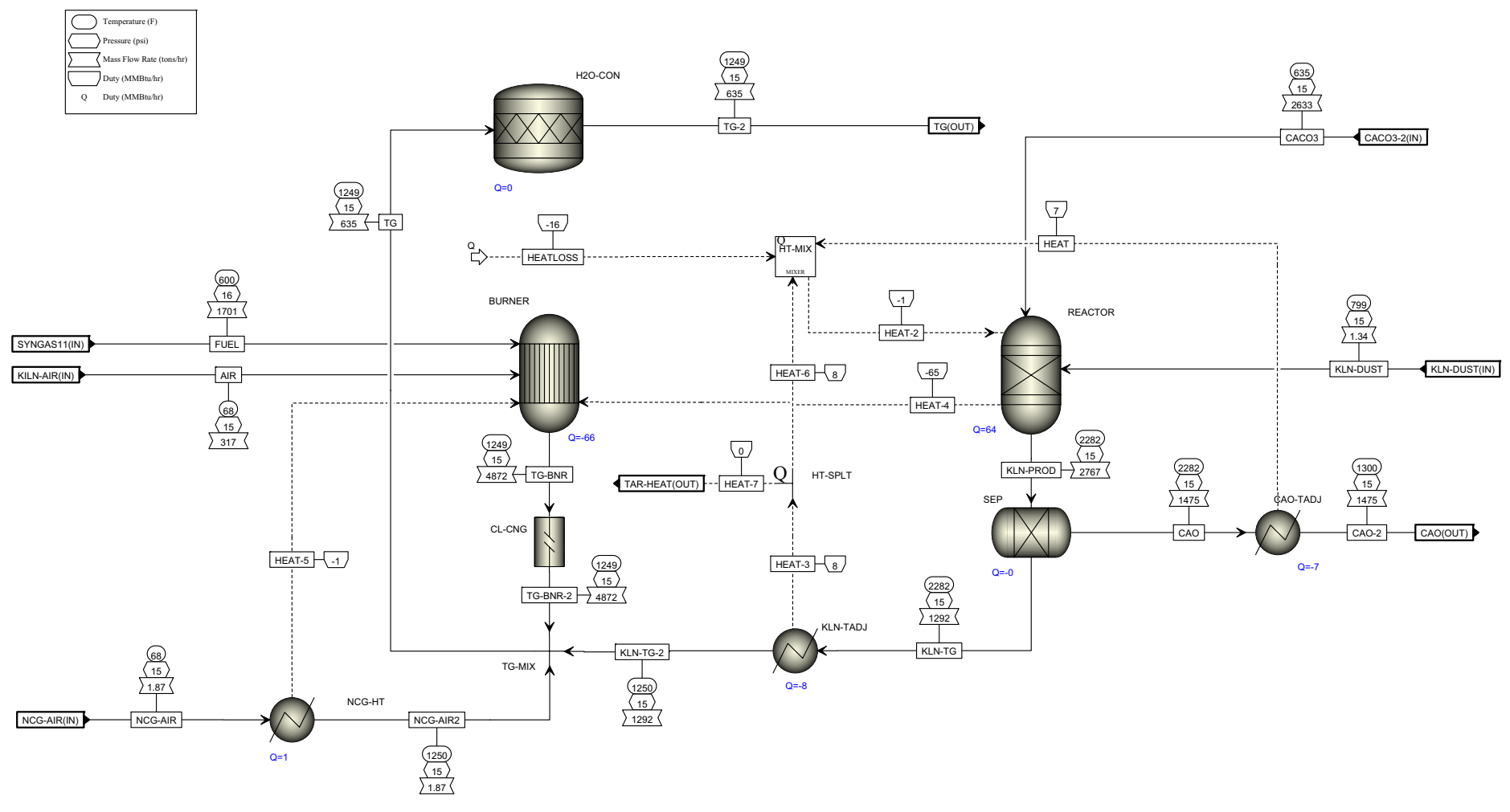

A-8 


\section{Case A Aspen Plus Flowsheets}
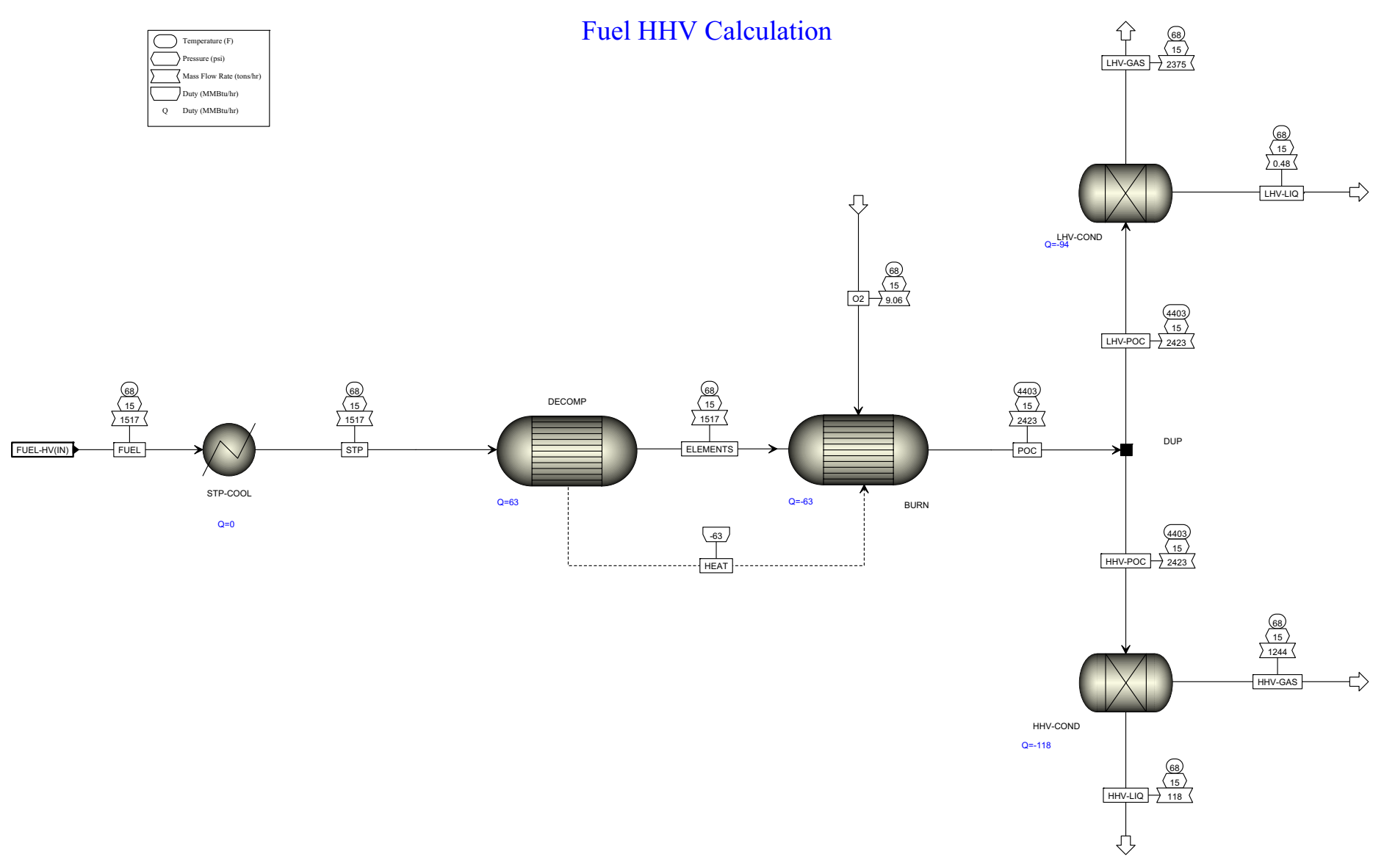

A-9 


\section{Case A Aspen Plus Flowsheets}

Gas HHV Calculation

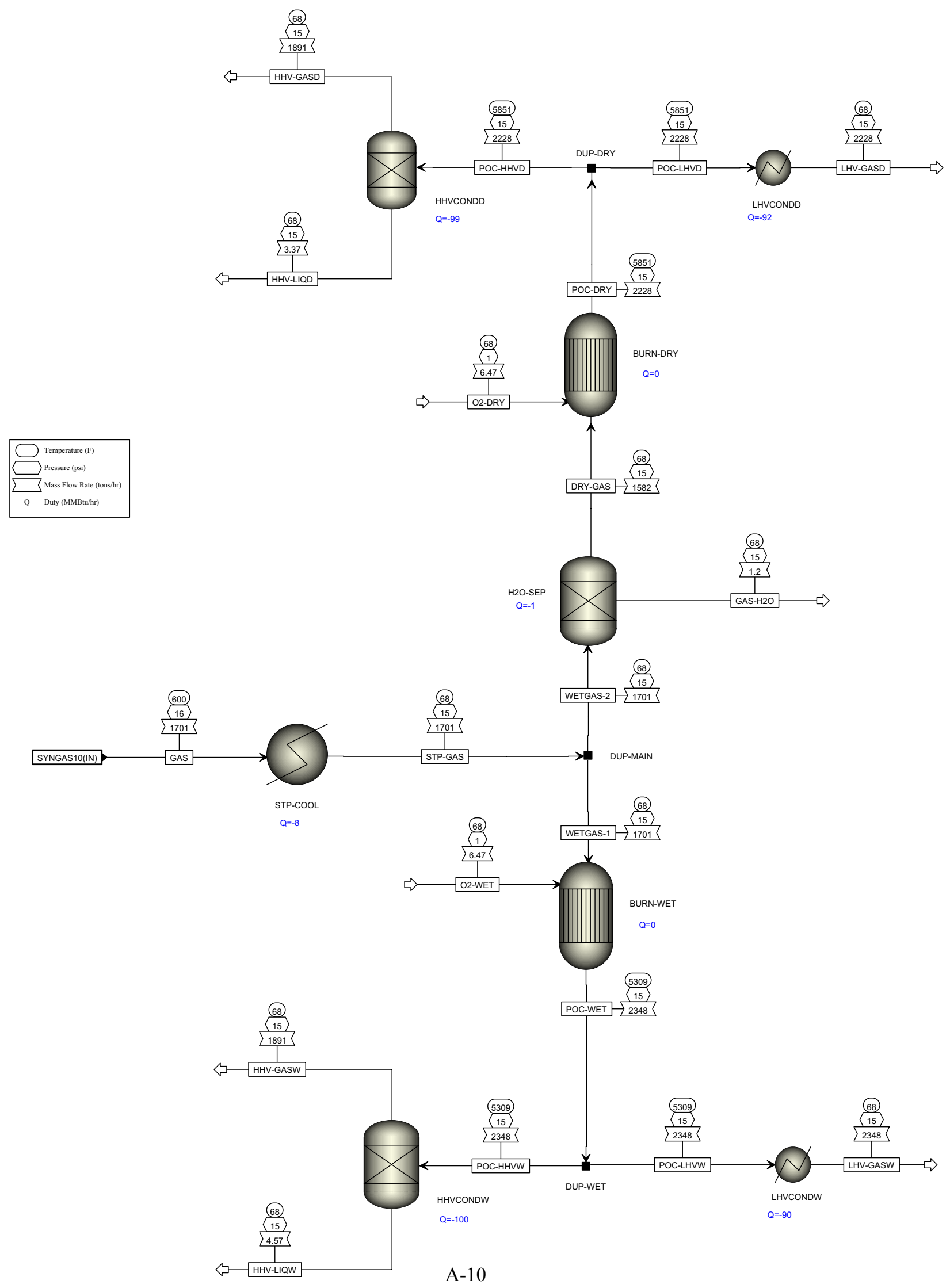




\section{Case A Aspen Plus Stream Results}

\begin{tabular}{|c|c|c|c|c|c|c|c|c|c|c|c|c|c|c|}
\hline \multirow{2}{*}{\multicolumn{15}{|c|}{ Mixed Substream }} \\
\hline & & & & & & & & & & & & & & \\
\hline Temperature F & 68 & 187.9 & 68 & 182.6 & & & & 210 & 635 & & 176 & 302 & & \\
\hline Pressure psi & 14.7 & 25 & 14.7 & 24.46 & 24.46 & 14.7 & 14.7 & 14.7 & 14.7 & 14.7 & 57.21 & 58.21 & 14.7 & 14.7 \\
\hline Vapor Frac & 1 & 1 & 1 & 1 & & & & & 1 & & & 1 & & \\
\hline Mole Flow $\mathrm{lbmol} / \mathrm{hr}$ & 433.935 & 433.935 & 204.303 & 204.303 & & & & 484.478 & & & 695.032 & 695.032 & & \\
\hline Mass Flow tons $/ \mathrm{hr}$ & 6.282 & 6.282 & 2.958 & 2.958 & & & & 4.364 & & & 6.261 & 6.261 & & \\
\hline Volume Flow cuft/hr & 167126.308 & 120635.19 & 78685.411 & 57578.454 & & & & 174.446 & 0.004 & & 246.144 & 95176.605 & & \\
\hline Enthalpy $\mathrm{MMBtu} / \mathrm{hr}$ & -0.096 & 0.266 & -0.045 & 0.118 & & & & -58.639 & & & -84.587 & -71.06 & & \\
\hline \multicolumn{15}{|l|}{ Mass Flow tons $/ \mathrm{hr}$} \\
\hline $\mathrm{N} 2$ & 4.738 & 4.738 & 2.231 & 2.231 & & & & & & & & & & \\
\hline $\mathrm{CO} 2$ & 0.003 & 0.003 & 0.001 & 0.001 & & & & & & & & & & \\
\hline \multirow{2}{*}{\multicolumn{15}{|c|}{$\mathrm{CACO} 3$}} \\
\hline \multicolumn{8}{|l|}{ CAO } & & & & & & & \\
\hline \multicolumn{15}{|l|}{$\mathrm{CO}$} \\
\hline $\mathrm{O} 2$ & 1.456 & 1.456 & 0.685 & 0.685 & & & & & & & & & & \\
\hline \multirow{2}{*}{\multicolumn{15}{|c|}{$\begin{array}{l}\mathrm{AR} \\
\mathrm{NO} 2\end{array}$}} \\
\hline & & & & & & & & & & & & & & \\
\hline \multicolumn{15}{|l|}{ No } \\
\hline \multirow{2}{*}{\multicolumn{15}{|c|}{$\begin{array}{l}\mathrm{H} 2 \mathrm{O} \\
\mathrm{H} 2\end{array}$}} \\
\hline & & & & & & & & & & & & & & \\
\hline \multicolumn{15}{|l|}{$\begin{array}{l}\mathrm{H} 2 \mathrm{O}-\mathrm{MUD} \\
\mathrm{CH} 4\end{array}$} \\
\hline \multirow{2}{*}{\multicolumn{15}{|c|}{$\begin{array}{l}\mathrm{CH} 4 \\
\mathrm{C}\end{array}$}} \\
\hline & & & & & & & & & & & & & & \\
\hline \multicolumn{15}{|l|}{ Mass Frac } \\
\hline $\mathrm{N} 2$ & 0.754 & 0.754 & 0.754 & 0.754 & & & & & & & & & & \\
\hline \multicolumn{15}{|l|}{$\begin{array}{l}\mathrm{CO} 2 \\
\mathrm{CACO} 3\end{array}$} \\
\hline \multicolumn{15}{|l|}{$\mathrm{CACO} 3$} \\
\hline $\mathrm{CAO}$ & & & & & & & & & & & & & & \\
\hline $\mathrm{CO}$ & & & & & & & & & & & & & & \\
\hline $\mathrm{O} 2$ & 0.232 & 0.232 & 0.232 & 0.232 & & & & & & & & & & \\
\hline $\mathrm{AR}$ & 0.013 & 0.013 & 0.013 & 0.013 & & & & & & & & & & \\
\hline $\mathrm{NO} 2$ & & & & & & & & & & & & & & \\
\hline No & & & & & & & & & & & & & & \\
\hline $\mathrm{H} 2 \mathrm{O}$ & 0.001 & 0.001 & 0.001 & 0.001 & & & & & & & 1 & 1 & & \\
\hline H2 & & & & & & & & & & & & & & \\
\hline H2O-MUD & & & & & & & & 1 & 1 & & & & & \\
\hline $\mathrm{CH} 4$ & & & & & & & & & & & & & & \\
\hline $\mathrm{C}$ & & & & & & & & & & & & & & \\
\hline Mole Flow $\mathrm{lbmol} / \mathrm{hr}$ & & & & & & & & & & & & & & \\
\hline N2 & 338.261 & 338.261 & 159.258 & 159.258 & & & & & & & & & & \\
\hline $\mathrm{CO} 2$ & 0.13 & 0.13 & 0.061 & 0.061 & & & & & & & & & & \\
\hline $\mathrm{CACO} 3$ & & & & & & & & & & & & & & \\
\hline $\mathrm{CAO}$ & & & & & & & & & & & & & & \\
\hline $\mathrm{CO}$ & & & & & & & & & & & & & & \\
\hline $\mathrm{O} 2$ & 90.992 & 90.992 & 42.84 & 42.84 & & & & & & & & & & \\
\hline AR & 4.075 & 4.075 & 1.919 & 1.919 & & & & & & & & & & \\
\hline $\mathrm{NO} 2$ & & & & & & & & & & & & & & \\
\hline NO & & & & & & & & & & & & & & \\
\hline $\mathrm{H} 2 \mathrm{O}$ & 0.434 & 0.434 & 0.204 & 0.204 & & & & & & & 695.032 & 695.032 & & \\
\hline $\mathrm{H} 2$ & 0.043 & 0.043 & 0.02 & 0.02 & & & & & & & & & & \\
\hline H2O-MUD & & & & & & & & 484.478 & & & & & & \\
\hline CH4 & & & & & & & & & & & & & & \\
\hline $\mathrm{C}$ & & & & & & & & & & & & & & \\
\hline Mole Frac & & & & & & & & & & & & & & \\
\hline $\mathrm{N} 2$ & 0.78 & 0.78 & 0.78 & 0.78 & & & & & & & & & & \\
\hline $\mathrm{CO} 2$ & & & & & & & & & & & & & & \\
\hline $\mathrm{CACO} 3$ & & & & & & & & & & & & & & \\
\hline
\end{tabular}




\section{Case A Aspen Plus Stream Results}

\begin{tabular}{|c|c|c|c|c|c|c|c|c|c|c|c|c|c|c|}
\hline & AIR & AIR-2 & AIR-CRK & AIR-CRK2 & ASH & BIOMASS & BIOMASS2 & $\mathrm{CACO} 3$ & CACO3-2 & CAO & DRTY-H2O & DRTY-STM & DRY-BIOM & FUEL-HV \\
\hline \multirow{2}{*}{\multicolumn{15}{|c|}{$\begin{array}{l}\text { CAO } \\
\text { CO }\end{array}$}} \\
\hline & & & & & & & & & & & & & & \\
\hline $\mathrm{O} 2$ & 0.21 & 0.21 & 0.21 & 0.21 & & & & & & & & & & \\
\hline $\begin{array}{l}\mathrm{AR} \\
\mathrm{NO} 2\end{array}$ & 0.009 & 0.009 & 0.009 & 0.009 & & & & & & & & & & \\
\hline \multicolumn{15}{|l|}{$\mathrm{NO} 2$} \\
\hline \multicolumn{15}{|l|}{ NO } \\
\hline $\mathrm{H} 2 \mathrm{O}$ & 0.001 & 0.001 & 0.001 & 0.001 & & & & & & & 1 & 1 & & \\
\hline $\mathrm{H} 2$ & & & & & & & & & & & & & & \\
\hline \multirow{2}{*}{\multicolumn{15}{|c|}{$\begin{array}{l}\mathrm{CH} 4 \\
\mathrm{C}\end{array}$}} \\
\hline & & & & & & & & & & & & & & \\
\hline c & & & & & & & & & & & & & & \\
\hline \multicolumn{15}{|c|}{$\begin{array}{c}\text { C } \\
\text { Nonconventional Substream }\end{array}$} \\
\hline Mass Flow tons $/ \mathrm{hr}$ & 6.282 & 6.282 & 2.958 & 2.958 & 0.479 & 15.175 & 15.175 & 30.69 & 26.326 & 14.75 & 6.261 & 6.261 & 8.43 & 15.175 \\
\hline Enthalpy MMBtu/hr & -0.096 & 0.266 & -0.045 & 0.118 & 0.552 & -132.811 & -132.811 & -330.268 & -266.345 & -135.746 & -84.587 & -71.06 & -40.47 & -132.811 \\
\hline Temperature F & & & & & 1999.9 & 68 & 68 & & & & & & 212 & 68 \\
\hline Pressure psi & 14.7 & 25 & 14.7 & 24.46 & 24.46 & 14.7 & 14.7 & & & & 57.21 & 58.21 & 14.7 & 14.7 \\
\hline \multicolumn{15}{|l|}{ Vapor Frac } \\
\hline Mass Flow tons $/ \mathrm{hr}$ & & & & & 0.479 & 15.175 & 15.175 & & & & & & 8.43 & 15.175 \\
\hline Enthalpy MMBtu/hr & & & & & 0.552 & -132.811 & -132.811 & & & & & & -40.47 & -132.811 \\
\hline \multirow{2}{*}{\multicolumn{15}{|c|}{ Mass Flow tons $/ \mathrm{hr}$}} \\
\hline \multicolumn{8}{|l|}{ CHAR } & & & & & & & \\
\hline \multirow{2}{*}{\multicolumn{15}{|c|}{$\begin{array}{l}\text { FUEL } \\
\text { TAR }\end{array}$}} \\
\hline & & & & & & & & & & & & & & \\
\hline \multirow{2}{*}{\multicolumn{15}{|c|}{$\begin{array}{l}\text { ASH } \\
\text { Mass Frac }\end{array}$}} \\
\hline & & & & & & & & & & & & & & \\
\hline \multicolumn{15}{|l|}{ CHAR } \\
\hline \multirow{2}{*}{\multicolumn{15}{|c|}{$\begin{array}{l}\text { FUEL } \\
\text { TAR }\end{array}$}} \\
\hline & & & & & & & & & & & & & & \\
\hline \multirow{2}{*}{\multicolumn{15}{|c|}{ Soid Substream }} \\
\hline & & & & & & & & & & & & & & \\
\hline Temperature $\mathrm{F}$ & & & & & & & & 210 & 635 & 1300 & & & & \\
\hline \multirow{2}{*}{\multicolumn{15}{|c|}{ Vapor Frac }} \\
\hline & & & & & & & & & & & & & & \\
\hline Mole Flow $\mathrm{lbmol} / \mathrm{hr}$ & & & & & & & & 526.061 & 526.061 & 526.061 & & & & \\
\hline Mass Flow tons $/ \mathrm{hr}$ & & & & & & & & 26.326 & 26.326 & 14.75 & & & & \\
\hline Volume Flow cuft/hr & & & & & & & & 311.289 & 312.885 & 143.299 & & & & \\
\hline Enthalpy MMBtu/hr & & & & & & & & -271.629 & -266.345 & -135.746 & & & & \\
\hline \multicolumn{15}{|l|}{ Mass Flow tons $/ \mathrm{hr}$} \\
\hline $\mathrm{CACO} 3$ & & & & & & & & 26.326 & 26.326 & & & & & \\
\hline $\mathrm{CAO}$ & & & & & & & & & & 14.75 & & & & \\
\hline \multicolumn{15}{|l|}{ Mass Frac } \\
\hline $\mathrm{CACO} 3$ & & & & & & & & 1 & 1 & & & & & \\
\hline CAO & & & & & & & & & & 1 & & & & \\
\hline \multicolumn{15}{|l|}{ Mole Flow $\mathrm{lbmol} / \mathrm{hr}$} \\
\hline $\mathrm{CACO} 3$ & & & & & & & & 526.061 & 526.061 & & & & & \\
\hline CAO & & & & & & & & & & 526.061 & & & & \\
\hline Mole Frac & & & & & & & & & & & & & & \\
\hline $\mathrm{CACO} 3$ & & & & & & & & 1 & 1 & & & & & \\
\hline CAO & & & & & & & & & & 1 & & & & \\
\hline
\end{tabular}




\section{Case A Aspen Plus Stream Results}

\begin{tabular}{|c|c|c|c|c|c|c|c|c|c|c|c|c|c|}
\hline \multicolumn{14}{|l|}{ Mixed Substream } \\
\hline Temperature F & 68 & & 68 & & 302 & 940.1 & 1652 & 1652 & 1742 & 1000.2 & 1000.2 & 1000.2 & 1000.2 \\
\hline Pressure psi & 14.7 & 14.7 & 14.7 & 16.46 & 58.21 & 24.46 & 22.46 & 22.46 & 20.46 & 18.46 & 16.46 & 16.46 & 16.46 \\
\hline Vapor Frac & 1 & & 1 & & 1 & 1 & 1 & 0.953 & 1 & 1 & 1 & 0.998 & 0.998 \\
\hline Mole Flow $\mathrm{lbmol} / \mathrm{hr}$ & 2190.038 & & 129.173 & & 53.704 & 1159.389 & 1363.691 & 1500.077 & 1542.765 & 1542.765 & 1542.765 & 1548.448 & 1548.448 \\
\hline Mass Flow tons/hr & 31.705 & & 1.87 & & 0.484 & 13.307 & 16.265 & 16.981 & 16.981 & 16.981 & 16.981 & 17.011 & 17.011 \\
\hline Volume Flow cuft/hr & 843475.129 & & 49749.865 & & 7354.099 & 712327.275 & $1.38 \mathrm{E}+06$ & $1.44 \mathrm{E}+06$ & $1.78 \mathrm{E}+06$ & $1.31 \mathrm{E}+06$ & $1.47 \mathrm{E}+06$ & $1.47 \mathrm{E}+06$ & $1.47 \mathrm{E}+06$ \\
\hline Enthalpy MMBtu/hr & -0.483 & & -0.029 & & -5.491 & -39.664 & -30.125 & -24.397 & -31.846 & -41.267 & -41.267 & -41.082 & -41.082 \\
\hline \multicolumn{14}{|l|}{ Mass Flow tons $/ \mathrm{hr}$} \\
\hline $\mathrm{N} 2$ & 23.912 & & 1.41 & & & 4.738 & 6.969 & 6.969 & 6.969 & 6.969 & 6.969 & 6.969 & 6.969 \\
\hline $\mathrm{CO} 2$ & 0.014 & & 0.001 & & & 1.092 & 1.093 & 1.093 & 2.311 & 2.311 & 2.311 & 2.311 & 2.311 \\
\hline \multicolumn{14}{|l|}{$\begin{array}{l}\mathrm{CACO} 3 \\
\mathrm{CAO}\end{array}$} \\
\hline \multicolumn{14}{|l|}{ CAO } \\
\hline $\mathrm{CO}$ & & & & & & 5.088 & 5.088 & 5.088 & 6.01 & 6.01 & 6.01 & 6.01 & 6.01 \\
\hline $\mathrm{O} 2$ & 7.347 & & 0.433 & & & & 0.685 & 0.925 & & & & 0.01 & 0.01 \\
\hline AR & 0.411 & & 0.024 & & & 0.081 & 0.12 & 0.12 & 0.12 & 0.12 & 0.12 & 0.12 & 0.12 \\
\hline \multirow{2}{*}{\multicolumn{14}{|c|}{$\begin{array}{l}\mathrm{NO} 2 \\
\text { NO }\end{array}$}} \\
\hline \multicolumn{6}{|l|}{ NO } & & & & & & & & \\
\hline $\mathrm{H} 2 \mathrm{O}$ & 0.02 & & 0.001 & & 0.484 & 1.743 & 1.745 & 1.745 & 1.196 & 1.196 & 1.196 & 1.196 & 1.196 \\
\hline H2 & & & & & & 0.162 & 0.162 & 0.212 & 0.375 & 0.375 & 0.375 & 0.377 & 0.377 \\
\hline \multicolumn{14}{|l|}{ H2O-MUD } \\
\hline $\mathrm{CH} 4$ & & & & & & 0.403 & 0.403 & 0.403 & & & & & \\
\hline \multirow{2}{*}{\multicolumn{14}{|c|}{ Mass Frac }} \\
\hline & & & & & & & & & & & & & \\
\hline $\mathrm{N} 2$ & 0.754 & & 0.754 & & & 0.356 & 0.428 & 0.41 & 0.41 & 0.41 & 0.41 & 0.41 & 0.41 \\
\hline \multirow{2}{*}{\multicolumn{14}{|c|}{$\mathrm{CACO} 3$}} \\
\hline & & & & & & & & & & & & & \\
\hline \multicolumn{14}{|l|}{ CAO } \\
\hline $\mathrm{CO}$ & & & & & & 0.382 & 0.313 & 0.3 & 0.354 & 0.354 & 0.354 & 0.353 & 0.353 \\
\hline $\mathrm{O} 2$ & 0.232 & & 0.232 & & & & 0.042 & 0.054 & & & & 0.001 & 0.001 \\
\hline $\mathrm{AR}$ & 0.013 & & 0.013 & & & 0.006 & 0.007 & 0.007 & 0.007 & 0.007 & 0.007 & 0.007 & 0.007 \\
\hline \multicolumn{14}{|l|}{$\mathrm{NO} 2$} \\
\hline \multicolumn{14}{|l|}{ NO } \\
\hline $\mathrm{H} 2 \mathrm{O}$ & 0.001 & & 0.001 & & 1 & 0.131 & 0.107 & 0.103 & 0.07 & 0.07 & 0.07 & 0.07 & 0.07 \\
\hline \multirow{2}{*}{\multicolumn{14}{|c|}{ H2O-MUD }} \\
\hline & & & & & & & & & & & & & \\
\hline $\mathrm{CH} 4$ & & & & & & 0.03 & 0.025 & 0.024 & & & & & \\
\hline \multirow{2}{*}{\multicolumn{14}{|c|}{ Mole Flow $1 \mathrm{bmol} / \mathrm{hr}$}} \\
\hline & & & & & & & & & & & & & \\
\hline $\mathrm{N} 2$ & 1707.18 & & 100.693 & & & 338.261 & 497.519 & 497.519 & 497.519 & 497.519 & 497.519 & 497.519 & 497.519 \\
\hline $\mathrm{CO} 2$ & 0.656 & & 0.039 & & & 49.607 & 49.669 & 49.669 & 105.04 & 105.04 & 105.04 & 105.04 & 105.04 \\
\hline $\mathrm{CACO} 3$ & & & & & & & & & & & & & \\
\hline CAO & & & & & & & & & & & & & \\
\hline $\mathrm{CO}$ & & & & & & 363.294 & 363.294 & 363.294 & 429.159 & 429.159 & 429.159 & 429.159 & 429.159 \\
\hline $\mathrm{O} 2$ & 459.23 & & 27.086 & & & & 42.84 & 57.802 & & & & 0.623 & 0.623 \\
\hline AR & 20.566 & & 1.213 & & & 4.075 & 5.993 & 5.993 & 5.993 & 5.993 & 5.993 & 5.993 & 5.993 \\
\hline $\mathrm{NO} 2$ & & & & & & & & & & & & & \\
\hline NO & & & & & & & & & & & & & \\
\hline $\mathrm{H} 2 \mathrm{O}$ & 2.188 & & 0.129 & & 53.704 & 193.537 & 193.741 & 193.741 & 132.737 & 132.737 & 132.737 & 132.737 & 132.737 \\
\hline H2 & 0.219 & & 0.013 & & & 160.333 & 160.354 & 210.787 & 372.28 & 372.28 & 372.28 & 374.381 & 374.381 \\
\hline H2O-MUD & & & & & & & & & & & & & \\
\hline $\mathrm{CH} 4$ & & & & & & 50.282 & 50.282 & 50.282 & 0.037 & 0.037 & 0.037 & 0.037 & 0.037 \\
\hline C & & & & & & & & 70.991 & & & & 2.958 & 2.958 \\
\hline Mole Frac & & & & & & & & & & & & & \\
\hline $\mathrm{N} 2$ & 0.78 & & 0.78 & & & 0.292 & 0.365 & 0.332 & 0.322 & 0.322 & 0.322 & 0.321 & 0.321 \\
\hline $\mathrm{CO} 2$ & & & & & & 0.043 & 0.036 & 0.033 & 0.068 & 0.068 & 0.068 & 0.068 & 0.068 \\
\hline $\mathrm{CACO}_{3}$ & & & & & & & & & & & & & \\
\hline
\end{tabular}




\section{Case A Aspen Plus Stream Results}

\begin{tabular}{|c|c|c|c|c|c|c|c|c|c|c|c|c|c|}
\hline \multicolumn{14}{|c|}{ KLN-DUST } \\
\hline $\mathrm{CO}$ & & & & & & 0.313 & 0.266 & 0.242 & 0.278 & 0.278 & 0.278 & 0.277 & 0.277 \\
\hline $\mathrm{O} 2$ & 0.21 & & 0.21 & & & & 0.031 & 0.039 & & & & & \\
\hline $\mathrm{AR}$ & 0.009 & & 0.009 & & & 0.004 & 0.004 & 0.004 & 0.004 & 0.004 & 0.004 & 0.004 & 0.004 \\
\hline \multirow{2}{*}{\multicolumn{14}{|c|}{$\mathrm{NO} 2$}} \\
\hline \multicolumn{13}{|l|}{ NO } & \\
\hline $\mathrm{H} 2 \mathrm{O}$ & 0.001 & & 0.001 & & 1 & 0.167 & 0.142 & 0.129 & 0.086 & 0.086 & 0.086 & 0.086 & 0.086 \\
\hline $\mathrm{H} 2$ & & & & & & 0.138 & 0.118 & 0.141 & 0.241 & 0.241 & 0.241 & 0.242 & 0.242 \\
\hline \multicolumn{14}{|l|}{ H2O-MUD } \\
\hline $\mathrm{CH} 4$ & & & & & & 0.043 & 0.037 & 0.034 & & & & & \\
\hline $\mathrm{C}$ & & & & & & & & 0.047 & & & & 0.002 & 0.002 \\
\hline \multicolumn{14}{|c|}{ Nonconventional Substream } \\
\hline Mass Flow tons $/ \mathrm{hr}$ & & 1.339 & & 0.18 & 0.484 & 14.234 & 17.191 & 17.191 & 17.191 & 17.191 & 17.011 & 17.011 & \\
\hline Enthalpy $\mathrm{MMBtu} / \mathrm{hr}$ & & -12.624 & & 0.299 & -5.491 & -41.158 & -31.619 & -24.17 & -31.619 & -41.04 & -41.339 & -41.082 & \\
\hline Temperature $\mathrm{F}$ & & & & 1000.2 & & 940.1 & 1652 & 1652 & 1742 & 1000.2 & 1000.2 & & \\
\hline Pressure psi & & & & 16.46 & 58.21 & 24.46 & 22.46 & 22.46 & 20.46 & 18.46 & 16.46 & 16.46 & \\
\hline \multicolumn{14}{|l|}{ Vapor Frac } \\
\hline Mass Flow tons $/ \mathrm{hr}$ & & & & 0.18 & & 0.926 & 0.926 & 0.21 & 0.21 & 0.21 & 0.03 & & \\
\hline Enthalpy MMBtu/hr & & & & 0.299 & & -1.494 & -1.494 & 0.227 & 0.227 & 0.227 & -0.072 & & \\
\hline \multicolumn{14}{|l|}{ Mass Flow tons $/ \mathrm{hr}$} \\
\hline \multirow{2}{*}{\multicolumn{14}{|c|}{$\begin{array}{l}\text { CHAR } \\
\text { FUEL }\end{array}$}} \\
\hline & & & & & & & & & & & & & \\
\hline TAR & & & & & & 0.746 & 0.746 & 0.03 & 0.03 & 0.03 & 0.03 & & \\
\hline ASH & & & & & & & & & & & & & \\
\hline \multicolumn{14}{|l|}{ Mass Frac } \\
\hline CHAR & & & & 1 & & 0.194 & 0.194 & 0.858 & 0.858 & 0.858 & & & \\
\hline \multicolumn{14}{|l|}{$\begin{array}{l}\text { CHAR } \\
\text { FUEL }\end{array}$} \\
\hline \multirow{2}{*}{\multicolumn{14}{|c|}{$\begin{array}{l}\text { TAR } \\
\text { ASH }\end{array}$}} \\
\hline & & & & & & & & & & & & & \\
\hline \multicolumn{14}{|l|}{ Soid Substream } \\
\hline Temperature $\mathrm{F}$ & & 798.9 & & & & & & & & & & & \\
\hline Pressure psi & & 14.7 & & & & & & & & & & & \\
\hline \multicolumn{14}{|l|}{ Vapor Frac } \\
\hline Mole Flow $\mathrm{lbmol} / \mathrm{hr}$ & & 47.759 & & & & & & & & & & & \\
\hline Mass Flow tons/hr & & 1.339 & & & & & & & & & & & \\
\hline Volume Flow cuft/hr & & 13.01 & & & & & & & & & & & \\
\hline \multirow{2}{*}{\multicolumn{14}{|c|}{$\begin{array}{l}\text { Enthalpy MMBth/hr } \\
\text { Mass Flow tons/hr }\end{array}$}} \\
\hline & & & & & & & & & & & & & \\
\hline \multicolumn{14}{|l|}{$\mathrm{CACO} 3$} \\
\hline \multirow{2}{*}{\multicolumn{14}{|c|}{$\begin{array}{l}\text { CAO } \\
\text { Mass Frac }\end{array}$}} \\
\hline & & & & & & & & & & & & & \\
\hline \multicolumn{14}{|l|}{$\mathrm{CACO} 3$} \\
\hline $\mathrm{CAO}$ & & 1 & & & & & & & & & & & \\
\hline Mole Flow $\mathrm{lbmol} / \mathrm{hr}$ & & & & & & & & & & & & & \\
\hline $\mathrm{CACO} 3$ & & & & & & & & & & & & & \\
\hline CAO & & 47.759 & & & & & & & & & & & \\
\hline Mole Frac & & & & & & & & & & & & & \\
\hline $\mathrm{CACO} 3$ & & & & & & & & & & & & & \\
\hline CAO & & 1 & & & & & & & & & & & \\
\hline
\end{tabular}




\section{Case A Aspen Plus Stream Results}

\begin{tabular}{|c|c|c|c|c|c|c|c|c|c|c|c|c|}
\hline \multirow{2}{*}{\multicolumn{13}{|c|}{ Mixed Substream }} \\
\hline & & & & & & & & & & & & \\
\hline Temperature F & 600 & 600 & 600 & 1249.2 & 798.9 & 798.9 & 798.9 & 798.9 & 250 & 250 & 250 & 307.7 \\
\hline Pressure psi & 15.96 & 15.96 & 15.96 & 14.7 & 14.7 & 13.7 & 13.7 & 13.7 & 11.7 & 11.7 & 11.7 & 14.7 \\
\hline Vapor Frac & 0.998 & 0.998 & 0.998 & 1 & 1 & 1 & 1 & 1 & 1 & 1 & 1 & 1 \\
\hline Mole Flow $\mathrm{lbmol} / \mathrm{hr}$ & 1548.448 & 1548.448 & 1548.448 & 3989.002 & 4473.479 & 4473.479 & 3685.268 & 788.211 & 3685.268 & 788.211 & 4473.479 & 4473.479 \\
\hline Mass Flow tons $/ \mathrm{hr}$ & 17.011 & 17.011 & 17.011 & 62.162 & 66.526 & 66.526 & 54.804 & 11.722 & 54.804 & 11.722 & 66.526 & 66.526 \\
\hline Volume Flow cuft/hr & $1.10 \mathrm{E}+06$ & $1.10 \mathrm{E}+06$ & $1.10 \mathrm{E}+06$ & $4.98 \mathrm{E}+06$ & $4.11 \mathrm{E}+06$ & $4.41 \mathrm{E}+06$ & $3.63 \mathrm{E}+06$ & 777384.367 & $2.40 \mathrm{E}+06$ & 512712.19 & $2.91 \mathrm{E}+06$ & $2.50 \mathrm{E}+06$ \\
\hline Enthalpy $\mathrm{MMBtu} / \mathrm{hr}$ & -45.889 & -45.889 & -45.889 & -193.168 & -256.821 & -256.821 & -211.57 & -45.251 & -228.462 & -48.864 & -277.325 & -275.27 \\
\hline \multicolumn{13}{|l|}{ Mass Flow tons $/ \mathrm{hr}$} \\
\hline N2 & 6.969 & 6.969 & 6.969 & 32.291 & 32.291 & 32.291 & 26.601 & 5.69 & 26.601 & 5.69 & 32.291 & 32.291 \\
\hline $\mathrm{CO} 2$ & 2.311 & 2.311 & 2.311 & 23.407 & 23.407 & 23.407 & 19.283 & 4.124 & 19.283 & 4.124 & 23.407 & 23.407 \\
\hline \multicolumn{13}{|l|}{$\mathrm{CACO} 3$} \\
\hline \multicolumn{13}{|l|}{$\mathrm{CAO}$} \\
\hline $\mathrm{CO}$ & 6.01 & 6.01 & 6.01 & 0.003 & 0.003 & 0.003 & 0.003 & 0.001 & 0.003 & 0.001 & 0.003 & 0.003 \\
\hline $\mathrm{O} 2$ & 0.01 & 0.01 & 0.01 & 1.314 & 1.314 & 1.314 & 1.083 & 0.232 & 1.083 & 0.232 & 1.314 & 1.314 \\
\hline \multirow{2}{*}{\multicolumn{13}{|c|}{$\mathrm{NO} 2$}} \\
\hline & & & & & & & & & & & & \\
\hline \multicolumn{13}{|l|}{ NO } \\
\hline $\mathrm{H} 2 \mathrm{O}$ & 1.196 & 1.196 & 1.196 & 4.591 & 4.591 & 4.591 & 3.782 & 0.809 & 3.782 & 0.809 & 4.591 & 4.591 \\
\hline $\mathrm{H} 2$ & 0.377 & 0.377 & 0.377 & & & & & & & & & \\
\hline H2O-MUD & & & & & 4.364 & 4.364 & 3.595 & 0.769 & 3.595 & 0.769 & 4.364 & 4.364 \\
\hline \multicolumn{13}{|l|}{$\mathrm{CH}_{4}$} \\
\hline \multirow{2}{*}{\multicolumn{13}{|c|}{ Mass Frac }} \\
\hline & & & & & & & & & & & & \\
\hline $\mathrm{N} 2$ & 0.41 & 0.41 & 0.41 & 0.519 & 0.485 & 0.485 & 0.485 & 0.485 & 0.485 & 0.485 & 0.485 & 0.485 \\
\hline $\mathrm{CO} 2$ & 0.136 & 0.136 & 0.136 & 0.377 & 0.352 & 0.352 & 0.352 & 0.352 & 0.352 & 0.352 & 0.352 & 0.352 \\
\hline \multirow{2}{*}{\multicolumn{13}{|c|}{$\mathrm{CACO} 3$}} \\
\hline \multicolumn{2}{|l|}{ CAO } & & & & & & & & & & & \\
\hline $\mathrm{CO}$ & 0.353 & 0.353 & 0.353 & & & & & & & & & \\
\hline $\mathrm{O} 2$ & 0.001 & 0.001 & 0.001 & 0.021 & 0.02 & 0.02 & 0.02 & 0.02 & 0.02 & 0.02 & 0.02 & 0.02 \\
\hline $\mathrm{AR}$ & 0.007 & 0.007 & 0.007 & 0.009 & 0.008 & 0.008 & 0.008 & 0.008 & 0.008 & 0.008 & 0.008 & 0.008 \\
\hline \multicolumn{13}{|l|}{$\begin{array}{l}\mathrm{AK} \\
\mathrm{NO} 2\end{array}$} \\
\hline \multicolumn{13}{|l|}{ NO } \\
\hline $\mathrm{H} 2 \mathrm{O}$ & 0.07 & 0.07 & 0.07 & 0.074 & 0.069 & 0.069 & 0.069 & 0.069 & 0.069 & 0.069 & 0.069 & 0.069 \\
\hline $\mathrm{H} 2$ & 0.022 & 0.022 & 0.022 & & & & & & & & & \\
\hline \multirow{2}{*}{\multicolumn{13}{|c|}{$\begin{array}{l}\mathrm{H} 2 \mathrm{O}-\mathrm{MUD} \\
\mathrm{CH} 4\end{array}$}} \\
\hline & & & & & & & & & & & & \\
\hline $\mathrm{C}$ & 0.001 & 0.001 & 0.001 & & & & & & & & & \\
\hline \multicolumn{13}{|l|}{ Mole Flow $\mathrm{lbmol} / \mathrm{hr}$} \\
\hline $\mathrm{N} 2$ & 497.519 & 497.519 & 497.519 & 2305.392 & 2305.392 & 2305.392 & 1899.19 & 406.202 & 1899.19 & 406.202 & 2305.392 & 2305.392 \\
\hline $\mathrm{CO} 2$ & 105.04 & 105.04 & 105.04 & 1063.712 & 1063.712 & 1063.712 & 876.29 & 187.422 & 876.29 & 187.422 & 1063.712 & 1063.712 \\
\hline $\mathrm{CACO} 3$ & & & & & & & & & & & & \\
\hline CAO & & & & & & & & & & & & \\
\hline $\mathrm{CO}$ & 429.159 & 429.159 & 429.159 & 0.238 & 0.238 & 0.238 & 0.196 & 0.042 & 0.196 & 0.042 & 0.238 & 0.238 \\
\hline $\mathrm{O} 2$ & 0.623 & 0.623 & 0.623 & 82.147 & 82.147 & 82.147 & 67.673 & 14.474 & 67.673 & 14.474 & 82.147 & 82.147 \\
\hline $\mathrm{AR}$ & 5.993 & 5.993 & 5.993 & 27.772 & 27.772 & 27.772 & 22.879 & 4.893 & 22.879 & 4.893 & 27.772 & 27.772 \\
\hline $\mathrm{NO} 2$ & & & & & & & & & & & & \\
\hline NO & & & & & & & & & & & & \\
\hline $\mathrm{H} 2 \mathrm{O}$ & 132.737 & 132.737 & 132.737 & 509.728 & 509.728 & 509.728 & 419.916 & 89.812 & 419.916 & 89.812 & 509.728 & 509.728 \\
\hline $\mathrm{H} 2$ & 374.381 & 374.381 & 374.381 & 0.013 & 0.013 & 0.013 & 0.011 & 0.002 & 0.011 & 0.002 & 0.013 & 0.013 \\
\hline H2O-MUD & & & & & 484.478 & 484.478 & 399.114 & 85.363 & 399.114 & 85.363 & 484.478 & 484.478 \\
\hline $\mathrm{CH} 4$ & 0.037 & 0.037 & 0.037 & & & & & & & & & \\
\hline C & 2.958 & 2.958 & 2.958 & & & & & & & & & \\
\hline Mole Frac & & & & & & & & & & & & \\
\hline $\mathrm{N} 2$ & 0.321 & 0.321 & 0.321 & 0.578 & 0.515 & 0.515 & 0.515 & 0.515 & 0.515 & 0.515 & 0.515 & 0.515 \\
\hline $\mathrm{CO} 2$ & 0.068 & 0.068 & 0.068 & 0.267 & 0.238 & 0.238 & 0.238 & 0.238 & 0.238 & 0.238 & 0.238 & 0.238 \\
\hline
\end{tabular}




\section{Case A Aspen Plus Stream Results}

\begin{tabular}{|c|c|c|c|c|c|c|c|c|c|c|c|c|}
\hline \multirow{2}{*}{\multicolumn{13}{|c|}{ SYNGAS10 }} \\
\hline & & & & & & & & & & & & \\
\hline $\mathrm{CO}$ & 0.277 & 0.277 & 0.277 & & & & & & & & & \\
\hline $\mathrm{O} 2$ & & & & 0.021 & 0.018 & 0.018 & 0.018 & 0.018 & 0.018 & 0.018 & 0.018 & 0.018 \\
\hline AR & 0.004 & 0.004 & 0.004 & 0.007 & 0.006 & 0.006 & 0.006 & 0.006 & 0.006 & 0.006 & 0.006 & 0.006 \\
\hline \multicolumn{13}{|l|}{$\mathrm{NO} 2$} \\
\hline \multicolumn{13}{|l|}{ NO } \\
\hline $\mathrm{H} 2 \mathrm{O}$ & 0.086 & 0.086 & 0.086 & 0.128 & 0.114 & 0.114 & 0.114 & 0.114 & 0.114 & 0.114 & 0.114 & 0.114 \\
\hline $\mathrm{H} 2$ & 0.242 & 0.242 & 0.242 & & & & & & & & & \\
\hline H2O-MUD & & & & & 0.108 & 0.108 & 0.108 & 0.108 & 0.108 & 0.108 & 0.108 & 0.108 \\
\hline \multicolumn{13}{|l|}{$\mathrm{CH} 4$} \\
\hline \multirow{2}{*}{\multicolumn{13}{|c|}{ Nonconventional Substream }} \\
\hline & & & & & & & & & & & & \\
\hline Mass Flow tons $/ \mathrm{hr}$ & & & & 63.501 & 67.865 & 66.526 & 54.804 & 11.722 & 54.804 & 11.722 & 66.526 & 66.526 \\
\hline Enthalpy $\mathrm{MMBtu} / \mathrm{hr}$ & & & & -205.522 & -269.445 & -256.821 & -211.57 & -45.251 & -228.462 & -48.864 & -277.325 & -275.27 \\
\hline \multicolumn{13}{|l|}{ Temperature $\mathrm{F}$} \\
\hline \multicolumn{13}{|l|}{ Pressure psi } \\
\hline \multicolumn{13}{|l|}{ Vapor Frac } \\
\hline \multirow{2}{*}{\multicolumn{13}{|c|}{ Mass Flow tons/hr }} \\
\hline \multirow{2}{*}{\multicolumn{11}{|c|}{$\begin{array}{l}\text { Enthalpy MMBtu/hr } \\
\text { Mass Flow tons/hr }\end{array}$}} & & \\
\hline \multirow{2}{*}{\multicolumn{13}{|c|}{$\begin{array}{l}\text { Mass Flow tons } / \mathrm{hr} \\
\text { CHAR }\end{array}$}} \\
\hline & & & & & & & & & & & & \\
\hline \multicolumn{13}{|l|}{$\begin{array}{l}\text { CHAR } \\
\text { FUEL }\end{array}$} \\
\hline \multicolumn{13}{|l|}{ TARL } \\
\hline \multicolumn{13}{|l|}{ ASH } \\
\hline \multirow{2}{*}{\multicolumn{13}{|c|}{$\begin{array}{l}\text { Mass Frac } \\
\text { CHAR }\end{array}$}} \\
\hline \multirow{2}{*}{\multicolumn{13}{|c|}{ CHAR }} \\
\hline & & & & & & & & & & & & \\
\hline \multirow{2}{*}{\multicolumn{13}{|c|}{$\begin{array}{l}\text { TAR } \\
\text { ASH }\end{array}$}} \\
\hline & & & & & & & & & & & & \\
\hline Soid Substream & & & & & & & & & & & & \\
\hline Temperature F & & & & 1249.2 & 798.9 & & & & & & & \\
\hline Pressure psi & & & & 14.7 & 14.7 & 13.7 & 13.7 & 13.7 & 11.7 & 11.7 & 11.7 & 14.7 \\
\hline Vapor Frac & & & & & & & & & & & & \\
\hline Mole Flow $\mathrm{lbmol} / \mathrm{hr}$ & & & & 47.759 & 47.759 & & & & & & & \\
\hline Mass Flow tons/hr & & & & 1.339 & 1.339 & & & & & & & \\
\hline Volume Flow cuft/hr & & & & 13.01 & 13.01 & & & & & & & \\
\hline Enthalpy $\mathrm{MMBtu} / \mathrm{hr}$ & & & & -12.355 & -12.624 & & & & & & & \\
\hline Mass Flow tons $/ \mathrm{hr}$ & & & & & & & & & & & & \\
\hline $\mathrm{CACO} 3$ & & & & & & & & & & & & \\
\hline $\mathrm{CAO}$ & & & & 1.339 & 1.339 & & & & & & & \\
\hline Mass Frac & & & & & & & & & & & & \\
\hline $\mathrm{CACO} 3$ & & & & & & & & & & & & \\
\hline $\mathrm{CAO}$ & & & & 1 & 1 & & & & & & & \\
\hline Mole Flow $1 \mathrm{bmol} / \mathrm{hr}$ & & & & & & & & & & & & \\
\hline $\mathrm{CACO} 3$ & & & & & & & & & & & & \\
\hline CAO & & & & 47.759 & 47.759 & & & & & & & \\
\hline $\begin{array}{l}\text { Mole Frac } \\
\text { CACO3 }\end{array}$ & & & & & & & & & & & & \\
\hline CAO & & & & 1 & 1 & & & & & & & \\
\hline
\end{tabular}




\section{Case B Aspen Plus Flowsheets}

Hog Fuel Gasification

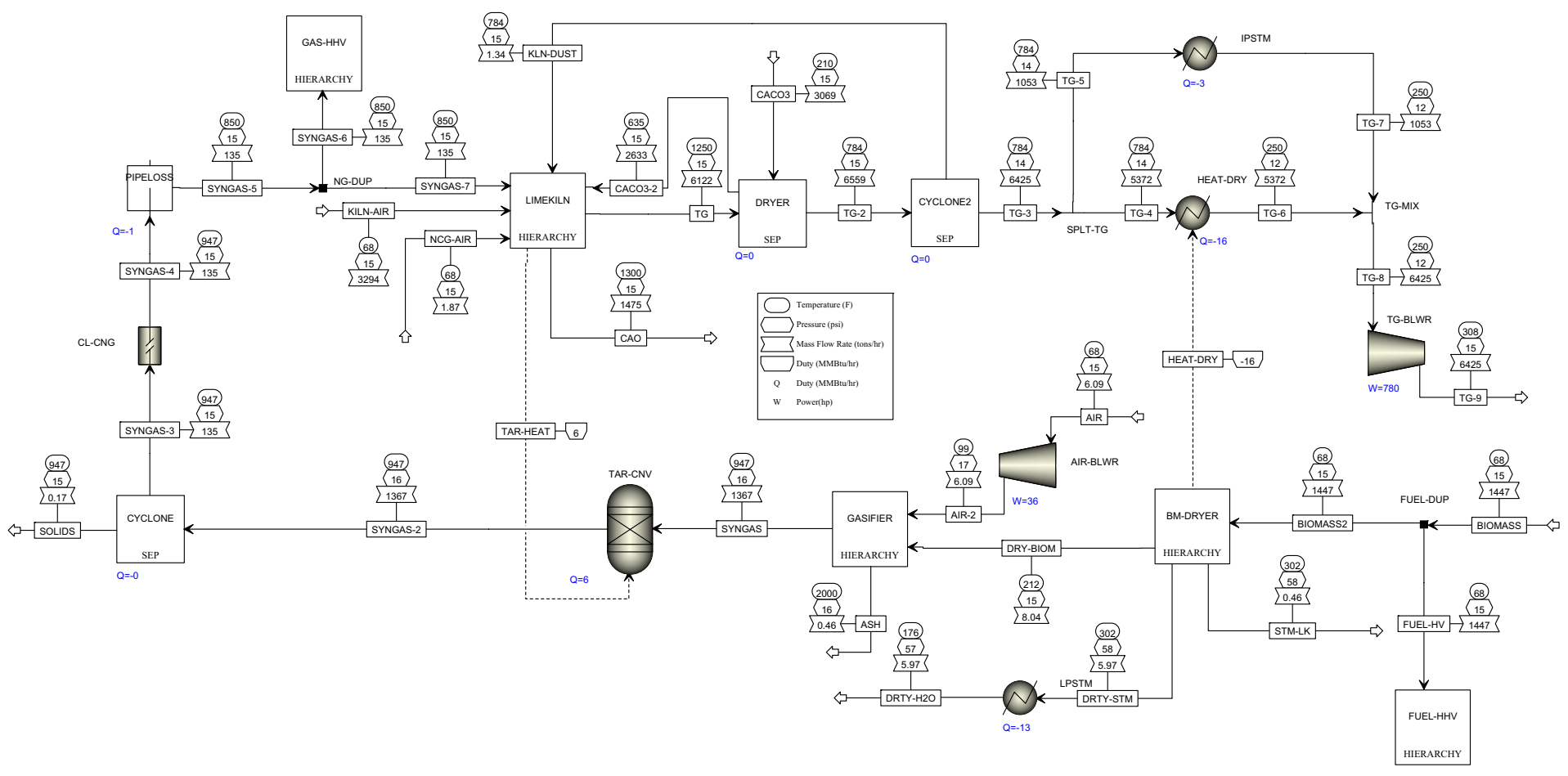

A-17 
Case B Aspen Plus Flowsheets

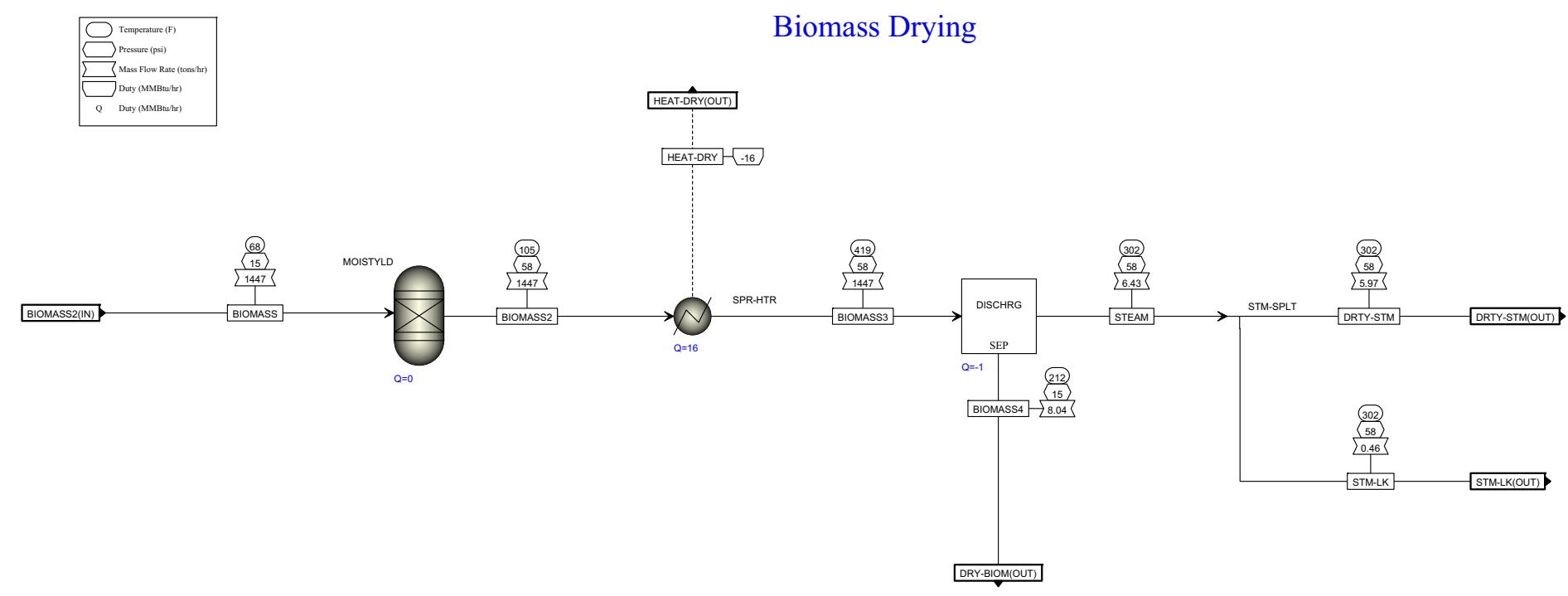




\section{Case B Aspen Plus Flowsheets}

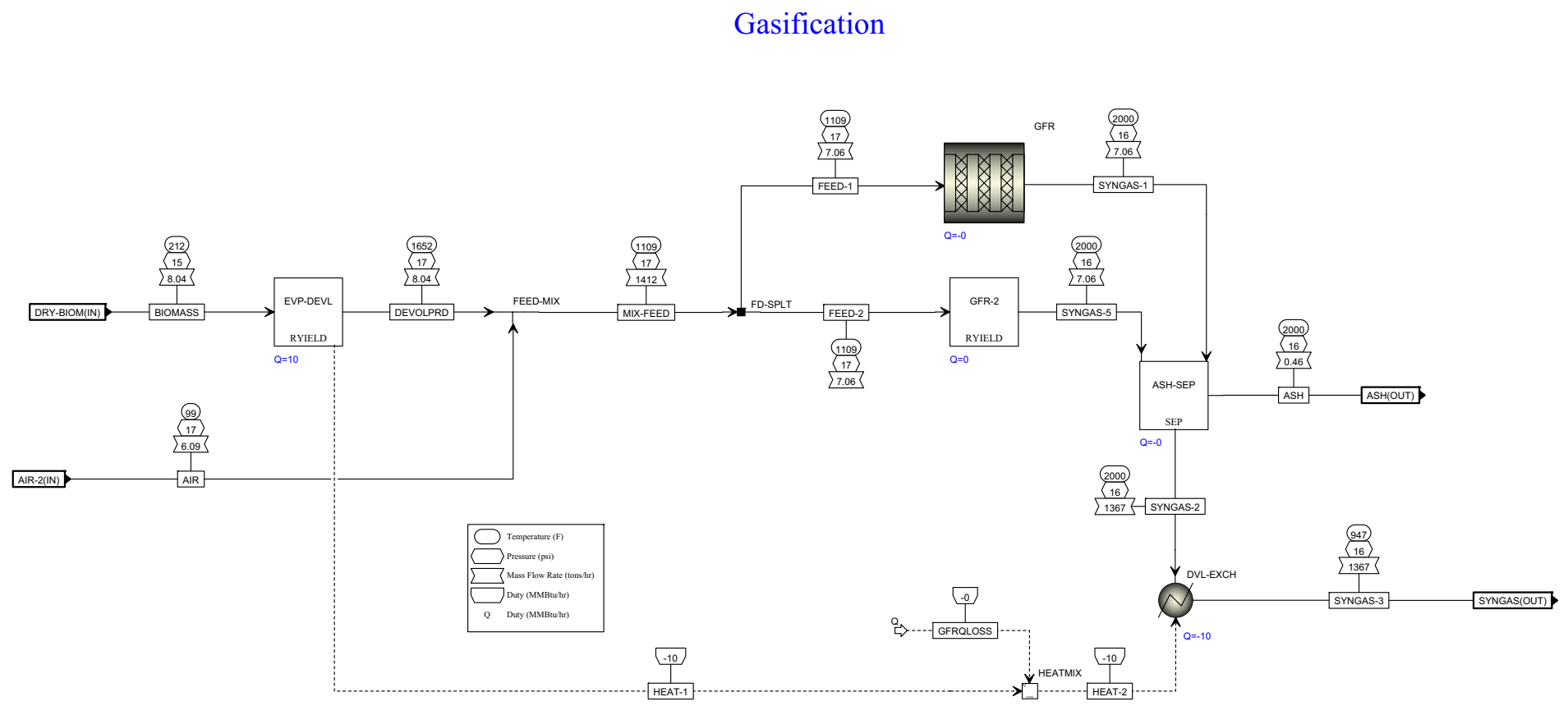

A-19 


\section{Case B Aspen Plus Flowsheets}

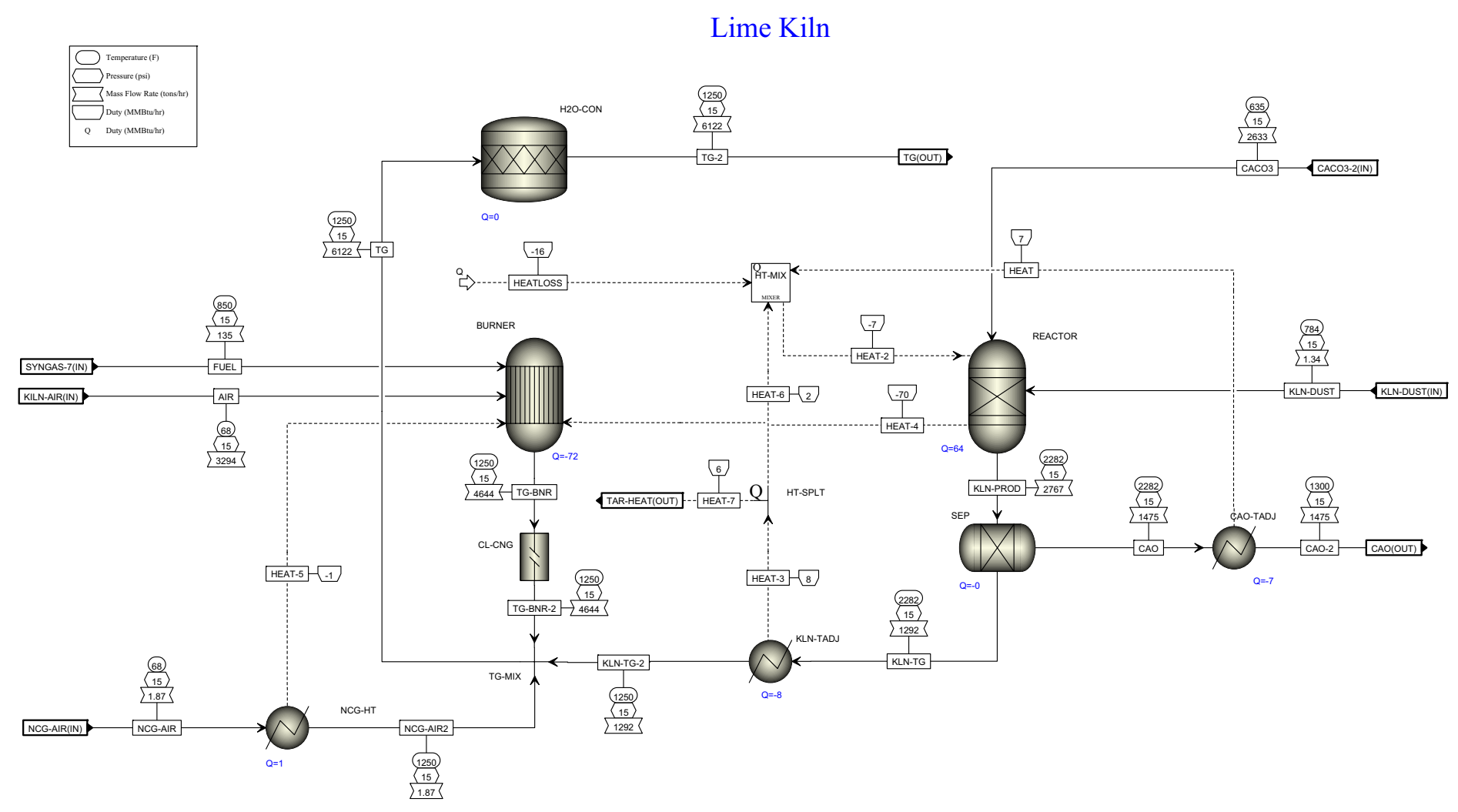

A-20 


\section{Case B Aspen Plus Flowsheets}

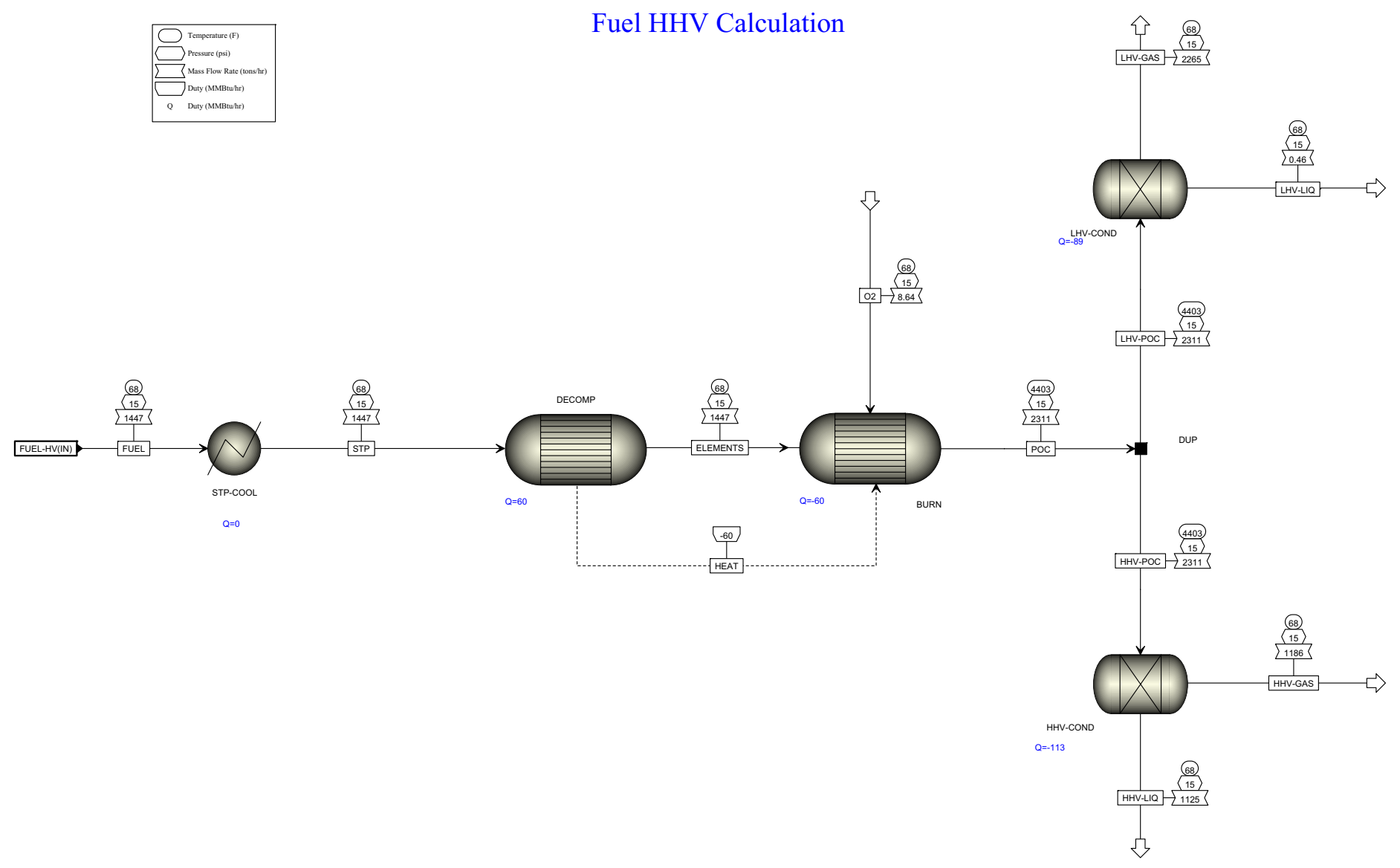




\section{Case B Aspen Plus Flowsheets}

Gas HHV Calculation

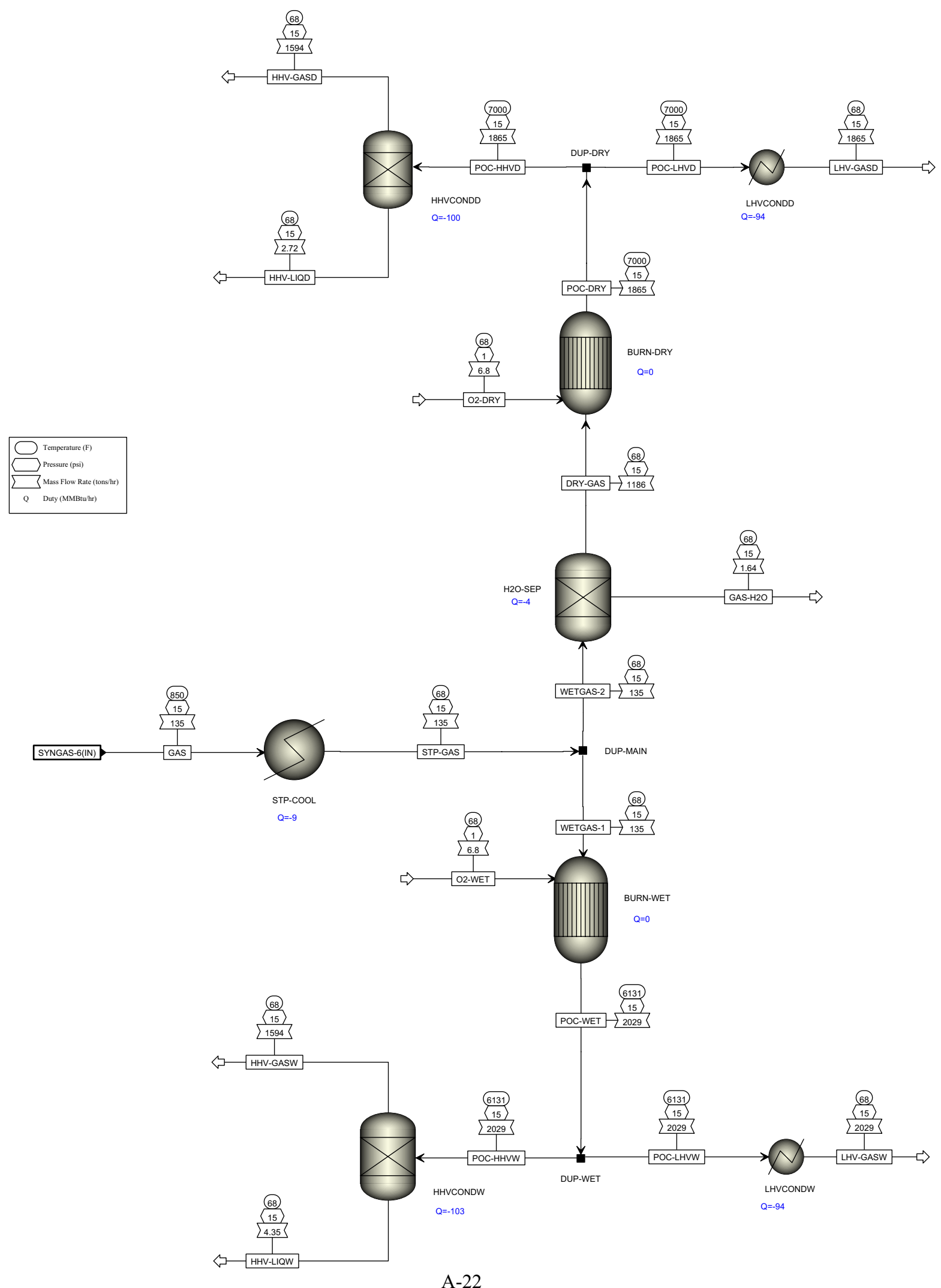




\section{Case B Aspen Plus Stream Results}

\begin{tabular}{|c|c|c|c|c|c|c|c|c|c|c|c|c|c|c|}
\hline \multirow{2}{*}{\multicolumn{15}{|c|}{ Mixed Substream }} \\
\hline & & & & & & & & & & & & & & \\
\hline Temperature F & 68 & 99.1 & & & & 210 & 635 & & 176 & 302 & & & 68 & \\
\hline Pressure $\mathrm{psi}$ & 14.7 & 17 & 16.46 & 14.7 & 14.7 & 14.7 & 14.7 & 14.7 & 57.21 & 58.21 & 14.7 & 14.7 & 14.7 & 14.7 \\
\hline Vapor Frac & 1 & 1 & & & & & 1 & & & 1 & & & 1 & \\
\hline Mole Flow $\mathrm{lbmol} / \mathrm{hr}$ & 420.37 & 420.37 & & & & 484.478 & & & 662.704 & 662.704 & & & 2275.541 & \\
\hline Mass Flow tons $/ \mathrm{hr}$ & 6.086 & 6.086 & & & & 4.364 & & & 5.969 & 5.969 & & & 32.942 & \\
\hline Volume Flow cuft/hr & 161901.883 & 148236.456 & & & & 174.446 & 0.004 & & 234.695 & 90749.585 & & & 876405.721 & \\
\hline Enthalpy MMBtu/hr & -0.093 & -0.002 & & & & -58.639 & & & -80.652 & -67.755 & & & -0.502 & \\
\hline \multicolumn{13}{|l|}{ Mass Flow tons $/ \mathrm{hr}$} & 24.846 & \\
\hline $\mathrm{CO} 2$ & 0.003 & 0.003 & & & & & & & & & & & 0.015 & \\
\hline \multicolumn{15}{|l|}{$\mathrm{CACO} 3$} \\
\hline \multirow{2}{*}{\multicolumn{15}{|c|}{$\begin{array}{l}\mathrm{CAO} \\
\mathrm{CO}\end{array}$}} \\
\hline & & & & & & & & & & & & & & \\
\hline \multicolumn{15}{|l|}{$\begin{array}{l}\mathrm{CO} \\
\mathrm{O} 2\end{array}$} \\
\hline $\mathrm{AR}$ & 0.079 & 0.079 & & & & & & & & & & & 0.427 & \\
\hline \multicolumn{15}{|l|}{$\mathrm{NO} 2$} \\
\hline \multicolumn{15}{|l|}{ NO } \\
\hline \multirow{2}{*}{\multicolumn{15}{|c|}{$\begin{array}{l}\mathrm{H} 2 \mathrm{O} \\
\mathrm{H} 2\end{array}$}} \\
\hline & & & & & & & & & & & & & & \\
\hline \multirow{2}{*}{\multicolumn{15}{|c|}{$\mathrm{CH} 4$}} \\
\hline & & & & & & & & & & & & & & \\
\hline \multicolumn{15}{|l|}{ C } \\
\hline \multicolumn{15}{|l|}{ Mass Frac } \\
\hline $\mathrm{N} 2$ & 0.754 & 0.754 & & & & & & & & & & & 0.754 & \\
\hline \multirow{2}{*}{\multicolumn{15}{|c|}{$\mathrm{CO} 2$}} \\
\hline \multirow{2}{*}{\multicolumn{15}{|c|}{$\begin{array}{l}\mathrm{CACO} 3 \\
\mathrm{CAO}\end{array}$}} \\
\hline & & & & & & & & & & & & & & \\
\hline $\mathrm{CO}$ & & & & & & & & & & & & & & \\
\hline $\mathrm{O} 2$ & 0.232 & 0.232 & & & & & & & & & & & 0.232 & \\
\hline $\mathrm{AR}$ & 0.013 & 0.013 & & & & & & & & & & & 0.013 & \\
\hline $\mathrm{NO} 2$ & & & & & & & & & & & & & & \\
\hline NO & & & & & & & & & & & & & & \\
\hline $\mathrm{H} 2 \mathrm{O}$ & 0.001 & 0.001 & & & & & & & 1 & 1 & & & 0.001 & \\
\hline $\mathrm{H} 2$ & & & & & & & & & & & & & & \\
\hline H2O-MUD & & & & & & 1 & 1 & & & & & & & \\
\hline $\mathrm{CH} 4$ & & & & & & & & & & & & & & \\
\hline C & & & & & & & & & & & & & & \\
\hline Mole Flow $1 \mathrm{bmol} / \mathrm{hr}$ & & & & & & & & & & & & & & \\
\hline $\mathrm{N} 2$ & 327.687 & 327.687 & & & & & & & & & & & 1773.831 & \\
\hline $\mathrm{CO} 2$ & 0.126 & 0.126 & & & & & & & & & & & 0.682 & \\
\hline $\mathrm{CACO} 3$ & & & & & & & & & & & & & & \\
\hline CAO & & & & & & & & & & & & & & \\
\hline $\mathrm{CO}$ & & & & & & & & & & & & & & \\
\hline $\mathrm{O} 2$ & 88.147 & 88.147 & & & & & & & & & & & 477.159 & \\
\hline $\mathrm{AR}$ & 3.948 & 3.948 & & & & & & & & & & & 21.369 & \\
\hline $\mathrm{NO} 2$ & & & & & & & & & & & & & & \\
\hline NO & & & & & & & & & & & & & & \\
\hline $\mathrm{H} 2 \mathrm{O}$ & 0.42 & 0.42 & & & & & & & 662.704 & 662.704 & & & 2.273 & \\
\hline H2 & 0.042 & 0.042 & & & & & & & & & & & 0.227 & \\
\hline H2O-MUD & & & & & & 484.478 & & & & & & & & \\
\hline $\mathrm{CH} 4$ & & & & & & & & & & & & & & \\
\hline C & & & & & & & & & & & & & & \\
\hline Mole Frac & & & & & & & & & & & & & & \\
\hline $\mathrm{N} 2$ & 0.78 & 0.78 & & & & & & & & & & & 0.78 & \\
\hline $\mathrm{CO} 2$ & & & & & & & & & & & & & & \\
\hline $\mathrm{CACO}$ & & & & & & & & & & & & & & \\
\hline
\end{tabular}




\section{Case B Aspen Plus Stream Results}

\begin{tabular}{|c|c|c|c|c|c|c|c|c|c|c|c|c|c|c|}
\hline \multirow{2}{*}{\multicolumn{15}{|c|}{ DRTY-H2O }} \\
\hline & & & & & & & & & & & & & & \\
\hline $\mathrm{O} 2$ & 0.21 & 0.21 & & & & & & & & & & & 0.21 & \\
\hline $\mathrm{AR}$ & 0.009 & 0.009 & & & & & & & & & & & 0.009 & \\
\hline \multicolumn{15}{|l|}{$\mathrm{NO} 2$} \\
\hline \multicolumn{15}{|l|}{ No } \\
\hline \multirow{2}{*}{\multicolumn{15}{|c|}{$\mathrm{H} 2$}} \\
\hline & & & & & & & & & & & & & & \\
\hline \multirow{2}{*}{\multicolumn{15}{|c|}{$\begin{array}{l}\text { H2O-MUD } \\
\text { CH4 }\end{array}$}} \\
\hline & & & & & & & & & & & & & & \\
\hline \multirow{2}{*}{\multicolumn{15}{|c|}{ C }} \\
\hline & & & & & \multicolumn{10}{|c|}{ Nonconventional Substream } \\
\hline Mass Flow tons $/ \mathrm{hr}$ & 6.086 & 6.086 & 0.456 & 14.469 & 14.469 & 30.69 & 26.326 & 14.75 & 5.969 & 5.969 & 8.038 & 14.469 & & 1.339 \\
\hline Enthalpy $\mathrm{MMBtu} / \mathrm{hr}$ & -0.093 & -0.002 & 0.527 & -126.634 & -126.634 & -330.268 & -266.345 & -135.746 & -80.652 & -67.755 & -38.587 & -126.634 & & -12.633 \\
\hline Temperature F & & & 2000 & 68 & 68 & & & & & & 212 & 68 & & \\
\hline Pressure psi & 14.7 & 17 & 16.46 & 14.7 & 14.7 & & & & 57.21 & 58.21 & 14.7 & 14.7 & & \\
\hline \multicolumn{15}{|l|}{ Vapor Frac } \\
\hline Mass Flow tons $/ \mathrm{hr}$ & & & 0.456 & 14.469 & 14.469 & & & & & & 8.038 & 14.469 & & \\
\hline Enthalpy MMBtu/hr & & & 0.527 & -126.634 & -126.634 & & & & & & -38.587 & -126.634 & & \\
\hline \multicolumn{15}{|l|}{ Mass Flow tons $/ \mathrm{hr}$} \\
\hline \multicolumn{15}{|l|}{ CHAR } \\
\hline FUEL & & & & 14.469 & 14.469 & & & & & & 8.038 & 14.469 & & \\
\hline TAR & & & & & & & & & & & & & & \\
\hline ASH & & & 0.456 & & & & & & & & & & & \\
\hline \multicolumn{15}{|l|}{ Mass Frac } \\
\hline \multicolumn{15}{|l|}{ CHAR } \\
\hline \multirow{2}{*}{\multicolumn{15}{|c|}{$\begin{array}{l}\text { FUEL } \\
\text { TAR }\end{array}$}} \\
\hline & & & & & & & & & & & & & & \\
\hline \multirow{2}{*}{\multicolumn{15}{|c|}{$\begin{array}{l}\text { ASH } \\
\text { Solid Substream }\end{array}$}} \\
\hline & & & & & & & & & & & & & & \\
\hline Temperature $\mathrm{F}$ & & & & & & 210 & 635 & 1300 & & & & & & 784.1 \\
\hline Pressure psi & & & & & & 14.7 & 14.7 & 14.7 & & & & & & 14.7 \\
\hline \multicolumn{15}{|l|}{ Vapor Frac } \\
\hline Mole Flow $\mathrm{lbmol} / \mathrm{hr}$ & & & & & & 526.061 & 526.061 & 526.061 & & & & & & 47.759 \\
\hline Mass Flow tons $/$ hr & & & & & & 26.326 & 26.326 & 14.75 & & & & & & 1.339 \\
\hline Volume Flow cuft/hr & & & & & & 311.289 & 312.885 & 143.299 & & & & & & 13.01 \\
\hline Enthalpy MMBtu/hr & & & & & & -271.629 & -266.345 & -135.746 & & & & & & -12.633 \\
\hline Mass Flow tons $/ \mathrm{hr}$ & & & & & & & & & & & & & & \\
\hline $\mathrm{CACO} 3$ & & & & & & 26.326 & 26.326 & & & & & & & \\
\hline CAO & & & & & & & & 14.75 & & & & & & 1.339 \\
\hline Mass Frac & & & & & & & & & & & & & & \\
\hline $\mathrm{CACO} 3$ & & & & & & 1 & 1 & & & & & & & \\
\hline CAO & & & & & & & & 1 & & & & & & 1 \\
\hline Mole Flow $\mathrm{lbmol} / \mathrm{hr}$ & & & & & & & & & & & & & & \\
\hline $\mathrm{CACO} 3$ & & & & & & 526.061 & 526.061 & & & & & & & \\
\hline $\mathrm{CAO}$ & & & & & & & & 526.061 & & & & & & 47.759 \\
\hline Mole Frac & & & & & & & & & & & & & & \\
\hline $\mathrm{CACO} 3$ & & & & & & 1 & 1 & & & & & & & \\
\hline $\mathrm{CAO}$ & & & & & & & & 1 & & & & & & 1 \\
\hline
\end{tabular}




\section{Case B Aspen Plus Stream Results}

\begin{tabular}{|c|c|c|c|c|c|c|c|c|c|c|c|c|c|c|}
\hline \multirow{2}{*}{\multicolumn{15}{|c|}{ Mixed Substream }} \\
\hline & & & & & & & & & & & & & & \\
\hline & 68 & & 302 & 946.9 & 946.9 & 946.9 & 946.9 & 850 & 850 & 850 & 1250.1 & 784.1 & 784.1 & 784.1 \\
\hline Pressure psi & 14.7 & 15.46 & 58.21 & 16.46 & 16.46 & 15.46 & 15.46 & 14.96 & 14.96 & 14.96 & 14.7 & 14.7 & 13.7 & 13.7 \\
\hline Vapor Frac & 1 & & 1 & 1 & 0.943 & 0.943 & 0.943 & 0.943 & 0.943 & 0.943 & 1 & 1 & 1 & 1 \\
\hline Mole Flow lbmol/hr & 129.173 & & 51.206 & 1111.036 & 1246.497 & 1246.497 & 1246.497 & 1246.497 & 1246.497 & 1246.497 & 3833.131 & 4317.609 & 4317.609 & 3610.212 \\
\hline Mass Flow tons $/ \mathrm{hr}$ & 1.87 & & 0.461 & 12.784 & 13.496 & 13.496 & 13.496 & 13.496 & 13.496 & 13.496 & 59.884 & 64.248 & 64.248 & 53.722 \\
\hline Volume Flow cuft/hr & 49749.865 & & 7012.032 & $1.02 \mathrm{E}+06$ & $1.08 \mathrm{E}+06$ & $1.15 \mathrm{E}+06$ & $1.15 \mathrm{E}+06$ & $1.11 \mathrm{E}+06$ & $1.11 \mathrm{E}+06$ & $1.11 \mathrm{E}+06$ & $4.79 \mathrm{E}+06$ & $3.92 \mathrm{E}+06$ & $4.21 \mathrm{E}+06$ & $3.52 \mathrm{E}+06$ \\
\hline Enthalpy MMBtu/hr & -0.029 & & -5.235 & -38.078 & -33.771 & -33.771 & -33.771 & -34.856 & -34.856 & -34.856 & -187.921 & -251.566 & -251.565 & -210.349 \\
\hline \multicolumn{14}{|l|}{ Mass Flow tons/hr } & 25.792 \\
\hline $\mathrm{CO} 2$ & 0.001 & & & 1.156 & 1.156 & 1.156 & 1.156 & 1.156 & 1.156 & 1.156 & 22.856 & 22.856 & 22.856 & 19.111 \\
\hline \multicolumn{15}{|l|}{$\mathrm{CACO} 3$} \\
\hline \multicolumn{15}{|l|}{$\mathrm{CAO}$} \\
\hline $\mathrm{CO}$ & & & & 4.78 & 4.78 & 4.78 & 4.78 & 4.78 & 4.78 & 4.78 & 0.003 & 0.003 & 0.003 & 0.003 \\
\hline $\mathrm{O} 2$ & 0.433 & & & & 0.238 & 0.238 & 0.238 & 0.238 & 0.238 & 0.238 & 1.271 & 1.271 & 1.271 & 1.063 \\
\hline AR & 0.024 & & & 0.079 & 0.079 & 0.079 & 0.079 & 0.079 & 0.079 & 0.079 & 0.53 & 0.53 & 0.53 & 0.443 \\
\hline \multicolumn{15}{|l|}{$\mathrm{NO} 2$} \\
\hline \multicolumn{15}{|l|}{ No } \\
\hline $\mathrm{H} 2 \mathrm{O}$ & 0.001 & & 0.461 & 1.639 & 1.639 & 1.639 & 1.639 & 1.639 & 1.639 & 1.639 & 4.378 & 4.378 & 4.378 & 3.661 \\
\hline $\mathrm{H} 2$ & & & & 0.157 & 0.208 & 0.208 & 0.208 & 0.208 & 0.208 & 0.208 & & & & \\
\hline H2O-MUD & & & & & & & & & & & & 4.364 & 4.364 & 3.649 \\
\hline $\mathrm{CH} 4$ & & & & 0.383 & 0.383 & 0.383 & 0.383 & 0.383 & 0.383 & 0.383 & & & & \\
\hline $\mathrm{C}$ & & & & & 0.423 & 0.423 & 0.423 & 0.423 & 0.423 & 0.423 & & & & \\
\hline \multicolumn{15}{|l|}{ Mass Frac } \\
\hline $\mathrm{N} 2$ & 0.754 & & & 0.359 & 0.34 & 0.34 & 0.34 & 0.34 & 0.34 & 0.34 & 0.515 & 0.48 & 0.48 & 0.48 \\
\hline $\mathrm{CO} 2$ & & & & 0.09 & 0.086 & 0.086 & 0.086 & 0.086 & 0.086 & 0.086 & 0.382 & 0.356 & 0.356 & 0.356 \\
\hline \multicolumn{15}{|l|}{$\mathrm{CACO} 3$} \\
\hline \multicolumn{15}{|l|}{ CAO } \\
\hline $\mathrm{CO}$ & & & & 0.374 & 0.354 & 0.354 & 0.354 & 0.354 & 0.354 & 0.354 & & & & \\
\hline $\mathrm{O} 2$ & 0.232 & & & & 0.018 & 0.018 & 0.018 & 0.018 & 0.018 & 0.018 & 0.021 & 0.02 & 0.02 & 0.02 \\
\hline $\mathrm{AR}$ & 0.013 & & & 0.006 & 0.006 & 0.006 & 0.006 & 0.006 & 0.006 & 0.006 & 0.009 & 0.008 & 0.008 & 0.008 \\
\hline \multirow{2}{*}{\multicolumn{15}{|c|}{$\mathrm{NO} 2$}} \\
\hline & & & & & & & & & & & & & & \\
\hline $\mathrm{H} 2 \mathrm{O}$ & 0.001 & & 1 & 0.128 & 0.121 & 0.121 & 0.121 & 0.121 & 0.121 & 0.121 & 0.073 & 0.068 & 0.068 & 0.068 \\
\hline $\mathrm{H} 2$ & & & & 0.012 & 0.015 & 0.015 & 0.015 & 0.015 & 0.015 & 0.015 & & & & \\
\hline H2O-MUD & & & & & & & & & & & & 0.068 & 0.068 & 0.068 \\
\hline $\mathrm{CH} 4$ & & & & 0.03 & 0.028 & 0.028 & 0.028 & 0.028 & 0.028 & 0.028 & & & & \\
\hline $\mathrm{C}$ & & & & & 0.031 & 0.031 & 0.031 & 0.031 & 0.031 & 0.031 & & & & \\
\hline \multicolumn{15}{|l|}{ Mole Flow $\mathrm{lbmol} / \mathrm{hr}$} \\
\hline $\mathrm{N} 2$ & 100.693 & & & 327.687 & 327.687 & 327.687 & 327.687 & 327.687 & 327.687 & 327.687 & 2202.21 & 2202.21 & 2202.21 & 1841.4 \\
\hline $\mathrm{CO} 2$ & 0.039 & & & 52.555 & 52.555 & 52.555 & 52.555 & 52.555 & 52.555 & 52.555 & 1038.675 & 1038.675 & 1038.675 & 868.498 \\
\hline \multicolumn{15}{|l|}{$\mathrm{CACO} 3$} \\
\hline $\mathrm{CAO}$ & & & & & & & & & & & & & & \\
\hline $\mathrm{CO}$ & & & & 341.307 & 341.307 & 341.307 & 341.307 & 341.307 & 341.307 & 341.307 & 0.238 & 0.238 & 0.238 & 0.199 \\
\hline $\mathrm{O} 2$ & 27.086 & & & & 14.86 & 14.86 & 14.86 & 14.86 & 14.86 & 14.86 & 79.445 & 79.445 & 79.445 & 66.429 \\
\hline AR & 1.213 & & & 3.948 & 3.948 & 3.948 & 3.948 & 3.948 & 3.948 & 3.948 & 26.529 & 26.529 & 26.529 & 22.183 \\
\hline $\mathrm{NO} 2$ & & & & & & & & & & & & & & \\
\hline NO & & & & & & & & & & & & & & \\
\hline $\mathrm{H} 2 \mathrm{O}$ & 0.129 & & 51.206 & 181.906 & 181.906 & 181.906 & 181.906 & 181.906 & 181.906 & 181.906 & 486.021 & 486.021 & 486.021 & 406.391 \\
\hline $\mathrm{H} 2$ & 0.013 & & & 155.875 & 205.966 & 205.966 & 205.966 & 205.966 & 205.966 & 205.966 & 0.013 & 0.013 & 0.013 & 0.011 \\
\hline H2O-MUD & & & & & & & & & & & & 484.478 & 484.478 & 405.101 \\
\hline $\mathrm{CH} 4$ & & & & 47.76 & 47.76 & 47.76 & 47.76 & 47.76 & 47.76 & 47.76 & & & & \\
\hline $\mathrm{C}$ & & & & & 70.51 & 70.51 & 70.51 & 70.51 & 70.51 & 70.51 & & & & \\
\hline Mole Frac & & & & & & & & & & & & & & \\
\hline $\mathrm{N} 2$ & 0.78 & & & 0.295 & 0.263 & 0.263 & 0.263 & 0.263 & 0.263 & 0.263 & 0.575 & 0.51 & 0.51 & 0.51 \\
\hline $\mathrm{CO} 2$ & & & & 0.047 & 0.042 & 0.042 & 0.042 & 0.042 & 0.042 & 0.042 & 0.271 & 0.241 & 0.241 & 0.241 \\
\hline $\mathrm{CACO}_{3}$ & & & & & & & & & & & & & & \\
\hline
\end{tabular}




\section{Case B Aspen Plus Stream Results}

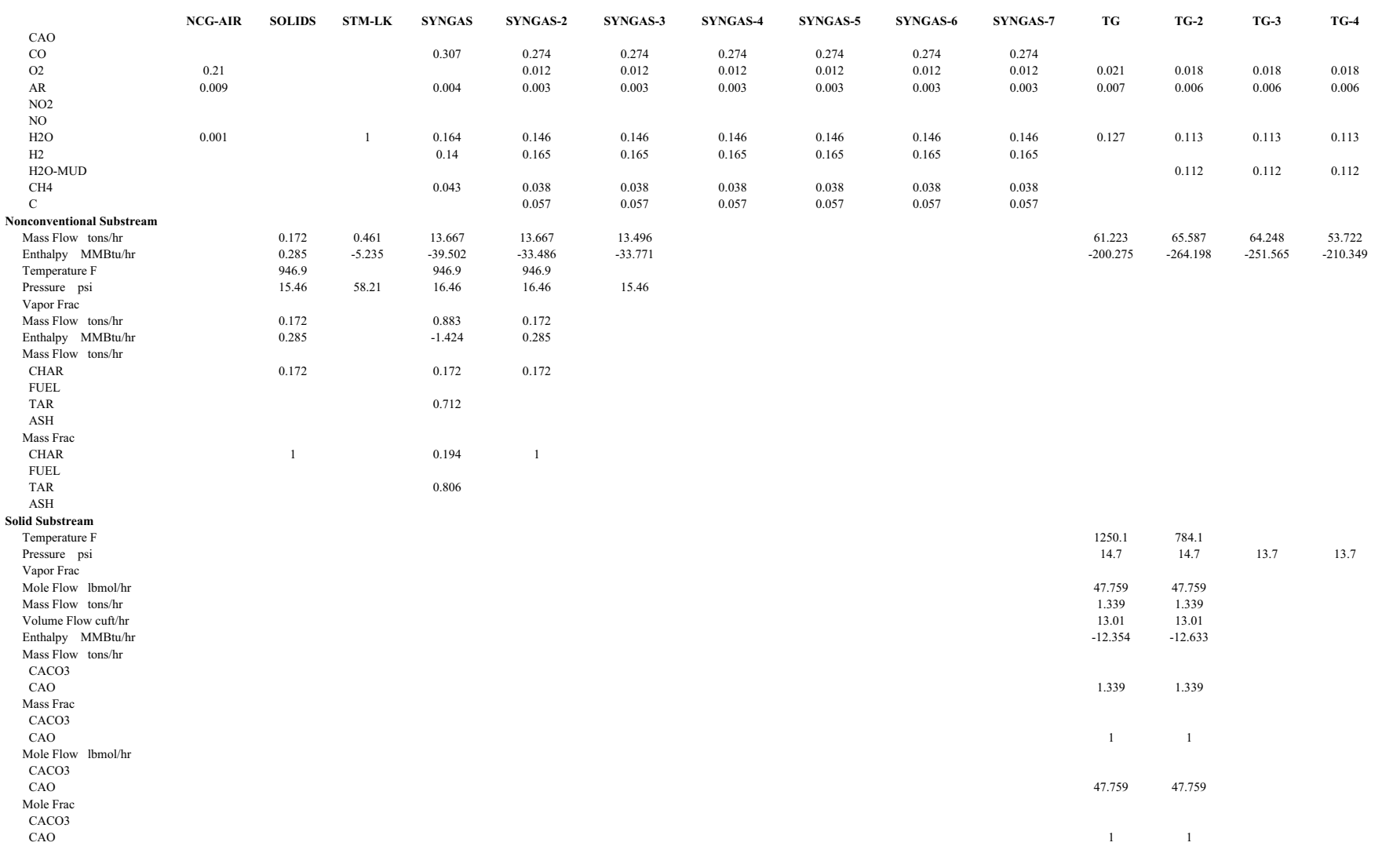




\section{Case B Aspen Plus Stream Results}

\begin{tabular}{|c|c|c|c|c|c|}
\hline \multirow{2}{*}{\multicolumn{6}{|c|}{ Mixed Substream }} \\
\hline & & & & & \\
\hline & 784.1 & 250 & 250 & 250 & 307.6 \\
\hline Pressure psi & 13.7 & 11.7 & 11.7 & 11.7 & 14.7 \\
\hline Vapor Frac & 1 & 1 & 1 & 1 & 1 \\
\hline Mole Flow $\mathrm{lbmol} / \mathrm{hr}$ & 707.397 & 3610.212 & 707.397 & 4317.609 & 4317.609 \\
\hline Mass Flow tons $/ \mathrm{hr}$ & 10.526 & 53.722 & 10.526 & 64.248 & 64.248 \\
\hline Volume Flow cuft/hr & 689431.89 & $2.35 \mathrm{E}+06$ & 460135.848 & $2.81 \mathrm{E}+06$ & $2.42 \mathrm{E}+06$ \\
\hline Enthalpy $\mathrm{MMBtu} / \mathrm{hr}$ & -41.216 & -226.455 & -44.372 & -270.827 & -268.843 \\
\hline \multicolumn{6}{|l|}{ Mass Flow tons $/ \mathrm{hr}$} \\
\hline $\mathrm{N} 2$ & 5.054 & 25.792 & 5.054 & 30.846 & 30.846 \\
\hline $\mathrm{CO} 2$ & 3.745 & 19.111 & 3.745 & 22.856 & 22.856 \\
\hline \multicolumn{6}{|l|}{$\mathrm{CACO} 3$} \\
\hline \multicolumn{6}{|l|}{$\mathrm{CAO}$} \\
\hline $\mathrm{CO}$ & 0.001 & 0.003 & 0.001 & 0.003 & 0.003 \\
\hline $\mathrm{O} 2$ & 0.208 & 1.063 & 0.208 & 1.271 & 1.271 \\
\hline $\mathrm{AR}$ & 0.087 & 0.443 & 0.087 & 0.53 & 0.53 \\
\hline \multicolumn{6}{|l|}{ NO2 } \\
\hline \multicolumn{6}{|l|}{ NO } \\
\hline $\mathrm{H} 2 \mathrm{O}$ & 0.717 & 3.661 & 0.717 & 4.378 & 4.378 \\
\hline \multicolumn{6}{|l|}{$\mathrm{H}_{2}$} \\
\hline H2O-MUD & 0.715 & 3.649 & 0.715 & 4.364 & 4.364 \\
\hline \multicolumn{6}{|l|}{ CH4 } \\
\hline \multirow{2}{*}{\multicolumn{6}{|c|}{$\begin{array}{l}\text { C } \\
\text { Mass Frac }\end{array}$}} \\
\hline Mass Frac & & & & & \\
\hline $\mathrm{N} 2$ & 0.48 & 0.48 & 0.48 & 0.48 & 0.48 \\
\hline $\mathrm{CO} 2$ & 0.356 & 0.356 & 0.356 & 0.356 & 0.356 \\
\hline \multicolumn{6}{|l|}{$\mathrm{CACO} 3$} \\
\hline \multicolumn{6}{|l|}{$\mathrm{CAO}$} \\
\hline \multicolumn{6}{|l|}{ CO } \\
\hline $\mathrm{O} 2$ & 0.02 & 0.02 & 0.02 & 0.02 & 0.02 \\
\hline AR & 0.008 & 0.008 & 0.008 & 0.008 & 0.008 \\
\hline \multicolumn{6}{|l|}{$\mathrm{NO} 2$} \\
\hline \multicolumn{6}{|l|}{ NO } \\
\hline \multirow{2}{*}{\multicolumn{6}{|c|}{$\begin{array}{l}\mathrm{H} 2 \mathrm{O} \\
\mathrm{H} 2\end{array}$}} \\
\hline & & & & & \\
\hline H2O-MUD & 0.068 & 0.068 & 0.068 & 0.068 & 0.068 \\
\hline \multicolumn{6}{|l|}{$\begin{array}{l}\text { H2O-MUD } \\
\text { CH4 }\end{array}$} \\
\hline C & & & & & \\
\hline Mole Flow $\mathrm{lbmol} / \mathrm{hr}$ & & & & & \\
\hline $\mathrm{N} 2$ & 360.81 & 1841.4 & 360.81 & 2202.21 & 2202.21 \\
\hline $\mathrm{CO} 2$ & 170.176 & 868.498 & 170.176 & 1038.675 & 1038.675 \\
\hline $\mathrm{CACO} 3$ & & & & & \\
\hline $\mathrm{CAO}$ & & & & & \\
\hline $\mathrm{CO}$ & 0.039 & 0.199 & 0.039 & 0.238 & 0.238 \\
\hline $\mathrm{O} 2$ & 13.016 & 66.429 & 13.016 & 79.445 & 79.445 \\
\hline $\mathrm{AR}$ & 4.347 & 22.183 & 4.347 & 26.529 & 26.529 \\
\hline $\mathrm{NO} 2$ & & & & & \\
\hline NO & & & & & \\
\hline $\mathrm{H} 2 \mathrm{O}$ & 79.63 & 406.391 & 79.63 & 486.021 & 486.021 \\
\hline $\mathrm{H} 2$ & 0.002 & 0.011 & 0.002 & 0.013 & 0.013 \\
\hline H2O-MUD & 79.377 & 405.101 & 79.377 & 484.478 & 484.478 \\
\hline CH4 & & & & & \\
\hline C & & & & & \\
\hline Mole Frac & & & & & \\
\hline N2 & 0.51 & 0.51 & 0.51 & 0.51 & 0.51 \\
\hline $\mathrm{CO} 2$ & 0.241 & 0.241 & 0.241 & 0.241 & 0.241 \\
\hline $\mathrm{CACO}$ & & & & & \\
\hline
\end{tabular}




\section{Case B Aspen Plus Stream Results}

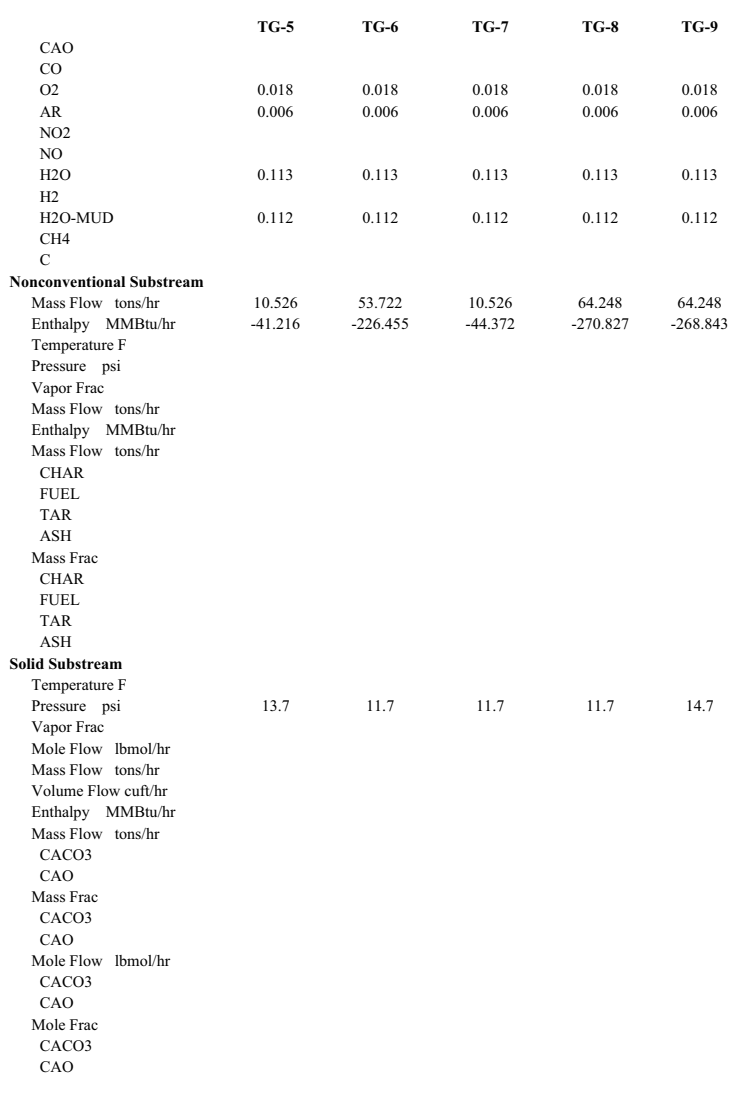


Appendix B

Aspen Plus Model Report for Case A 


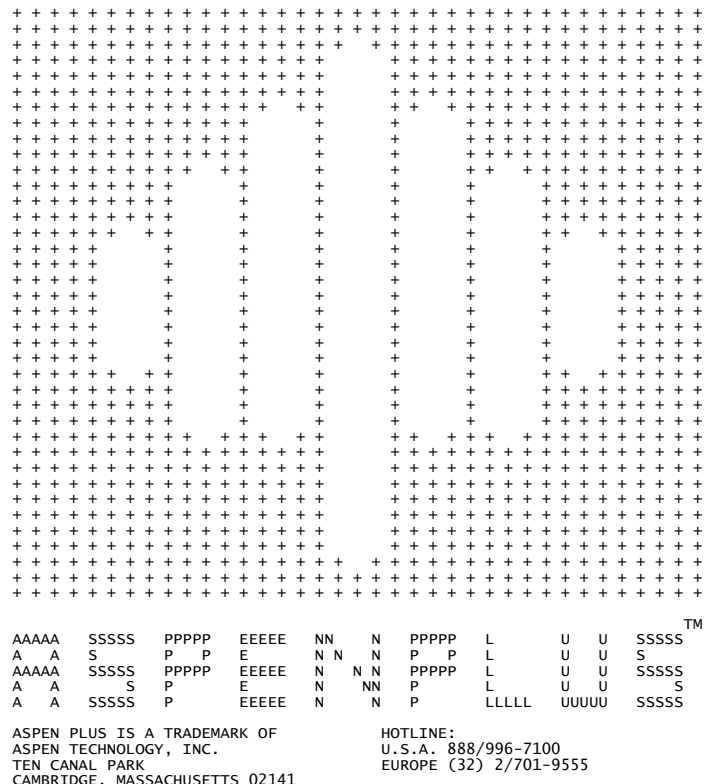
CAMBRIDGE, MASSACHUSETTS 0214

PLATFORM: WIN32
VERSION: 20.01 Build 75

ASPEN PLUS PLAT: WIN32 VER: 20.01

SEPTEMBER 27, 2007 THURSDAY $12: 03$ A.M.

09/27/2007 PAGE I ASPEN PLUS (R) IS A PROPRIETARY PRODUCT OF ASPEN TECHNOLOGY, INC.
(ASPENTECH), AND MAY BE USED ONLY UNDER AGREEMENT WITH ASPENTECH.
RESRICTED RIGTS LEEND: USE, REPRODUCTION, OR DISCLOSURE BY TH
EST LISTED (i) FAR $52.227-14$, Alt. III, (ii) FAR $52.227-19$, (iii) DFARS
u. GOENMENT IN

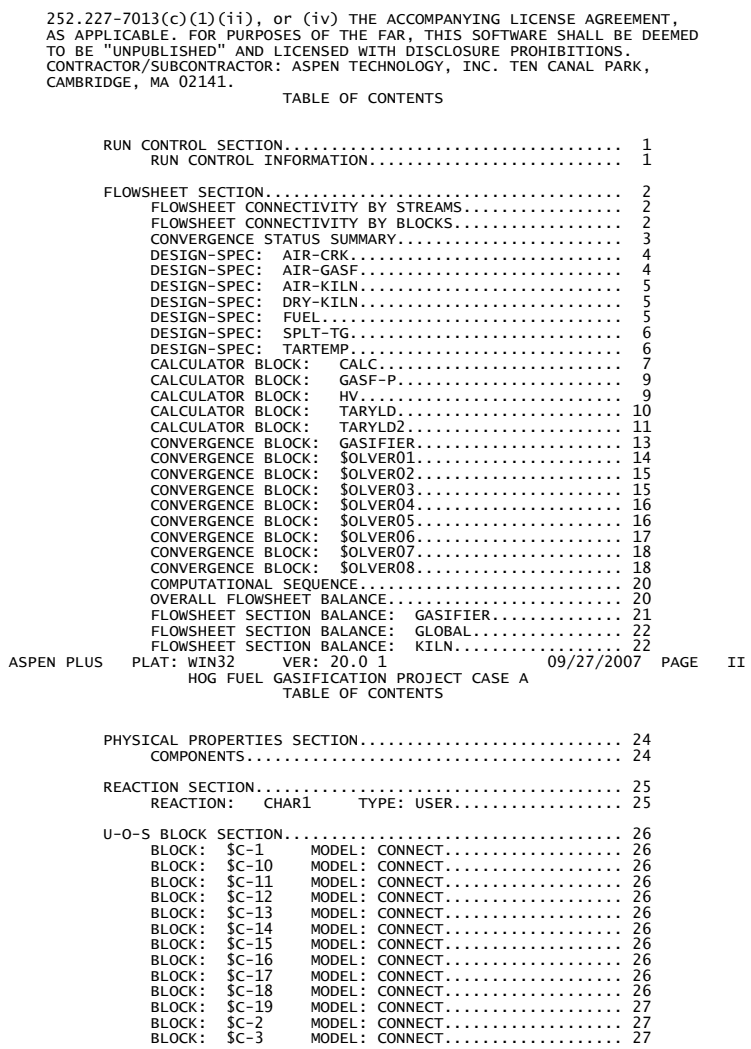

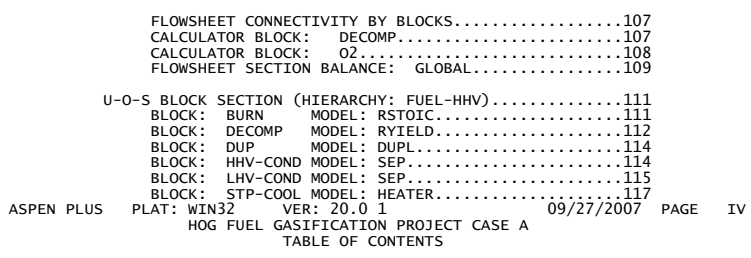

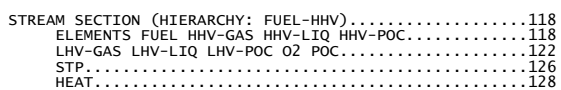

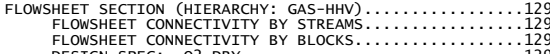

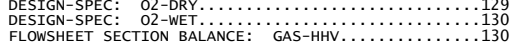

U-O-S BLOCK SECTION (HIERARCHY: GAS-HHV)

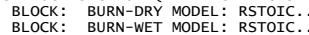

BLOCK: DUP-MAIN MODEE: DUP

$\begin{array}{lll}\text { BLOCK: } & \text { DUP-WET MODEL: DUPL } \\ \text { BLOCK: } & \text { H2O-SEP MODEL: SEP. }\end{array}$

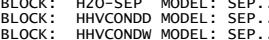

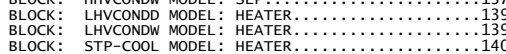

STREAM SECTION (HIERARCHY: GAS-HHV) $\ldots \ldots \ldots \ldots \ldots \ldots 142$

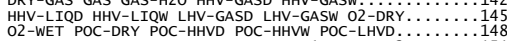

FLOWSHEET SECTION (HIERARCHY: GASTFIER) $\ldots$
FLOWSHET CONECTIVITY BY STREAMS $\ldots .$.
FLOWSHETT CONNECTIVITY BY BLOCKS $\ldots \ldots$

$\begin{array}{ll}\text { CALCULATOR BLOCK: } & \text { EVPDVLL........... } \\ \text { CALCULATOR BLOCK: } & \text { GFRQLOSS. }\end{array}$

CALCULATTR BLOCK: $\quad$ RXN-2 $\ldots \ldots \ldots \ldots .$.

U-O-S BLOCK SECTION (HIERARCHY: GASIFIER)

BLOCK: $\begin{aligned} & \text { DVL-EXCH MODEL: } \\ & \text { BEATER. }\end{aligned}$

$\begin{array}{ll}\text { BLOCK: } & \text { EVP-DEVL MODEL: REATELD } \\ \text { BLOCK: } & \text { FD-SPLT MODEL: FSPLIT } \\ \text { F }\end{array}$

$\begin{array}{ll}\text { BLOCK: } & \text { FD-SPLT MODEL: } \\ \text { BLOCK } & \text { FELIT } \\ \text { FED-MIX MODEL : MIXER. }\end{array}$

\begin{tabular}{llll} 
BLLCK: & GFR & MODEL: RPLUG. \\
BLOCK: & GRR-2 & MODEL: RYILLD \\
\hline
\end{tabular} 


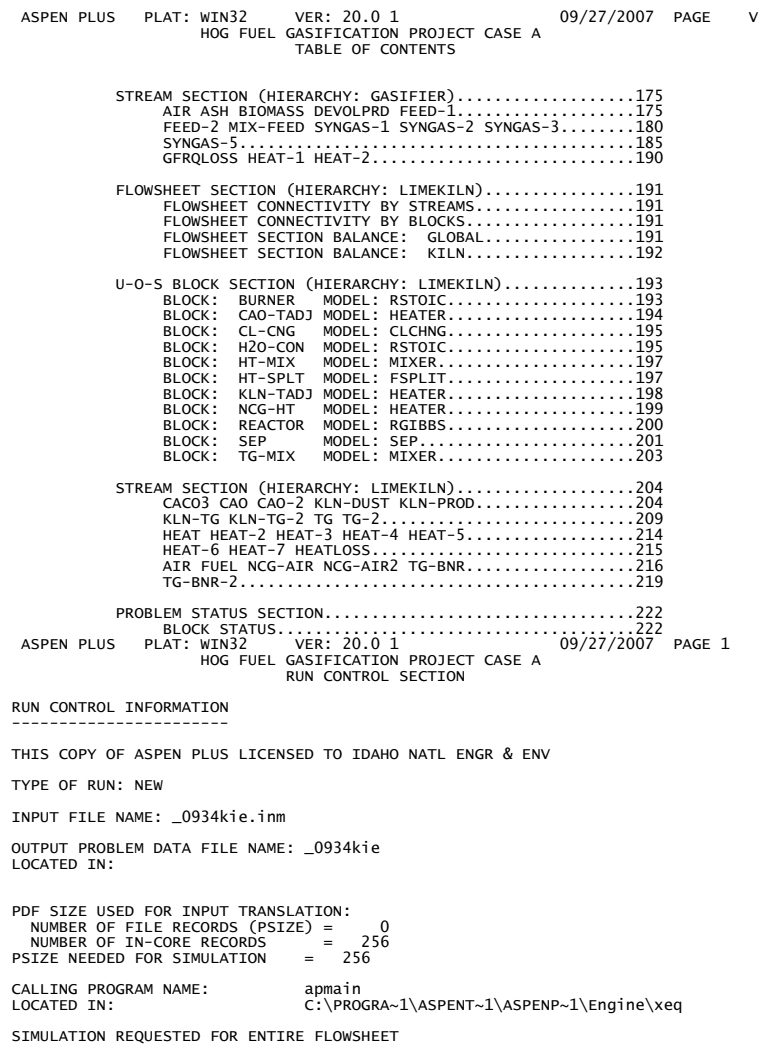

THIS COPY OF ASPEN PLUS LICENSED TO IDAHO NATL ENGR \& EN

PDF SIZE USED FOR INPUT TRANSLATION:
NUMER OF FILE RECORDS (PSIZ) $=$
NUMBER OF IN-CORE RECORDS $=$
PSIZE NEEDED FOR SIMULATION $=256$

$\begin{array}{ll}\text { CALLING PROGRAM NAME: } & \text { apmain } \\ \text { LOCATED IN: } & \text { C: } \backslash \text { PROGRA } 1 \backslash \text { ASPENT } 1 \backslash \text { ASPENP } 1 \backslash \text { Engine } \backslash x e q \\ \end{array}$

SIMULATION REQUESTED FOR ENTIRE FLOWSHEET

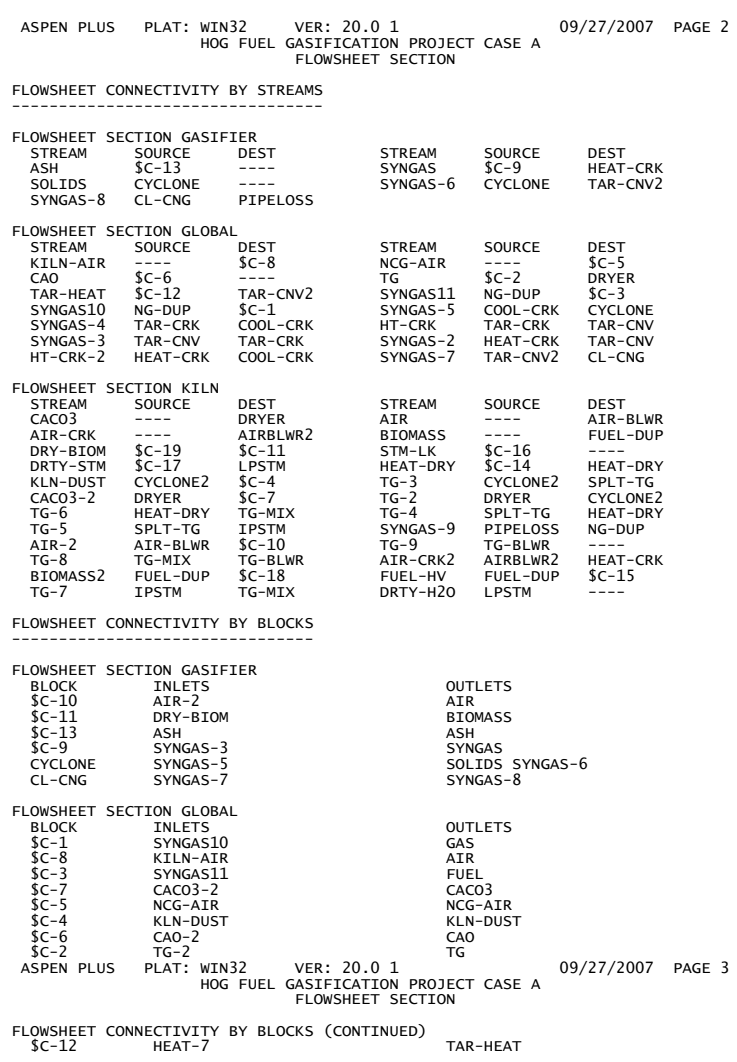

$\underset{\text { FLOWSHEET CONNECTIVITY BY BLOCKS (CONTINUED) }}{\text { HEAT-7 }}$ TAR-HEAT

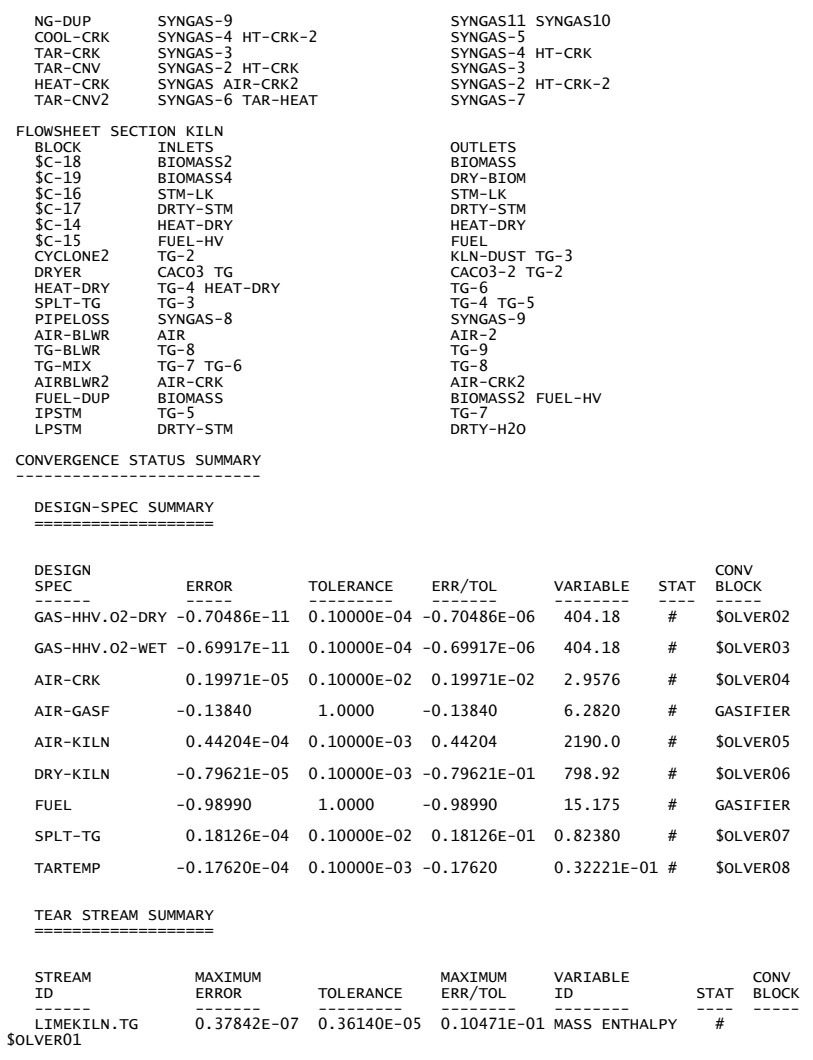

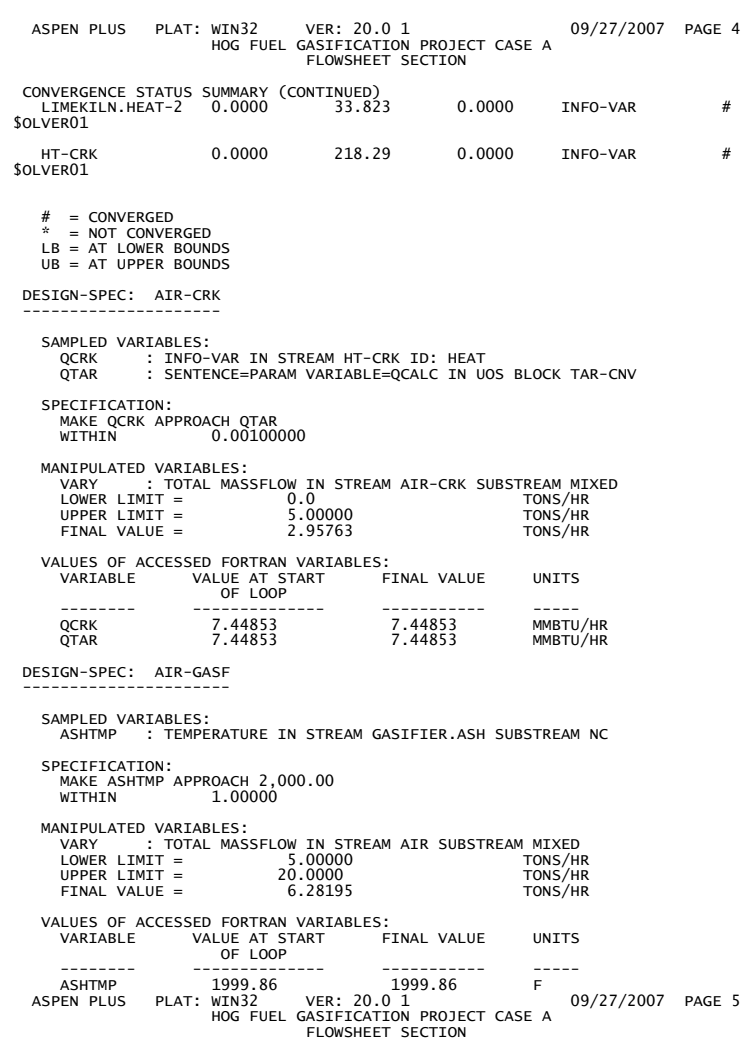


DESIGN-SPEC: AIR-KILN

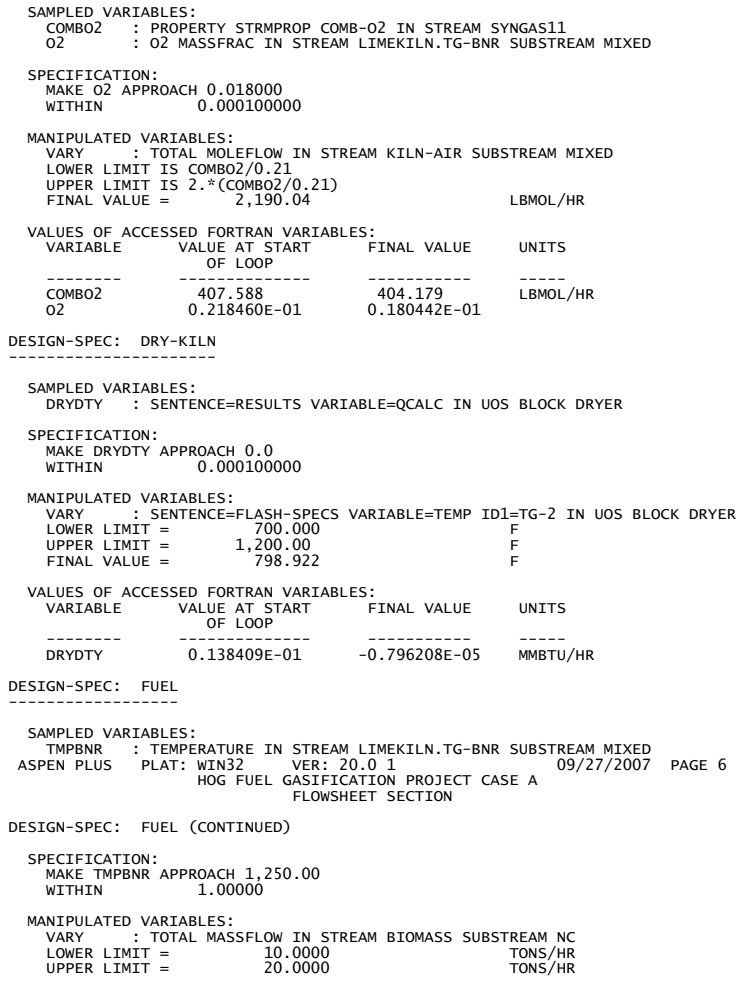

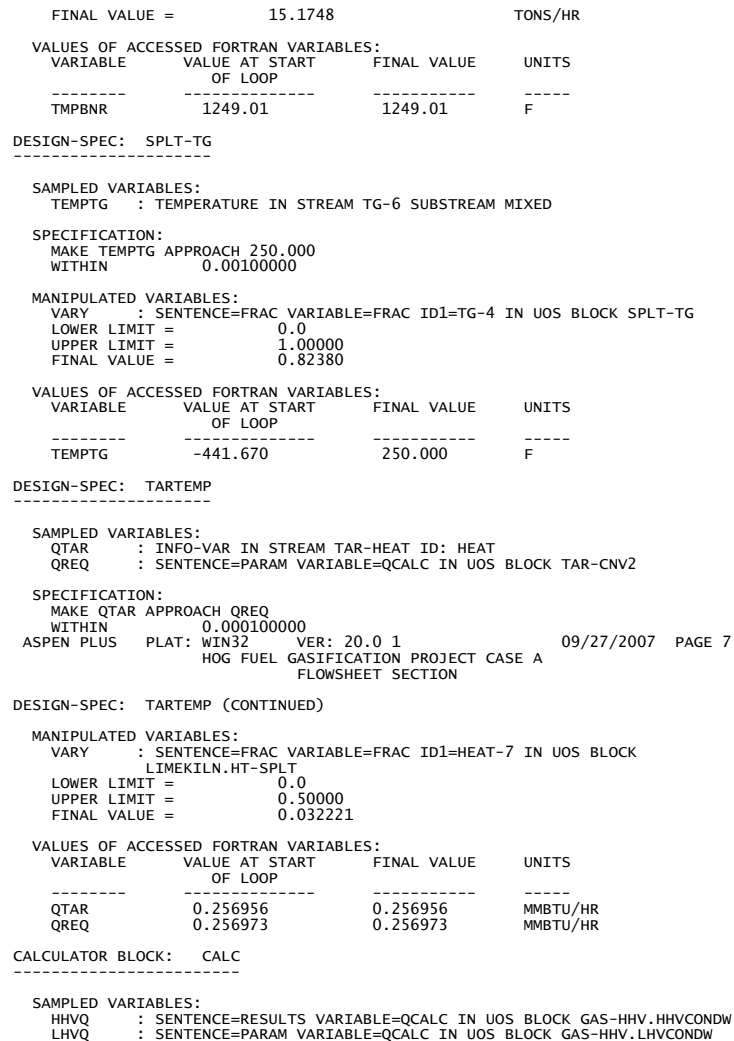



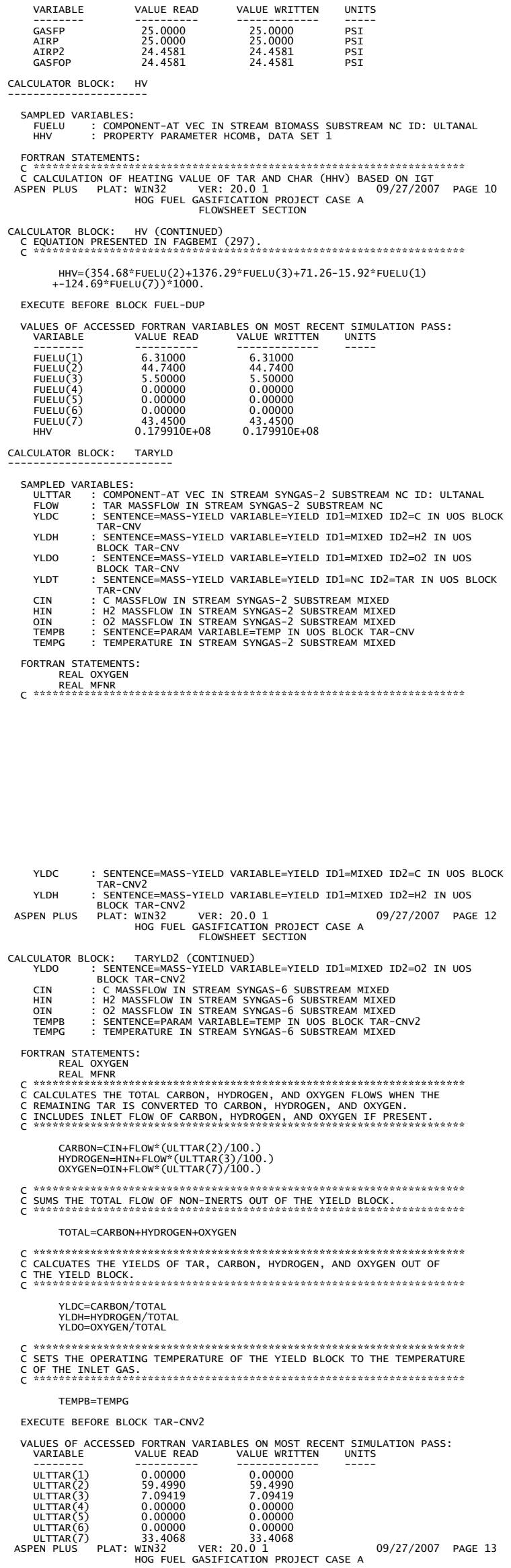
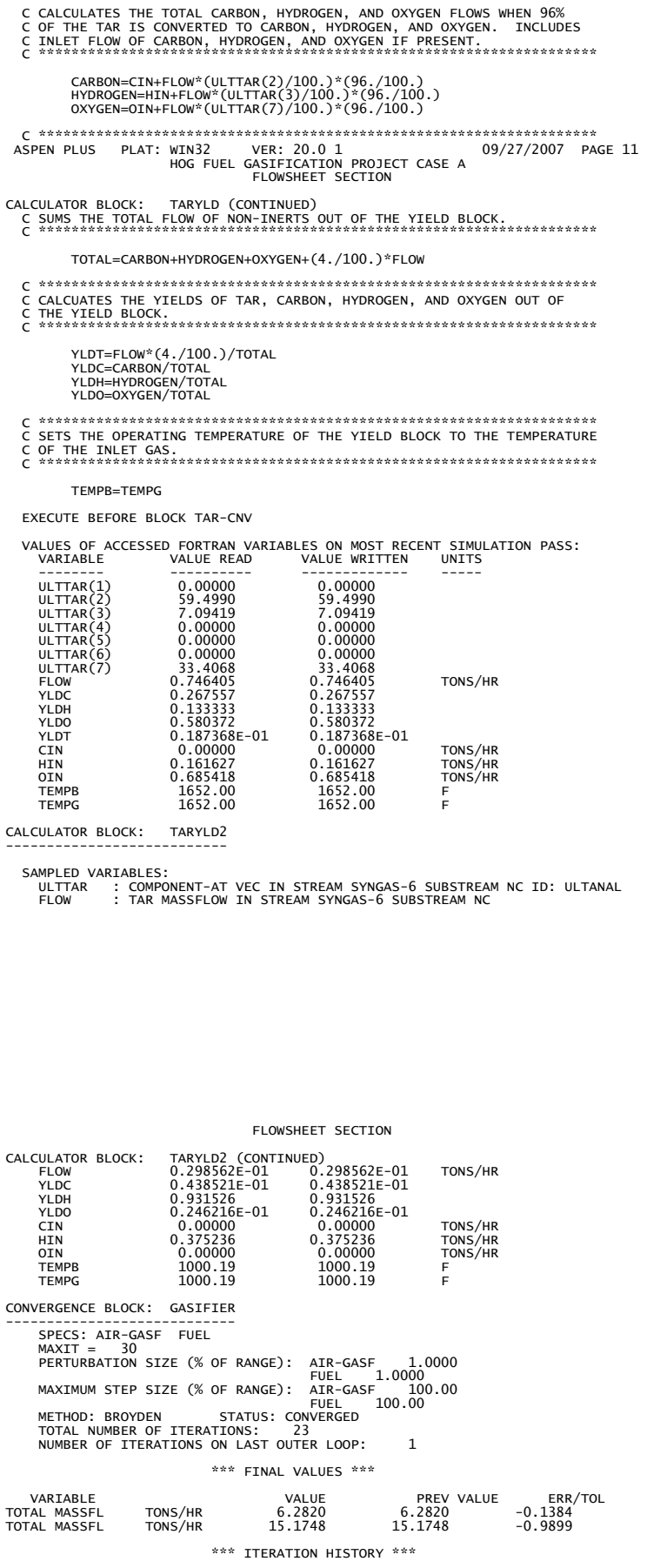

DESIGN-SPEC ID: AIR-GASF

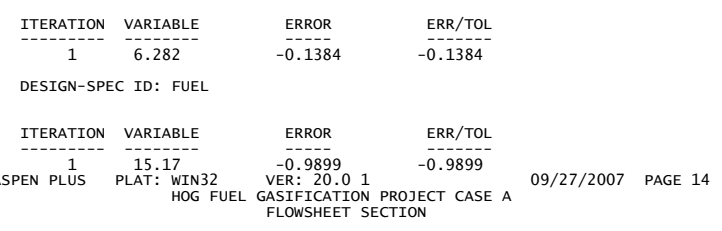

CONVERGENCE BLOCK: SOLVER01

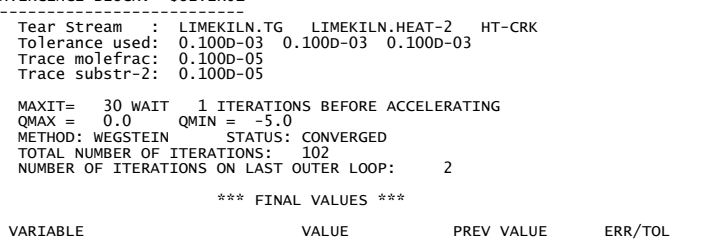




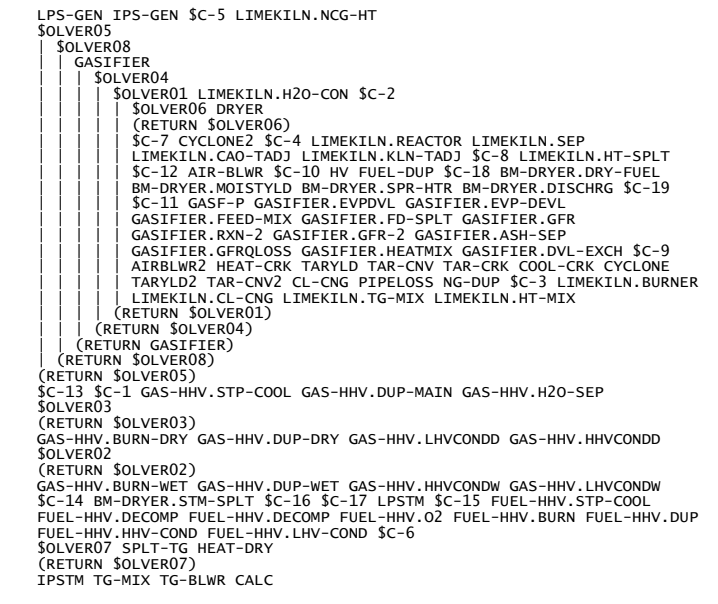

OVERALL FLOWSHEET BALANCE
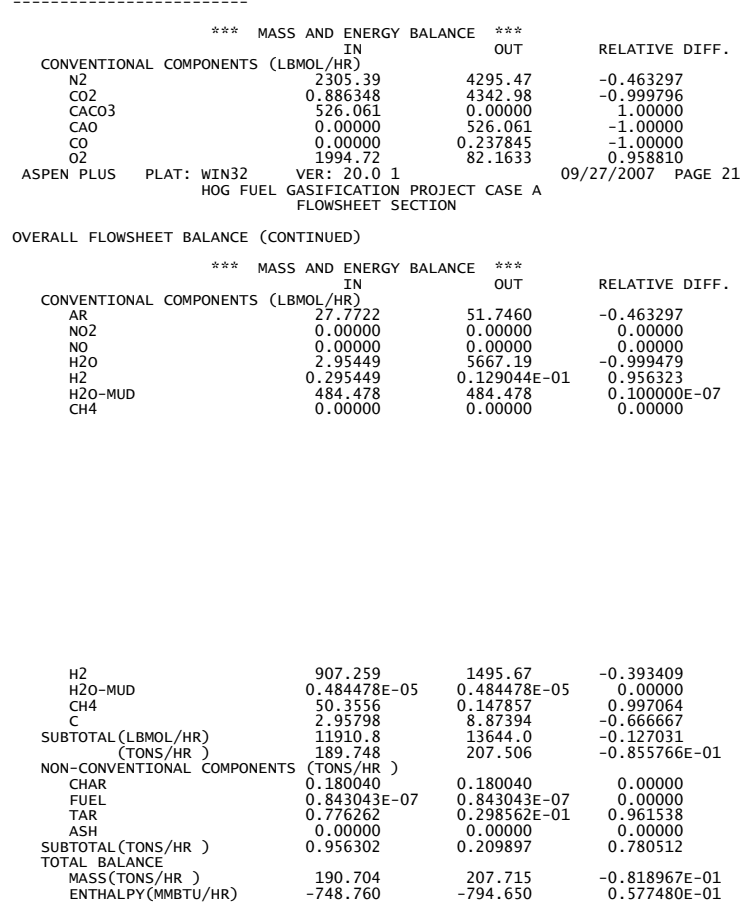
FLOWSHEET SECTION BALANCE: KILN

$\begin{array}{cccc}\text { ASPEN PLUS PLAT: WIN32 } & \text { VER: } 20.01 & 1 \\ \text { HOG FUEL GASTICATION PROJECT CASE A } & \text { 09/27/2007 PAGE } 23 \\ \text { FLOWSHEET SECTION } & & \end{array}$ FLowsheet SECtion baLANCE: KiLn (CONTINUed)

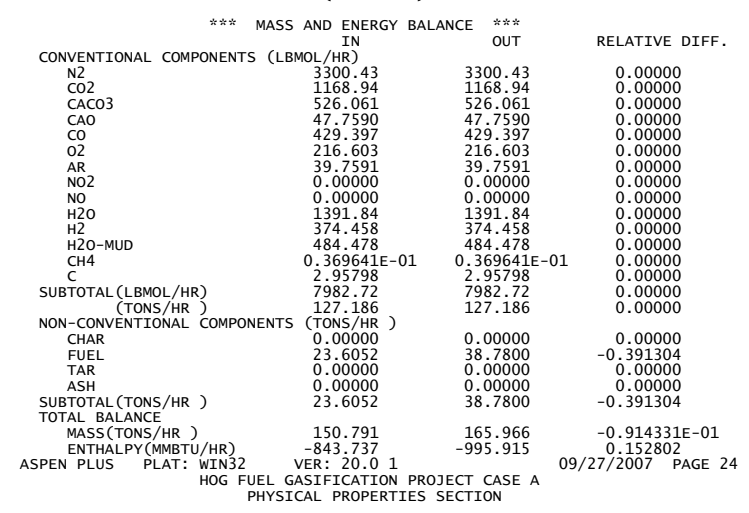

COMPONENTS

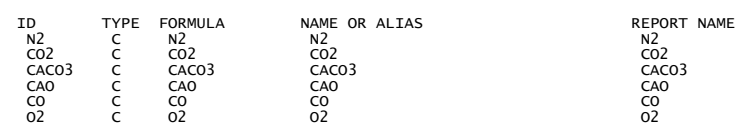

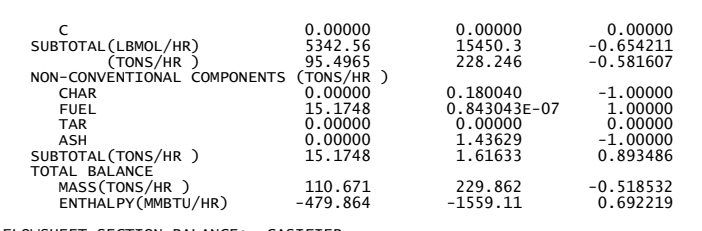

FLOWSHEET SECTION BALANCE: GASIFIER

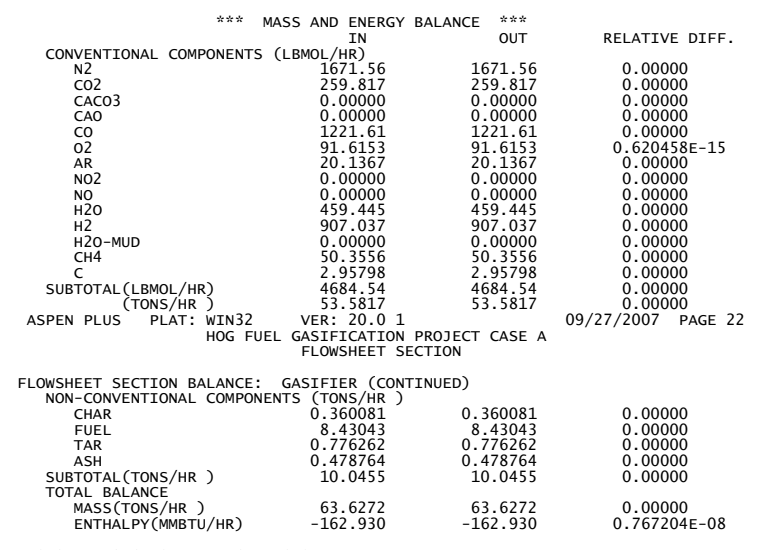

FLOWSHEET SECTION BALANCE: GLOBAL
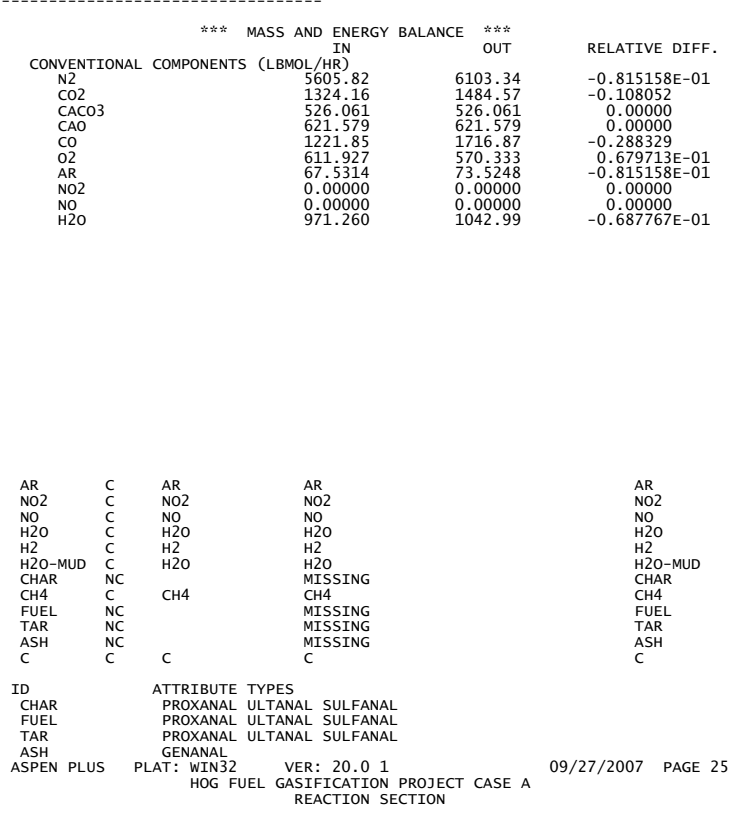

REACTION: CHAR1 TYPE: USER

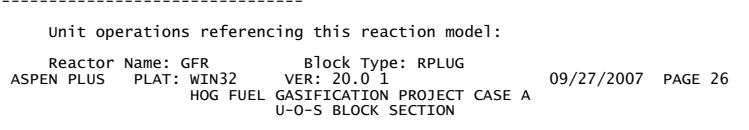

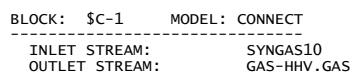

BLOCK: \$C-10 MODEL: CONNECT

$\begin{array}{ll}\text { INLET STREAM: } & \text { AIR-2 } \\ \text { OUTLET STREAM: } & \text { GASIFIER.AIR }\end{array}$

BLOCK: \$C-11 MODEL: CONNECT

$\begin{array}{ll}\text { INET STEAM: } & \text { DRY-BIOM } \\ \text { OUTLET STREAM: } & \text { GASIFIER. BIOMASS }\end{array}$

BLOCK: \$C-12 MODEL: CONNECT

$\begin{array}{ll} & \text { LIMLET STREM: } \\ \text { OUTLET STREAM: } & \text { TAR-HEAT }\end{array}$

BLOCK: \$C-13 MODEL: CONNECT

INLET STREAM:
OUTLET STREAM:

BLOCK: \$C-14 MODEL: CONNECT

$\begin{array}{ll}\text { INLET STREAM: } & \text { BM-DRYER. HEAT-DRY } \\ \text { OUTLET STREAM: } & \text { HEAT-DRY }\end{array}$

BLOCK: \$C-15 MODEL: CONNECT

INLET STREAM:
OUTLET STREAM: 

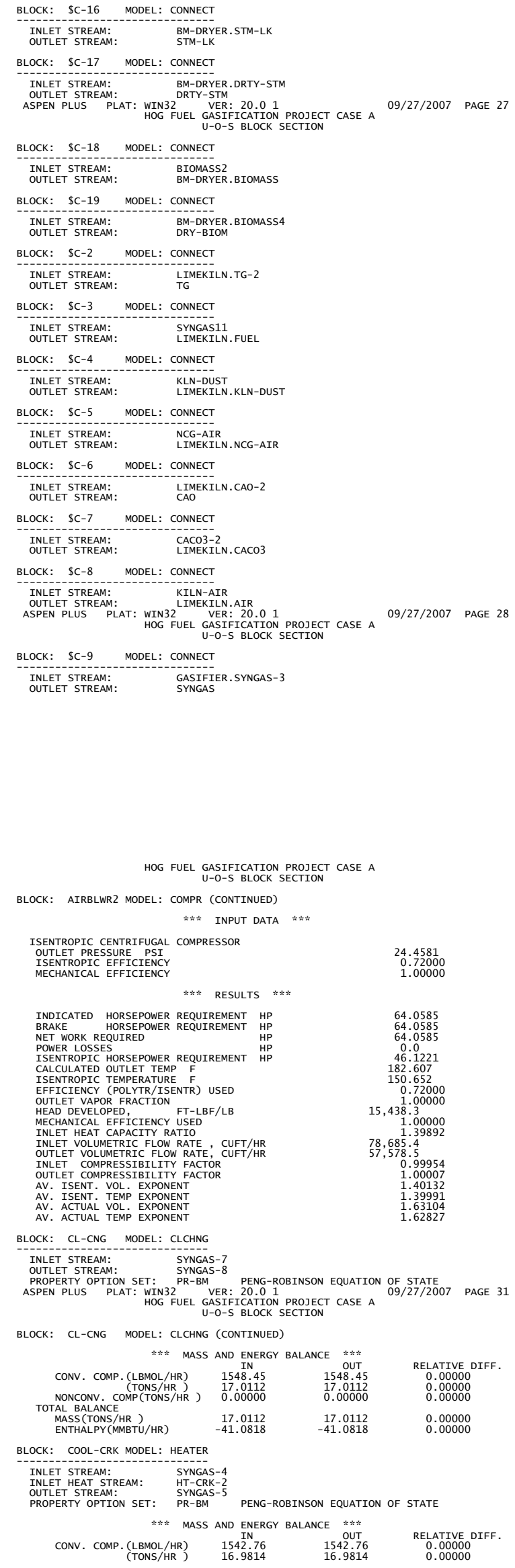

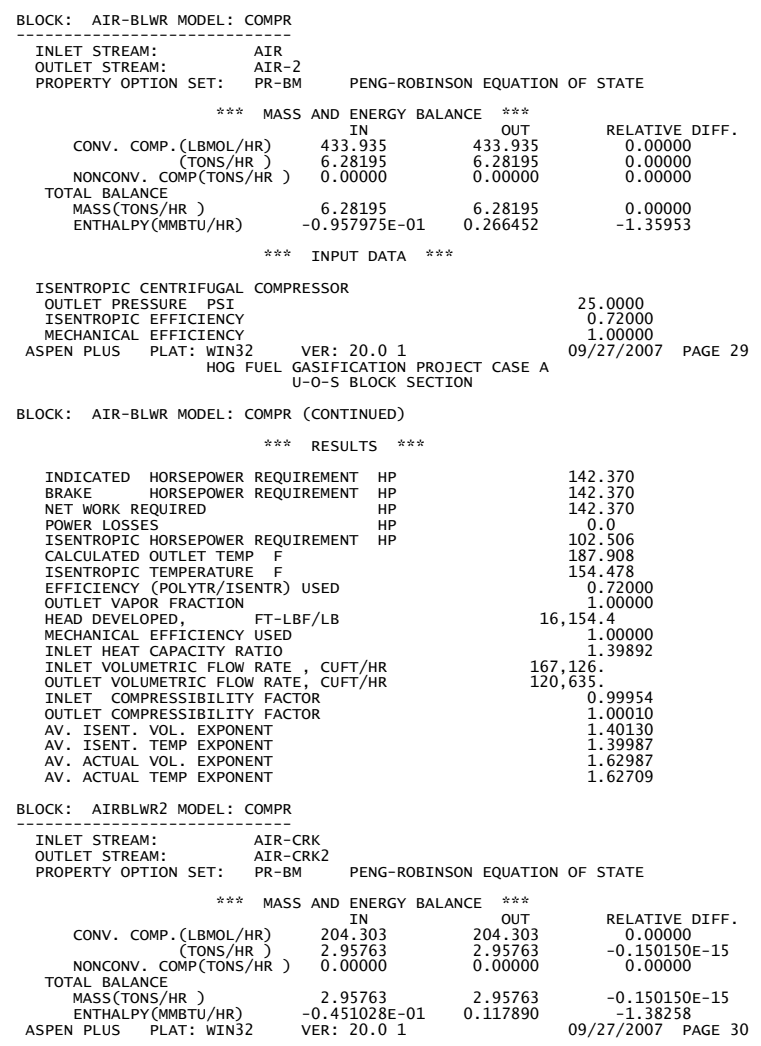

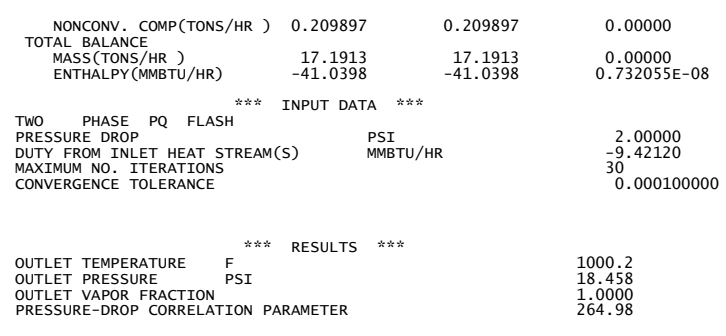

$\begin{array}{llll}\text { ASPEN PLUS PLAT: WIN32 } & \text { VER: } 20.01 & 1 \\ \text { HOG FUEL GASIFICATION PROJECT CASE A } & \text { 09/27/2007 PAGE } 32 \\ \text { U-O-S BLOCK SECTION } & & \end{array}$ BLOCK: COOL-CRK MODEL: HEATER (CONTINUED)

V-L PHASE EQUILIBRIUM :

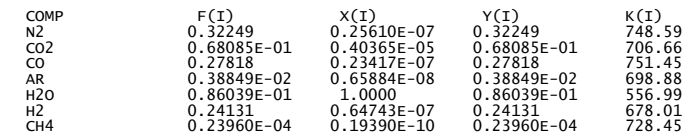

BLOCK: CYCLONE MODEL: SEP

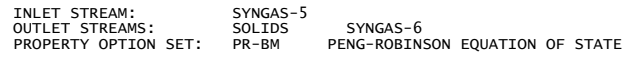

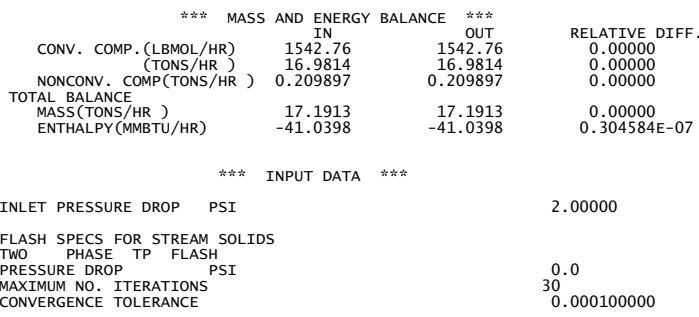

FLASH SPECS FOR STREAM SYNGAS- 6
TWO PHASE TP FLASH 

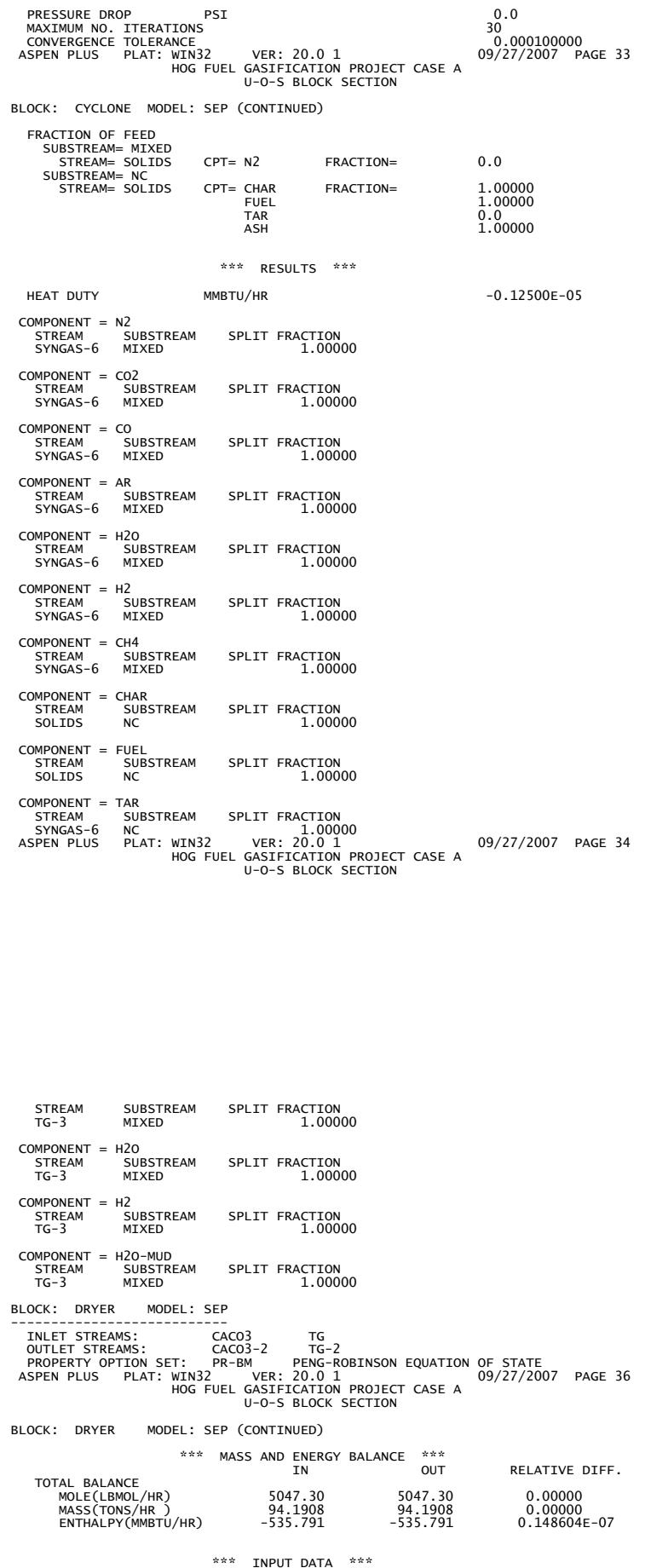

INLET PRESSURE: MINIMUM OF INLET STREAM PRESSURES

FLASH SPECS FOR STREAM CACO3-2

\begin{tabular}{|c|c|c|c|}
\hline $\begin{array}{l}\text { TWO PHASE TP FL F } \\
\text { SPECIFIED TEMPERATUR } \\
\text { PRESSURE DROP } \\
\text { MAXIMUM NO. ITERATIO } \\
\text { CONVERGENCE TOLERANC }\end{array}$ & $\begin{array}{l}\text { ASH } \\
\text { F } \\
\text { NSSI } \\
\text { PS }\end{array}$ & & $\begin{array}{l}635.000 \\
0.0 \\
30 \\
0.000100000\end{array}$ \\
\hline $\begin{array}{l}\text { FLASH SPECS FOR STRE } \\
\text { TWO PHASE TP FL FIF } \\
\text { SPECIFIED TEMPERATUR } \\
\text { PRESSURE DROP } \\
\text { MAXIMUM NO. ITERATIO } \\
\text { CONVERGENCE TOLERANC }\end{array}$ & $\begin{array}{l}\text { AM TG-2 } \\
\text { ASH } \\
\text { E F } \\
\text { PSI } \\
\text { NS } \\
\text { E }\end{array}$ & & $\begin{array}{l}798.922 \\
0.0 \\
30 \\
0.000100000\end{array}$ \\
\hline $\begin{array}{l}\text { FRACTION OF FEED } \\
\text { SUBSTREAM = MIXED } \\
\text { STREAM= CACO3-2 }\end{array}$ & $C P T=H 2 O-M U D$ & FRACTION= & $0.100000-07$ \\
\hline $\begin{array}{l}\text { SUBSTREAM }=\text { CACO3 }-2 \\
\text { STREAM }\end{array}$ & $\mathrm{CPT}=\underset{\mathrm{CAO}}{\mathrm{CACO3}}$ & FRACTION= & $\begin{array}{l}1.00000 \\
0.0\end{array}$ \\
\hline & ***: RESULTS & $* * * *$ & \\
\hline HEAT DUTY & MMBTU/HR & & $-0.79621 \mathrm{E}-05$ \\
\hline
\end{tabular}

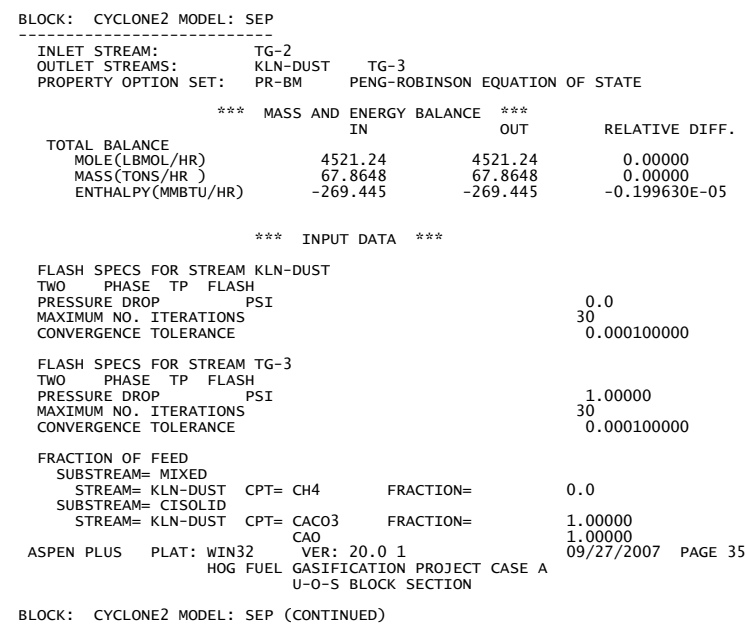

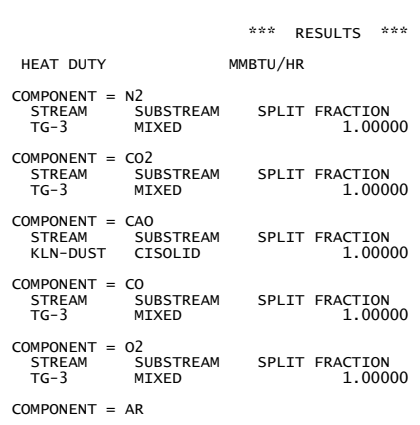

$0.53789 \mathrm{E}-03$

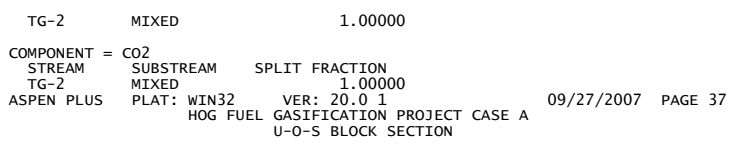
BLOCK: DRYER MODEL: SEP (CONTINUED)

COMPONENT $=$ CACO3

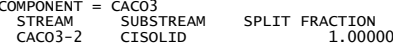

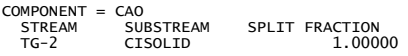

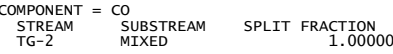

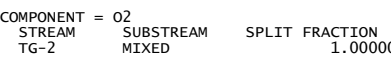

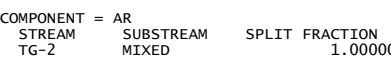

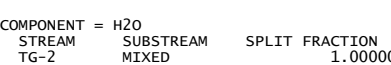

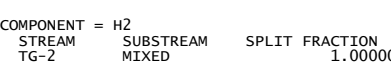

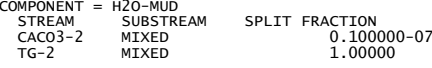

BLOCK: FUEL-DUP MODEL: DUPL

$\begin{array}{ll} & \\ \text { INLET STREAM: } & \text { BIOMASS } \\ \text { OUTLET STREAMS: } & \text { BIOMASS2 }\end{array}$

BLOCK: HEAT-CRK MODEL: HEATER

$\begin{array}{lll}\text { INLET STREAMS: } & \text { SYNGAS } & \text { AIR-CRK2 } \\ & \end{array}$

$\begin{array}{ll}\text { OUTLET STREAM: } & \text { SYNGAS-2 } \\ \text { OUTLET HEAT STREAM: } & \text { HT-CRK-2 } \\ \text { PROPRTY OPTION SEE } & \text { PR-BM }\end{array}$

PROPERTY OPTION SET: PR-BM
ASPEN PLUS PLAT: WIN32 HOG FUEL GASIFICATION PROJECT CASE A
U-O-S BLOCK SECTION

BLOCK: HEAT-CRK MODEL: HEATER (CONTINUED)

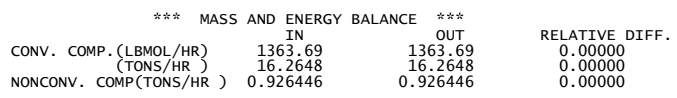




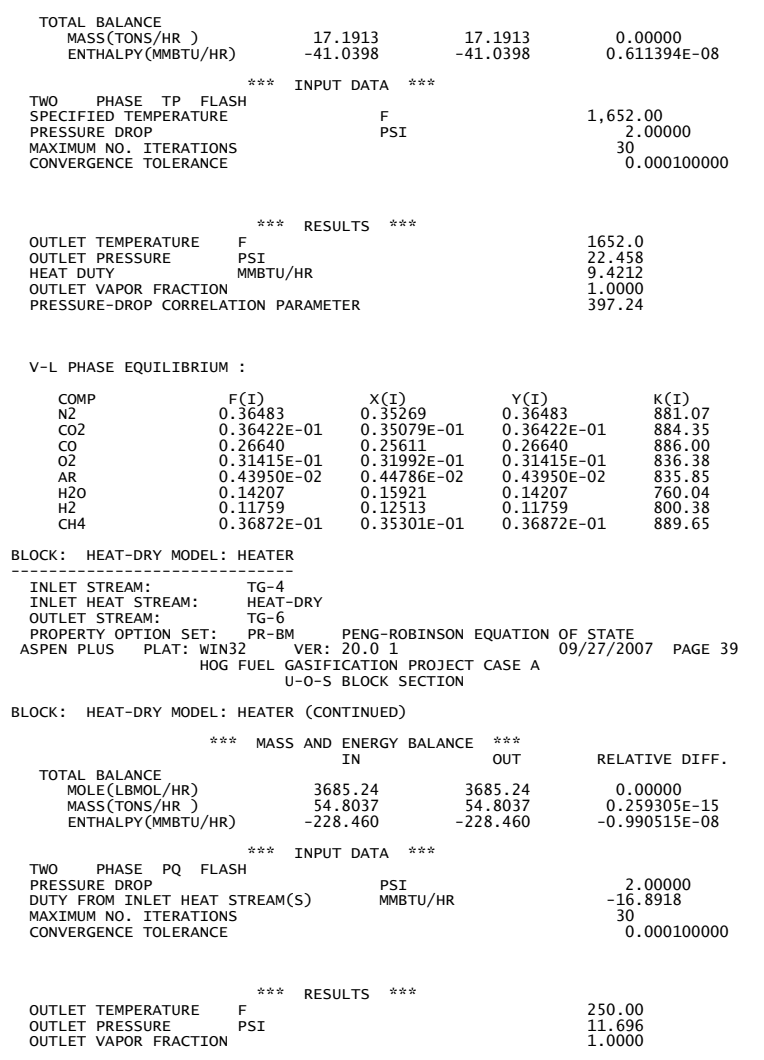

PRESSURE-DROP CORRELATION PARAMETER

42.091

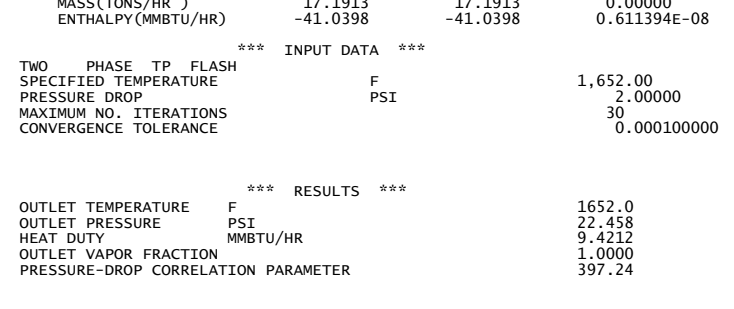

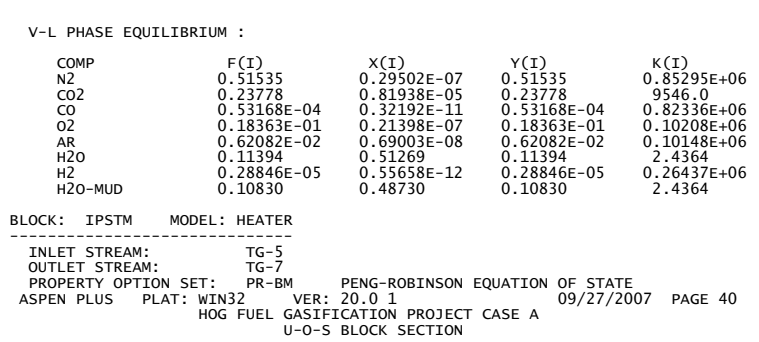

BLOCK: IPSTM MODEL: HEATER (CONTINUED)
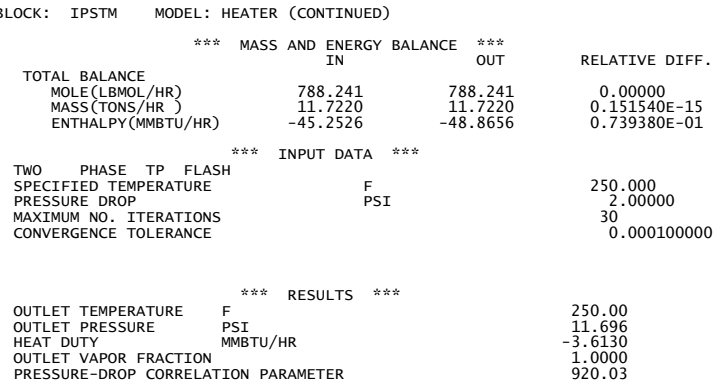

V-L PHASE EQUILIBRIUM :
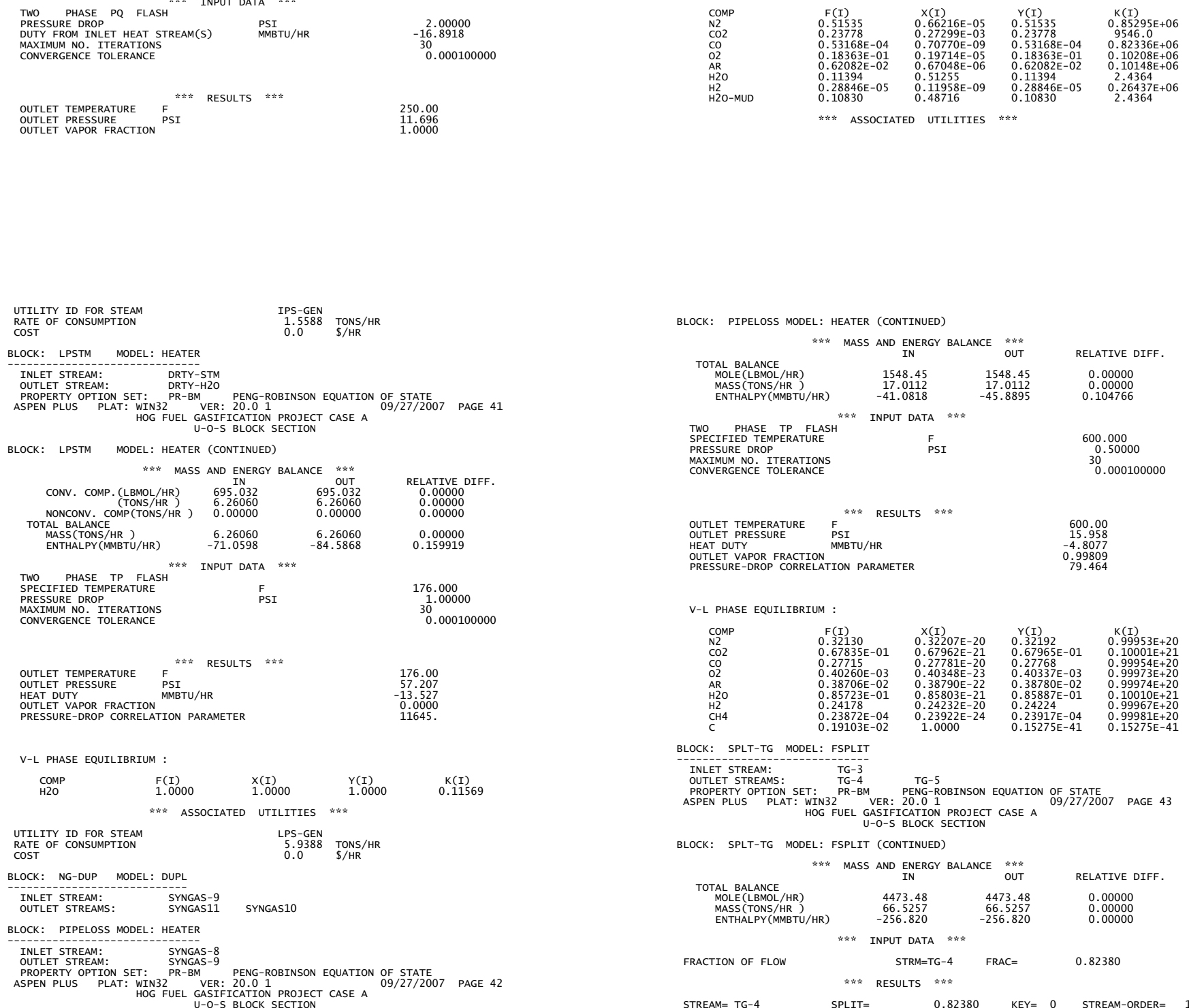


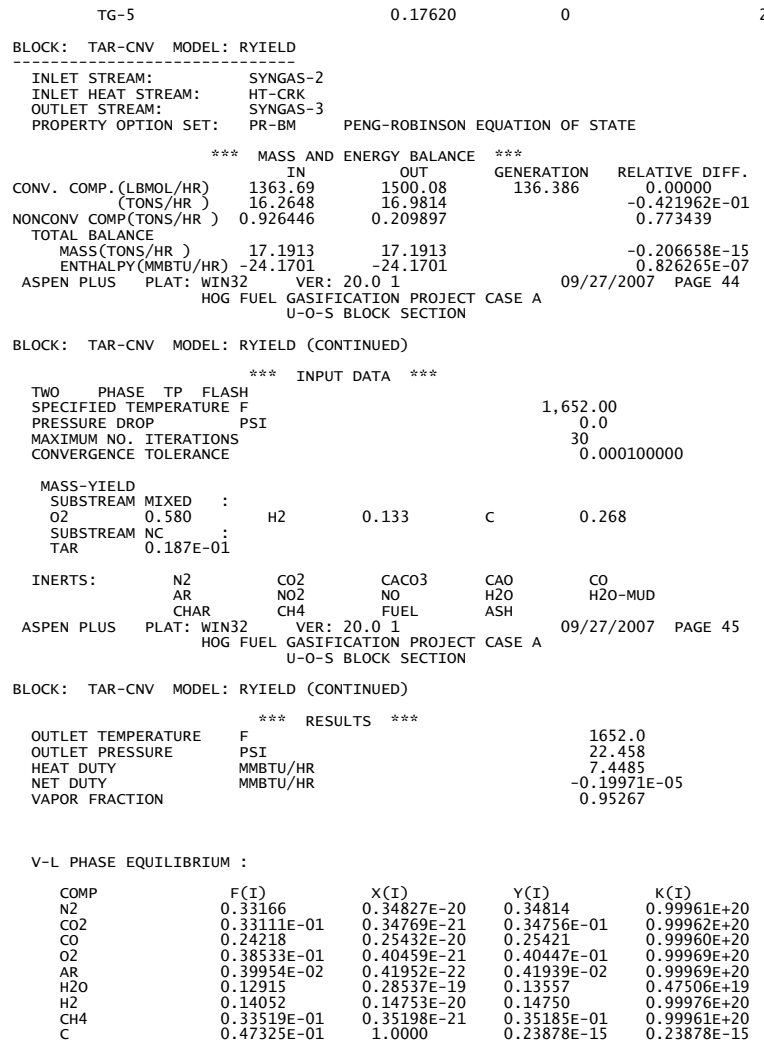

$\begin{array}{ll}\text { INLET STREAM: } & \text { SYNGAS-3 } \\ \text { OUTLET STREAM: } & \text { SYNGAS-4 }\end{array}$

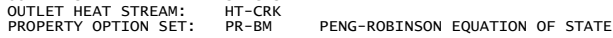
*** MASS AND ENERGY BALANCE ***

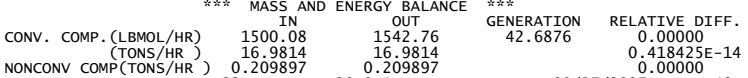

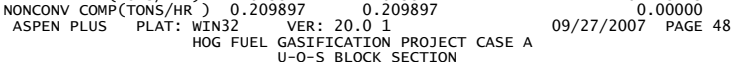
BLOCK: TAR-CRK MODEL: RGIBBS (CONTINUED)
TOTAL BALANEE
$\begin{array}{lrrr}\text { MASS (TONS/HR) } & 17.1913 & 17.1913 & 0.413316 \mathrm{E}-14 \\ \text { ENTHALPY(MMBTU/HR) } & -24.1701 & -24.1701 & 0.146988 \mathrm{E}-15\end{array}$

$$
* * * \text { INPUT DATA } * \ldots *
$$

EQUILIBRIUM SPECIFICATIONS:
ONLY CHEMICL EQULIBRIUM IS CONSIDERED, THE FLUID PHASE IS VAPOR
SYSTEM TEMPERATURE
TEMERATURE FOR FREE ENERGY EVALUATION F
SYSTEM PRESSURE DROP PSI

FLUID PHASE SPECIES IN PRODUCT LIST:
N2 CO2 CO 02 AR H2O H2 CH4 C

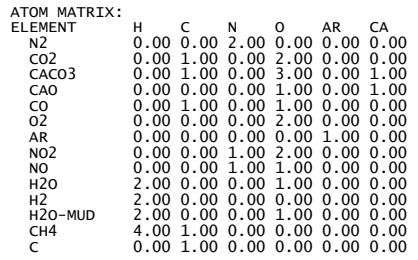

$\begin{array}{ccc}\text { PRODUCT SPECIFICATIONS: } & \\ \text { N2 } & 1.0000 & \text { FRACTION OF FEED } \\ \text { AR } & 1.0000 & \text { FRACTION OF FEED }\end{array}$

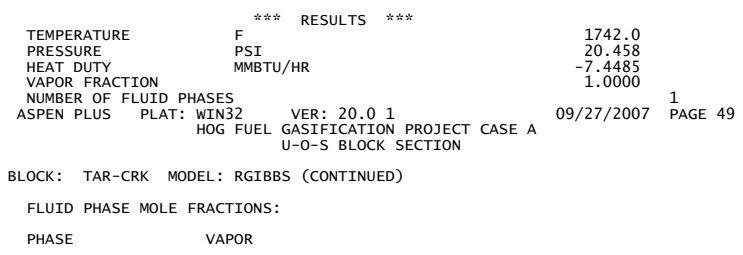

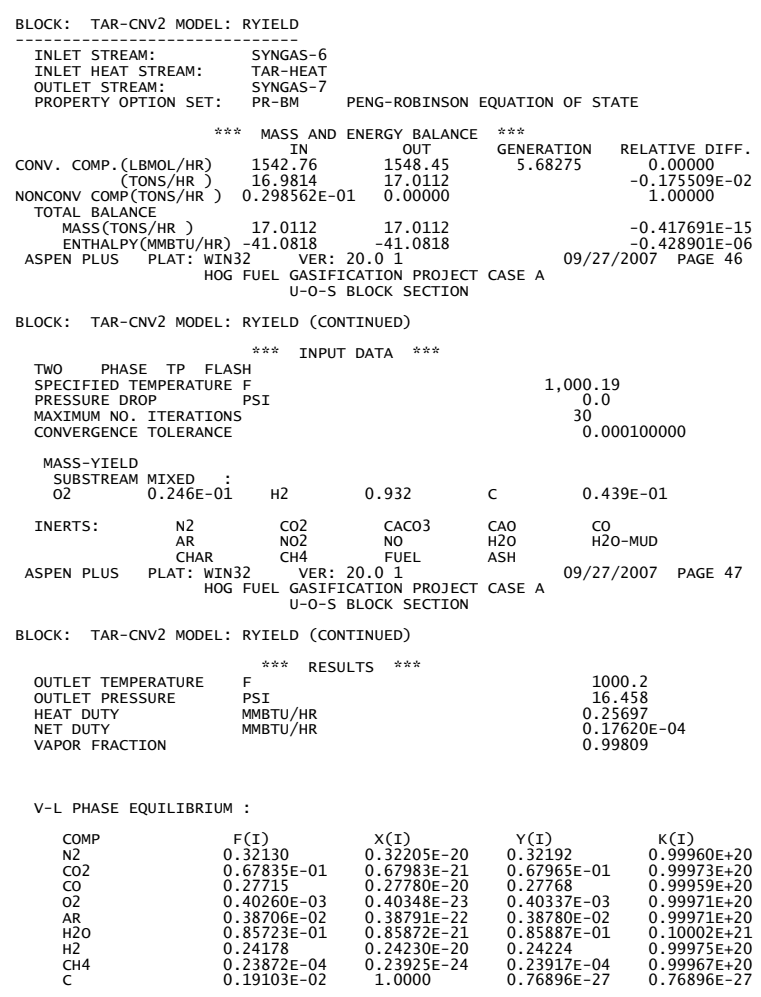

BLOCK: TAR-CRK MODEL: RGIBBS
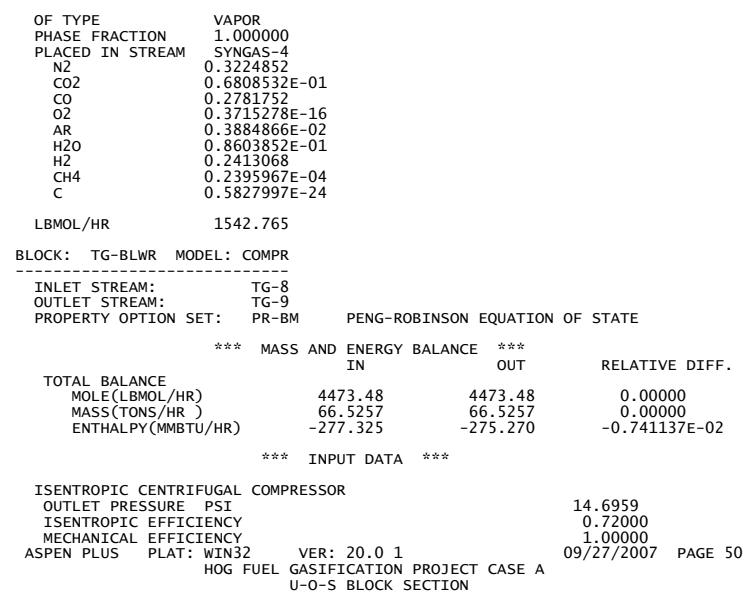

BLOCK: TG-BLWR MODEL: COMPR (CONTINUED)

$$
\text { \#\#* RESULTS *\#* }
$$

$\begin{array}{lll}\text { INDICATED HORSEPOWER REQUIREMENT } & \text { HP } \\ \text { BRAKE } & \text { HORSEPOWER REQUIREMENT HPP }\end{array}$

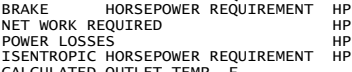

ISENTROPIC TEMPERATURE

EFFICIENCY (POLYTR/ISENTR) USED

HEAD DEVELOPED, FT-LBF/LB

MECHANICAL EFFICIENCY USED

INLET VOLUMETRIC FLOW RATIO

INLET COMPRESSIBILITY FACTOR
OUTLET COMPRESSIBILITY FACTOR

AV. ISENT. VOL. EXPONENT
AV. ISENT. TEMP. EXPONENT

AV: ACTUAL VOL. EXPONENT
AV. ACTUAL TEMP EXPONENT

BLOCK: TG-MIX MODEL: MIXER

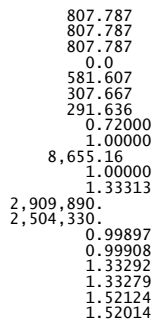

$\begin{array}{lll}\text { INLET STREAMS: } & \text { TG-7 } & \text { TG-6 }\end{array}$ 
OUTLET STREAM:
PROPERTY OPTION SET: $\begin{aligned} & \text { TG-8 } \\ & \text { PR-BM }\end{aligned}$ PENG-RobINSON Equatton OF STATE
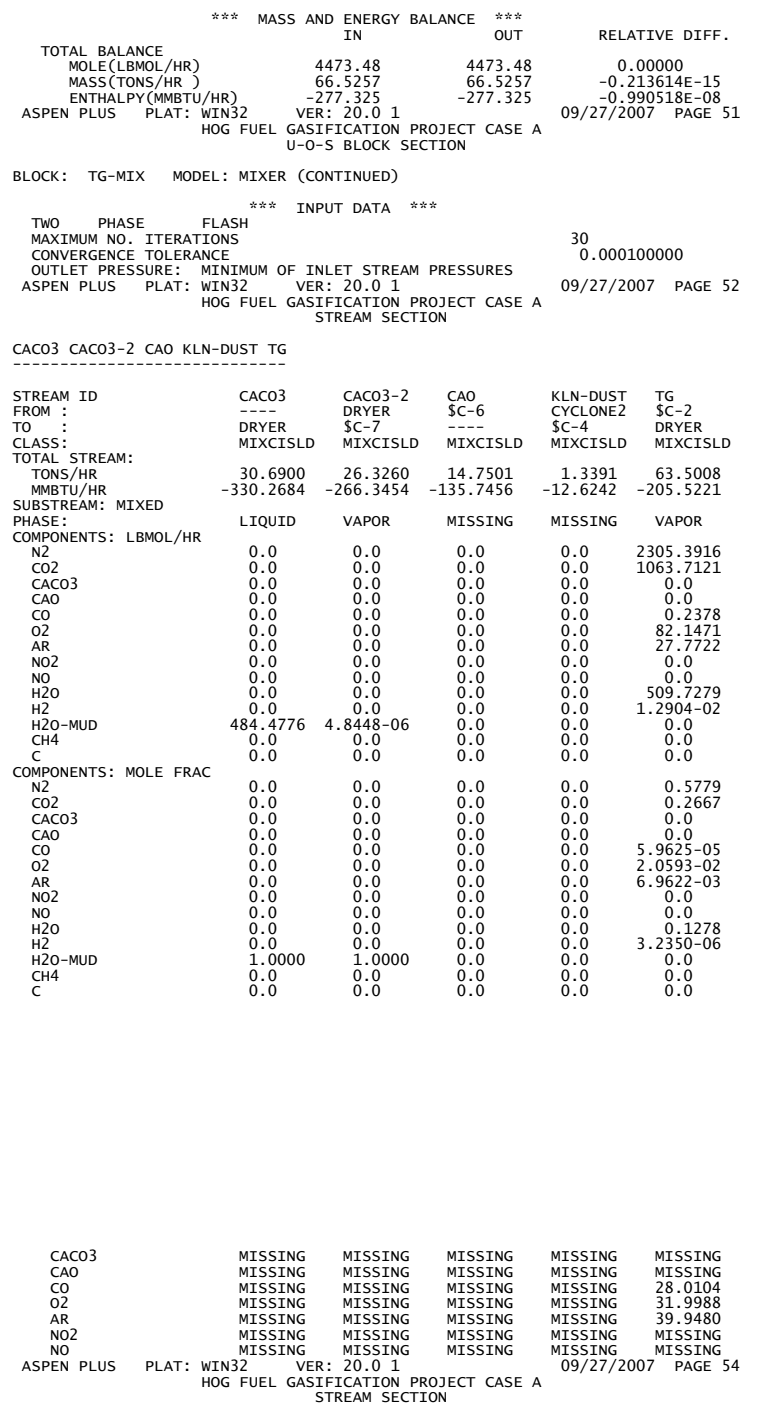

CACO3 CACO3-2 CAO KLN-DUST TG (CONTINUED)

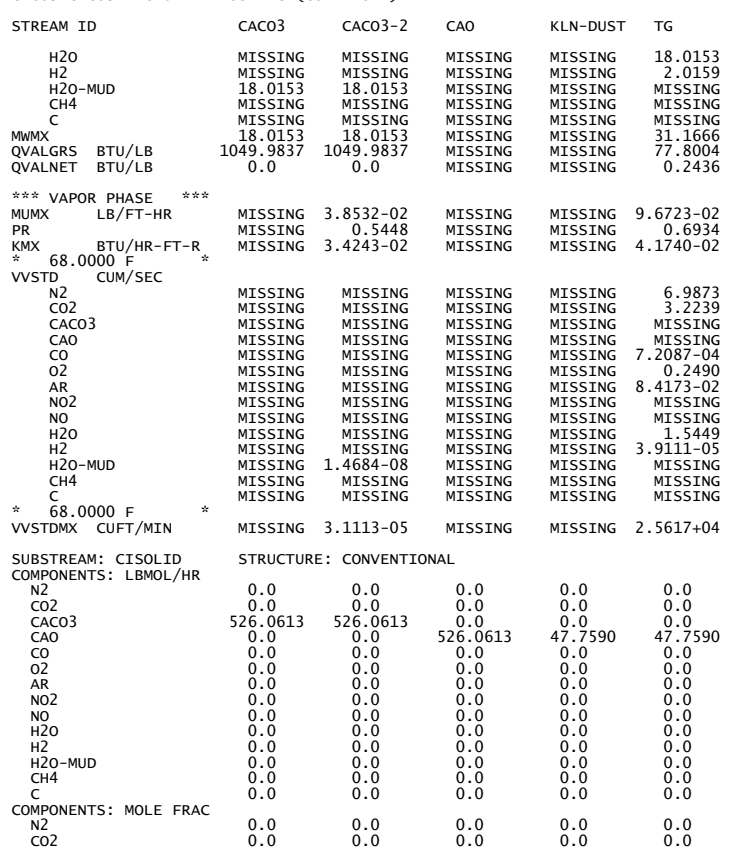

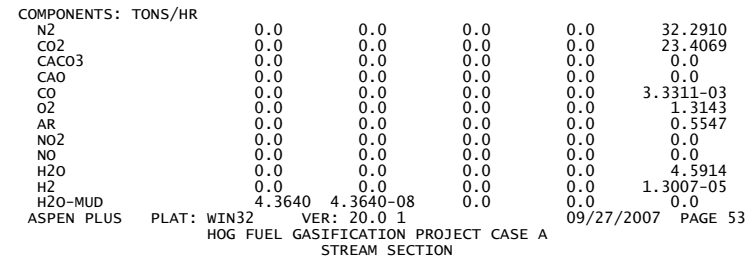

CACO3 CACO3-2 CAO KLN-DUST TG (CONTINUED)
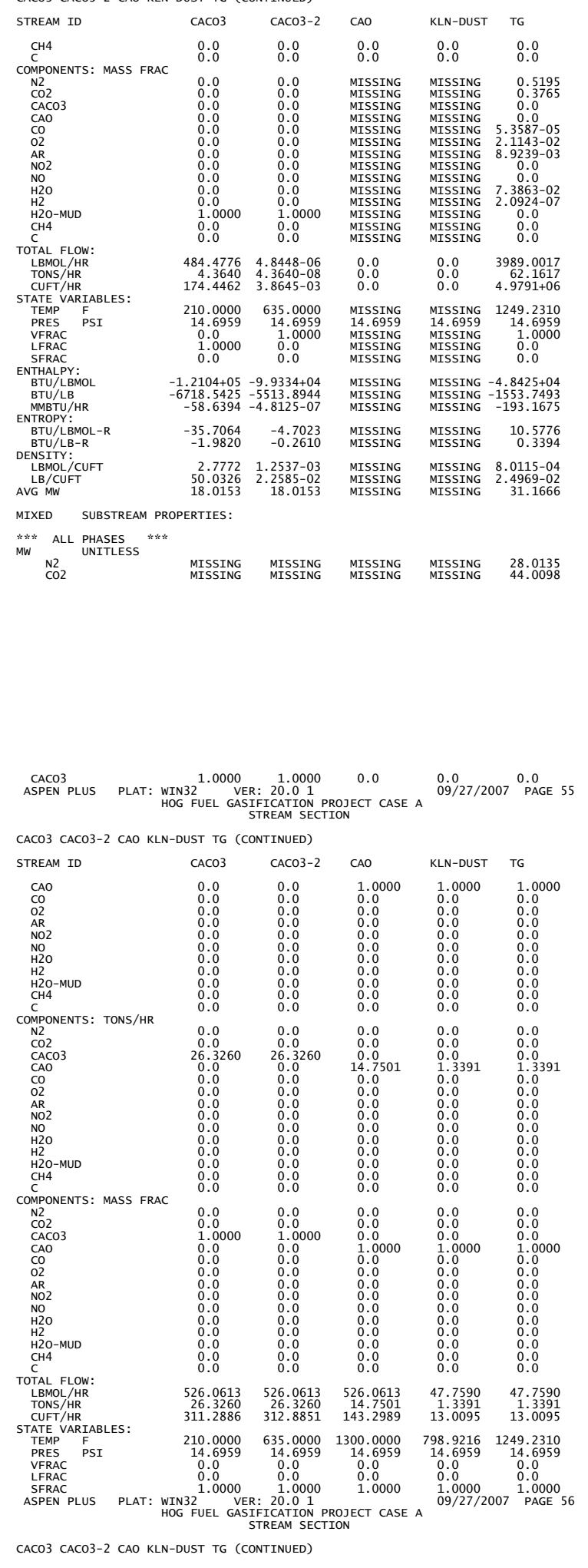


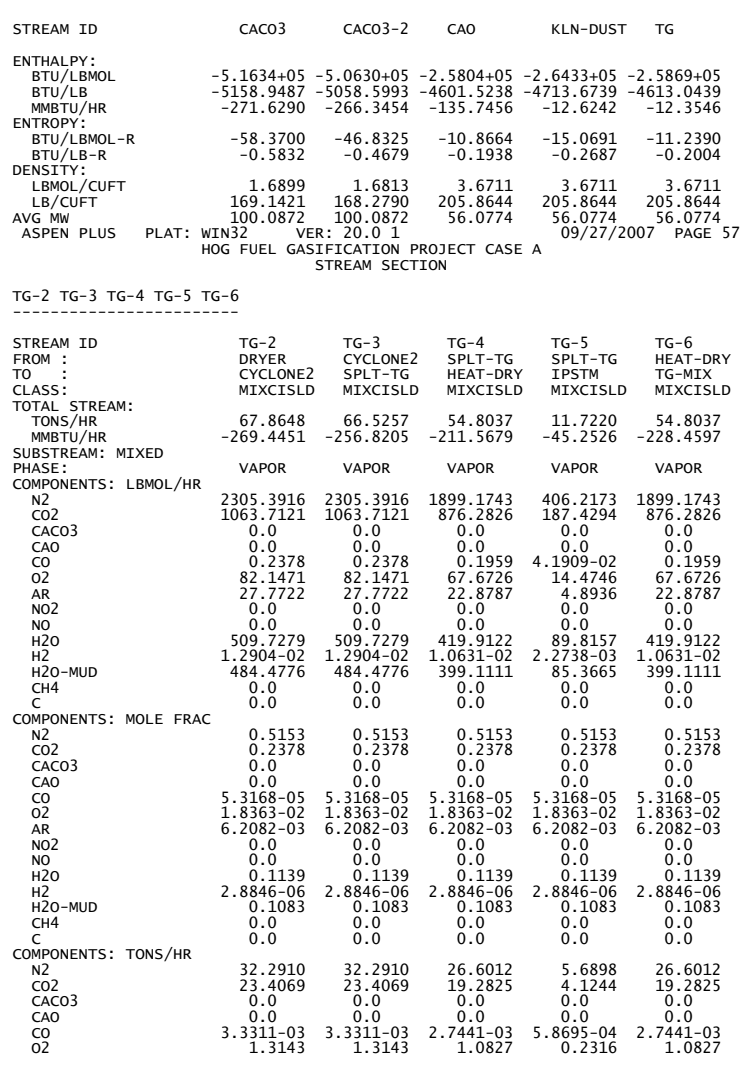

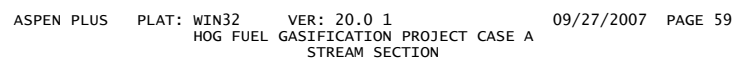
TG-2 TG-3 TG-4 TG-5 TG-6 (CONTINUED)

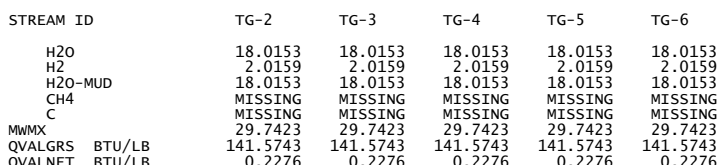

**** VAPOR PHASE ****

$\begin{array}{lllllll}\text { MUMX } & \text { LB/FT-HR } & 7.3961-02 & 7.3959-02 & 7.3959-02 & 7.3959-02 & 4.5910-02 \\ \text { PR } & \text { BTU/HR-FT-R } & 0.6571 & 0.36571 & 0.6571 & 0.6571 & 0.5648 \\ \text { KMX } & \text { BTU } & 3.3127-02 & 3.3127-02 & 3.3127-02 & 2.1718-02\end{array}$ VUSTD $68.0000 \mathrm{~F} / \mathrm{FEC}$

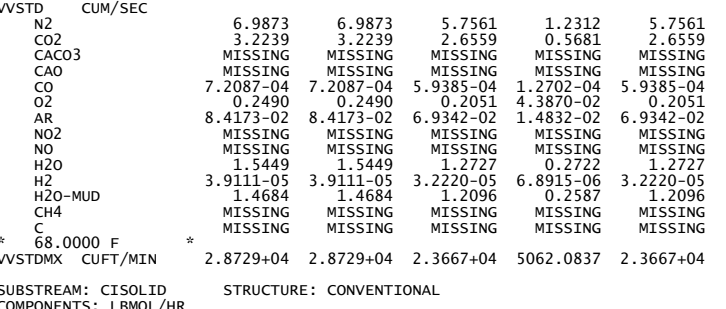

SUBSTREAM: CISOLID
COMPONENTS: LBMOL/HR

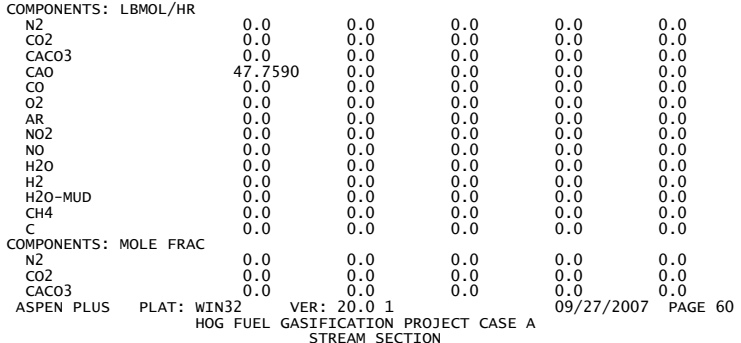

TG-2 TG-3 TG-4 TG-5 TG-6 (CONTINUED)

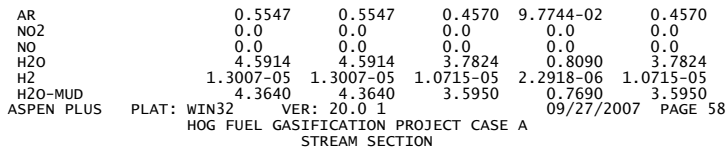

TG-2 TG-3 TG-4 TG-5 TG-6 (CONTINUED)

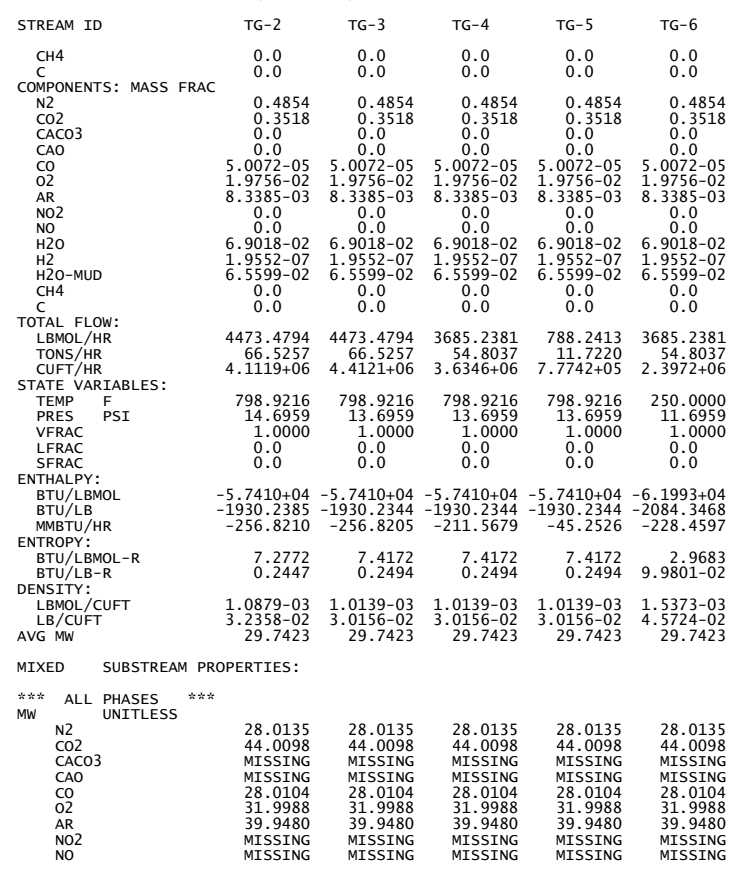

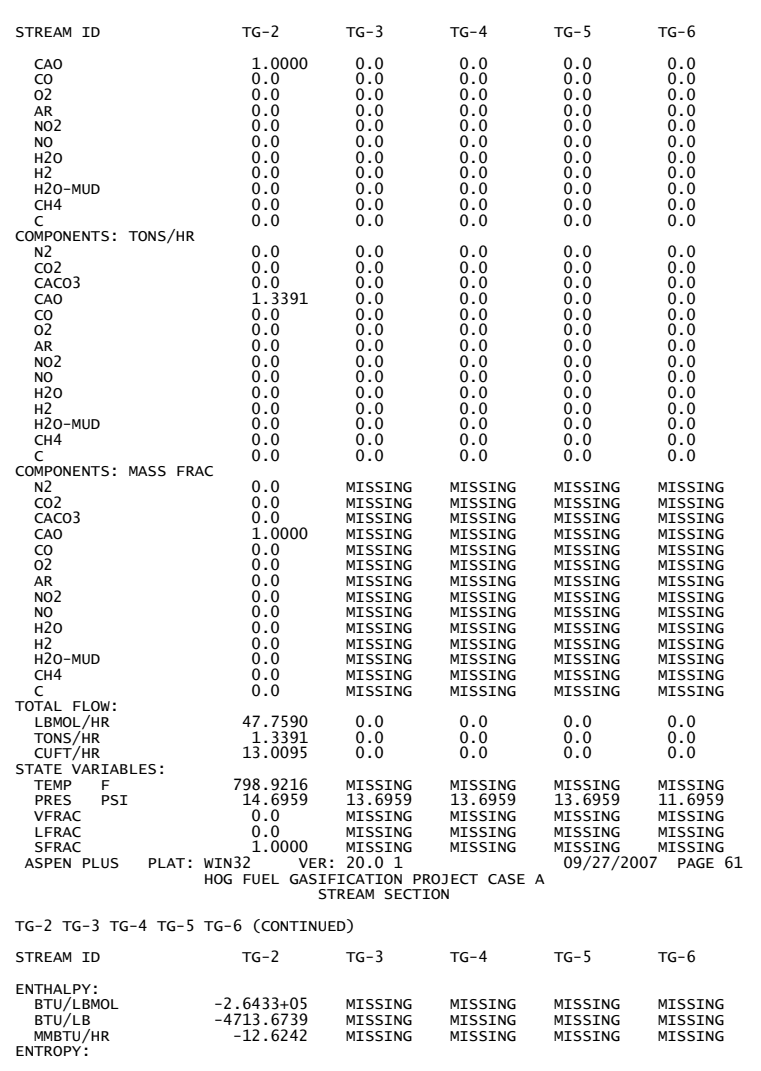




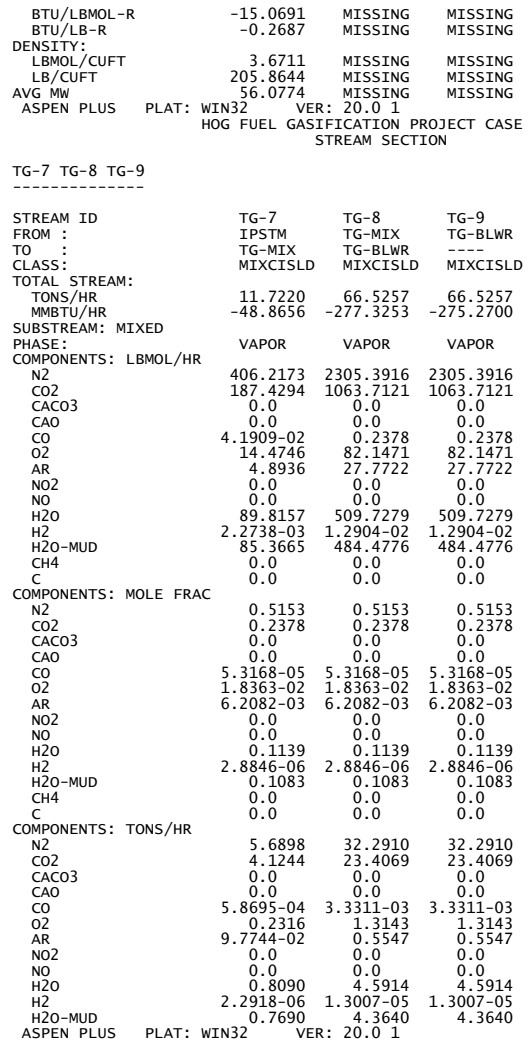

09/27/2007 PAGE 63

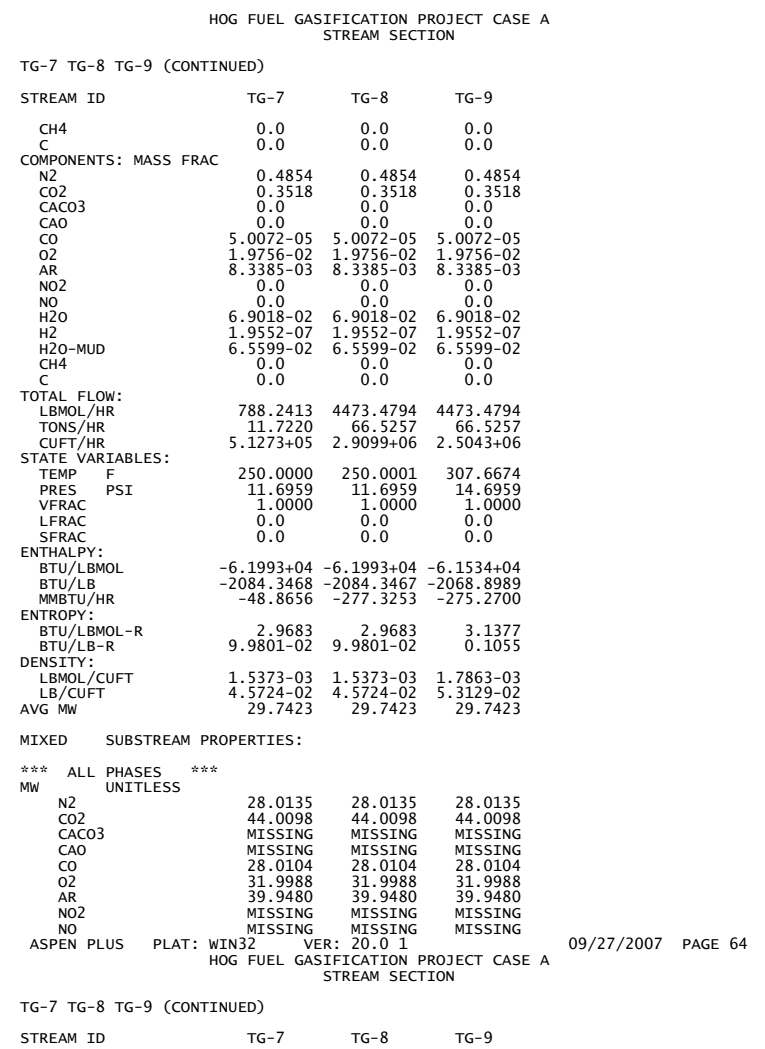

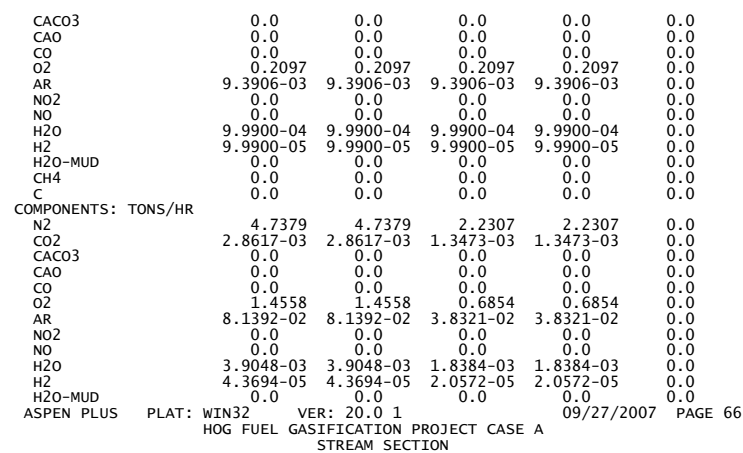

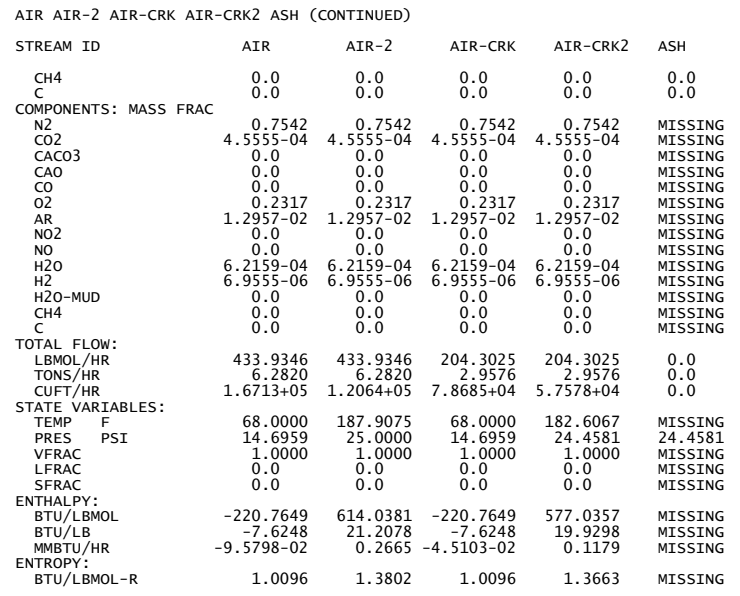



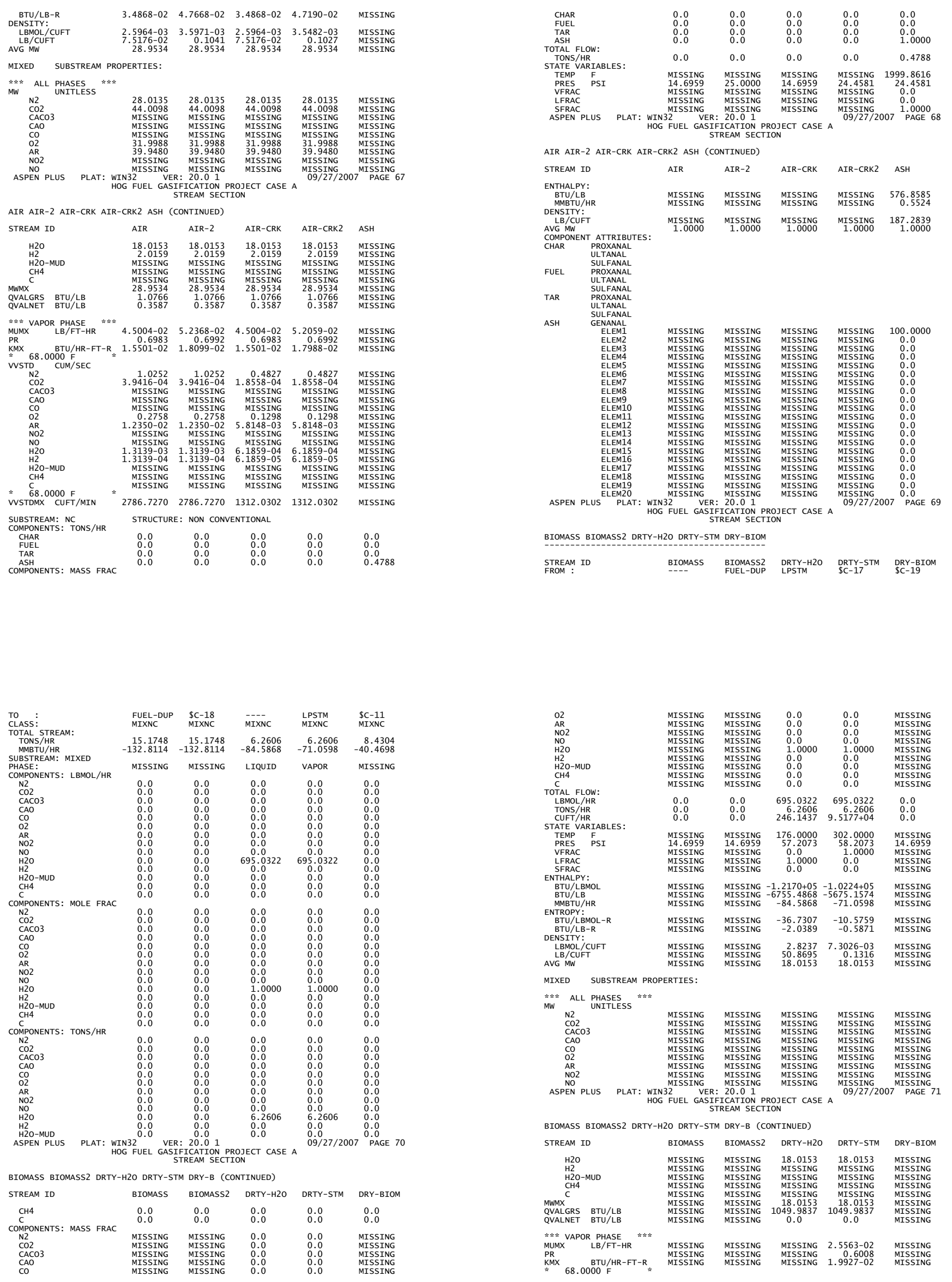

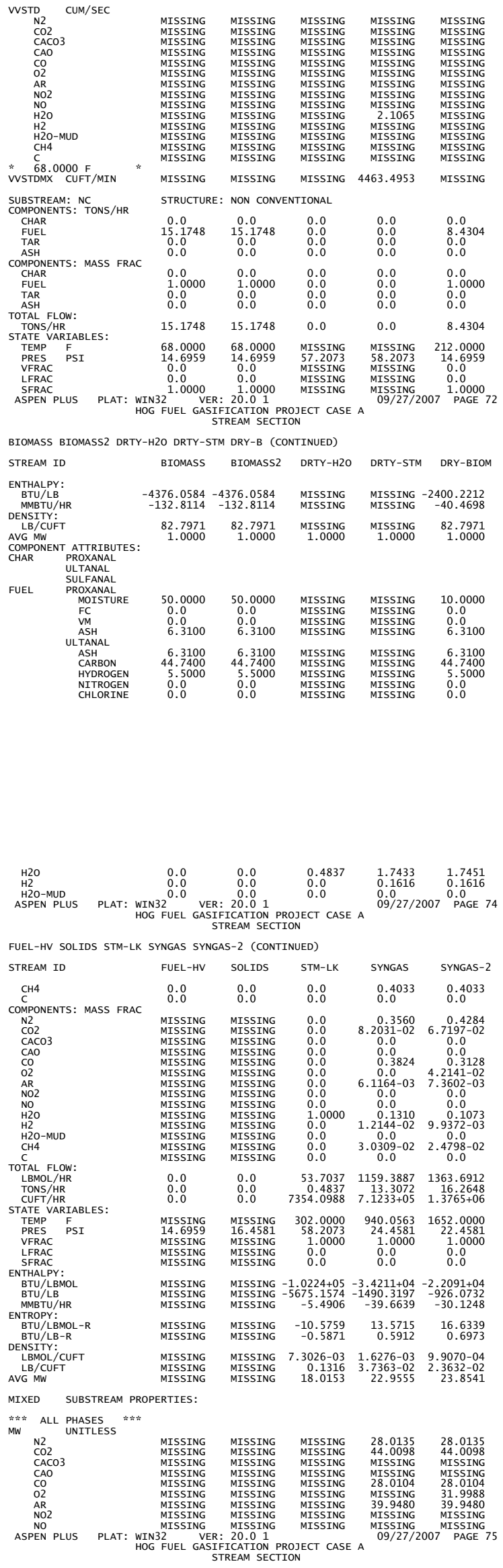

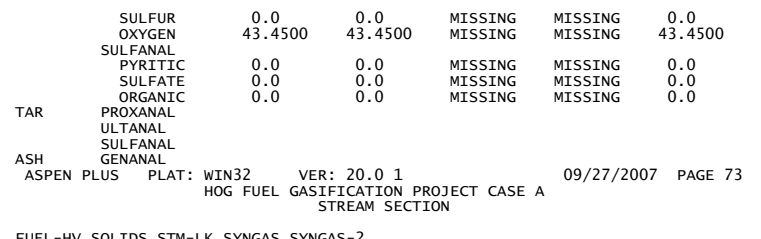

FUEL-HV SOLIDS STM-LK SYNGAS SYNGAS-2

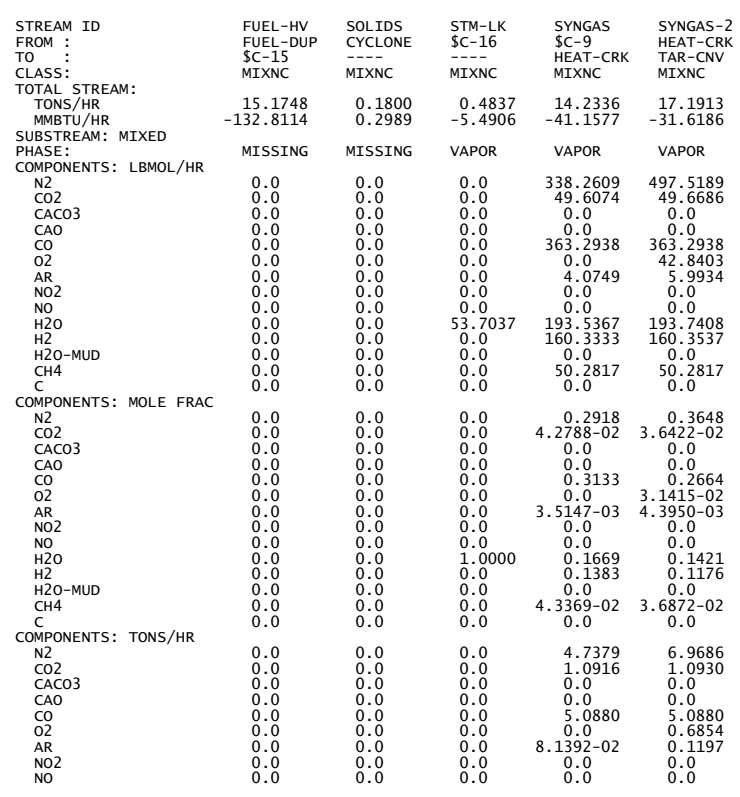



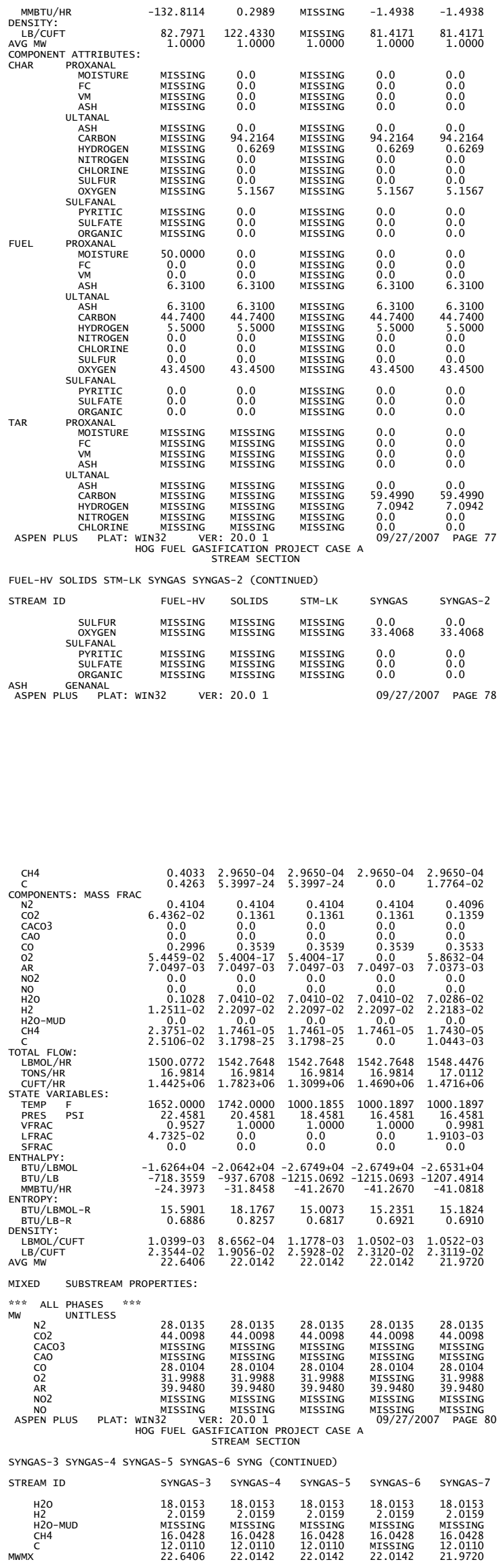

HOG FUEL GASIFICATION PROJECT CASE A
STREAM SECTION

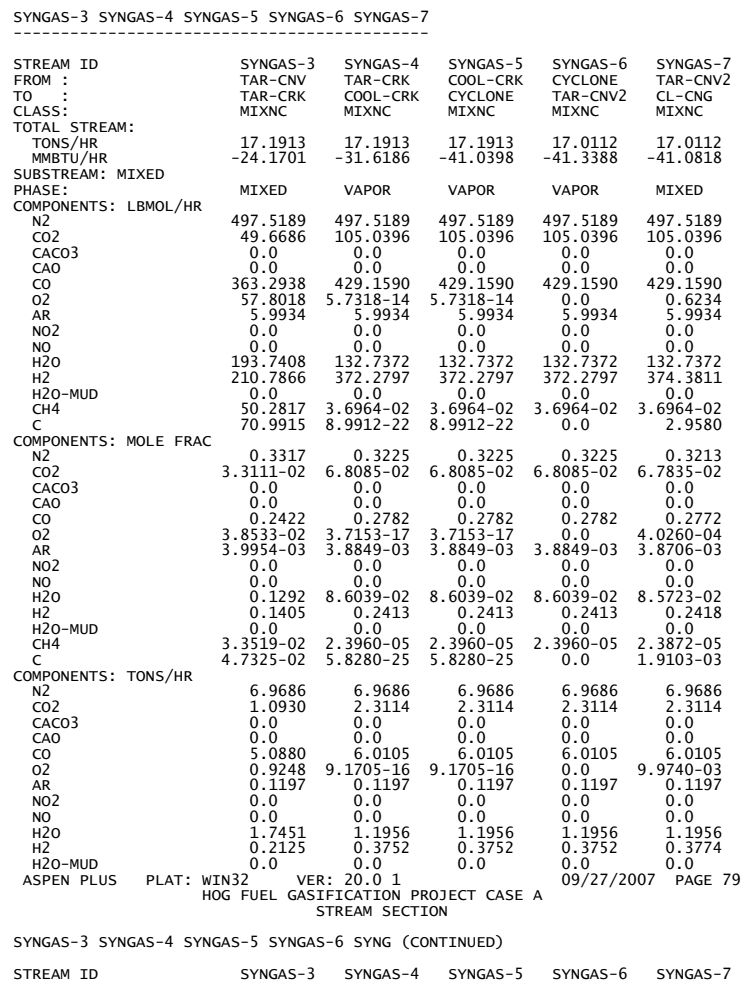

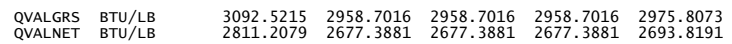

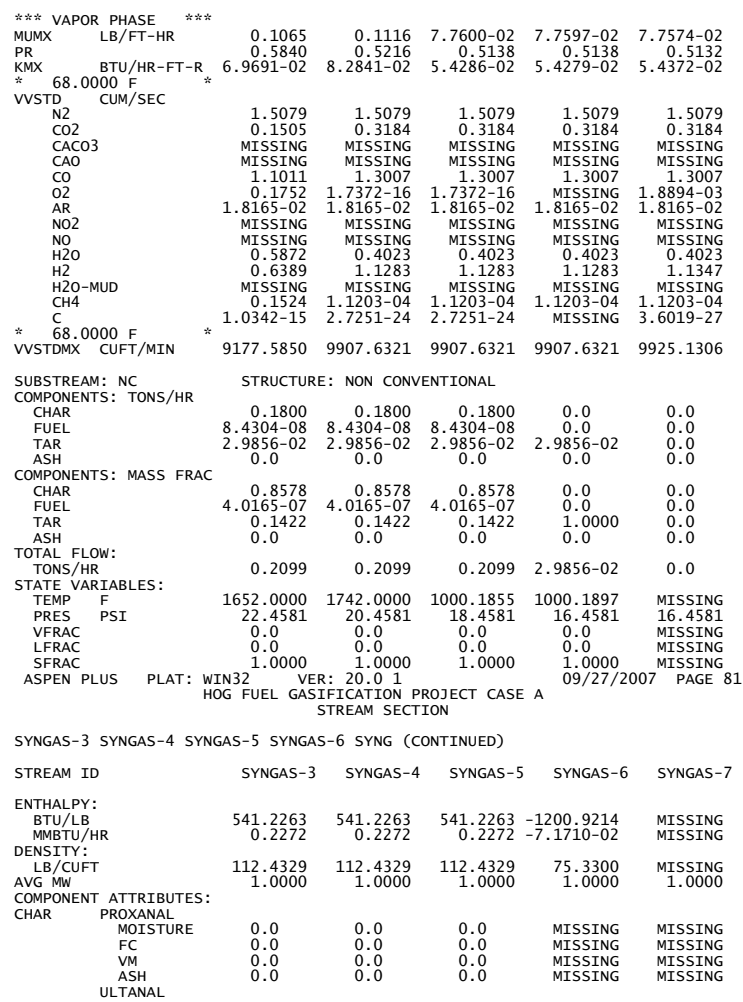




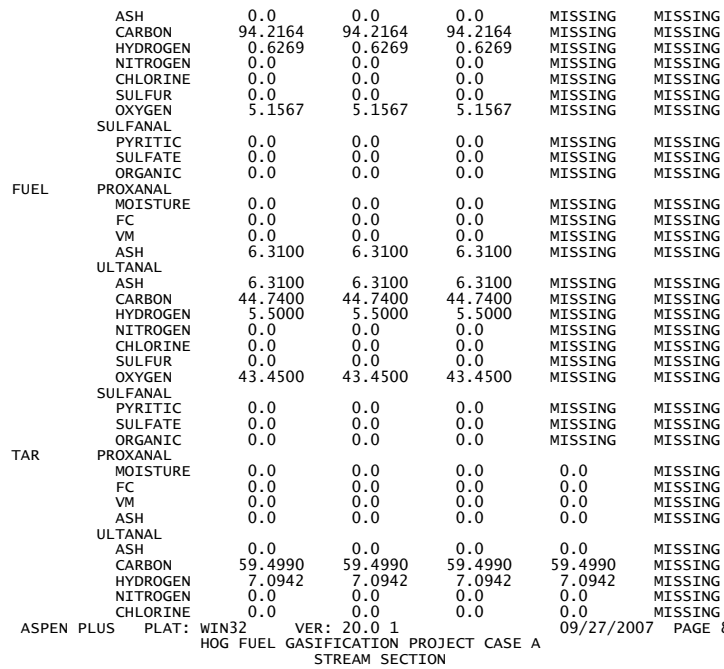

SYNGAS- 3 SYNGAS- 4 SYNGAS- 5 SYNGAS- 6 SYNG (CONTINUED)

$\begin{array}{ccccccc}\text { STREAM ID } & & \text { SYNGAS-3 } & \text { SYNGAS-4 } & \text { SYNGAS-5 } & \text { SYNGAS-6 } & \text { SYNGAS-7 } \\ & \text { SULFUR } & 0.0 & 0.0 & 0.0 & 0.0 & \text { MISSING } \\ \text { OLYGEN } & 33.4068 & 33.4068 & 33.4068 & 33.4068 & \text { MISSING } \\ \text { SULFANAL } & 0.0 & 0.0 & 0.0 & 0.0 & \text { MISSING } \\ \text { PYRITIC } & 0.0 & 0.0 & 0.0 & 0.0 & \text { MISSING } \\ \text { SULFATE } & 0.0 & 0.0 & 0.0 & 0.0 & \text { MISSING }\end{array}$ ASH GENANAL
ASPEN PLUS PLAT: WIN32 VER: 20.01
HOG FUEL GASIFICATION PROJECT CASE A HEAT-DRY HT-CRK HT-CRK-2 TAR-HEAT

$\begin{array}{lllll}\text { STREAM ID } & \text { HEAT-DRY } & \text { HT-CRK } & \text { HT-CRK-2 } & \text { TAR-HEAT } \\ \text { FROM }: & \text { SC-14 } & \text { TAR-CRK } & \text { HEAT-CRK } & \text { SC-12 } \\ \text { TO } & \text { HEAT-DRY } & \text { TRR-CNV } & \text { COOL-CRK } & \text { TAR-CNV2 } \\ \text { CLASS: } & \text { HEAT } & \text { HEAT } & \text { HEAT } & \text { HEAT }\end{array}$

HOG FUEL GASIFICATION PROJECT CASE A

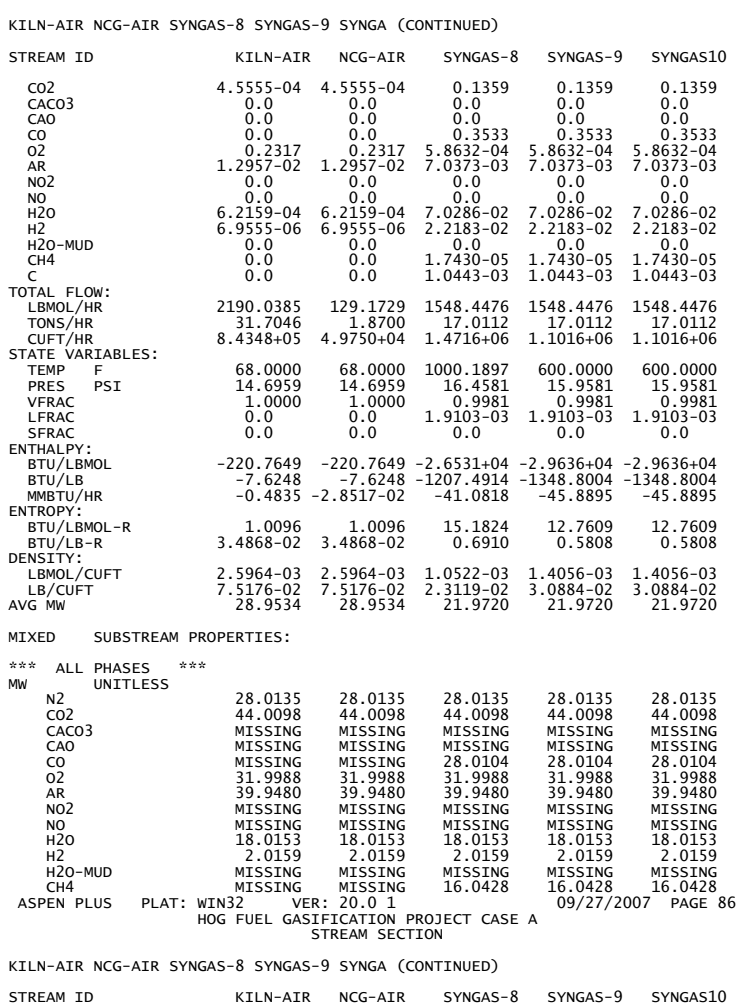

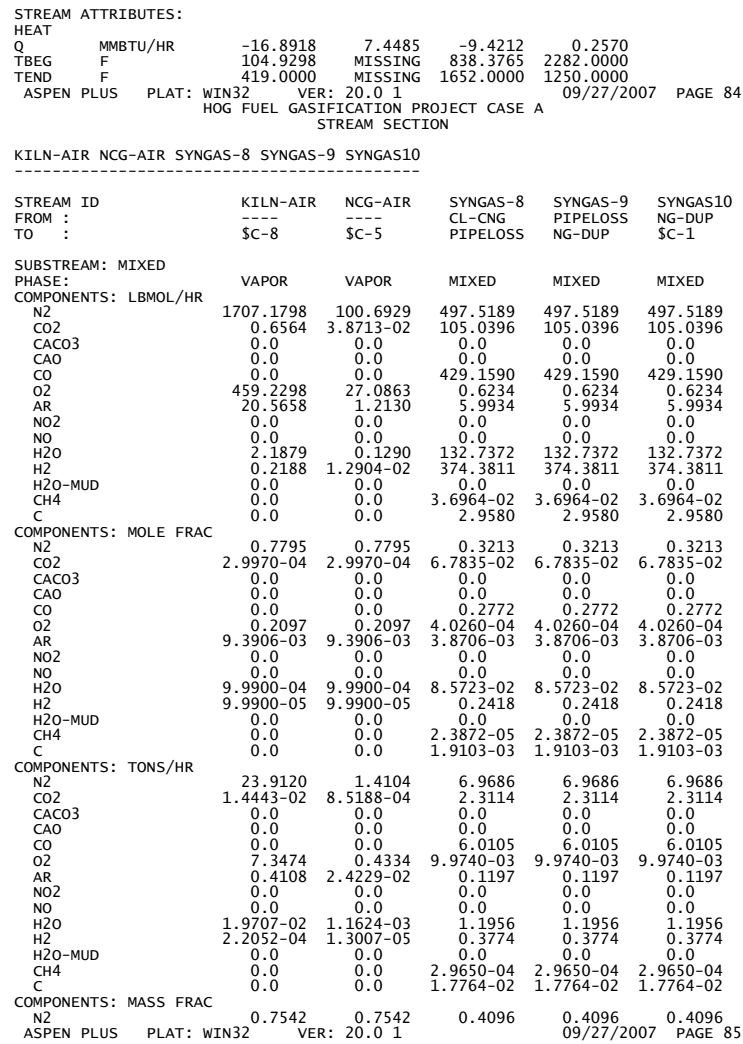

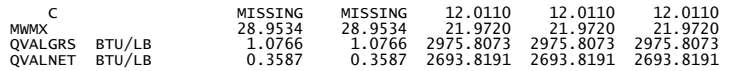

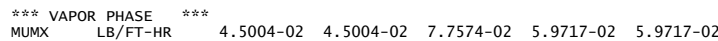
$\begin{array}{lllllll}\text { MUMX } & \text { LB/FT-HR } & 4.5004-02 & 4.5004-02 & 7.7574-02 & 5.9717-02 & 5.9717-02 \\ \text { PR } & 0.6983 & 0.6983 & 0.5132 & 0.5068 & 0.5068 \\ \text { KMX } & \text { BTU/HR-FT-R } & 1.5501-02 & 1.5501-02 & 5.4372-02 & 4.0454-02 & 4.0454-02\end{array}$ $\because 68.0000 \mathrm{~F}$

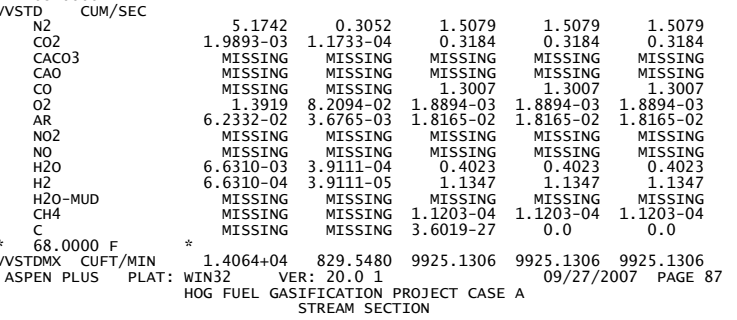

SYNGAS11

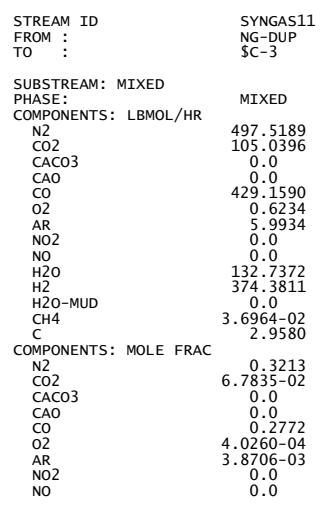




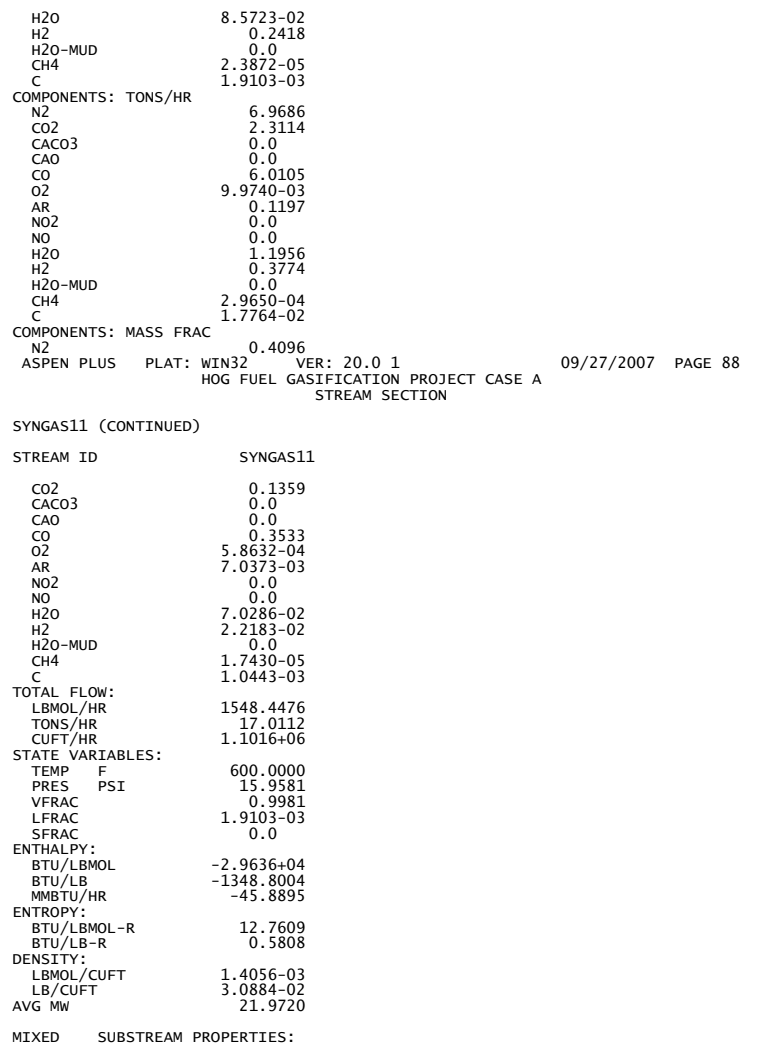

RESULT:

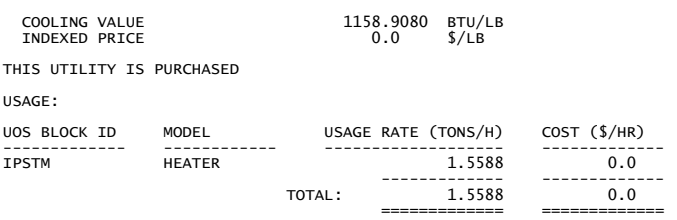

$\begin{array}{lll}\text { ASPEN PLUS PLAT: WIN32 } & \text { VER: } 20.01 & 1 \\ \text { HOG FUEL GASIFICATION PROJECT CASE A } & \text { 09/27/2007 PAGE } 91 \\ \text { UTILITY SECTION } & & \end{array}$ UTILITY USAGE: LPS-GEN (STEAM)

INPUT DATA:

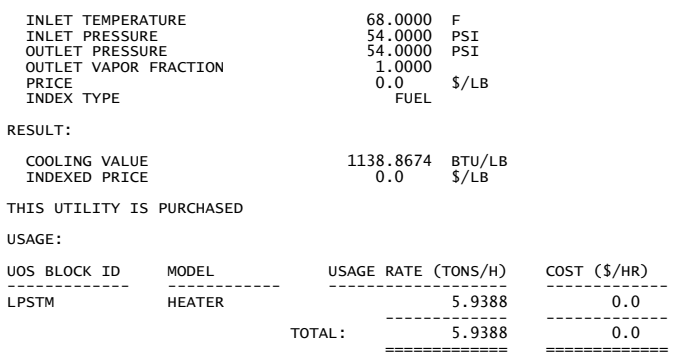

ASPEN PLUS PLAT: WIN32 VER: 20.01 GOAEL GASIFICATION PROJECT CASE A 09/27/2007 PAGE 92 HOG FUEL GASIFICATION PROJECT CASE A
FLOWSHEET SECTION (HIERARCHY: BM-DRYER)

FLOWSHEET CONNECTIVITY BY STREAMS

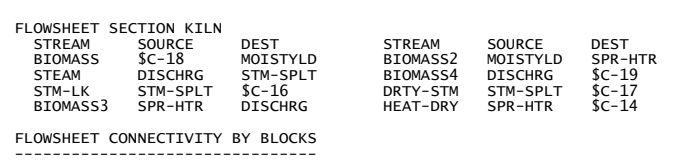

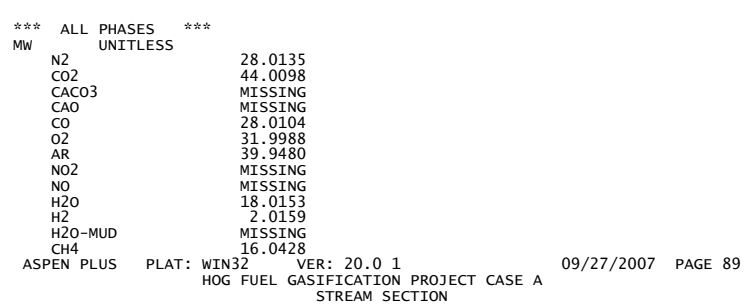

SYNGAS11 (CONTINUED)

STREAM ID SYNGAS11

$\begin{array}{lrr}\text { C } & & 12.0110 \\ \text { MWMX } & 21.9720 \\ \text { QVALGRS } & \text { BTU/LB } & 2975.8073 \\ \text { QVALNET } & \text { BTU/LB } & 2693.8191\end{array}$

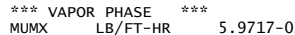

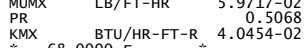

VVSTD CUM/SEC

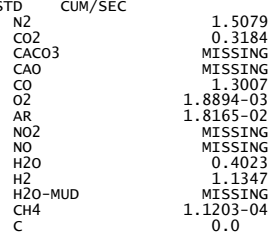

C $68.0000 \mathrm{~F} * 0.00$

$\begin{array}{llll}\text { VVSTDM CUFT/MIN } & 9925.1306 & & \\ \text { ASPEN PLUS PLAT: WIN32 } & \text { VER: } 20.01 & & \\ \text { HOG FUEL GASIFICATION PROJECT CASE A } & \text { 09/27/2007 PAGE } 90\end{array}$ UTILITY USAGE: IPS-GEN (STEAM)

INPUT DATA:

INLET TEMPERATURE

OUTLET PRESSURE

OUTLET VAPOR FRACTION

PRICE INDEX TYPE

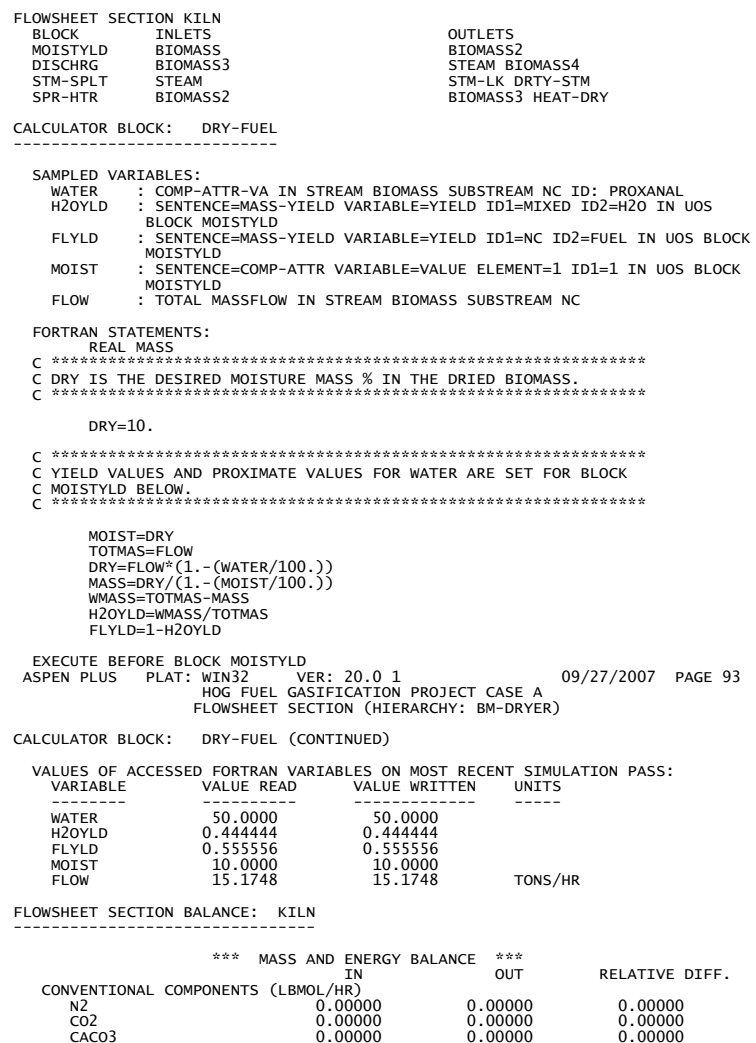




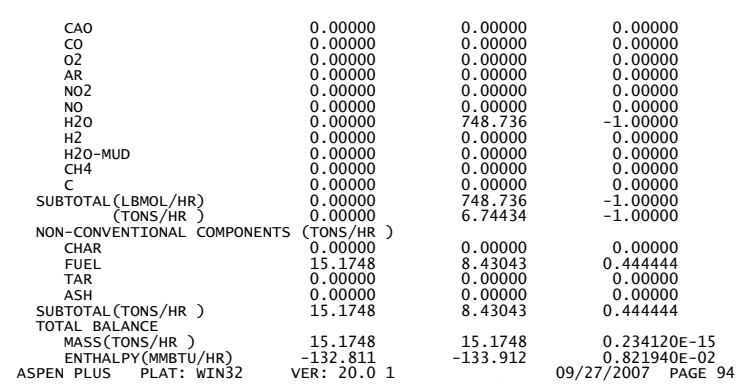
ENTHALPY(MMBTU/HR)
ASPEN PLUS PLAT: WIN32 VER: 20.01 HOG FUEL GASIFICATION PROJECT CASE A
U-O-S BLOCK SECTION (HIERARCHY: BM-DRYER)

\section{BLOCK: DISCHRG MODEL: SEP}

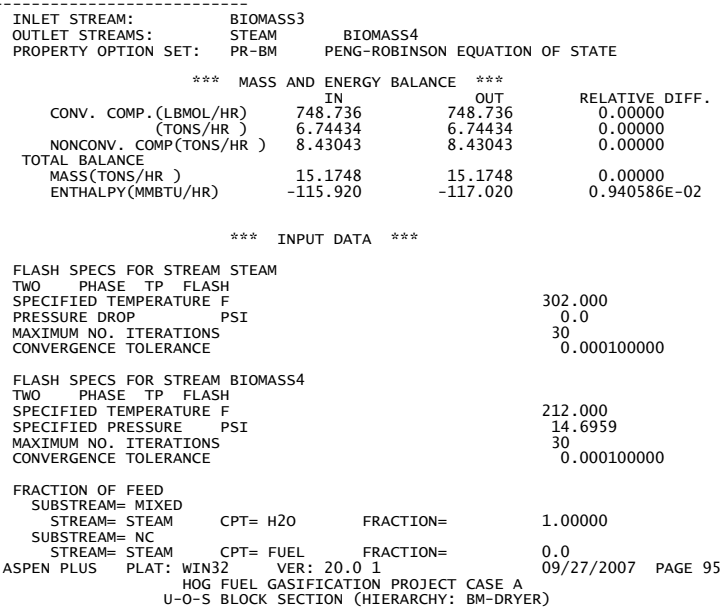

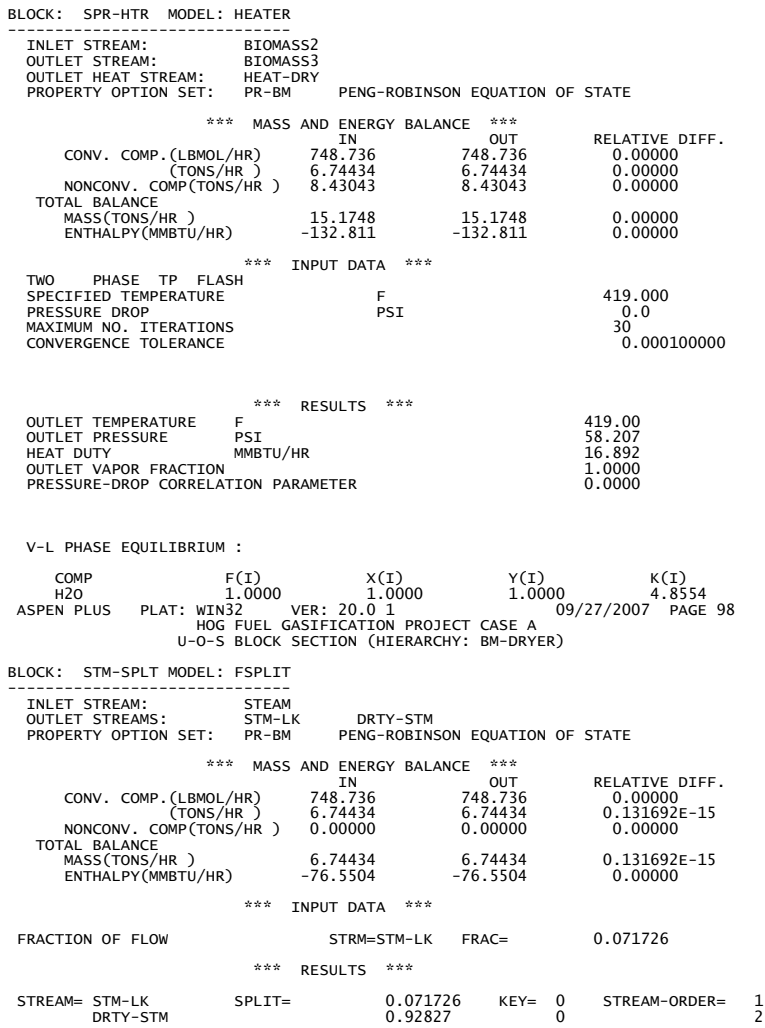

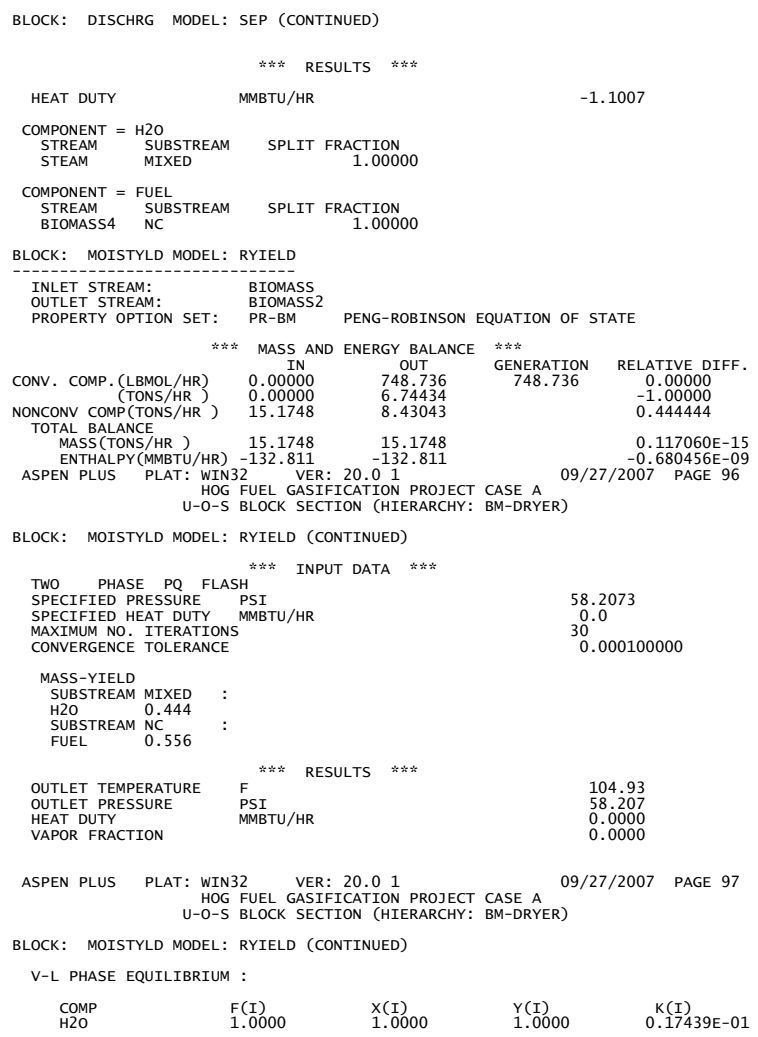

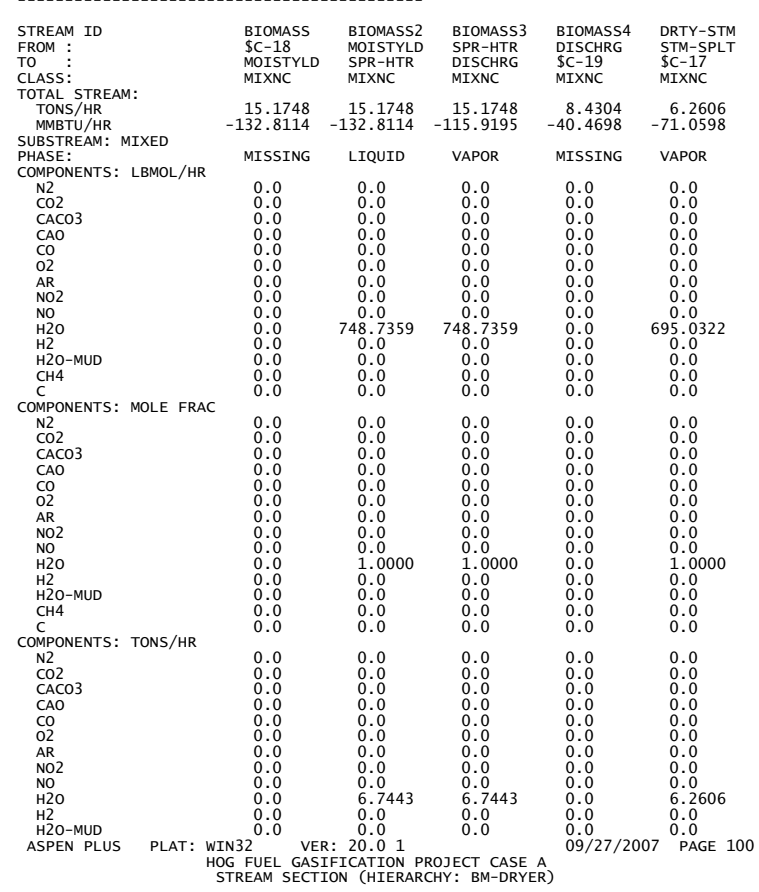

STREAM ID BIOMASS BIOMASS2 BIOMASS3 BIOMASS4 DRTY-STM 

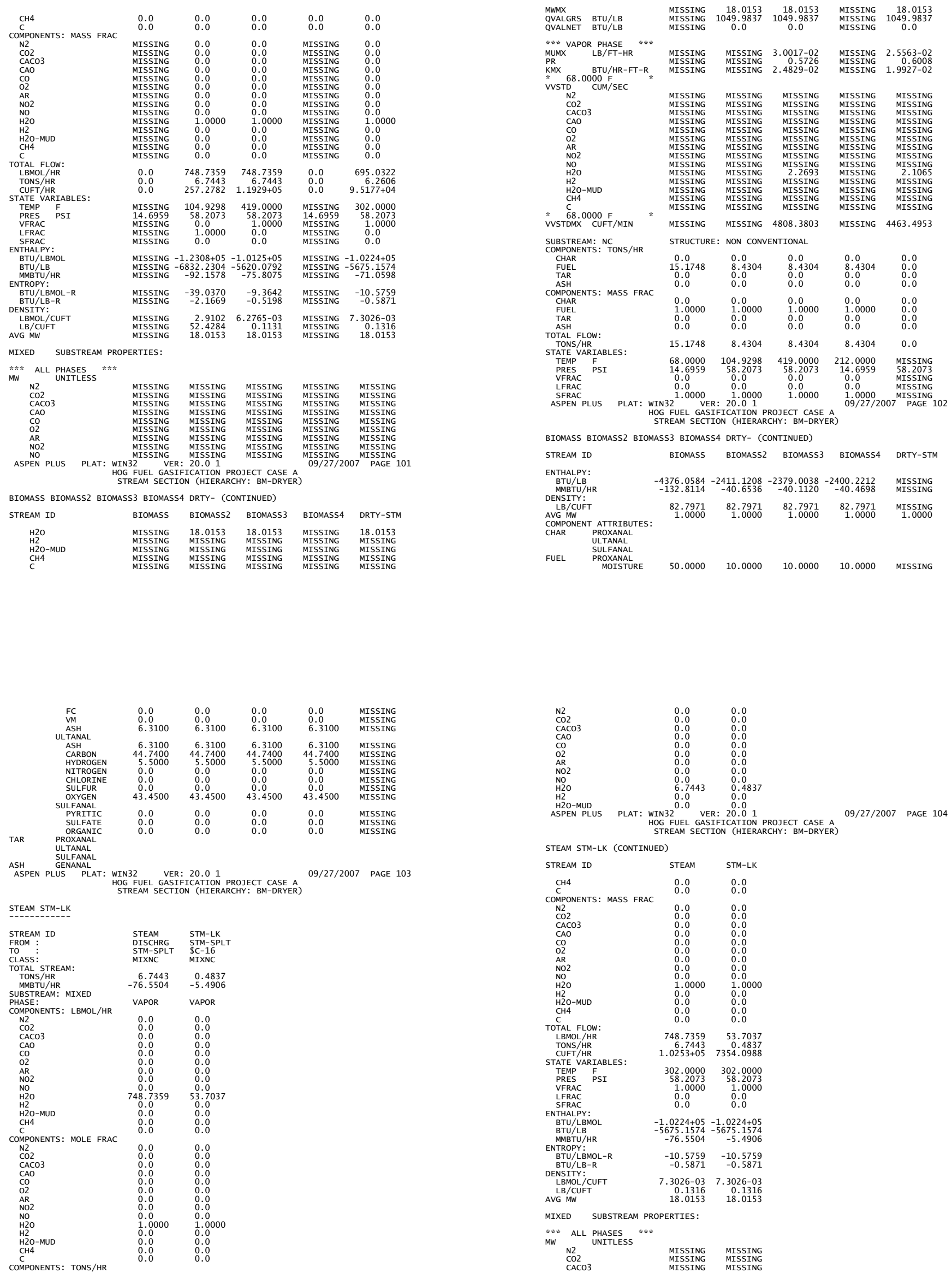


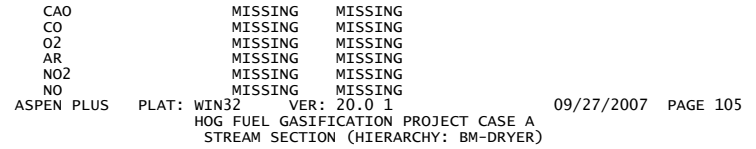

STEAM STM-LK (CONTINUED)

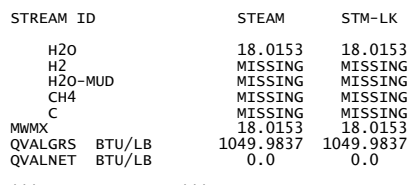

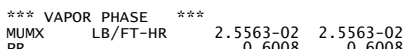

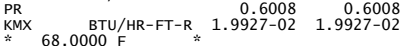

$\begin{array}{lll}* \\ \text { USSTD }\end{array} 68.0000 \mathrm{CUM} / \mathrm{SEC}$

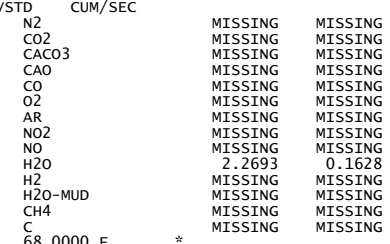

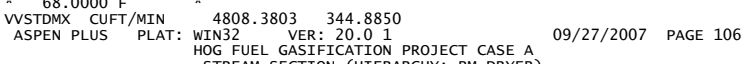

HEAT-DRY

$\begin{array}{ll}\text { STREAM ID } & \text { HEAT-DRY } \\ \text { FROM } & \text { SPR } \\ \text { TOOTR } & \text { SC-14 } \\ \text { CLASS: } & \text { HEAT }\end{array}$

STREAM ATTRIBUtES:

$\begin{array}{llr}\text { HEAT } & \text { MMBTU/HR } & -16.8918 \\ Q_{O} & 104.9298 \\ \text { TEEG } & \text { F } & 104 \\ \text { TEND } & \text { F } & 419.0000\end{array}$

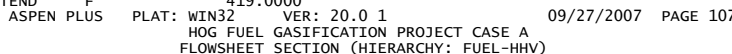

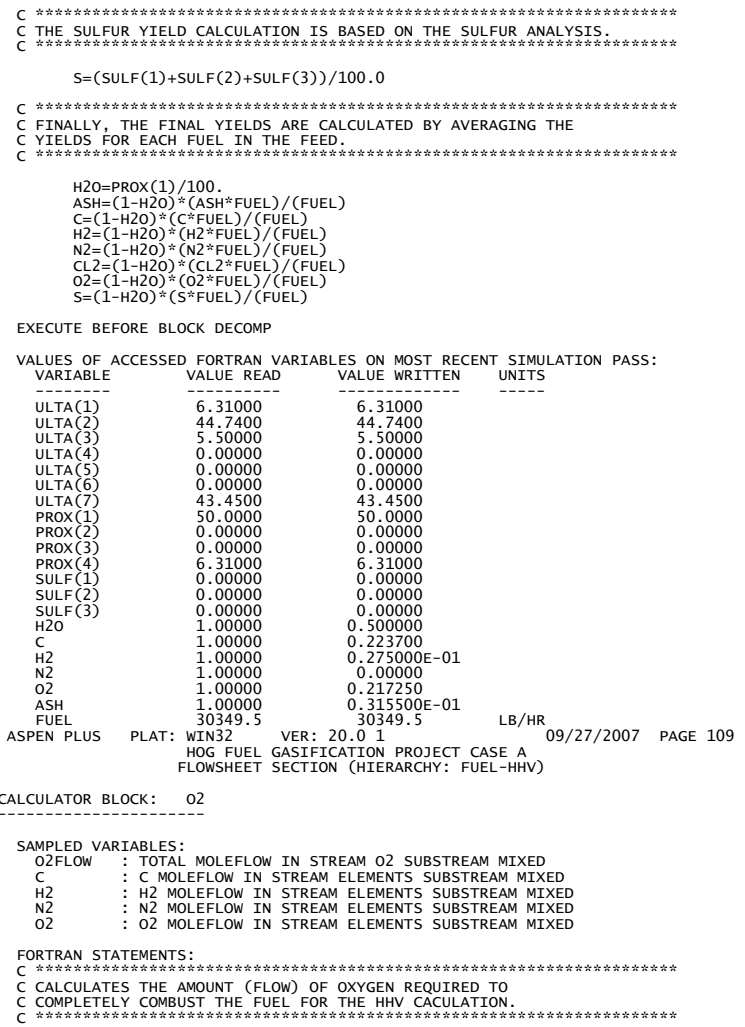

FLOWSHEET CONNECTIVITY BY STREAMS

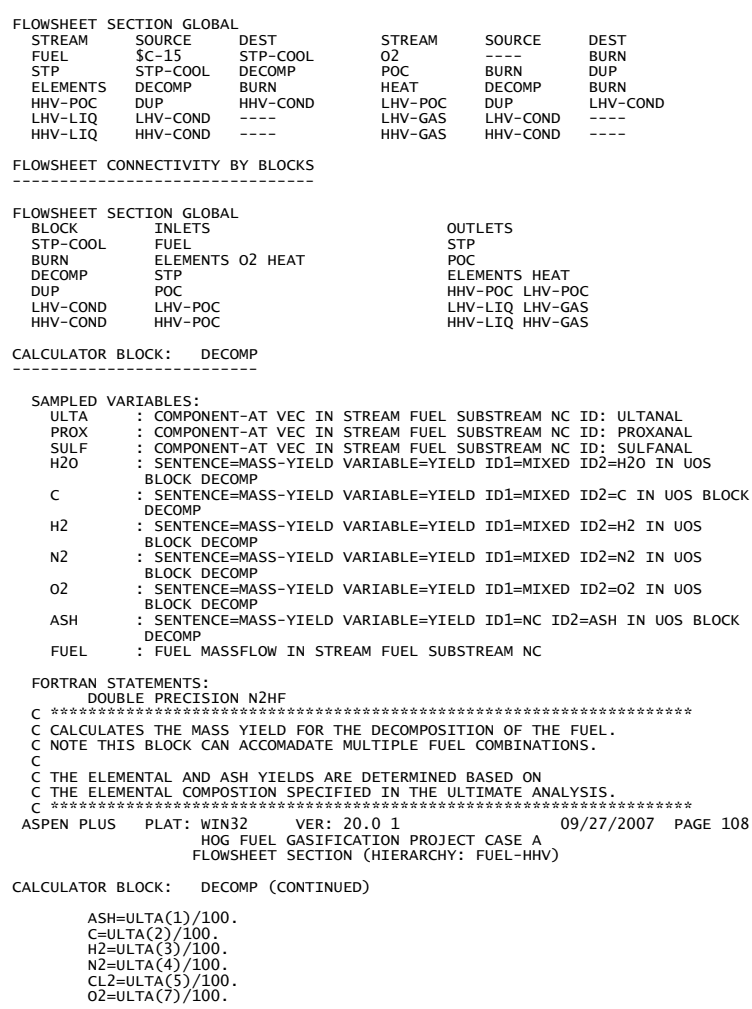

STP
POC
ELEMENTS HEAT
HHV-POC LHV-POC HHV-POC LHV-POC
LHV-LIQ LHV-GAS

ock

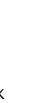$$
\text { 09/27/2007 PAGE } 107
$$

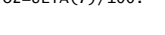




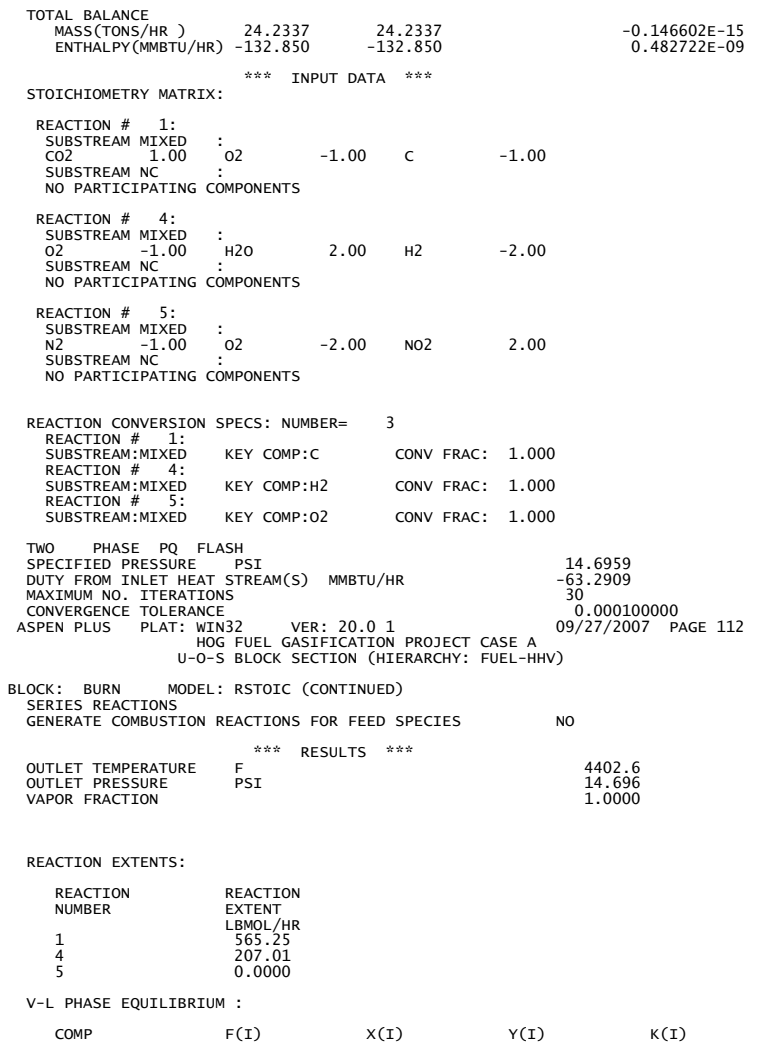

$\begin{array}{lll}\text { INLET STREAM: } & \text { HHV-POC } \\ \text { OUTLET STREAMS: } & \text { HHV-LIQ } & \text { HHV-GAS } \\ \text { PROPERTY OPTION SET: } & \text { PR-BM }\end{array} \quad$ PENG-ROBINSON EQUATION OF STATE

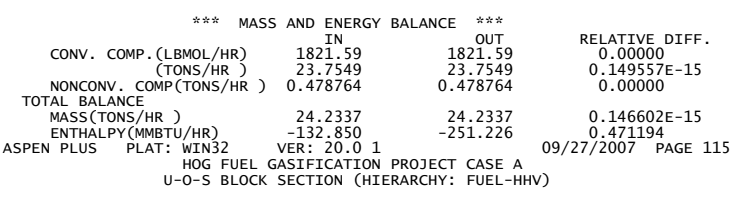
BLOCK: HHV-COND MODEL: SEP (CONTINUED)

$$
* * * * \quad \text { INPUT DATA } * * * *
$$

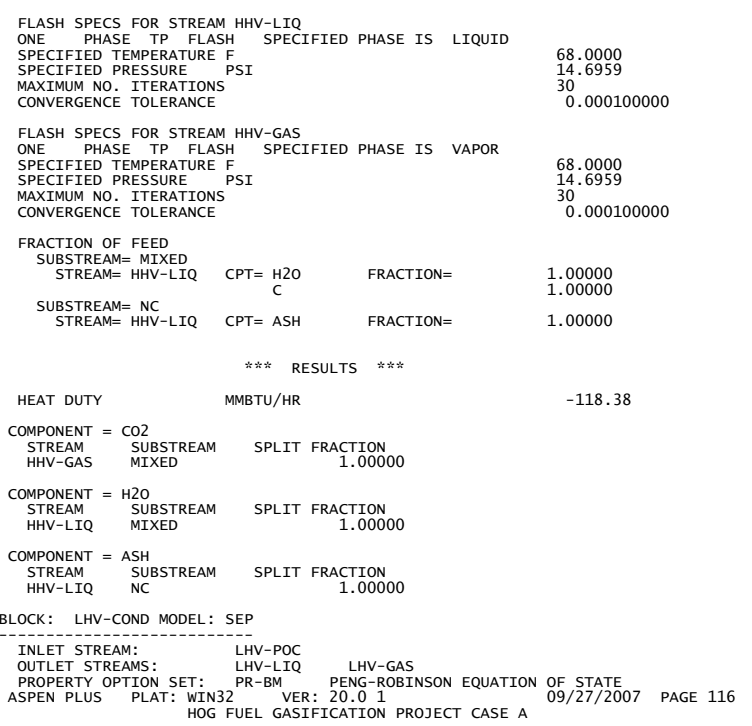

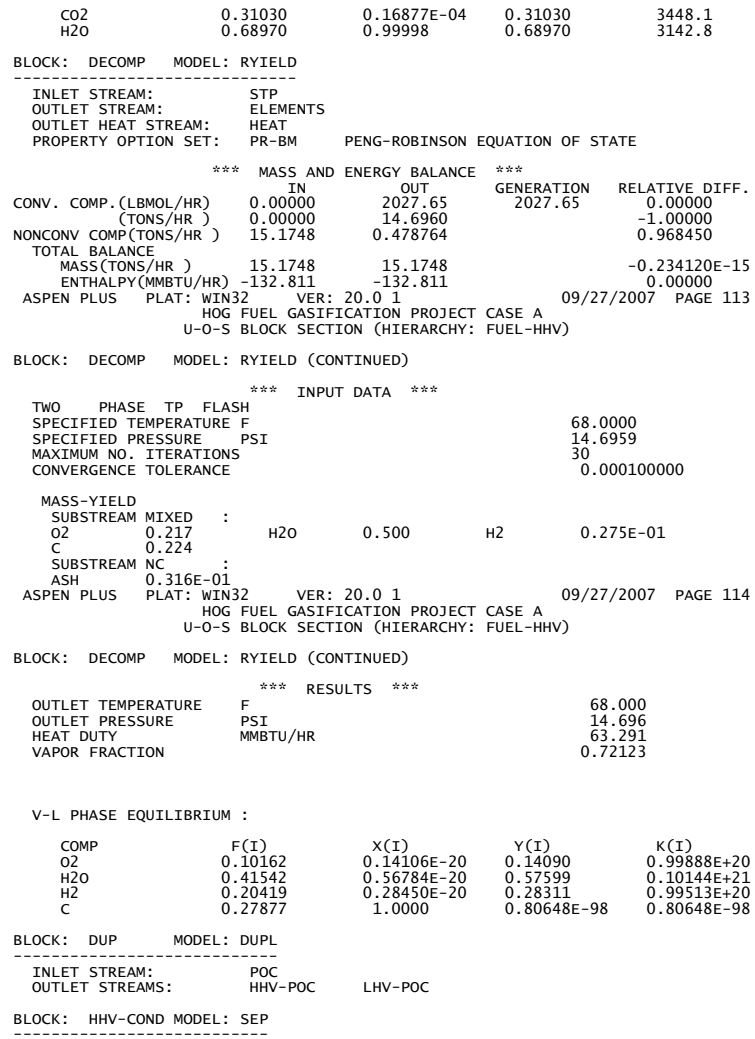

U-O-S BLOCK SECTION (HIERARCHY: FUEL-HHV) BLOCK: LHV-COND MODEL: SEP (CONTINUED)

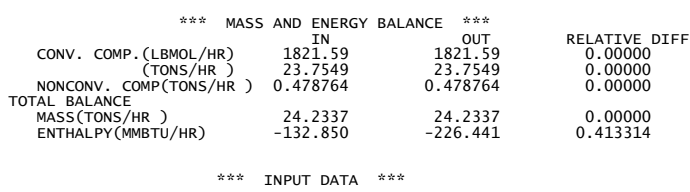

FLASH SPECS FOR STREAM LHV-LIQ
ONE PHASE TP FLASH SPECIFIED PHASE IS LIQUID

SPECIFIED TEMPERATURE F

SPECIFIED PRESSURE PS
MAXIMUM NO. ITERATIONS
CONVERGENCE TOLERANCE

68.0000
14.6959

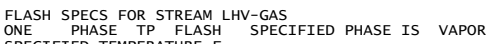

SPECIFIED TEMPERATURE PSI

MAXIMUM NO. ITERATIONS
CONVERGENCE TOLERANCE

0.000100000

FRACTION OF FEED

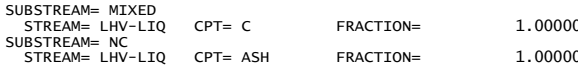

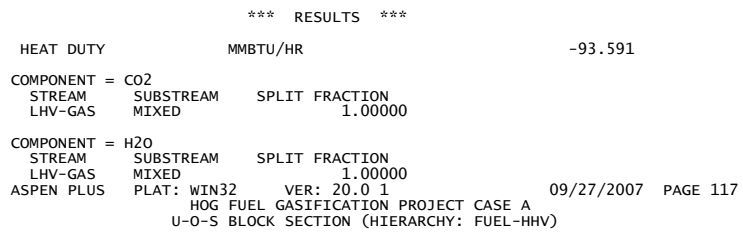

BLOCK: LHV-COND MODEL: SEP (CONTINUED)

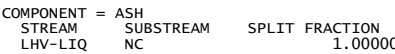

BLOCK: STP-COOL MODEL: HEATER

$\begin{array}{ll}\text { INLET STREAM: } & \text { FUEL } \\ \text { OUTLET STREAM: } & \text { STP }\end{array}$

PROPERTY OPTION SET: PR-BM PENG-ROBINSON EQUATION OF STATE

$$
\begin{aligned}
& * * * * \\
& \text { MASS AND ENERGY BALANCE } \\
& \text { IN }
\end{aligned}
$$



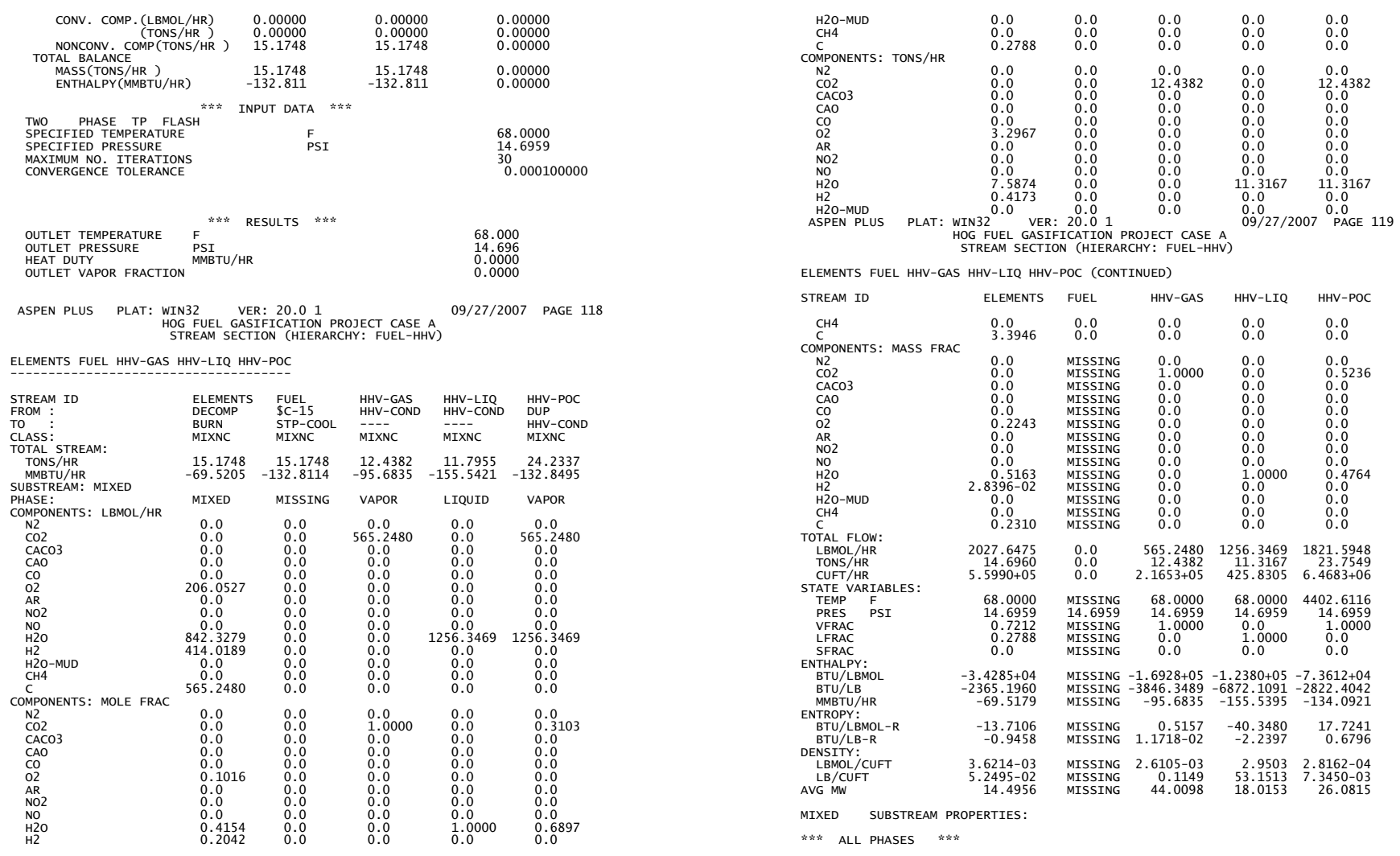

ELEMENTS FUEL HHV-GAS HHV-LIQ HHV-POC (CONTINUED)
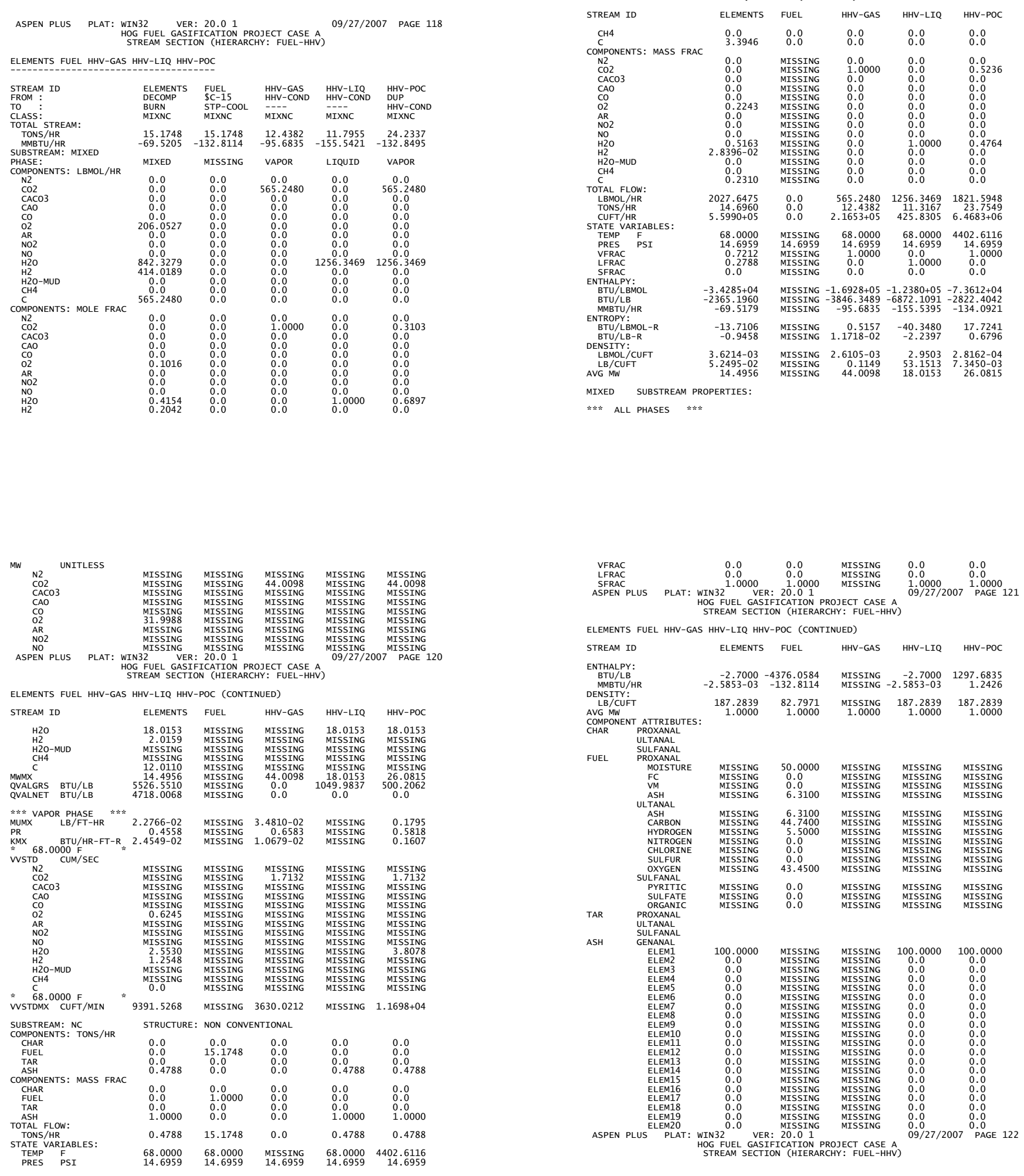
LHV-GAS LHV-LIQ LHV-POC 02 POC

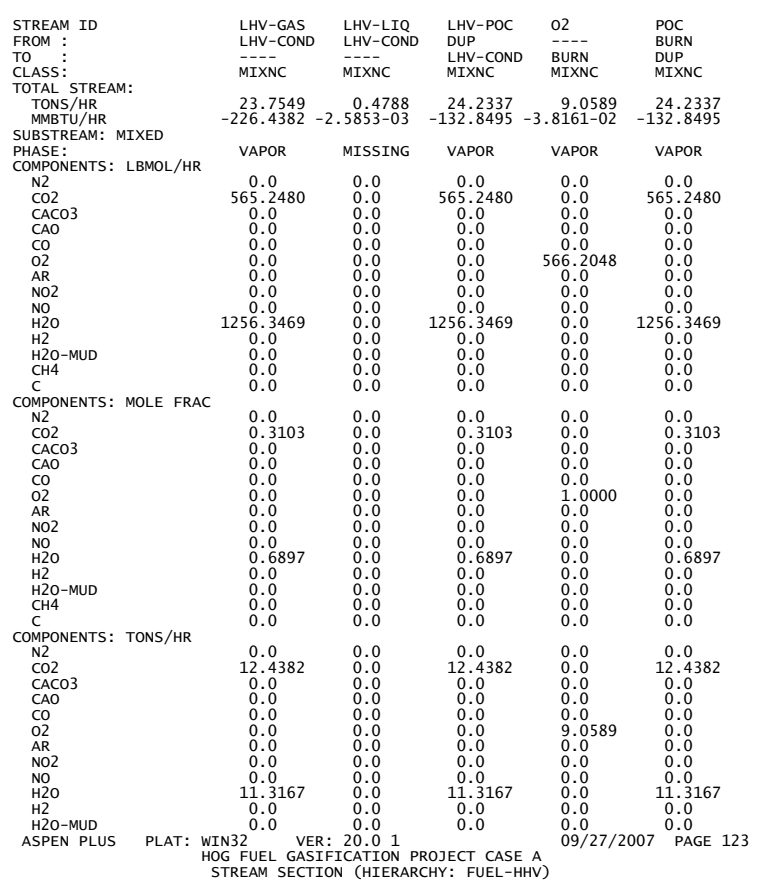

LHV-GAS LHV-LIQ LHV-POC 02 POC (CONTINUED)

$\begin{array}{cccccc}\text { STREAM ID } & \text { LHV-GAS } & \text { LHV-LIQ } & \text { LHV-POC } & 02 & \text { POC } \\ \text { CH4 } & 0.0 & 0.0 & 0.0 & 0.0 & 0.0\end{array}$

$\begin{array}{cccccc} & 0.0 & 0.0 & 0.0 & 0.0 & 0.0 \\ \text { C } & 0.0 & 0.0 & 0.0 & 0.0 & 0.0 \\ \text { COMPONENTS: MASS FRAC } & & & & & \end{array}$
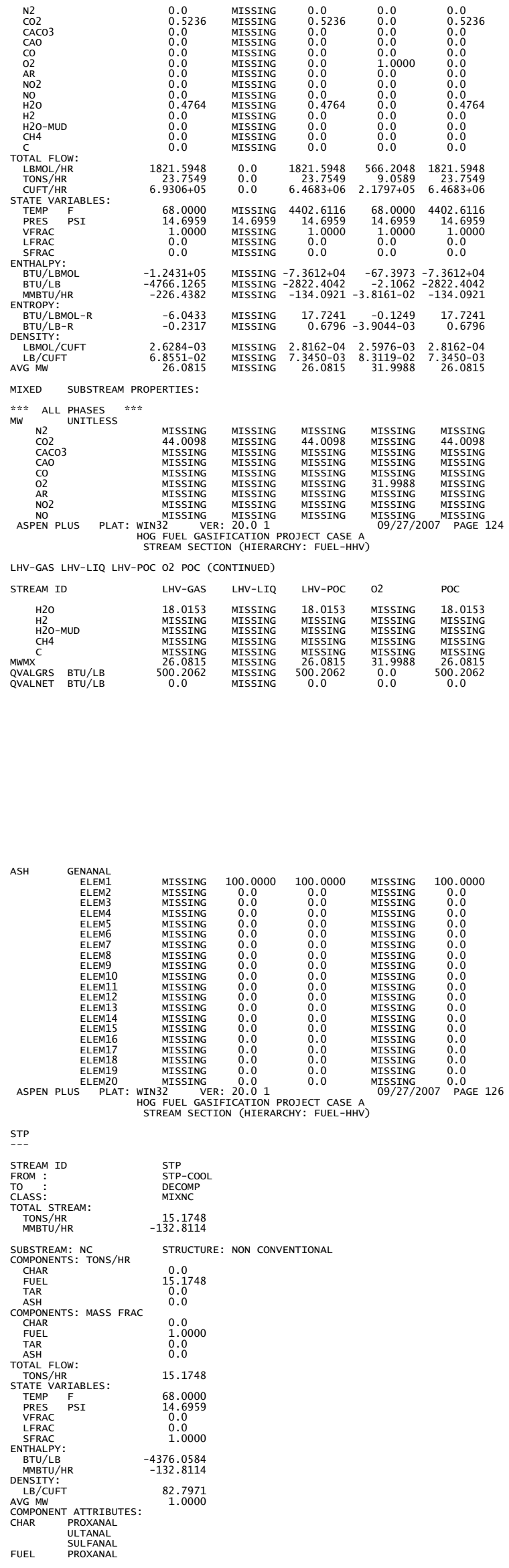

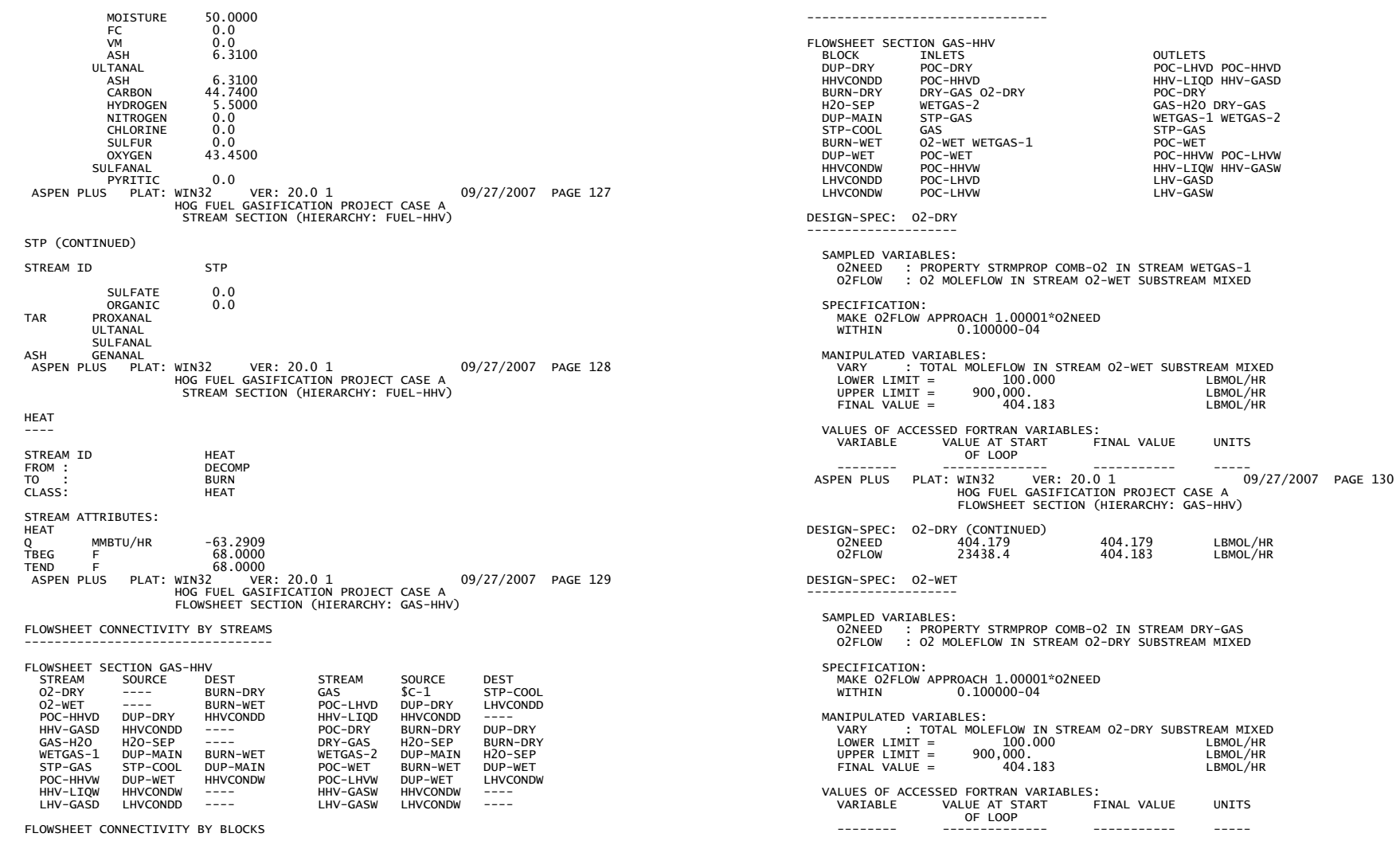

$\begin{array}{llll}\text { O2NEED } & 404.179 & 404.179 & \text { LEMOL/AR } \\ \text { O2FLOW } & 23438.4 & 404.183 & \text { LEMOL/HR }\end{array}$

FLOWSHEET SECTION BALANCE: GAS-HHV

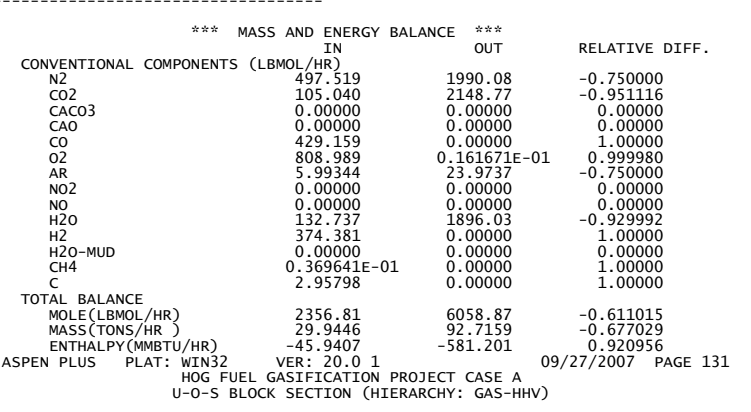

BLOCK: BURN-DRY MODEL: RSTOIC

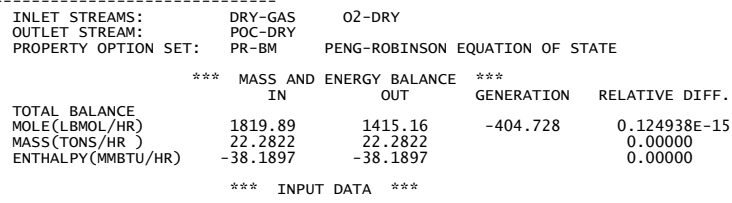

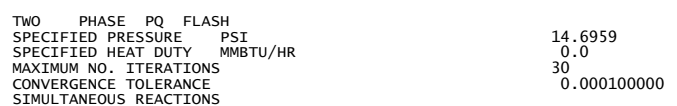

$\begin{array}{ll}\text { SIMULTANEOUS REACTIONS } & \text { YES } \\ \text { GENEATE COMBUSTION REACTIONS FOR FEED SPECIES } & \text { NO2 } \\ \text { COMBUSTION PRODUCT FOR CHEMICALLY BOUND NITROGEN } & \text { NOL }\end{array}$

$\begin{array}{llll} & & \\ \text { OUTLET TEMPERATURE } & \text { F } & \text { RESULTS } & * * * \\ \text { OUTLET PRESSURE } & \text { PSI } & & 5851.1 \\ \text { VAPOR FRACTION } & & & 14.696 \\ & & \end{array}$

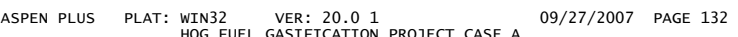
HOG FUEL GASIFICATION PROJECT CASE A
$U-0-S$ BLOCK SECTION (HIERARCHY: GAS-HHV) 


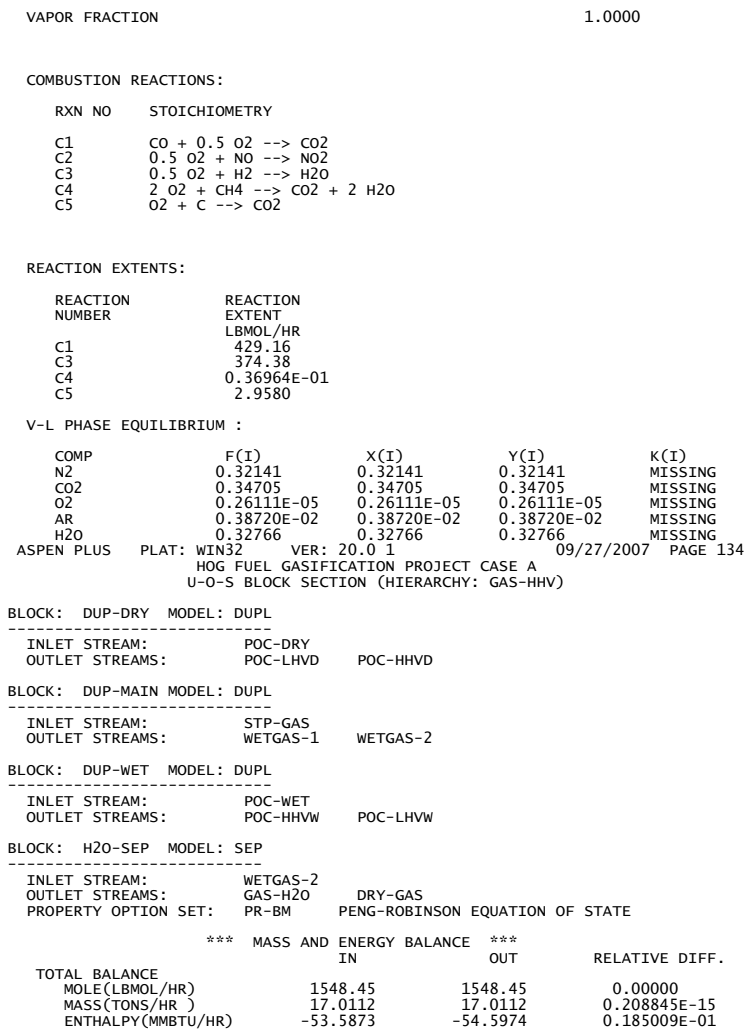

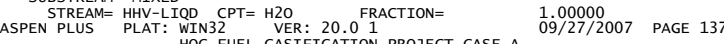

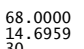

0.000100000

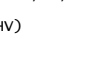




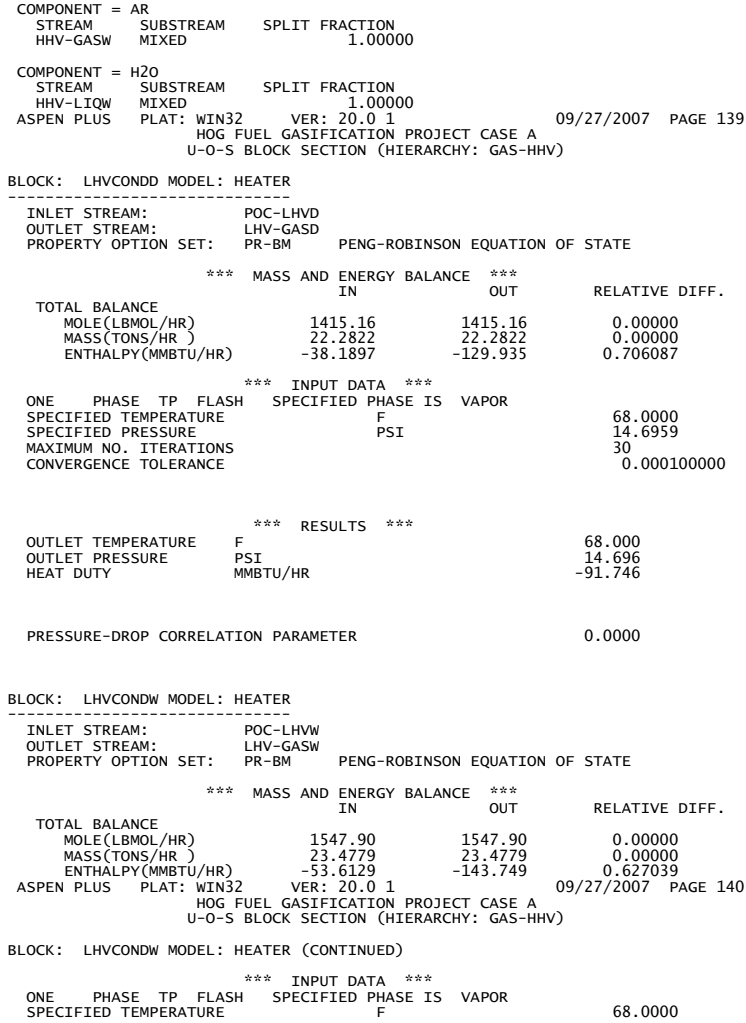

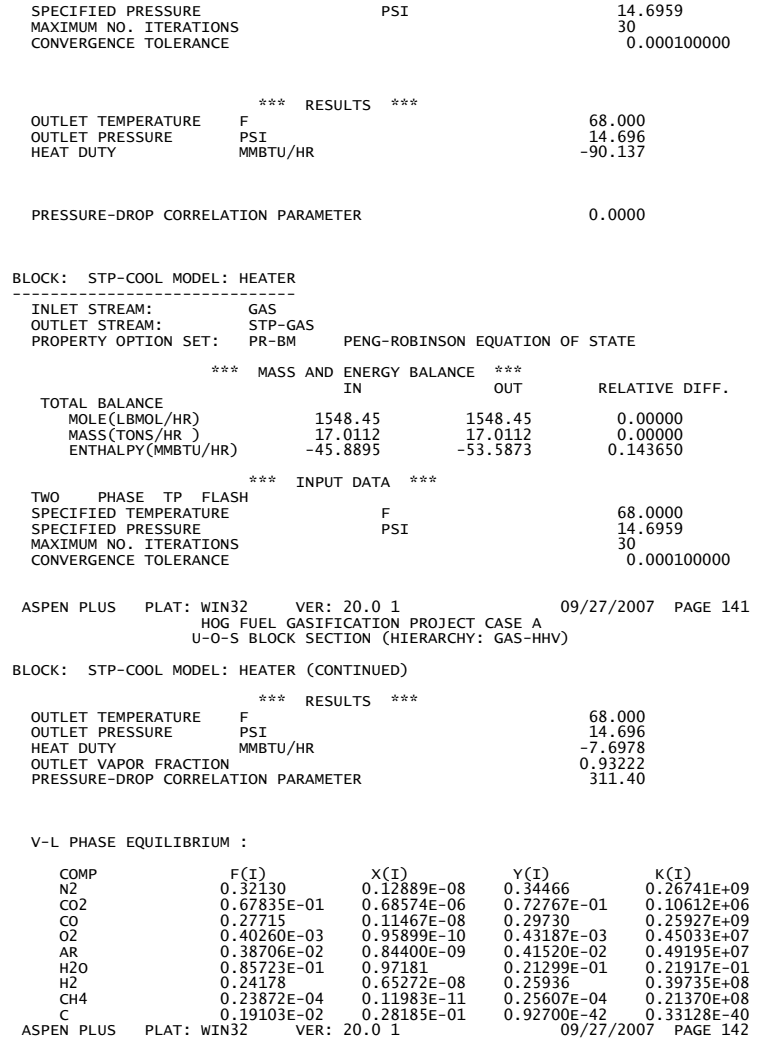



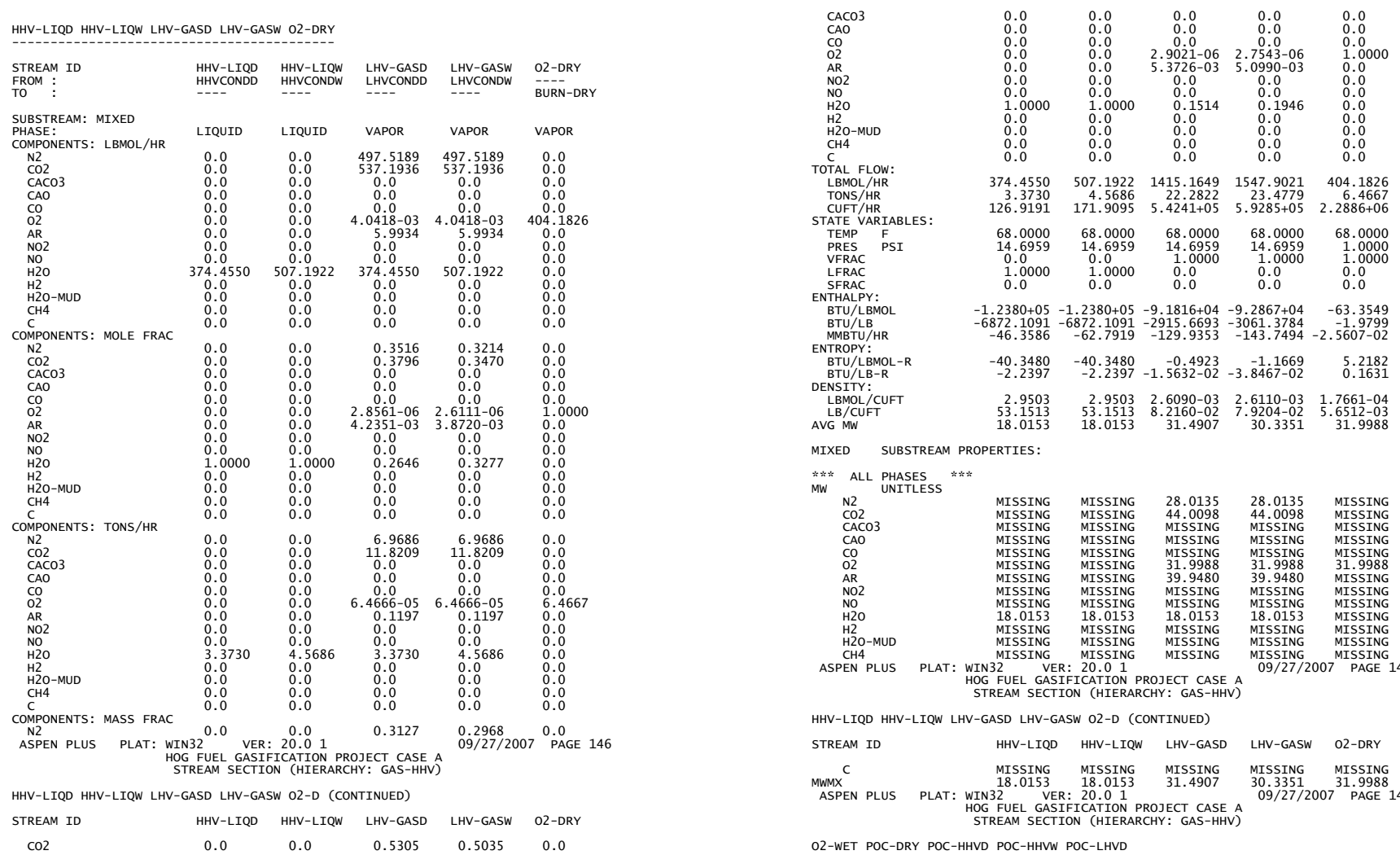

$* * * *$ ALL PHASES
MW UNITLESS

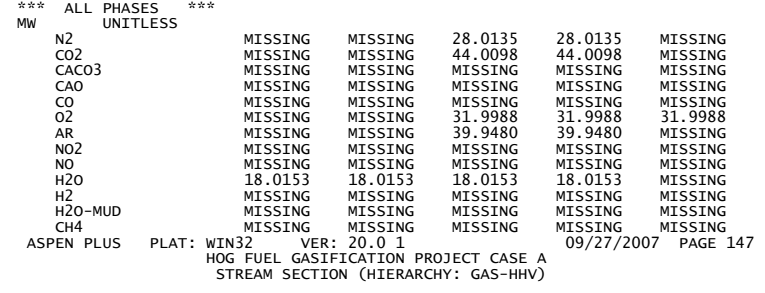

HHV-LIQD HHV-LIQW LHV-GASD LHV-GASW O2-D (CONTINUED)

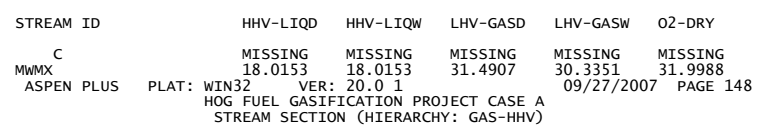

O2-WET POC-DRY POC-HHVD POC-HHVW POC-LHVD
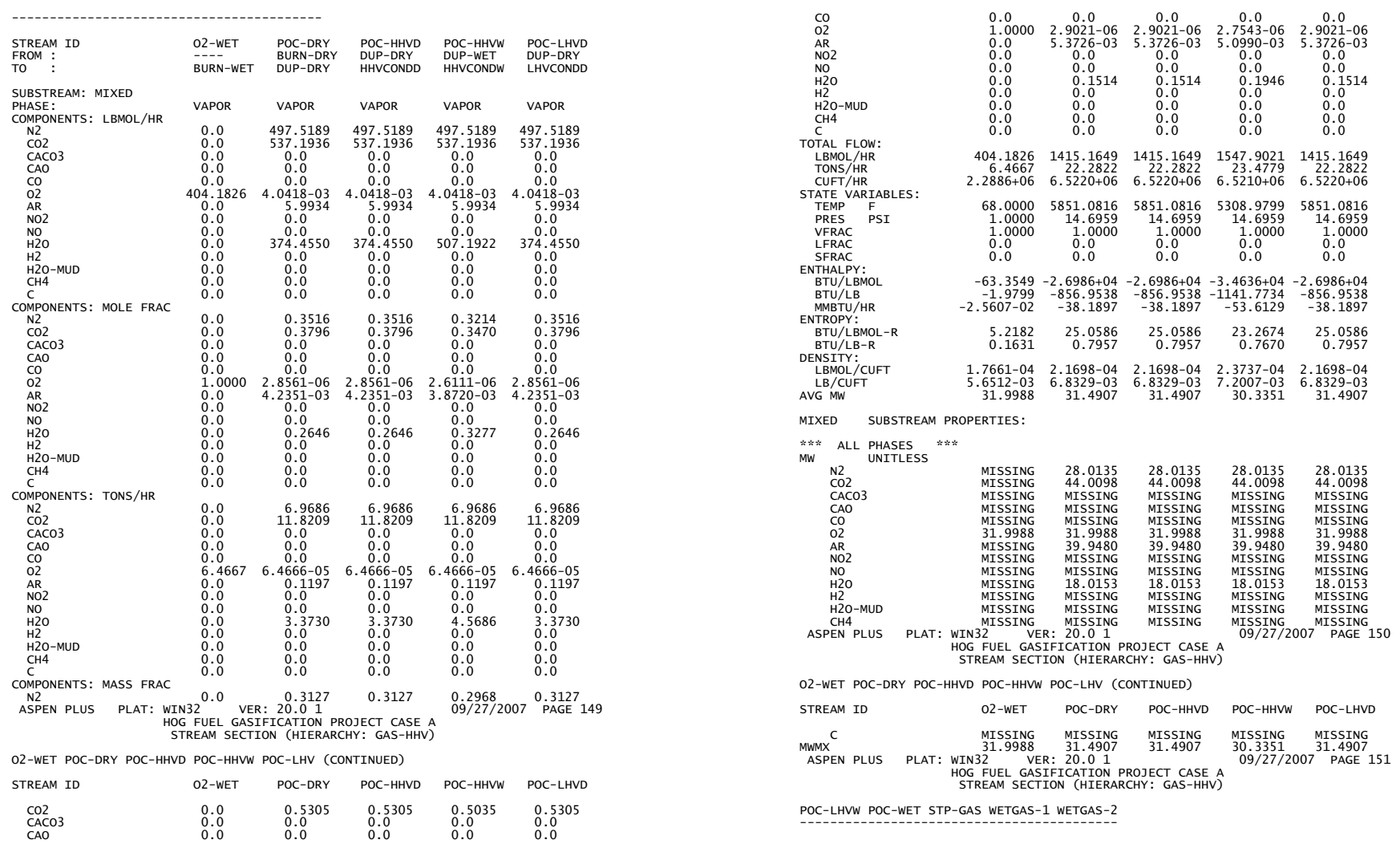

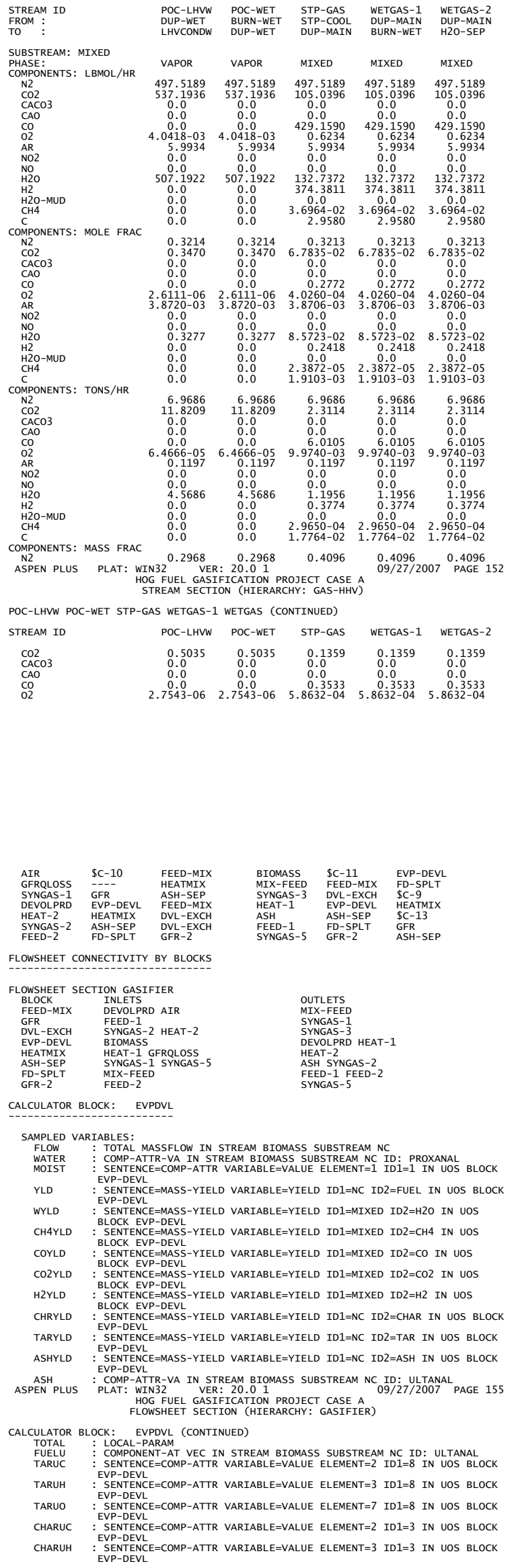
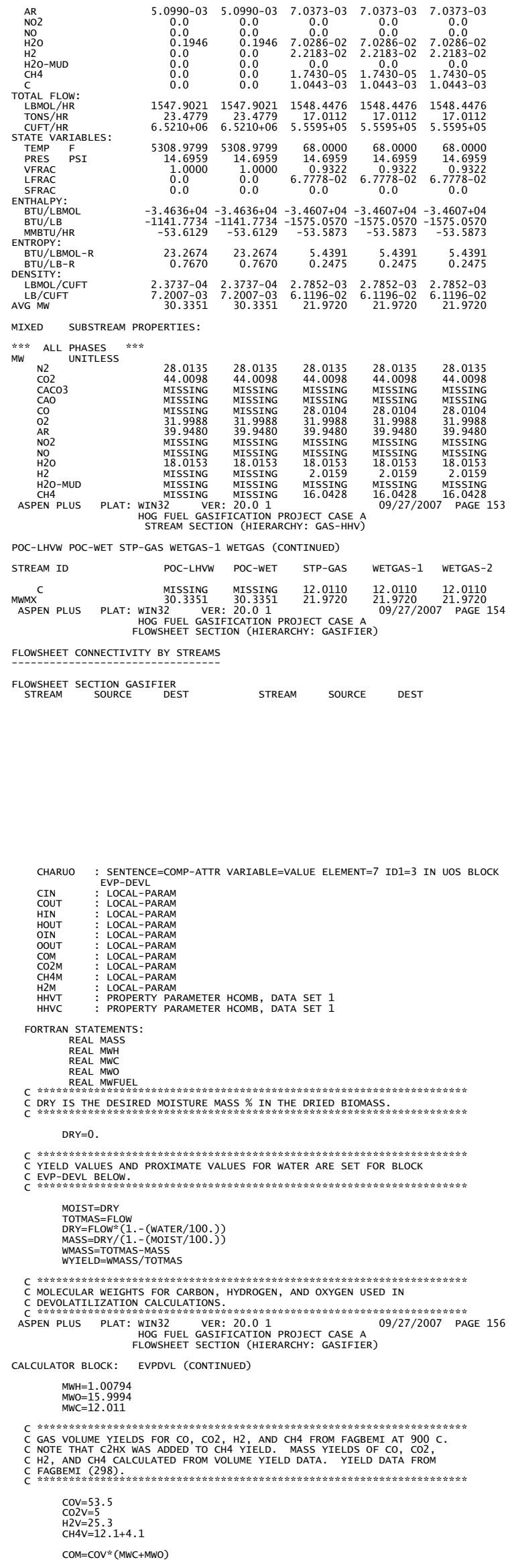

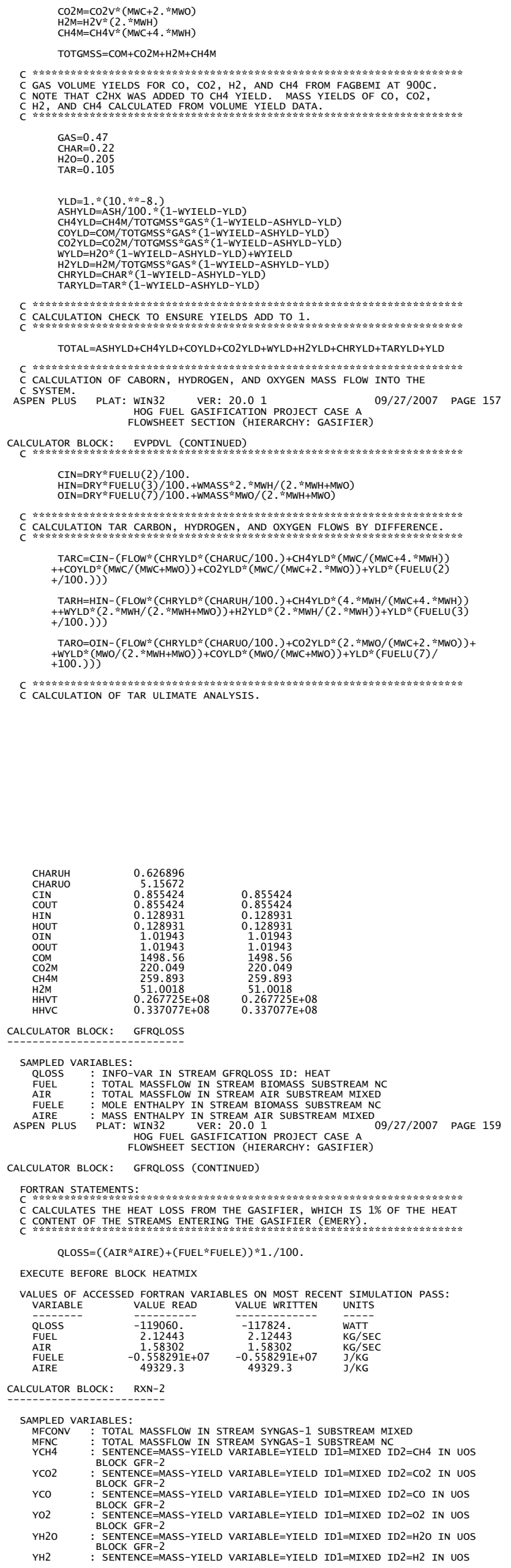
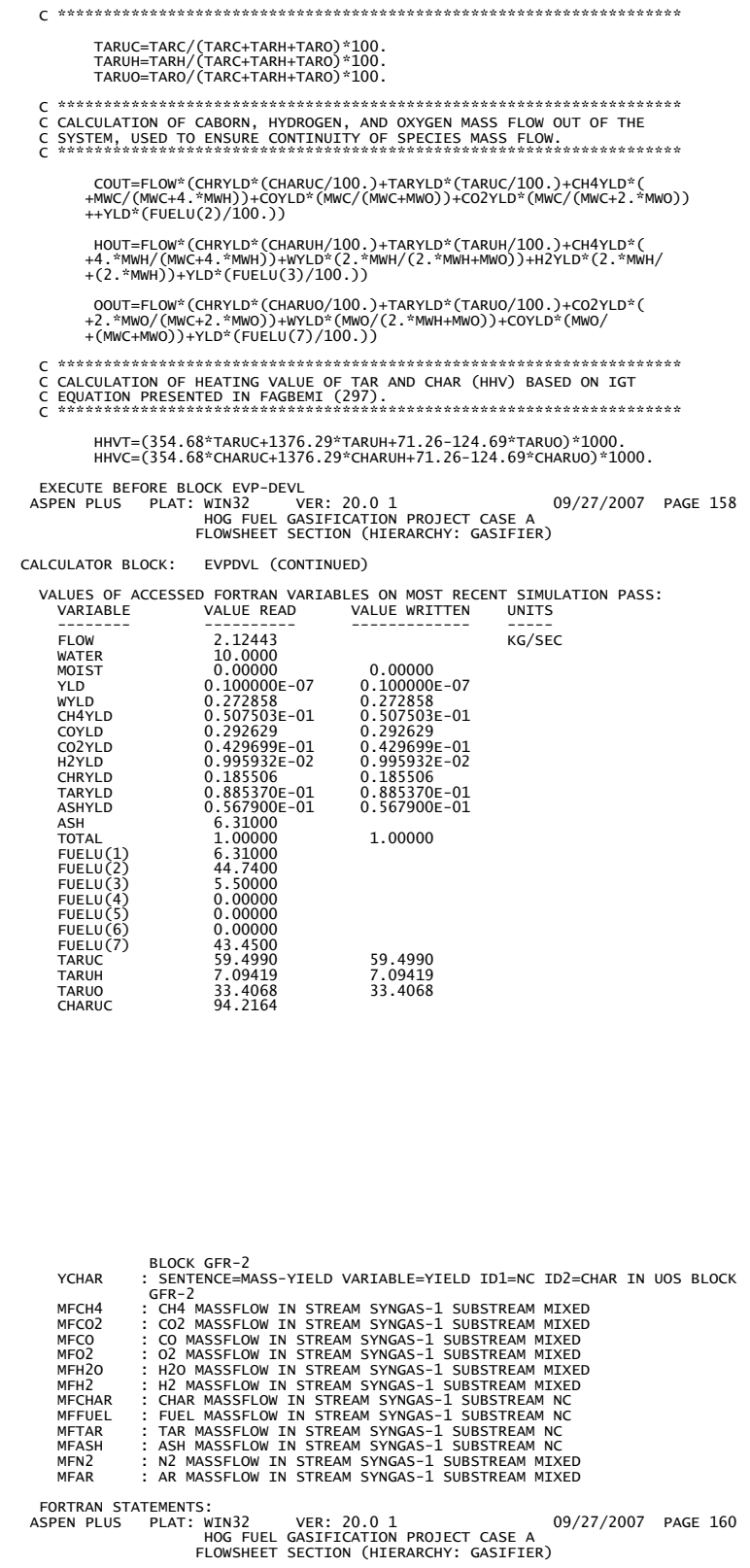

CALCULATOR BLOCK: RXN-2 (CONTINUED)

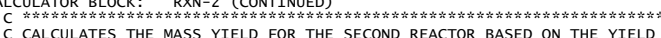

C OF THE FIRST REACTOR BLOCK.

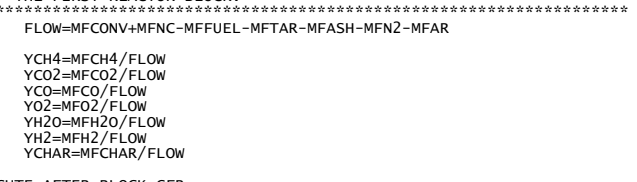

EXECUTE AFTER BLOCK GFR

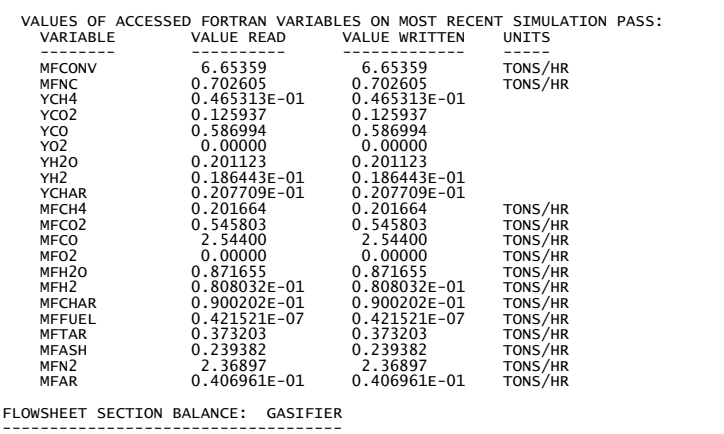




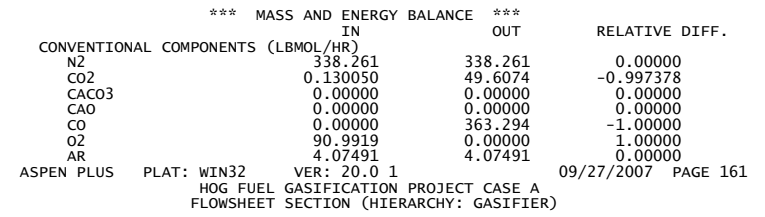

FLOWSHEET SECTION BALANCE: GASIFIER (CONTINUED)

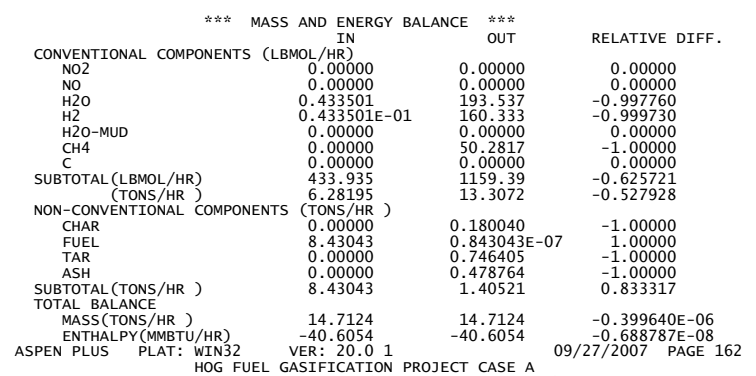
HOG FUEL GASIFICATION PROJECT CASE A
$\mathrm{U}-0-\mathrm{S}$ BLOCK SECTION (HIERARCHY: GASIFIER)

BLOCK: ASH-SEP MODEL: SEP

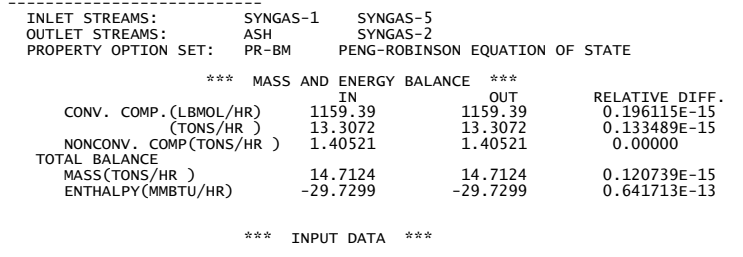

INLET PRESSURE: MINIMUM OF INLET STREAM PRESSURES

FLASH SPECS FOR STREAM ASH

TLASH PPESE TP FLASH
PRESSURE DROP

MAXIMUM NO. ITERATIONS
CONVERGENCE TOLERANCE

0.0
30
0.000100000

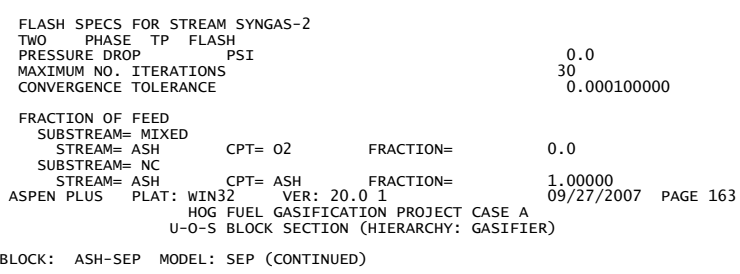

BLOCK: ASH-SEP MODEL: SEP (CONTINUED)

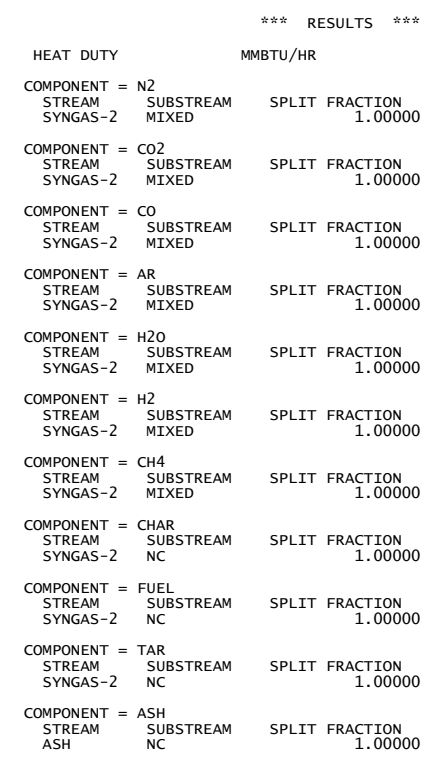

ASPEN PLUS PLAT: WIN32 VER: 20.011096 HOG FUEL GASIFICATION PROJECT CASE A
$U-0-S$ BLOCK SECTION (HIERARCHY: GASIFIER)

BLOCK: EVP-DEVL MODEL: RYIELD (CONTINUED)

BLOCK: DVL-EXCH MODEL: HEATER

\begin{tabular}{l} 
BLOCK: DVL-EXCH MODEL: HEATER \\
\hline INLET STREAM:
\end{tabular}

INLET HEAT STREAM: HEAT-2

OUTLET STREAM:
PROPERTY OPTION SET:
PR-BM

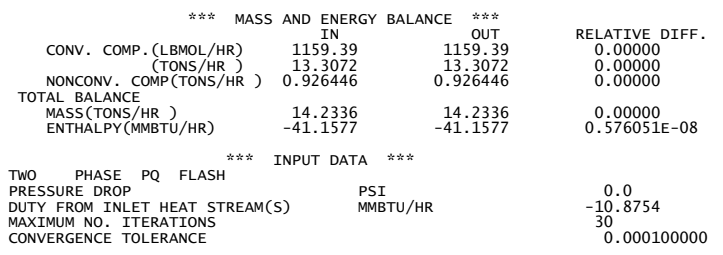

$\begin{array}{lll}\text { OUTLET TEMPERATURE } & \text { F } * * * & \text { RESULTS } \\ \text { OUTLET PRESSURE } & \text { PSI }\end{array}$

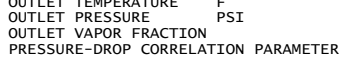

V-L PHASE EQUILIBRIUM :

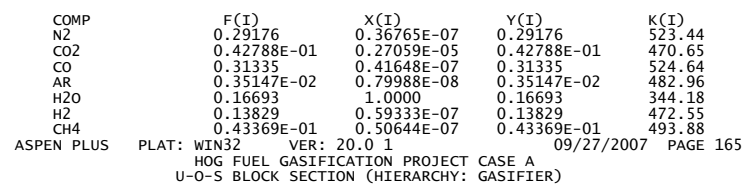

BLOCK: EVP-DEVL MODEL: RYIELD

$\begin{array}{ll}\text { INLET STREAM: } & \text { BIOMASS } \\ \text { OUTLET STREAM: } & \text { DEVOLPRD }\end{array}$

$\begin{array}{lll}\text { OUTLET HEAT STREAM: } & \text { HEAT-1 } \\ \text { PROPERTY OPTION SET: } & \text { PR-BM } & \text { PENG-ROBINSON EQUATION OF STATE }\end{array}$

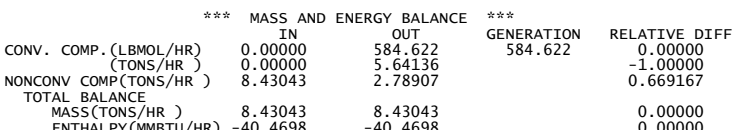

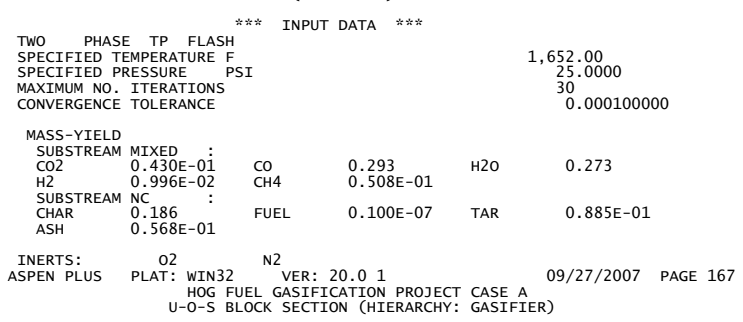

BLOCK: EVP-DEVL MODEL: RYIELD (CONTINUED)

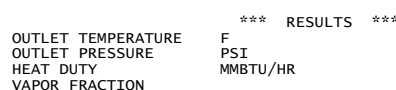

1652.0
25.000
10.473

V-L PHASE EQUILIBRIUM :

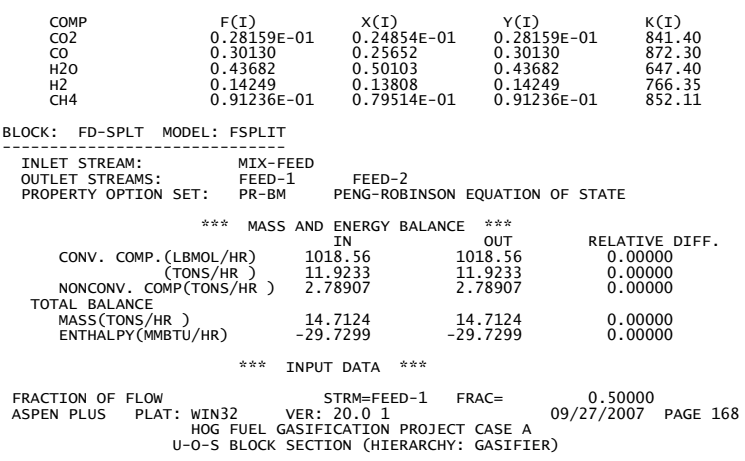



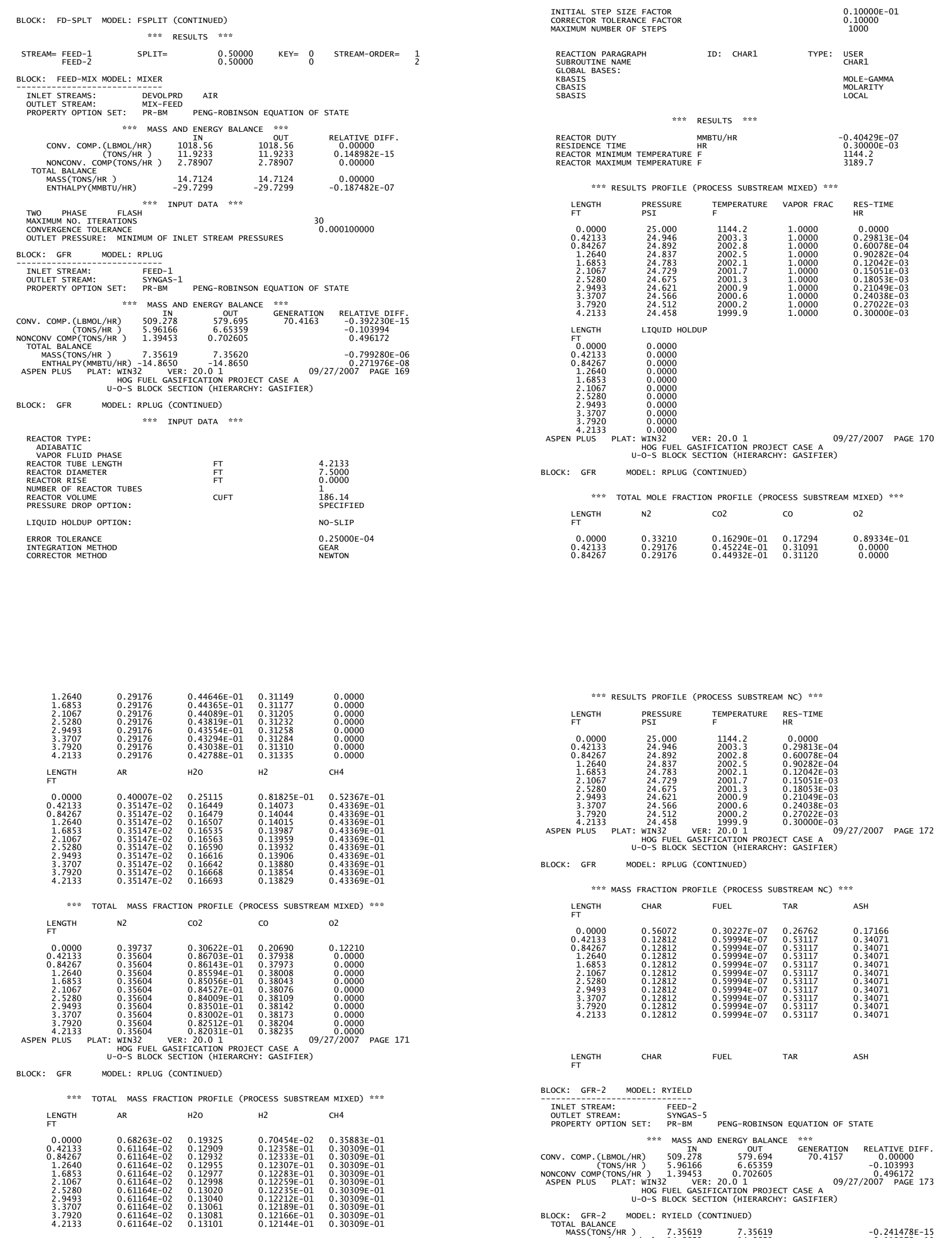

BLOCK: GFR-2 MODEL: RYIELD

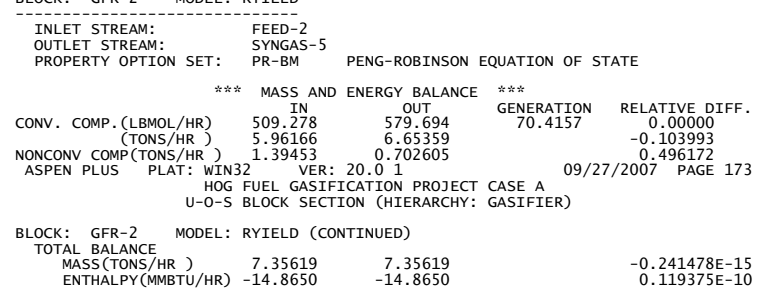




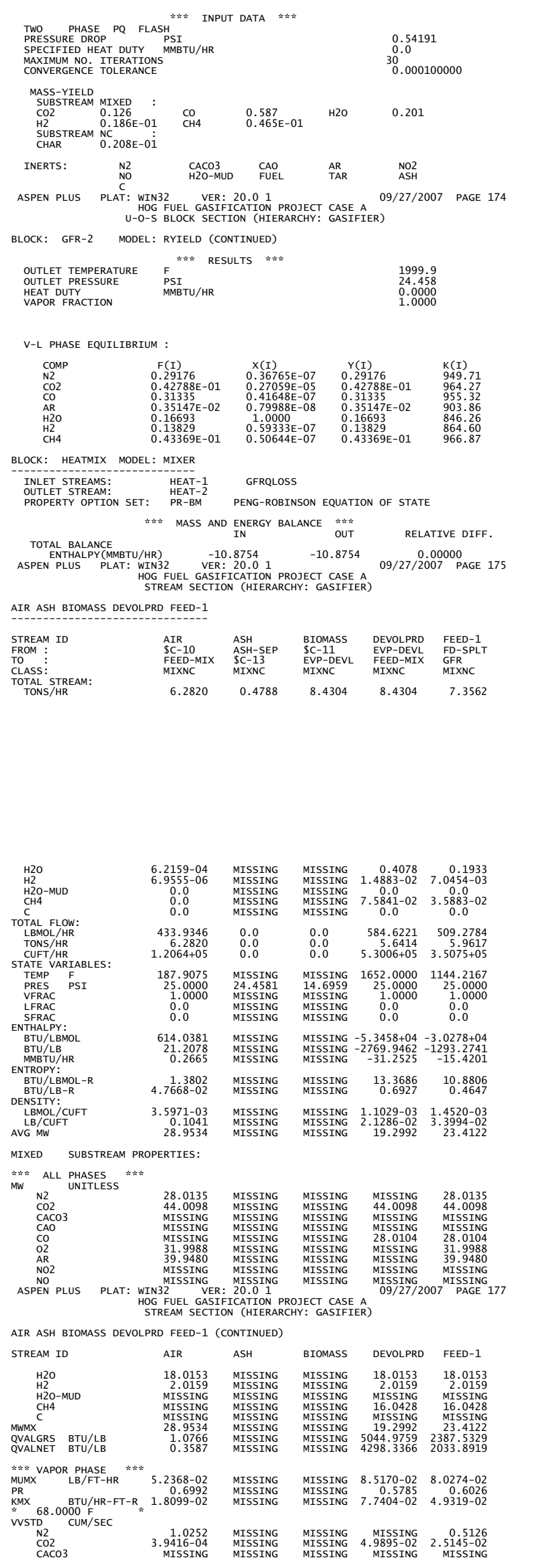

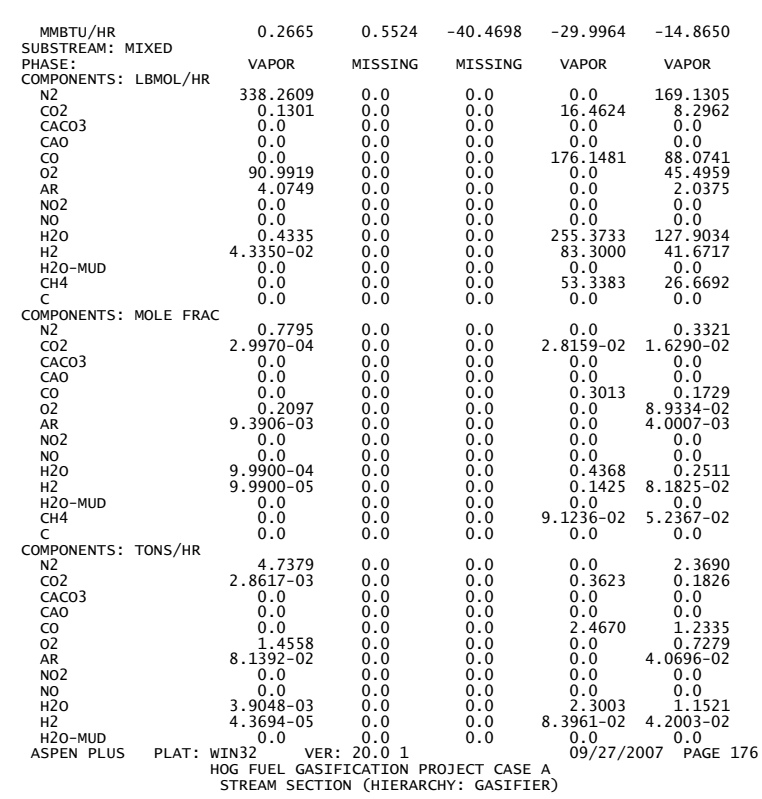

AIR ASH BIOMASS DEVOLPRD FEED-1 (CONTINUED)

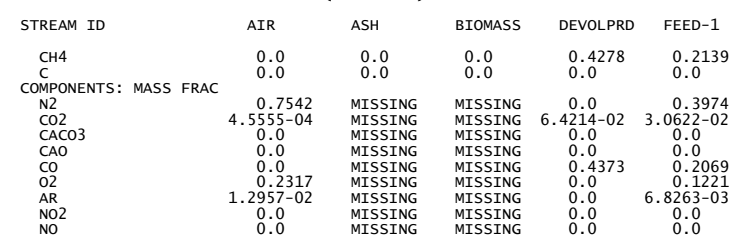

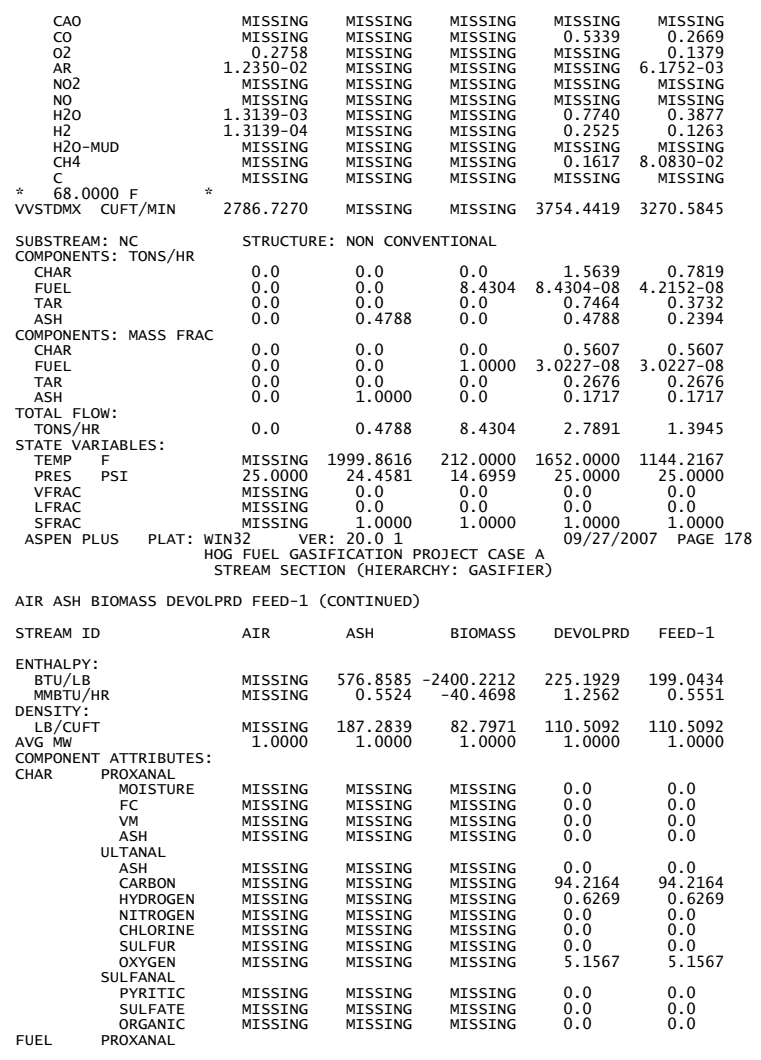



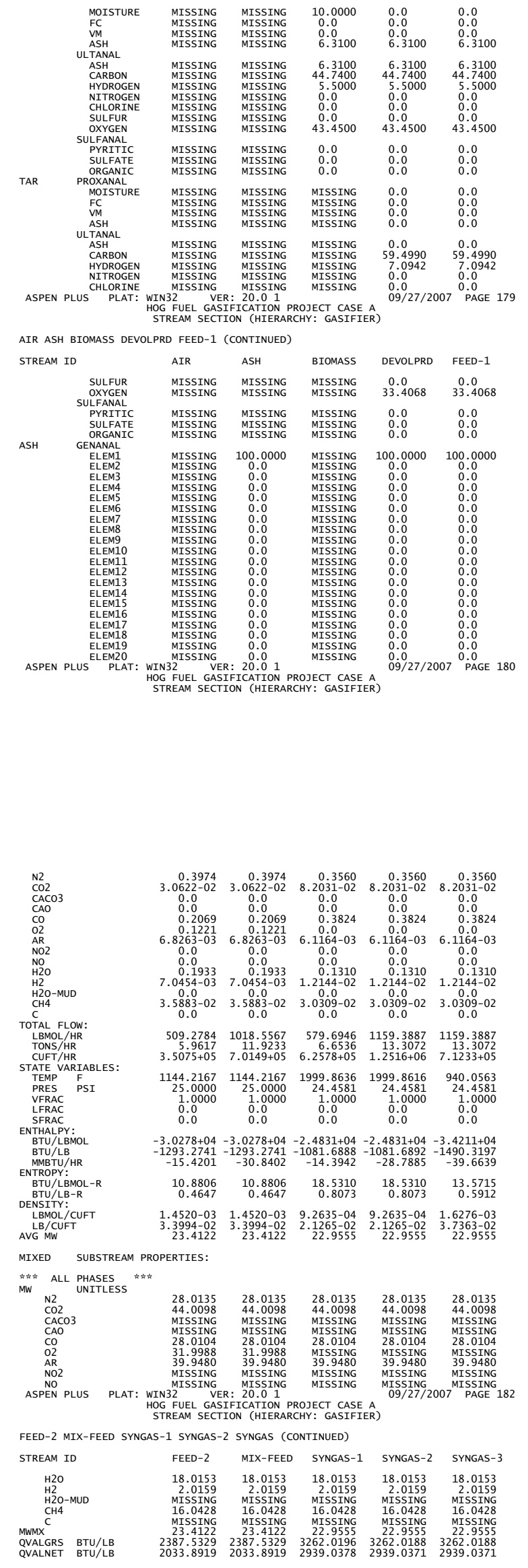
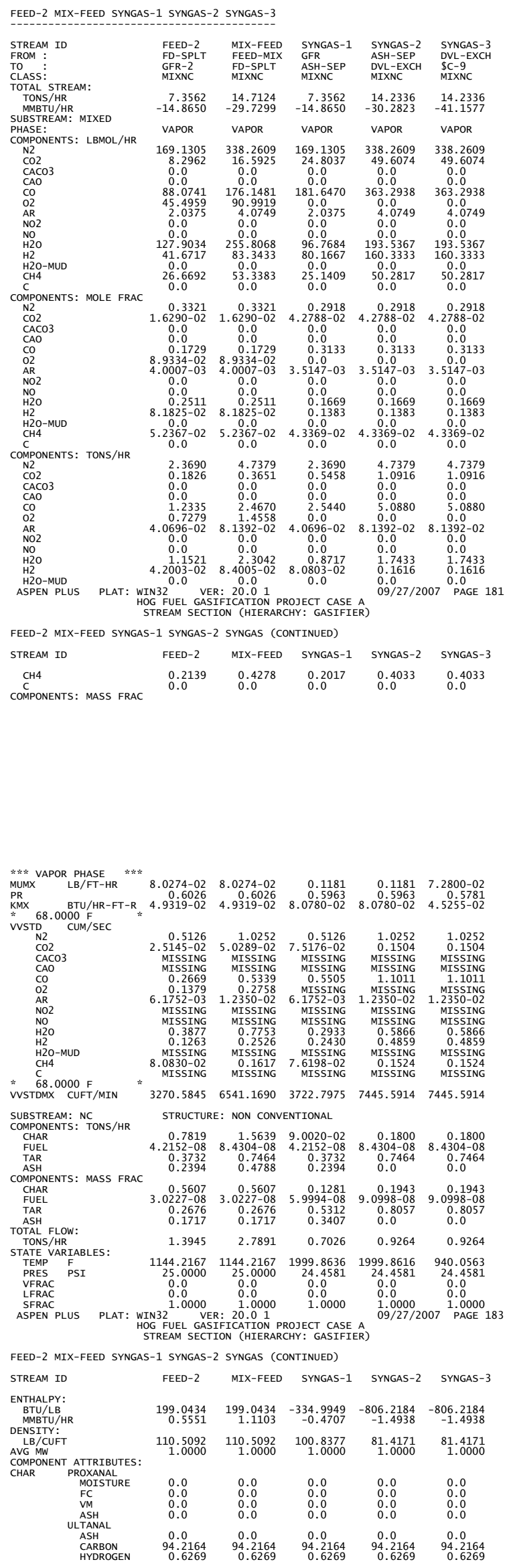


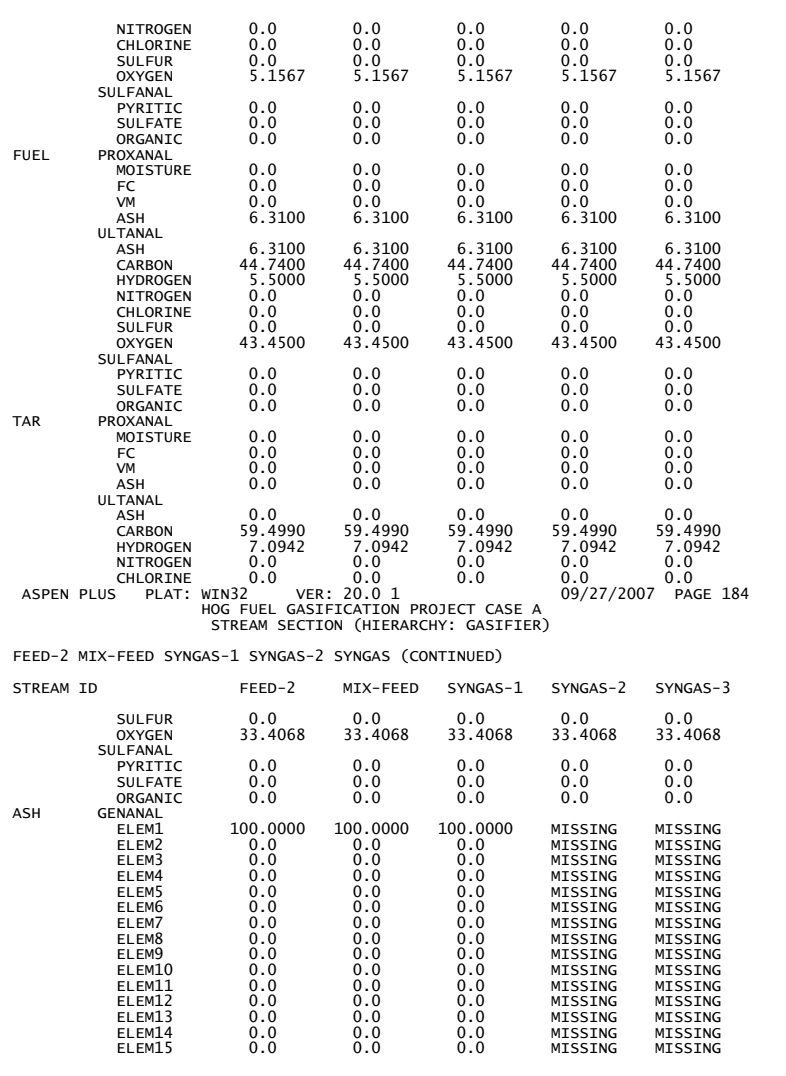

STREAM SECTION (HIERARCHY: GASIFIER)

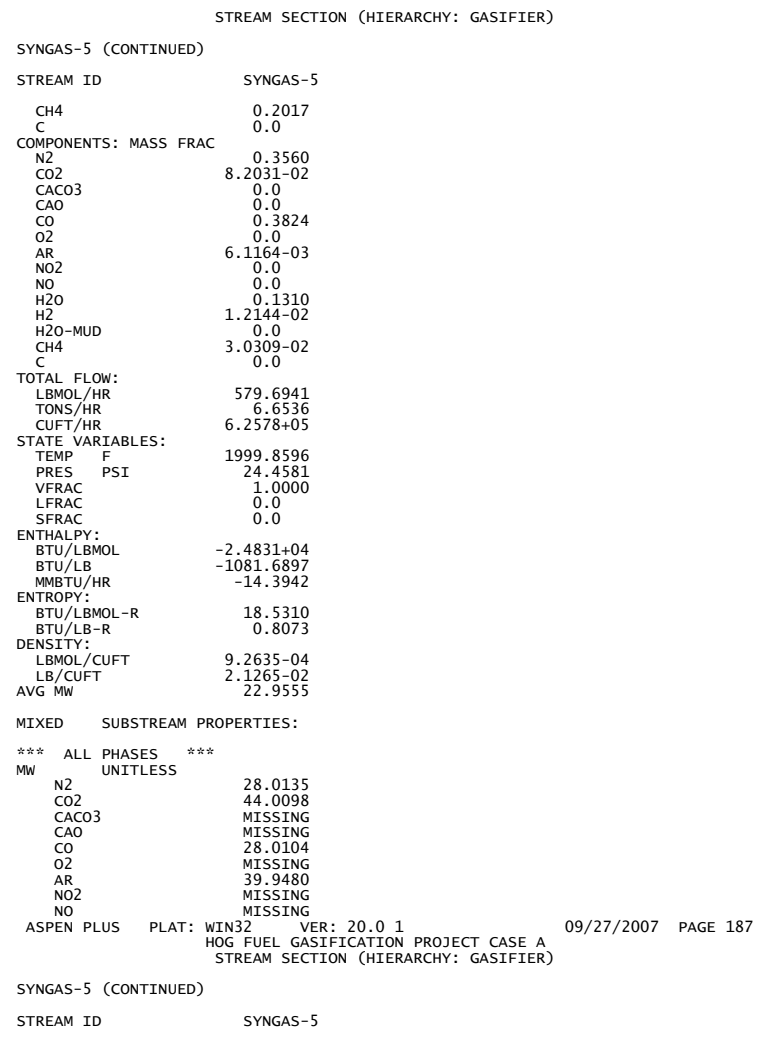

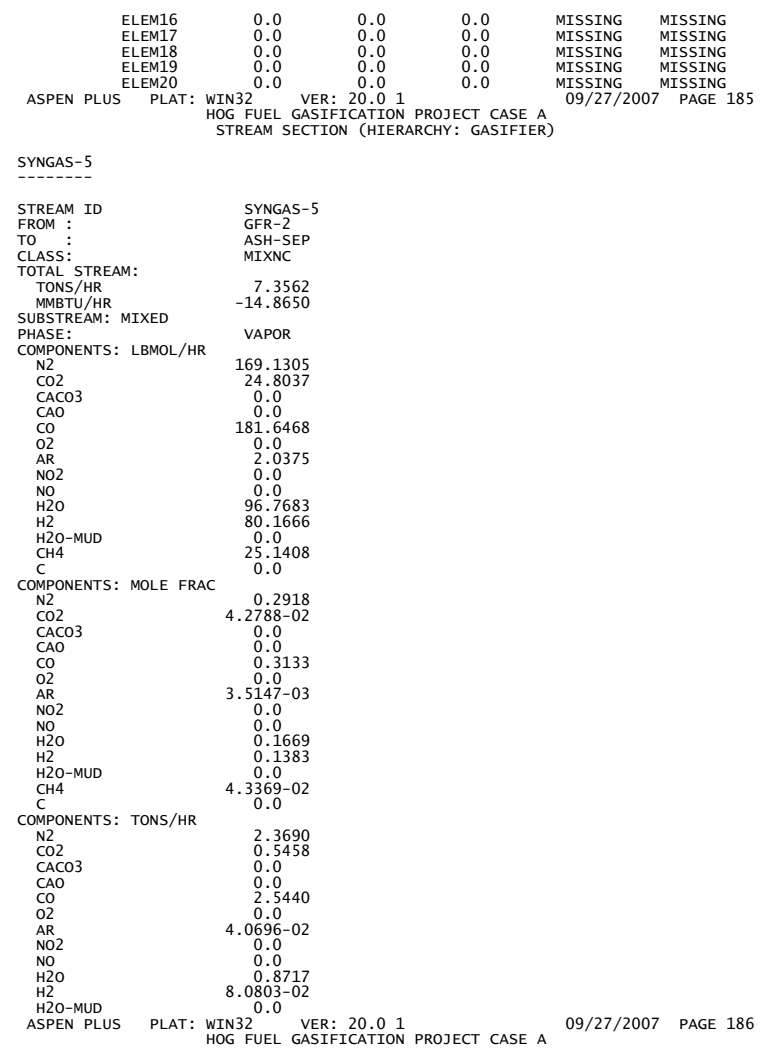

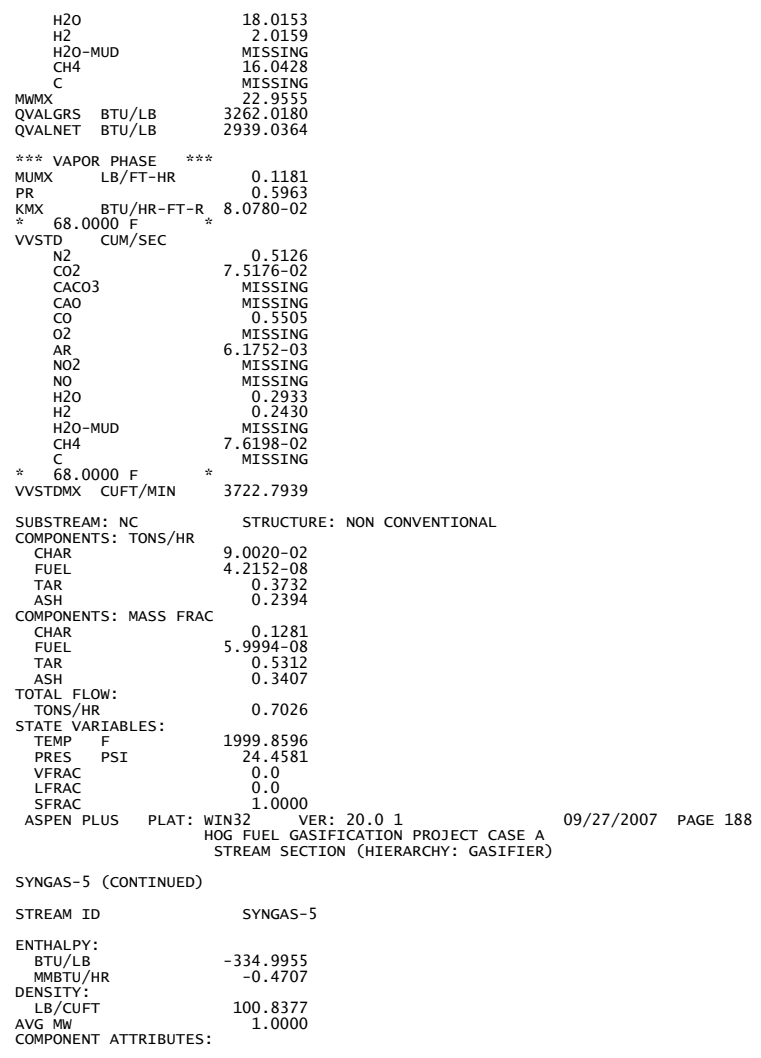



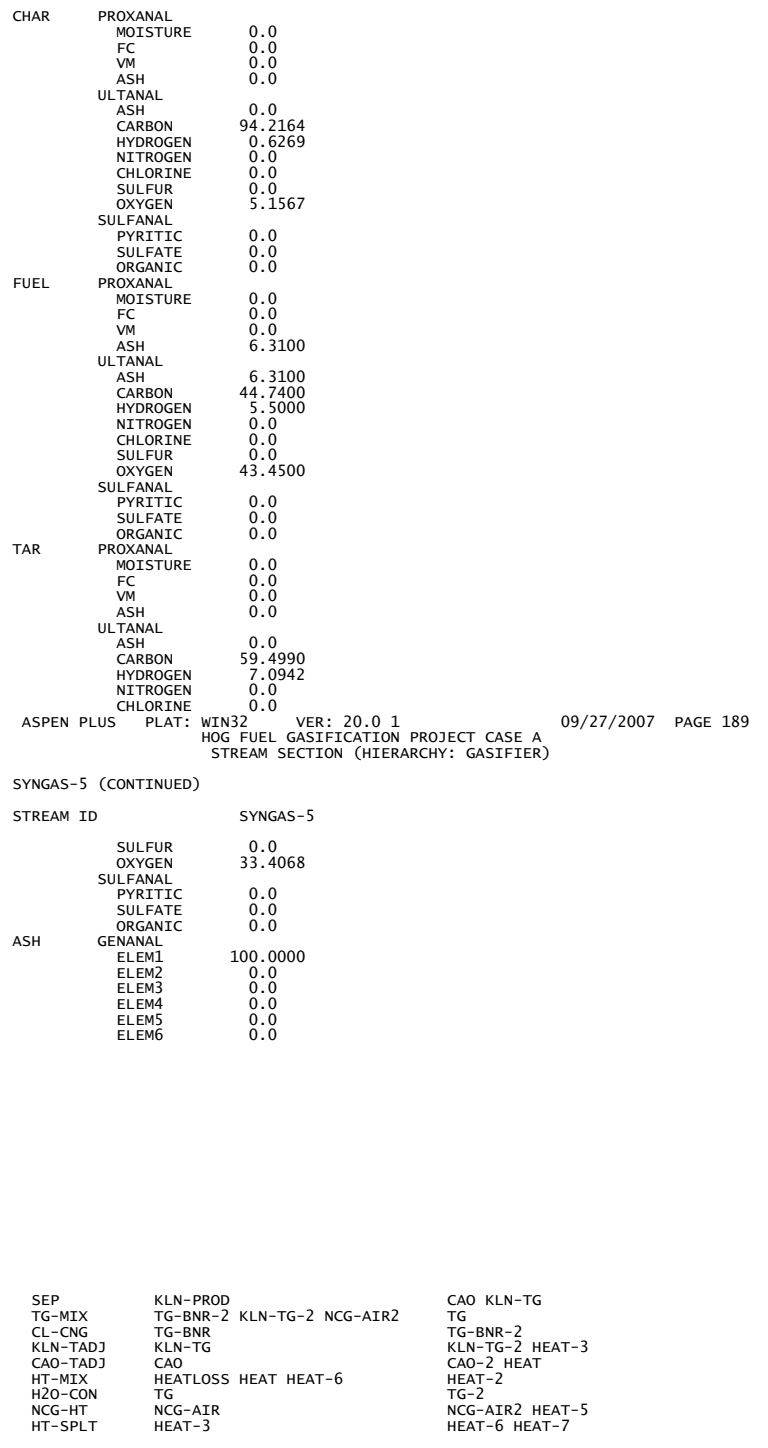

FLOWSHEET SECTION BALANCE: GLOBAL

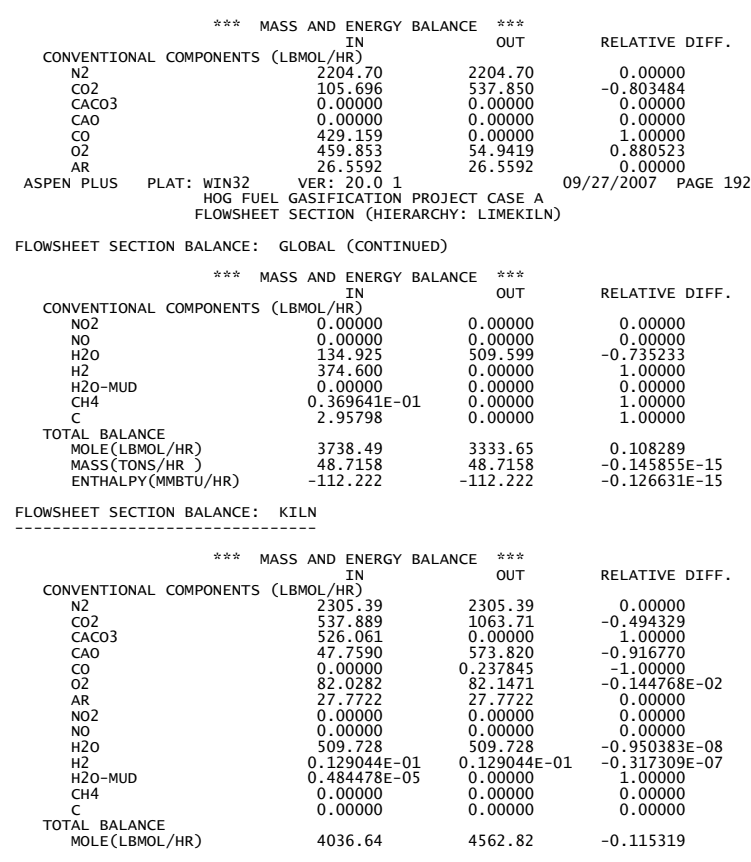

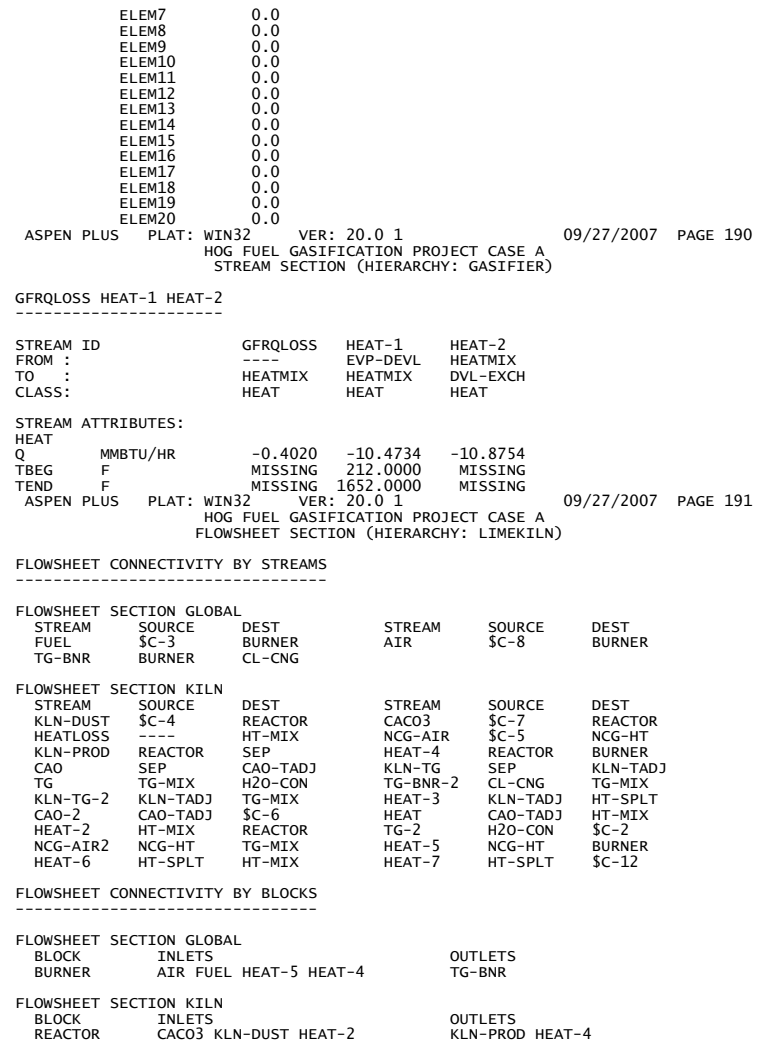

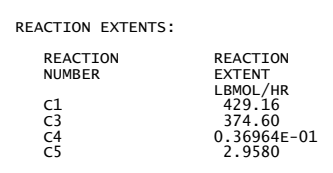



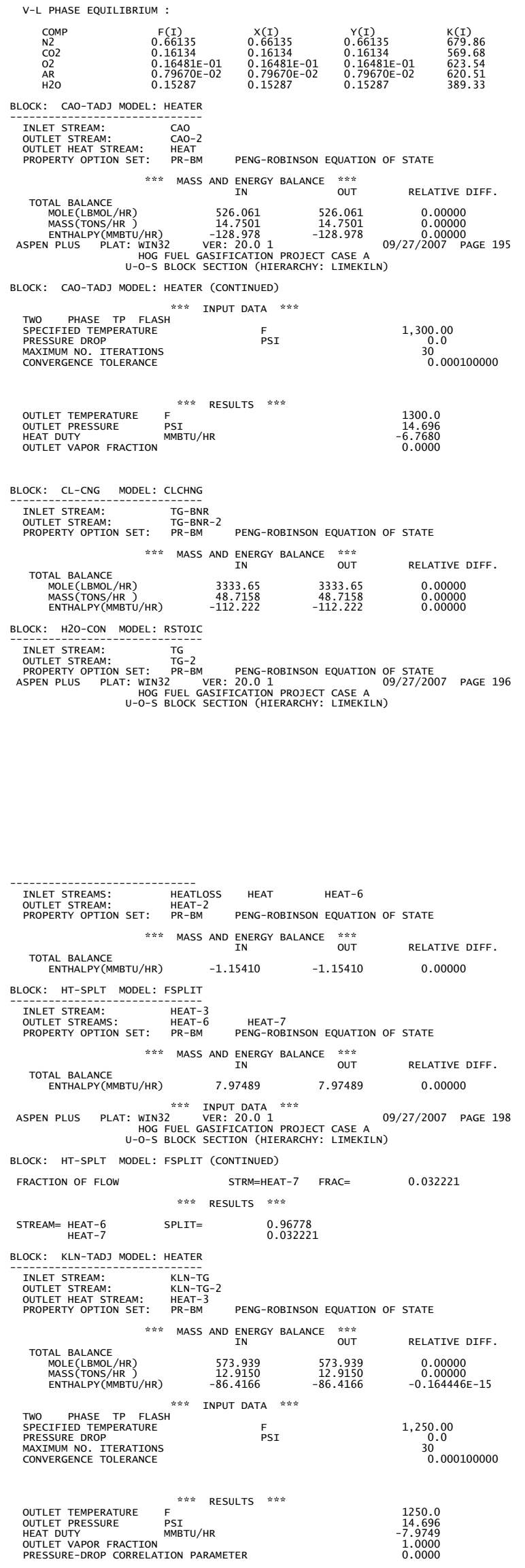

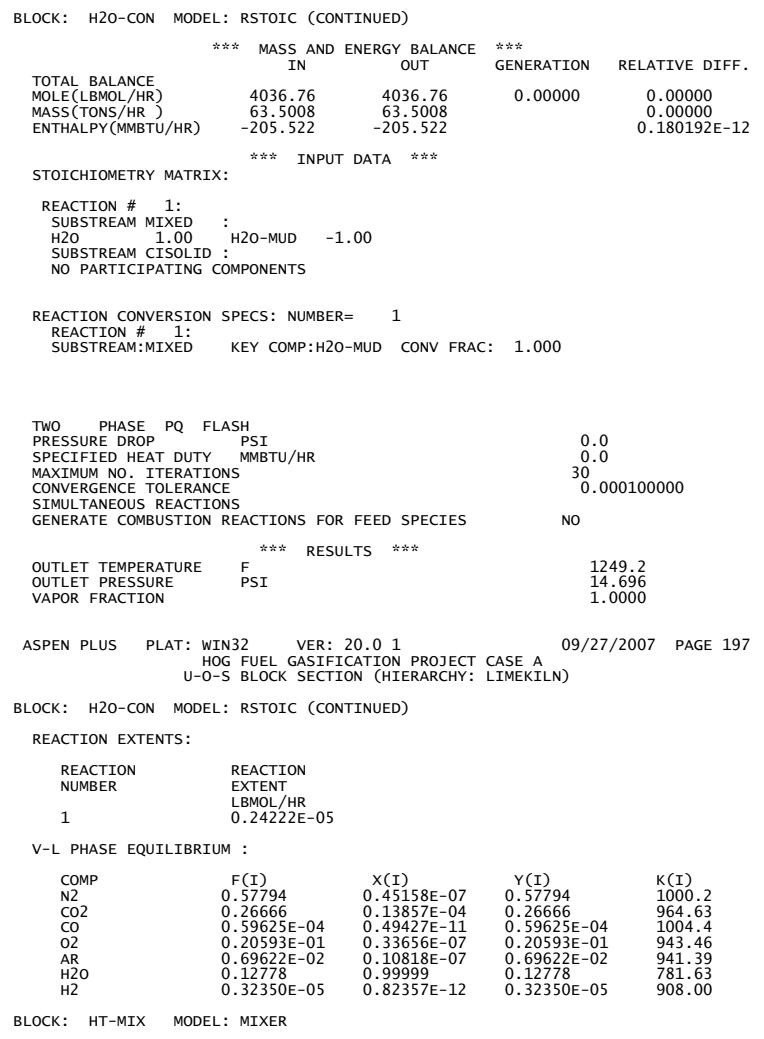



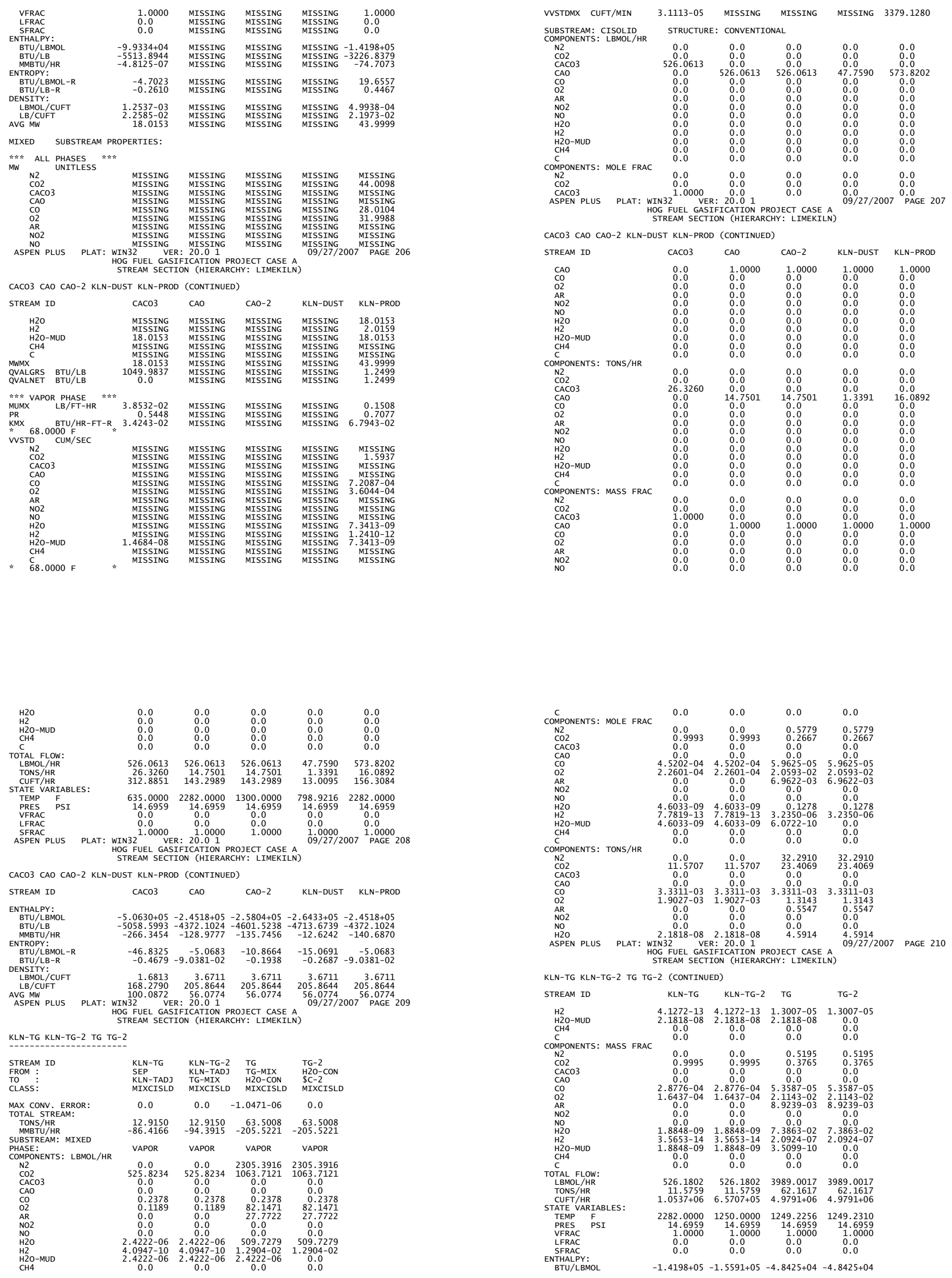

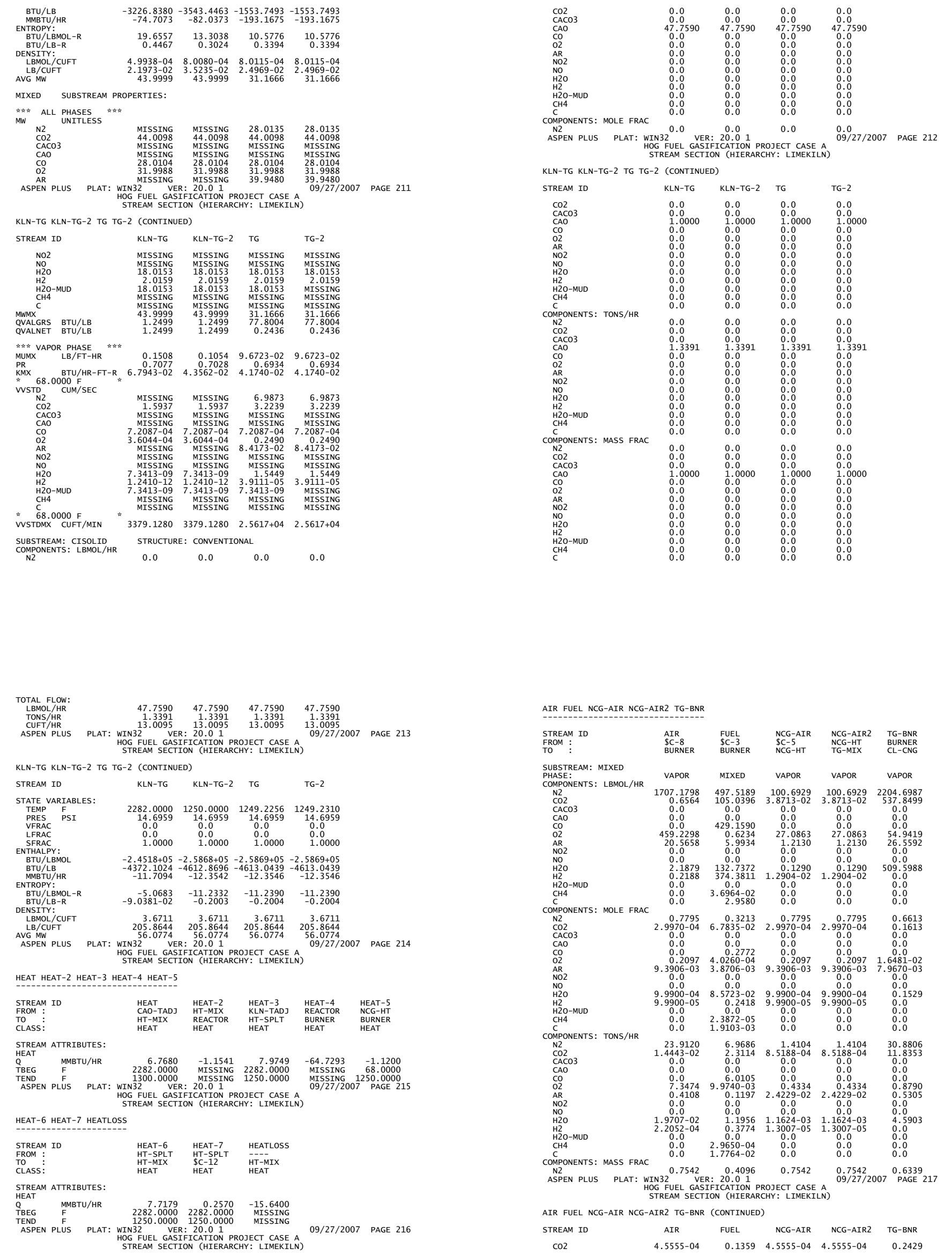

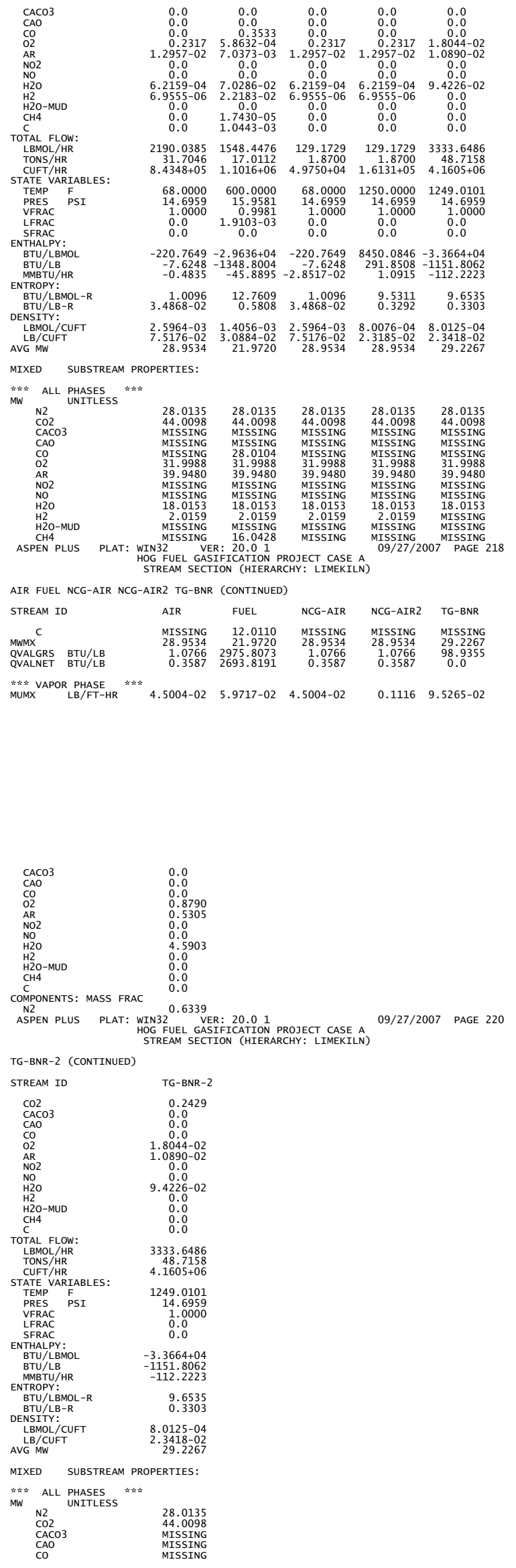

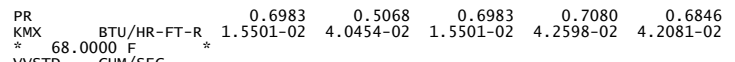

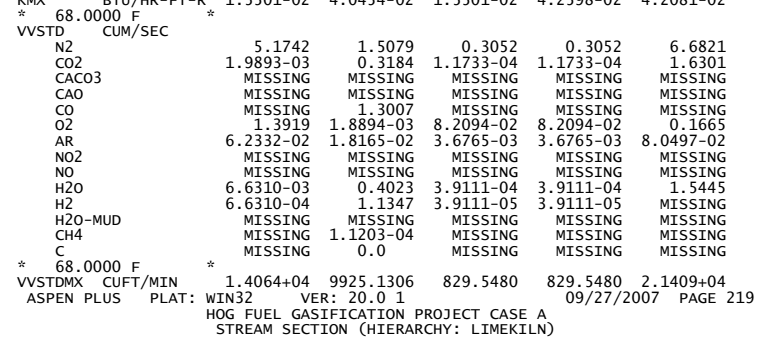

TG-BNR-2
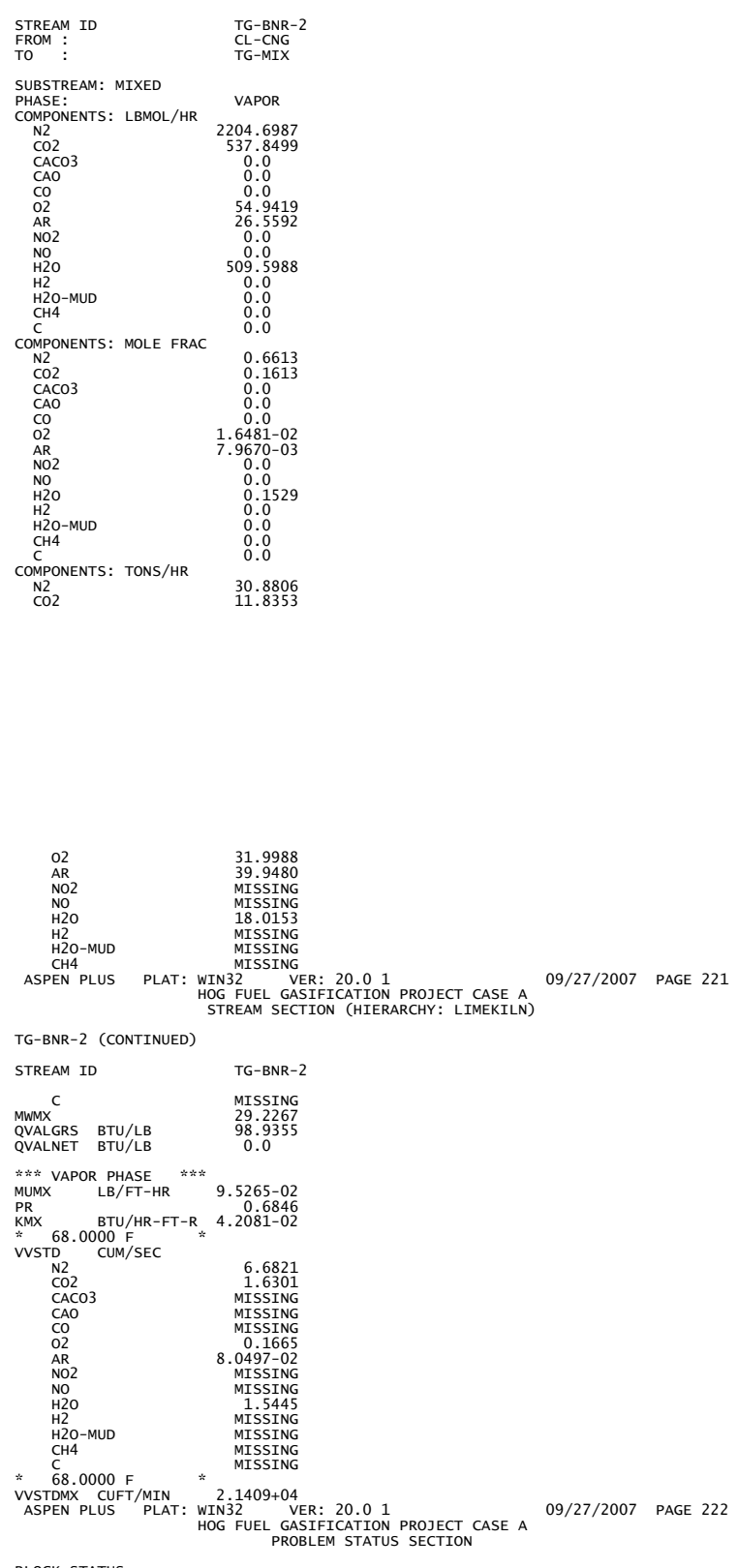

BLoCK STATUS

Calculations were completed normally

* A11 unit operation blocks were completed normally

* A11 streams were flashed normally

*A11 Utility blocks were completed normally

*A11 Convergence blocks were completed normally

* All calculator blocks were completed normally 



\section{Appendix C}

Fortran User Kinetic Subroutine 



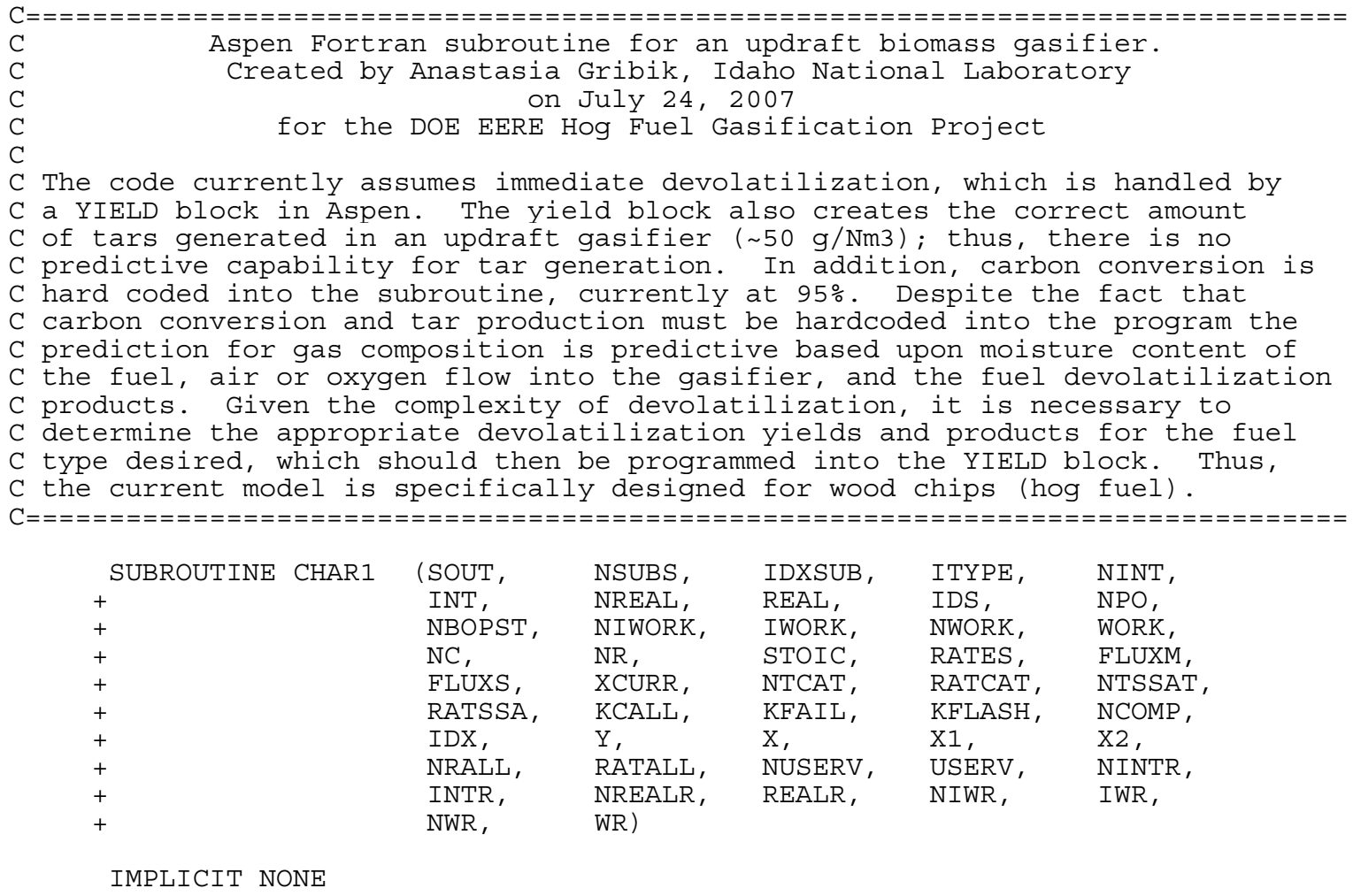

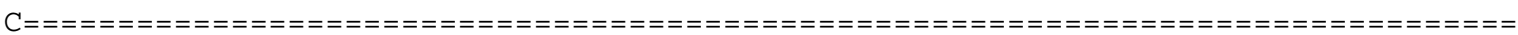
C Declare variables used in dimensioning.

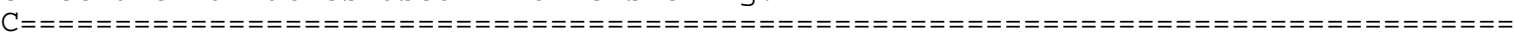

\begin{tabular}{lllll}
\multicolumn{1}{r}{ INTEGER } & NSUBS, NINT, NPO, NIWORK, NWORK, \\
+ & NC, & NR, & NTCAT, NTSSAT, NCOMP, \\
+ & NRALL, NUSERV, NINTR, NREALR, NIWR, \\
+ & NWR & &
\end{tabular}

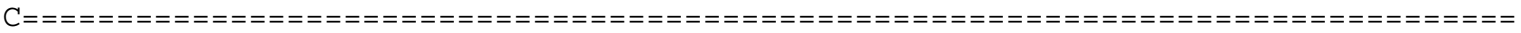
C Labeled commons to pass data for RPLUG.

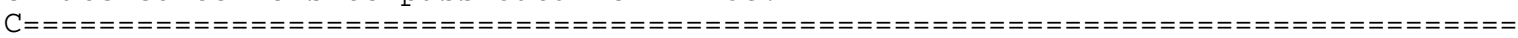

\#include "rplg rplugi.cmn"

EQUIVALENCE (NTUBE，RPLUGI_NTUBE)

\#include "rplg rplugr.cmn"

EQUIVALENTCE (XLEN, RPLUGR UXLONG)

EQUIVALENCE (DIAM, RPLUGR_UDIAM)

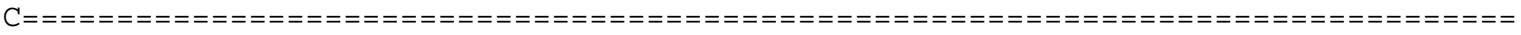
C General labeled commons to pass physical property data.

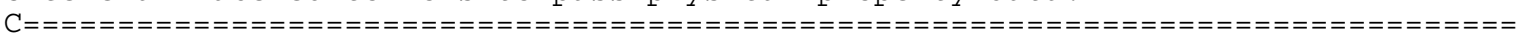

\#include "rxn rprops.cmn"

EQUIVALENCE (TEMP, RPROPS UTEMP)

EQUIVALENCE (PRES, RPROPS UPRES)

EQUIVALENCE (VFRAC, RPROP $\bar{S}$ UVFRAC)

EQUIVALENCE (BETA, RPROPS_UBETA)

EQUIVALENCE (VVAP, RPROPS UVVAP)

EQUIVALENCE (VLIQ, RPROPS UVLIQ)

EQUIVALENCE (VLIQS, RPROPS UVLIQS)

\#include "pputl_ppglob.cmn"

\#include "dms_ncomp.cmn" 


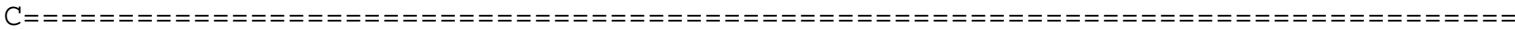

C General user common for all user-specified routines.

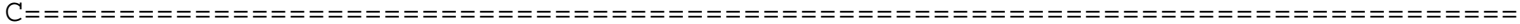

\#include "ppexec user.cmn"

EQUIVALENCE $\bar{E}$ (RMISS, USER_RUMISS)

EQUIVALENCE (IMISS, USER_IUMISS)

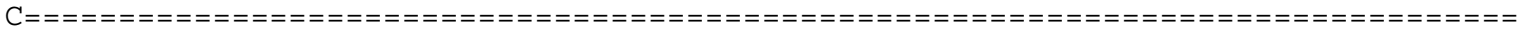

C Declarations

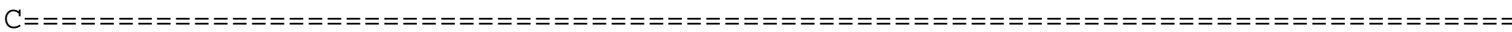

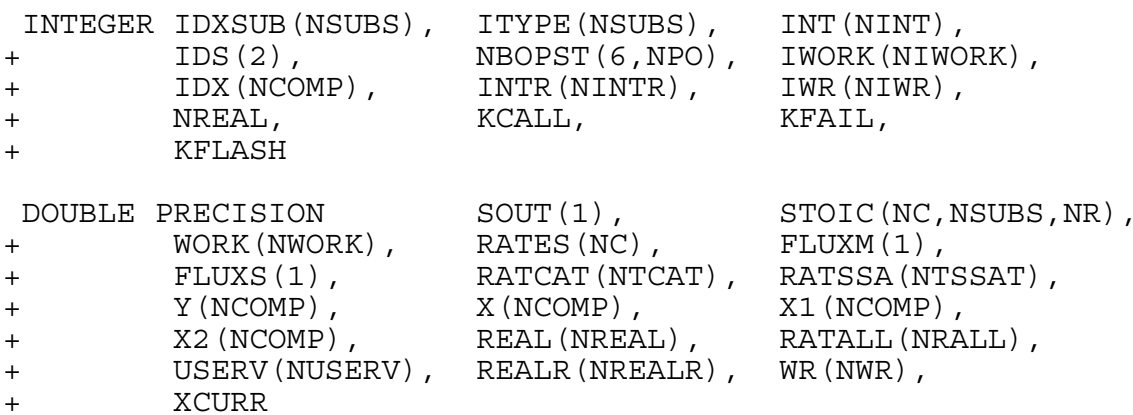

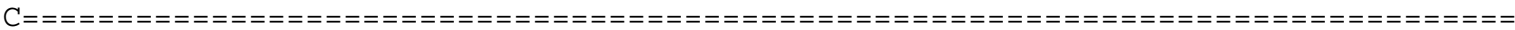
C Declare local variables

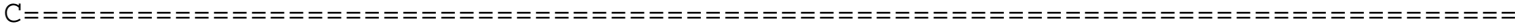

\begin{tabular}{|c|c|c|c|c|}
\hline INTEGER & DMS KFORMC, & DMS KNCIDC, & $I$, & $\mathrm{ICH} 4$, \\
\hline+ & ICHĀR, & $\mathrm{ICO}^{-}$ & ICO2, & IFUEL , \\
\hline+ & IH2, & IH2O, & IMISS, & IN2, \\
\hline+ & IO2, & IPROG ( 2) , & ITAR, & NTUBE \\
\hline DOUBLE & PRECISION & $\mathrm{ACH} 4$, & $\mathrm{ACHCO} 2$, & $\mathrm{ACHH} 2$, \\
\hline+ & АCHH2O, & $\mathrm{ACHO} 2$, & $\mathrm{ACO}$ & $\mathrm{ACO} 2$, \\
\hline+ & $\mathrm{AH} 2$, & $\mathrm{AH} 2 \mathrm{O}$, & ALPHA, & AREACONV, \\
\hline+ & BETA, & BETAA, & CARBON , & CARBONC, \\
\hline+ & CARBONO, & CHARUC, & CHARUH , & CHARUO , \\
\hline+ & $\mathrm{CHI}$, & $\mathrm{CONCCH} 4$, & CONCCO, & $\mathrm{CONCCO} 2$, \\
\hline+ & $\mathrm{CONCH} 2$, & $\mathrm{CONCH} 2 \mathrm{O}$, & $\mathrm{CONCO} 2$, & DIAM \\
\hline+ & $\mathrm{ECH} 4$ ， & ECHCO2， & ECHH2， & ECHH2O, \\
\hline+ & ECHO2， & $\mathrm{ECO}$, & $\mathrm{ECO} 2$, & EH2， \\
\hline+ & EH2O, & EPSILON, & FUELH, & FUELO, \\
\hline+ & FUELUC, & FUELUH , & FUELUO, & GAMMA, \\
\hline+ & GAMMAP , & HYDROGEN, & HYDROGENO, & $\mathrm{kCHCO} 2$, \\
\hline+ & $\mathrm{kCHH} 2$, & $\mathrm{kCHH} 2 \mathrm{O}$, & $\mathrm{kCHO} 2$, & $\mathrm{km}$, \\
\hline+ & MFTARO, & MWC, & MWCHAR , & MWFUEL , \\
\hline+ & MWH， & MWO , & MWTAR, & NUp , \\
\hline+ & OXYGEN, & OXYGENO, & PI, & PRES, \\
\hline+ & $\mathrm{R}$ ， & $\mathrm{RC}$ ， & $\mathrm{RCH} 4$ ， & $\mathrm{RCH} 4 \mathrm{CO} 2$ ， \\
\hline+ & $\mathrm{RCH} 4 \mathrm{H} 2 \mathrm{O}$, & $\mathrm{RCH} 4 \mathrm{O} 2$ & RCHCO2， & $\mathrm{RCHCO} 2 \mathrm{CO}$, \\
\hline+ & $\mathrm{RCHCO} 2 \mathrm{CO} 2$, & $\mathrm{RCHCO} 2 \mathrm{H} 2$, & $\mathrm{RCHCO} 2 \mathrm{H} 2 \mathrm{O}$, & $\mathrm{RCHH} 2$ ， \\
\hline+ & $\mathrm{RCHH} 2 \mathrm{CH} 4$ ， & $\mathrm{RCHH} 2 \mathrm{H} 2$ ， & RCHH2H2O, & RCHH2O, \\
\hline+ & $\mathrm{RCHH} 2 \mathrm{OCO}$, & RCHH2OH2， & RCHH2OH2O, & $\mathrm{RCHO} 2$, \\
\hline+ & $\mathrm{RCHO} 2 \mathrm{CO}$, & $\mathrm{RCHO} 2 \mathrm{CO} 2$, & $\mathrm{RCHO} 2 \mathrm{H} 2 \mathrm{O}$, & $\mathrm{RCHO} 2 \mathrm{O} 2$ ， \\
\hline+ & $\mathrm{RCO}$ ， & $\mathrm{RCO} 2$, & $\mathrm{RCO} 2 \mathrm{CO}$, & $\mathrm{RCO} 2 \mathrm{H} 2$, \\
\hline+ & $\mathrm{RCO} 2 \mathrm{H} 2 \mathrm{O}$, & $\mathrm{RCOCO} 2$, & $\mathrm{RCOO} 2$, & RH2， \\
\hline+ & $\mathrm{RH} 2 \mathrm{H} 2 \mathrm{O}$, & RH2O， & RH2O2， & $\mathrm{RH} 2 \mathrm{OCO}$, \\
\hline+ & $\mathrm{RH} 2 \mathrm{OCO} 2$ ， & RH2OH2， & RMISS, & Ro, \\
\hline+ & TARH， & TARO, & TARRAT, & TARUC, \\
\hline+ & TARUH, & TARUO, & TEMP, & Urat, \\
\hline
\end{tabular}




\begin{tabular}{|c|c|c|c|c|}
\hline+ & Us, & Uso, & VFRAC, & VLIQ, \\
\hline+ & VLIQS, & VOLFLOW, & VVAP, & XLEN, \\
\hline+ & YCH4, & $\mathrm{YCO}$ & YCO2, & YH2， \\
\hline+ & YH2O, & YN2， & YO2 & \\
\hline
\end{tabular}

open (unit=1, name= ' output . out ' , access= ' append ' , type= ' unknown' )

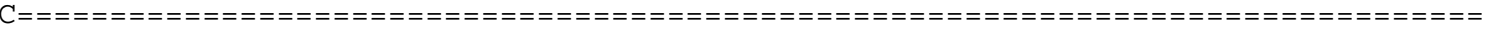

C Initialize rates vector.

$C$ This vector is used to specify the rate of change for each component.

C

C BEGIN EXECUTABLE CODE

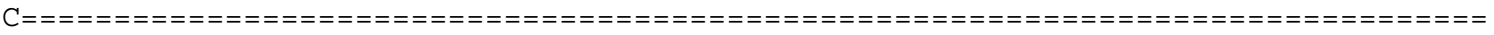

$\mathrm{DO} I=1, \mathrm{NC}$

END DO $\operatorname{RATES}(I)=0$

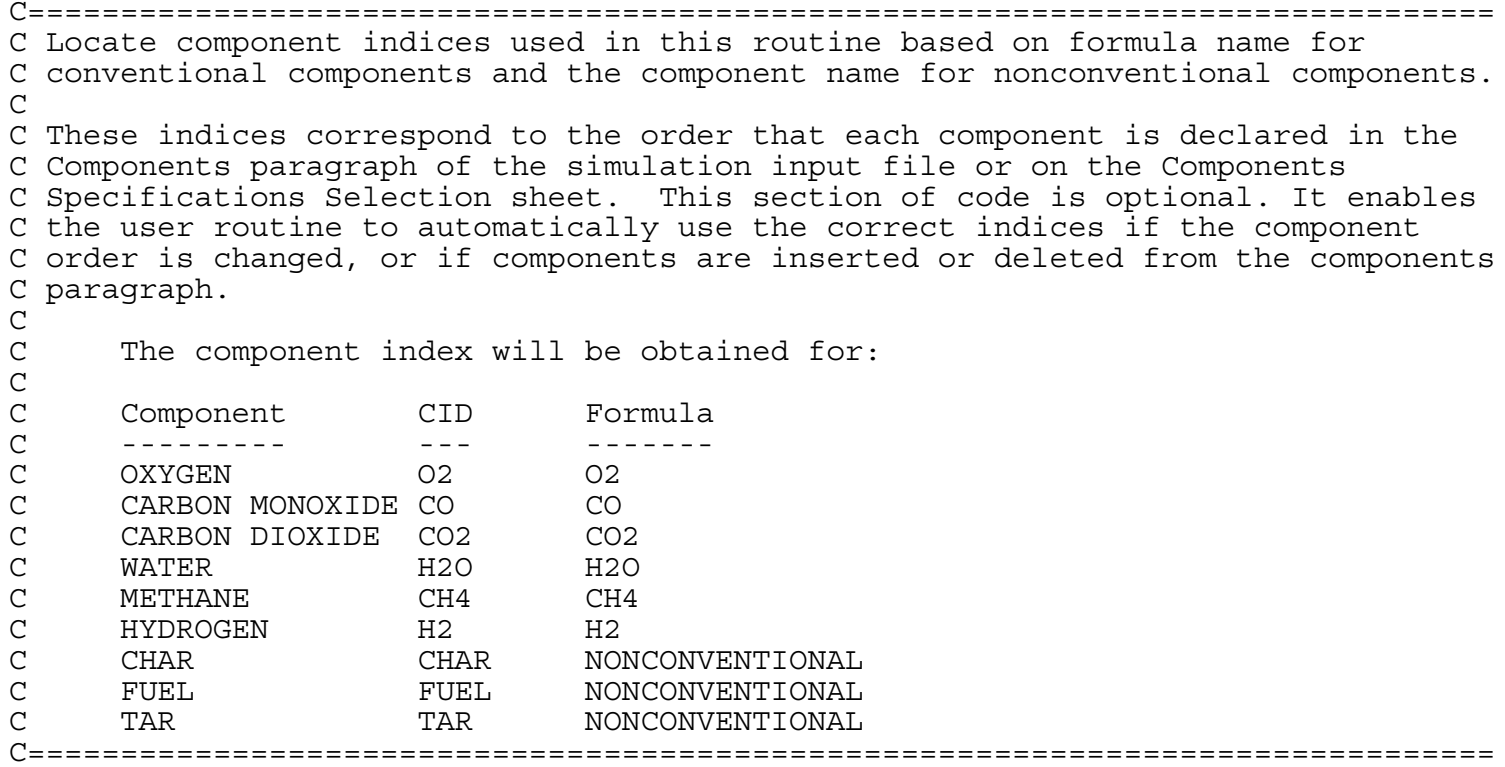

IO2 $=$ DMS KFORMC ('O2')

ICO $=$ DMS KFORMC (' $\mathrm{CO}$ ')

$\mathrm{ICO} 2=\mathrm{DM} \overline{\mathrm{S}} \mathrm{KFORMC}\left(\mathrm{CO}^{\prime}\right.$ ')

IH2O =DMS ${ }^{-} \mathrm{KFORMC}\left(\right.$ ' $\left.\mathrm{H} 2 \mathrm{O}^{\prime}\right)$

ICH4 $=$ DMS ${ }^{-} \mathrm{KFORMC}\left(\mathrm{CH}^{\prime}\right.$ ' $)$

IH2 $=$ DMS_ $\bar{K} F O R M C(' H 2$ ' $)$

IN2 $=\mathrm{DMS}{ }^{-} \mathrm{KFORMC}($ 'N2')

$I C H A R=N C O M P$ NCC + DMS KNCIDC ( ' CHAR')

IFUEL=NCOMP NCC+DMS KNCIDC ('FUEL')

ITAR $=$ NCOMP_NCC+DMS_KNCIDC ( ' TAR' )

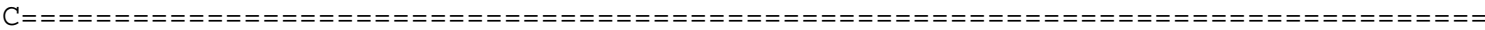

C The mass fractions of carbon, hydrogen, and oxygen are passed from the

C ultimate analysis for calculation of the molar fuel composition.

$\mathrm{C}$ The values for the hydrogen and oxygen in the fuel (which are used to balance

$C$ the reaction equations) are determined from the ultimate analysis of the fuel. C Molecular weight has units of $\mathrm{kg} / \mathrm{kmol}$.

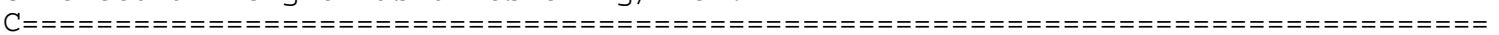

IF (XCURR.EQ.0.) THEN 
FUELUC $=$ SOUT $($ NCOMP $\mathrm{NCC}+9+$ NCOMP NNCC $+15+14)$ FUELUH $=$ SOUT $\left(\right.$ NCOMP $\left.{ }^{-} \mathrm{NCC}+9+\mathrm{NCOMP}^{-} \mathrm{NNCC}+16+14\right)$ FUELUO=SOUT (NCOMP_NCC+9+NCOMP_NNCC $+20+14$ )
! Fuel carbon content ! Fuel hydrogen content ! Fuel oxygen content
$\mathrm{MWH}=1.00794$

$\mathrm{MWO}=15.9994$

$\mathrm{MWC}=12.011$

FUELH $=($ FUELUH $/$ MWH $) /($ FUELUC $/$ MWC $)$ FUELO $=($ FUELUO $/$ MWO $) /($ FUELUC $/$ MWC $)$ MWFUEL $=$ MWC $+($ FUELH *MWH $)+($ FUELO $*$ MWO $)$
!Molecular weight of hydrogen !Molecular weight of oxygen !Molecular weight of carbon

!Calculation for hydrogen in fuel !Calculation for oxygen in fuel ! Molecular weight of fuel

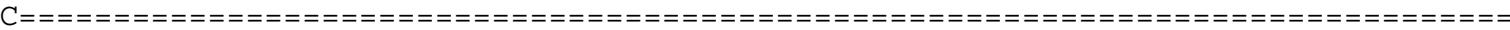
C The mass fractions of carbon, hydrogen, and oxygen are passed from the C ultimate analysis for calculation of the molar char composition.

C The values for alpha and beta (which are used to balance the reaction $C$ equations) are determined from the ultimate analysis of the char. The value $C$ for gamma is set to be equal to one.

C Molecular weight has units of $\mathrm{kg} / \mathrm{kmol}$.

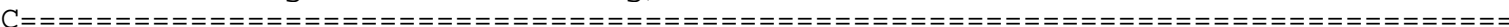

CHARUC $=$ SOUT $($ NCOMP NCC $+9+$ NCOMP NNCC +15$)$ CHARUH $=$ SOUT $\left(\right.$ NCOMP $\left.-\mathrm{NCC}+9+\mathrm{NCOMP}^{-} \mathrm{NNCC}+16\right)$ CHARUO $=$ SOUT $($ NCOMP_NCC $+9+$ NCOMP_NNCC +20$)$
! Char carbon content ! Char hydrogen content ! Char oxygen content

\begin{abstract}
$\mathrm{ALPHA}=(\mathrm{CHARUH} / \mathrm{MWH}) /(\mathrm{CHARUC} / \mathrm{MWC})$ BETAA $=($ CHARUO $/$ MWO $) /($ CHARUC $/$ MWC $)$ $\mathrm{MWCHAR}=\mathrm{MWC}+(\mathrm{ALPHA} * \mathrm{MWH})+(\mathrm{BETAA} * \mathrm{MWO})$
\end{abstract}

! Calculation for ALPHA (hydrogen) !Calculation for BETAA (oxygen) !Molecular weight of char

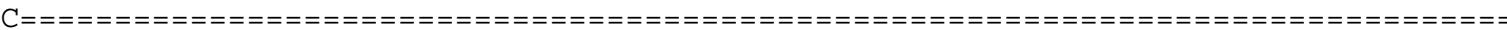
C The mass fractions of carbon, hydrogen, and oxygen are passed from the C ultimate analysis for calculation of the molar tar composition.

C The values for the hydrogen and oxygen in the tar (which are used to balance $C$ the reaction equations) are determined from the ultimate analysis of the tar. C Molecular weight has units of $\mathrm{kg} / \mathrm{kmol}$.

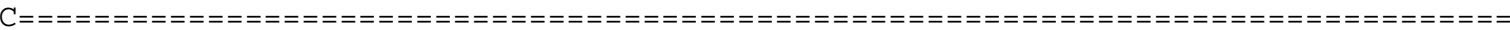

TARUC $=$ SOUT $($ NCOMP NCC $+9+$ NCOMP NNCC+15+14+14) ! Tar carbon content TARUH=SOUT (NCOMP NCC+9+NCOMP NNCC+16+14+14) ! Tar hydrogen content TARUO=SOUT (NCOMP_NCC+9+NCOMP_NNCC+20+14+14) ! Tar oxygen content

TARH $=($ TARUH $/$ MWH $) /($ TARUC $/$ MWC $)$ TARO $=($ TARUO $/$ MWO $) /($ TARUC $/$ MWC $)$ MWTAR $=$ MWC $+($ TARH $*$ MWH $)+($ TARO $*$ MWO $)$
! Calculation for hydrogen in tar !Calculation for oxygen in tar ! Molecular weight of tar

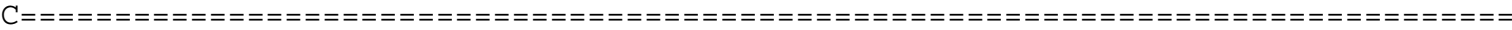
C Calculation of mass flow of initial carbon, hydrogen, and oxygen in system.

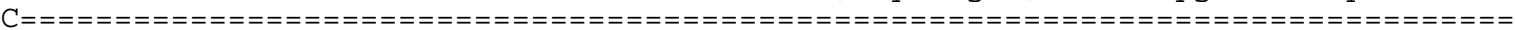

CARBONO $=($ SOUT $($ ICO $)+$ SOUT $($ ICO2 $)+$ SOUT $($ ICH4 $)+($ SOUT $($ ICHAR +9$) /$ MWCHAR $)+($ SOUT $($ IFUEL +9) /MWFUEL $)+($ SOUT $($ ITAR+9) $/$ MWTAR $)) *$ MWC

$+$

$+$

$+$ $+$

END IF HYDROGENO $=(2 . *$ SOUT $($ IH2O $)+4 . *$ SOUT $($ ICH 4$)+2 . *$ SOUT $($ IH2 $)+$ $($ SOUT $($ ICHAR+9) /MWCHAR $) * A L P H A+($ SOUT $($ IFUEL+9) /MWFUEL $) *$ FUELH+ (SOUT (ITAR+9) /MWTAR)*TARH)*MWH

OXYGENO $=(2 . *$ SOUT $($ IO2 $)+$ SOUT $($ ICO $)+2$. *SOUT $($ ICO2 $)+\operatorname{SOUT}($ IH $2 O)+$ (SOUT ( ICHAR+9) /MWCHAR) *BETAA+ (SOUT ( IFUEL+9) /MWFUEL $)$ * FUELO+ (SOUT ( ITAR+9) /MWTAR) *TARO) *MWO

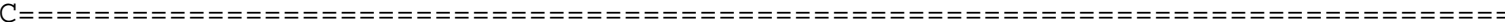
C Calculation of quantities used for reaction expressions. The following $\mathrm{C}$ information is taken from Di Blasi (2004). Note that it is assumed that the $C$ particle velocity is equivalent to the particle flow for the char, since $\mathrm{C}$ density and area are constant and would cancel in the ratio equation. Also the $C$ mass transfer coefficient used in the reaction rate equation is $\mathrm{km}$, or the C maximum value for mass transfer.

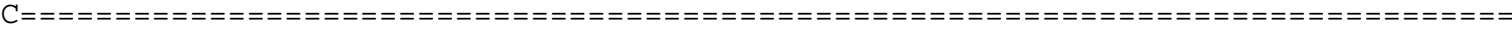




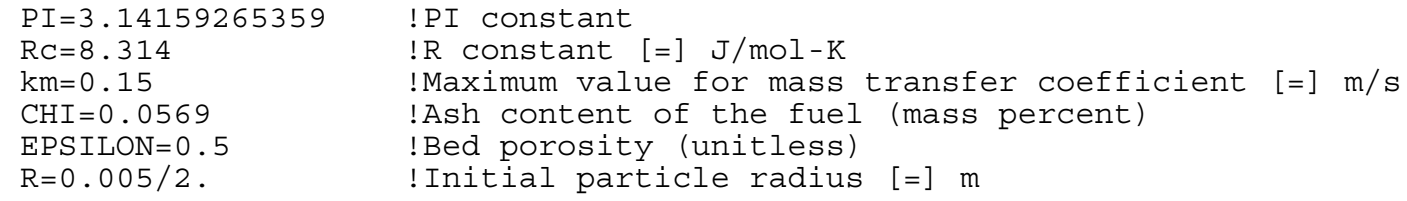

IF (XCURR.EQ.0.) THEN

Uso=SOUT(ICHAR+9) ! Initial char flow after devolatilization [=] $\mathrm{kg} / \mathrm{s}$ MFTARO=SOUT (ITAR+9) ! Initial tar flow after devolatilization [=] kg/s

!Erases the previous output file(s) REWIND (unit $=1$ )

!Writes the header for the output file(s)

write $(1,5)$

$+$

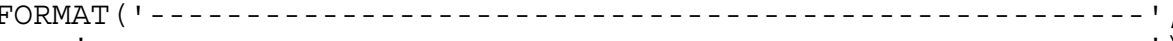

write $(1,10)$

10

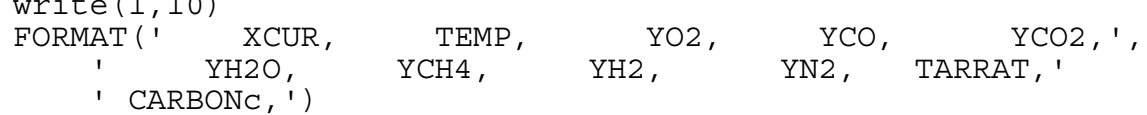

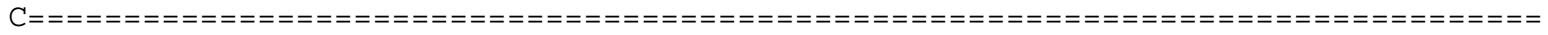
C Calculate the vapor concentration of each component and the current grams $\mathrm{C}$ of tar per standard cubic meter.

C

C The rate expression in this example is based on molar concentration. The C component concentration can be calculated by dividing the molar flow of the C species (kmol/s) by the current volumetric flowrate $(\mathrm{m} 3 / \mathrm{s})$. Note that the $C$ volumetric flow includes the volume flow of the tar species.

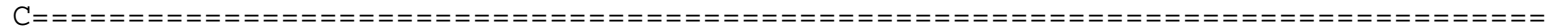

!Calculation of current volumetric gas flow, including tar [=] m3/s

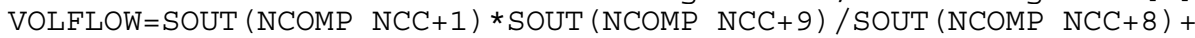

$+\quad((\operatorname{SOUT}($ ITAR +9$) \overline{/ M W T A R}) * \mathrm{RC} * 1000 *$ TEMP $/$ SOUT $($ NCOMP_NCC+3 $))$

CONCO2 =SOUT ( IO2 $) /$ VOLFLOW

$\mathrm{CONCCO}=\mathrm{SOUT}(\mathrm{ICO}) / \mathrm{VOLFLOW}$ $\mathrm{CONCCO} 2=\mathrm{SOUT}(\mathrm{ICO} 2) / \mathrm{VOLFLOW}$

CONCH2O=SOUT $($ IH2O $) /$ VOLFLOW

CONCCH4 =SOUT $($ ICH4 $) /$ VOLFLOW

$\mathrm{CONCH} 2=\mathrm{SOUT}($ IH2 $) /$ VOLFLOW

!g of Tar/Nm3

TARRAT $=$ SOUT $($ ITAR+9) $/(($ VOLFLOW $/($ TEMP*101325. $)) *(298.15 *$ PRES $)) * 1000$.
! Concentration of $02[=] \mathrm{kmol} / \mathrm{m} 3$ ! Concentration of $\mathrm{CO}[=] \mathrm{kmol} / \mathrm{m} 3$ ! Concentration of $\mathrm{CO} 2[=] \mathrm{kmol} / \mathrm{m} 3$ ! Concentration of $\mathrm{H} 2 \mathrm{O}[=] \mathrm{kmol} / \mathrm{m} 3$ ! Concentration of $\mathrm{CH} 4 \mathrm{l=} \mathrm{kmol} / \mathrm{m} 3$ ! Concentration of $\mathrm{H} 2$ [=] $\mathrm{kmol} / \mathrm{m} 3$ 


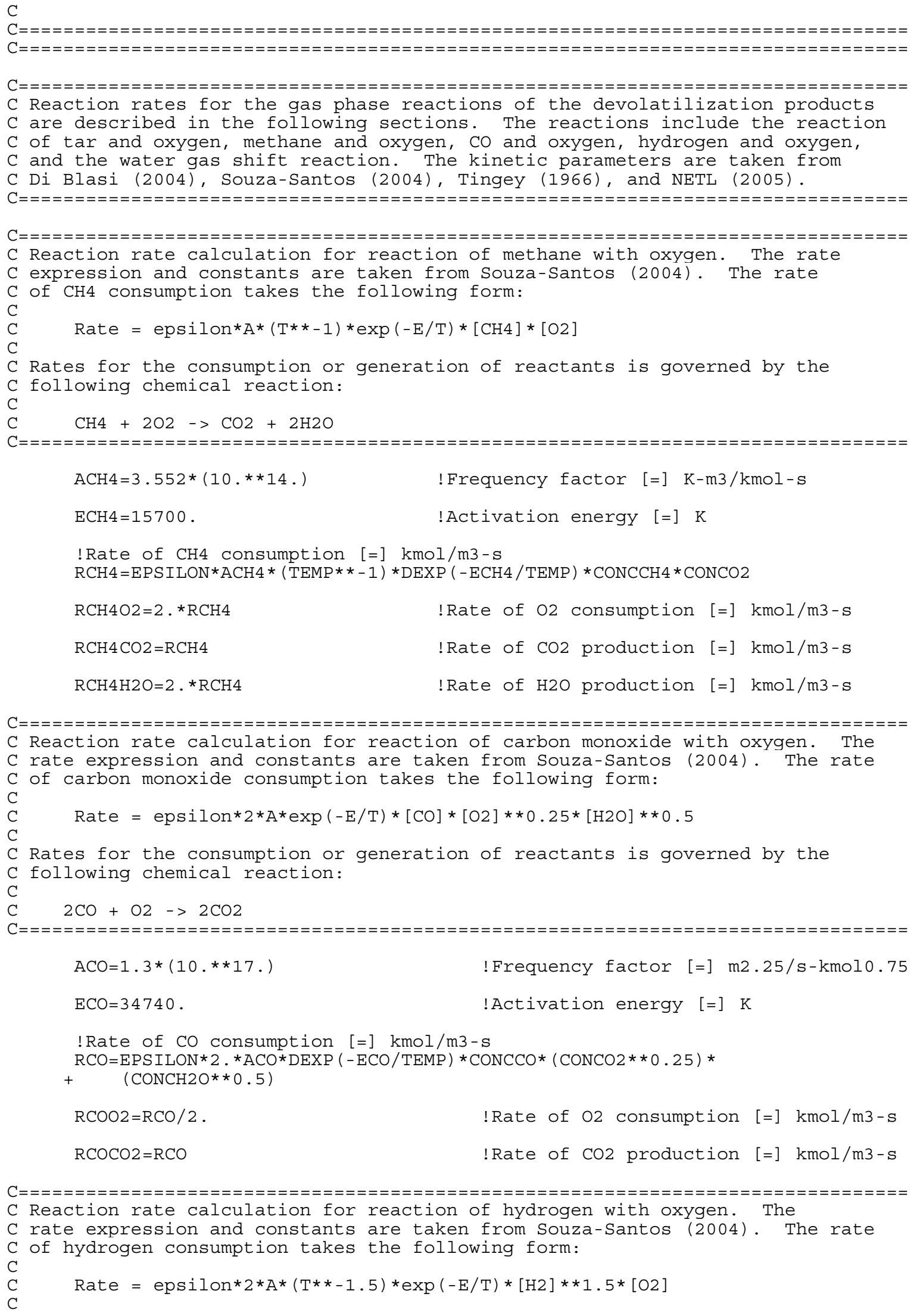


C Rates for the consumption or generation of reactants is governed by the C following chemical reaction:

C

$\mathrm{C} 2 \mathrm{H} 2+\mathrm{O} 2->2 \mathrm{H} 2 \mathrm{O}$

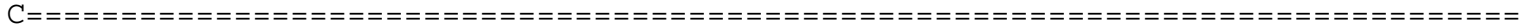

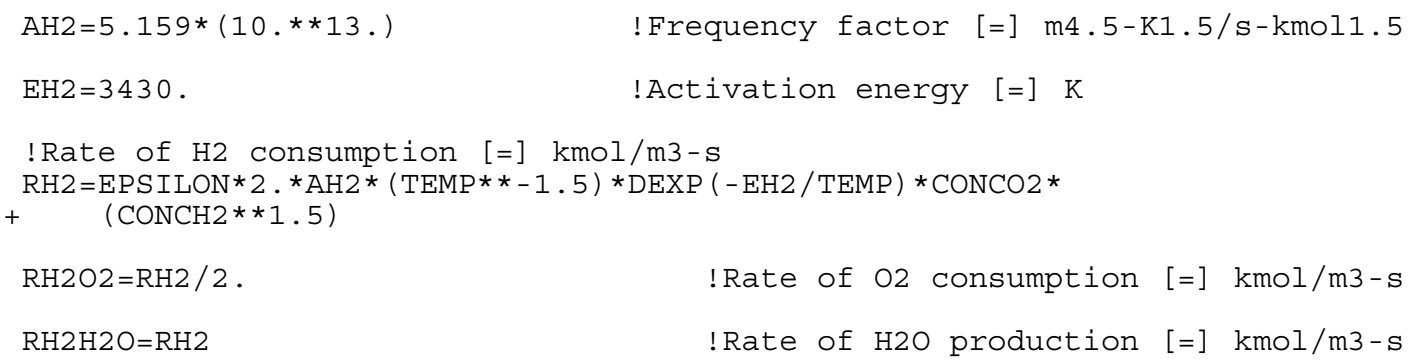

! Reverse Reaction

IF (TEMP.LT.1073.) THEN
$\mathrm{ACO} 2=7.6 *(10 . * * 4$.
!Frequency factor [=] ml.5/kmolo.333-s
$\mathrm{ECO} 2=39200 . * 4.1868$
! Activation energy $[=] \mathrm{J} / \mathrm{mol}$

!Rate of $\mathrm{CO} 2$ consumption [=] $\mathrm{kmol} / \mathrm{m3}-\mathrm{s}$ 


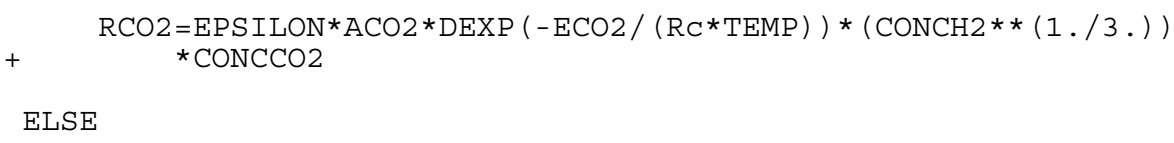

END IF

$\mathrm{RCO} 2 \mathrm{H} 2=\mathrm{RCO} 2$

! Rate of $\mathrm{H} 2$ consumption [=] $\mathrm{kmol} / \mathrm{m} 3-\mathrm{s}$

$\mathrm{RCO} 2 \mathrm{CO}=\mathrm{RCO} 2$

! Rate of CO production [=] $\mathrm{kmol} / \mathrm{m} 3-\mathrm{s}$

$\mathrm{RCO} 2 \mathrm{H} 2 \mathrm{O}=\mathrm{RCO} 2$

! Rate of $\mathrm{H} 2 \mathrm{O}$ production [=] $\mathrm{kmol} / \mathrm{m} 3-\mathrm{s}$

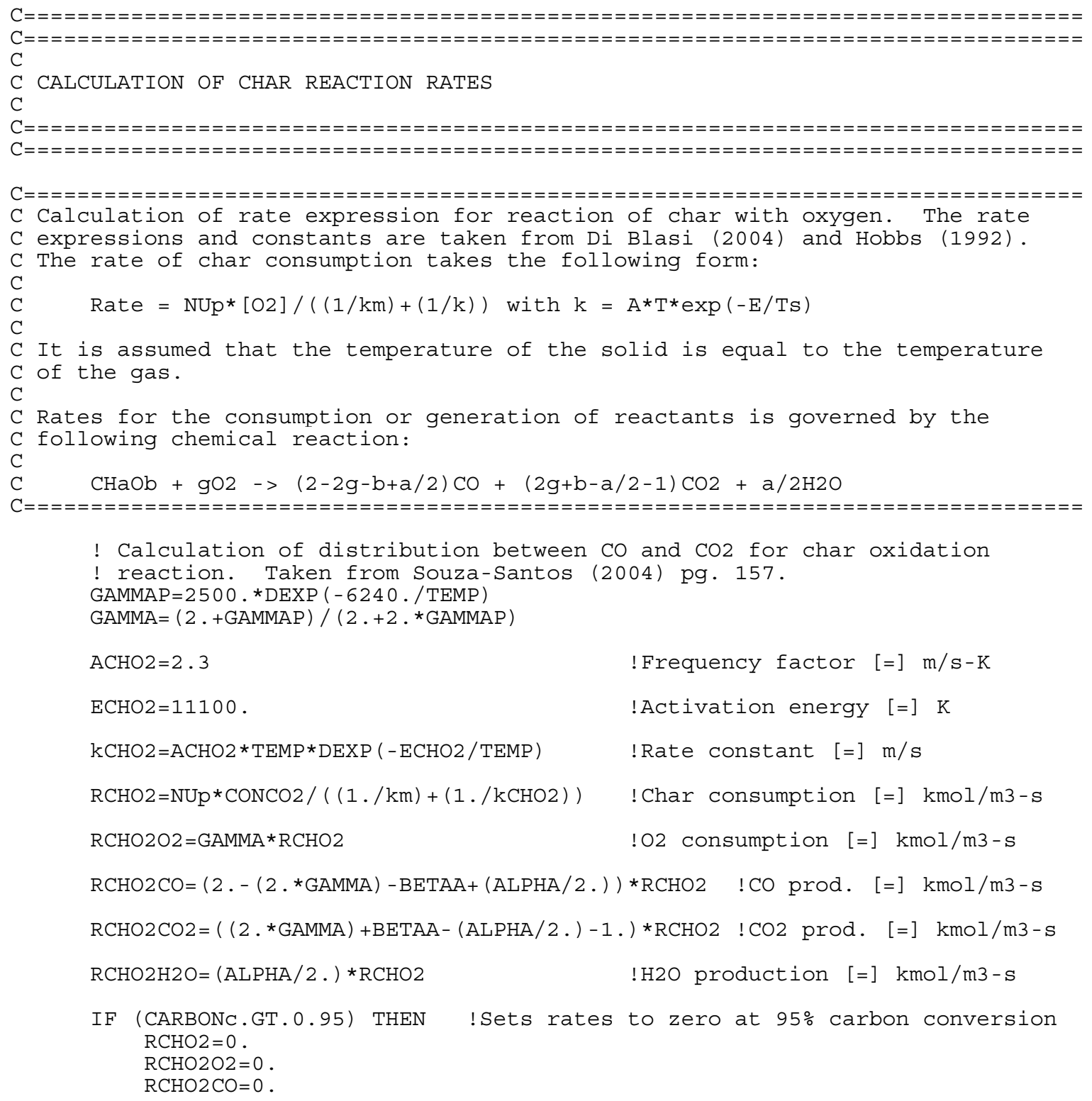




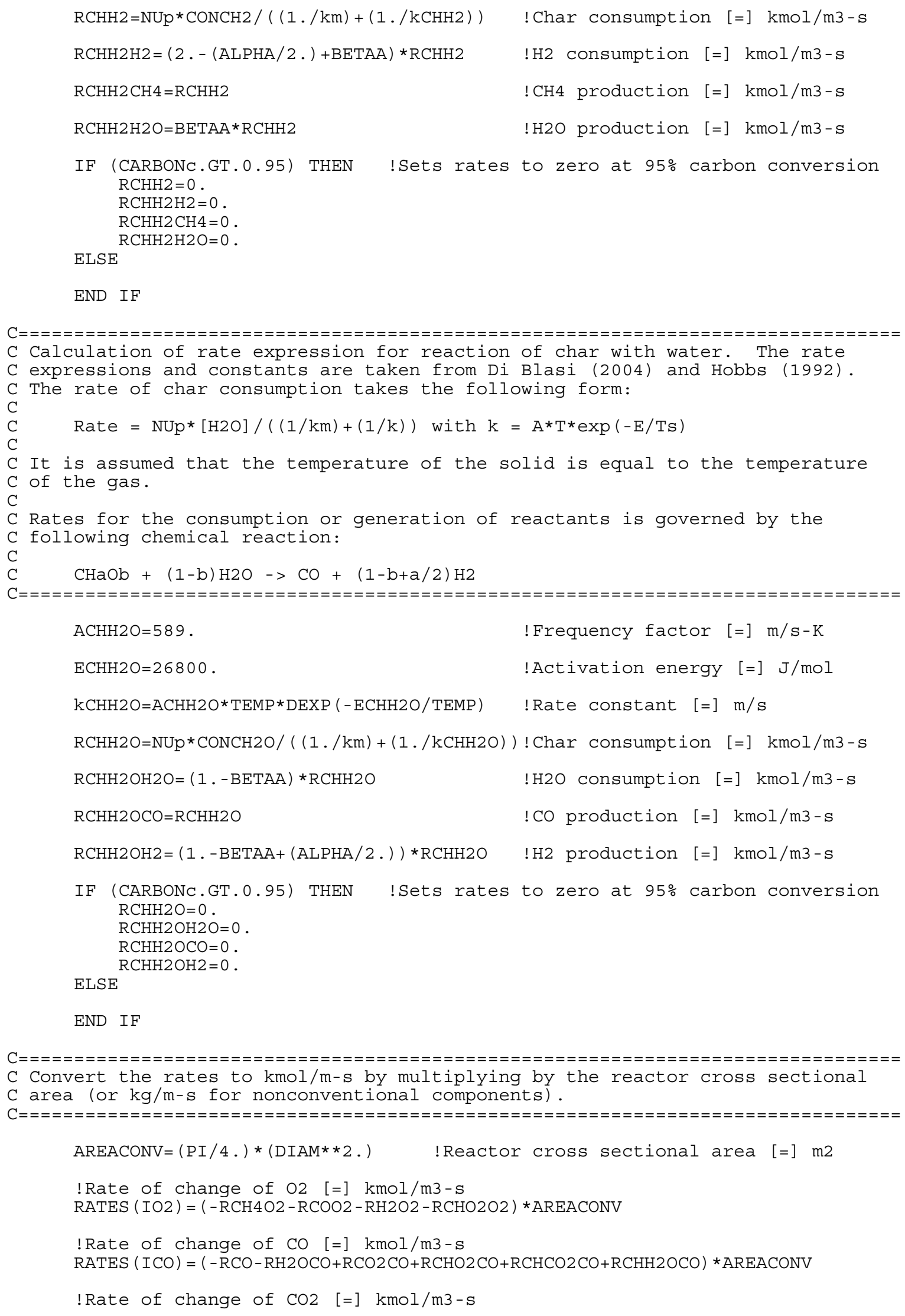




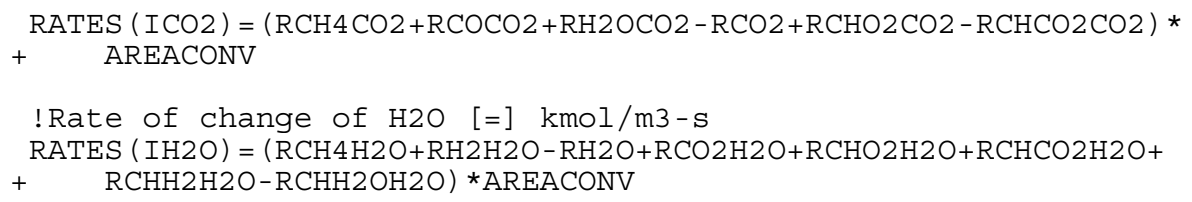

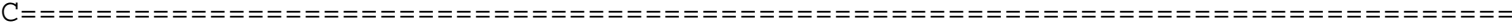
C Calculation of mass flow of current carbon, hydrogen, and oxygen in system.

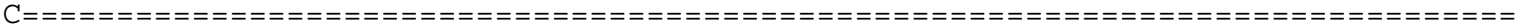

CARBON $=($ SOUT $($ ICO $)+$ SOUT $($ ICO2 $)+$ SOUT $($ ICH4 $)+($ SOUT $($ ICHAR+9. $) /$ MWCHAR $)+$

$+\quad$ (SOUT (IFUEL+9. ) /MWFUEL $)+($ SOUT $($ ITAR+9. $) /$ MWTAR $)) *$ MWC

HYDROGEN $=(2 . * \operatorname{SOUT}($ IH2O $)+4 . * \operatorname{SOUT}($ ICH4 $)+2 . *$ SOUT $($ IH2 $)+($ SOUT $($ ICHAR +9.$)$

$+\quad /$ MWCHAR $) *$ ALPHA $+($ SOUT $($ IFUEL+9. $) /$ MWFUEL $) *$ FUELH+ (SOUT $($ ITAR+9 . $) /$

$+\quad$ MWTAR $) *$ TARH $) *$ MWH

OXYGEN $=(2$. * SOUT $($ IO2 $)+\operatorname{SOUT}($ ICO $)+2$. *SOUT $($ ICO2 $)+\operatorname{SOUT}($ IH2O $)+$

$+\quad$ (SOUT (ICHAR+9.) /MWCHAR) * BETAA+ (SOUT ( IFUEL+9 . ) /MWFUEL $)$ *

$+\quad$ FUELO+ (SOUT $($ ITAR+9. $) /$ MWTAR $) *$ TARO $) *$ MWO

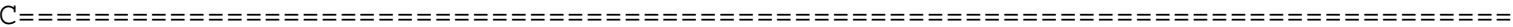
C Create output file

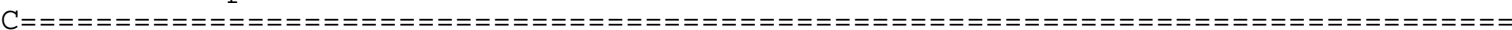

write $(1,30) \mathrm{XCURR}, \mathrm{TEMP}, \mathrm{YO} 2, \mathrm{YCO}, \mathrm{YCO} 2, \mathrm{YH} 2 \mathrm{O}, \mathrm{YCH} 4, \mathrm{YH} 2, \mathrm{YN} 2$, $+\quad$ TARRAT, CARBONC

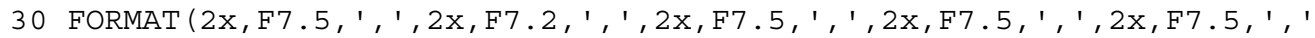

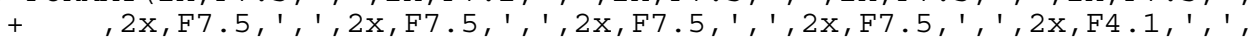

$\left.+\quad 2 \mathrm{x}, \mathrm{F} 7.5,{ }^{\prime},{ }^{\prime}\right)$

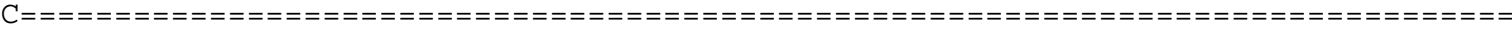
C END PROGRAM

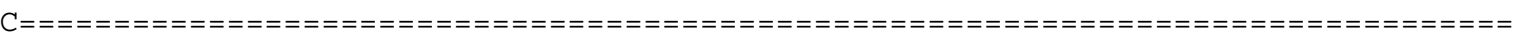

close (unit=1)

RETURN

END 
